\title{
Coastal Processes Study at Ocean Beach, San Francisco, CA: Summary of Data Collection 2004-2006
}

By Patrick L. Barnard, Jodi Eshleman, Li Erikson and Daniel M. Hanes

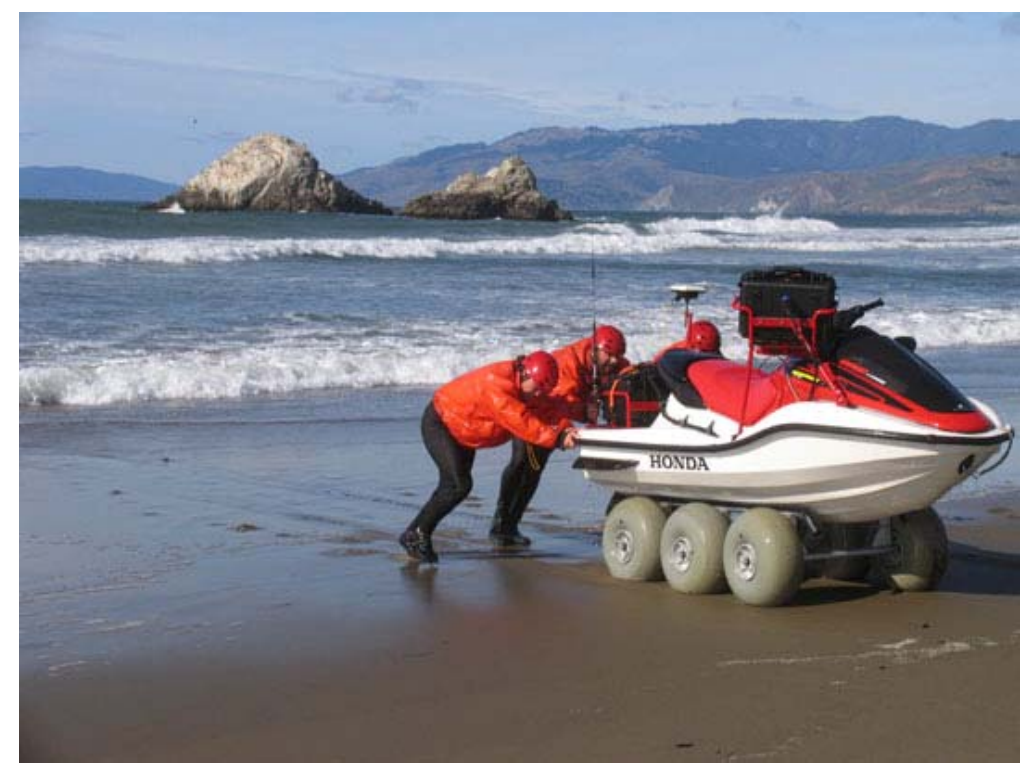

Open-File Report 2007-1217 


\section{U.S. Department of the Interior \\ DIRK KEMPTHORNE, Secretary}

\section{U.S. Geological Survey \\ Mark D. Myers, Director}

\section{U.S. Geological Survey, Reston, Virginia 2007}

For product and ordering information:

World Wide Web: http://www.usgs.gov/pubprod

Telephone: 1-888-ASK-USGS

For more information on the USGS - the Federal source for science about the Earth, its natural and living resources, natural hazards, and the environment:

World Wide Web: http://www.usgs.gov

Telephone: 1-888-ASK-USGS

Barnard, P.L.., Eshleman, J., Erikson, L., and Hanes, D.M., 2007, Coastal processes study at Ocean Beach, San Francisco, CA; summary of data collection 2004-2006: U. S. Geological Survey Open-File Report 20071217, 171 p. [http://pubs.usgs.gov/of/2007/1217/].

Any use of trade, product, or firm names is for descriptive purposes only and does not imply endorsement by the U.S. Government.

Although this report is in the public domain, permission must be secured from the individual copyright owners to reproduce any copyrighted material contained within this report. 


\section{Contents}

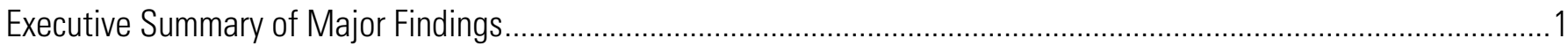

Chapter 2 - Beach Topographic Mapping …………………………………………………………....

Chapter 3 - Nearshore Surveys with Coastal Profiling System ...................................................................

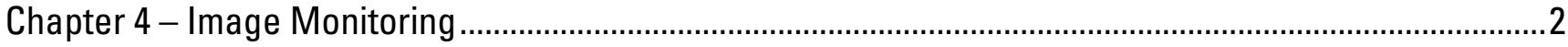

Chapter 5 - Offshore Instrument Deployments ………………..................................................................

Chapter 6 - Surf Zone Instrument Deployments ..........................................................................................

Chapter 7 - Multibeam Mapping...............................................................................................................

Chapter 8 - Grain Size Mapping.............................................................................................................

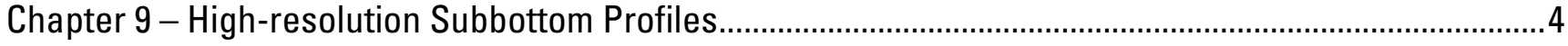

Chapter 10 - Numerical Modeling ...................................................................................................

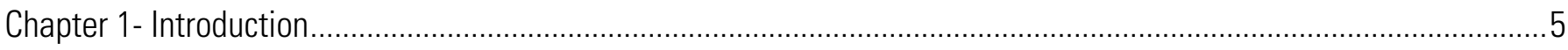

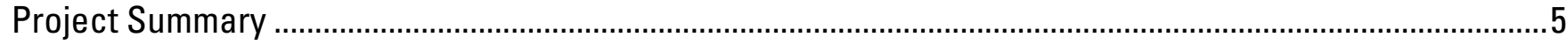

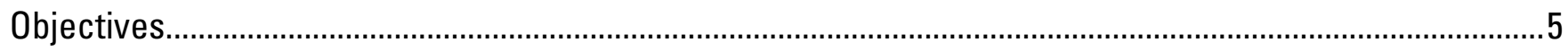

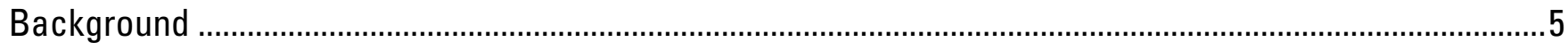

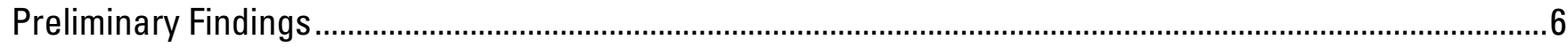

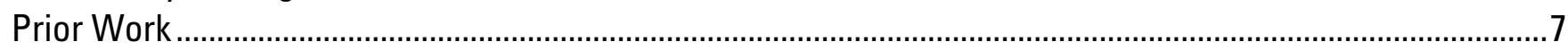

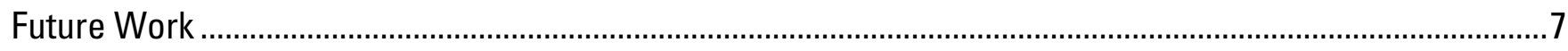

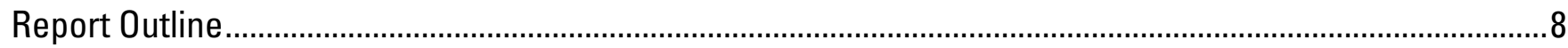

Project Support and Collaboration ...........................................................................................................

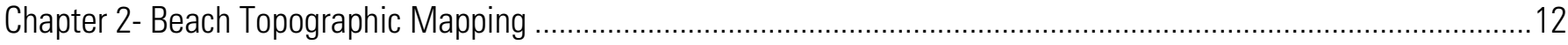

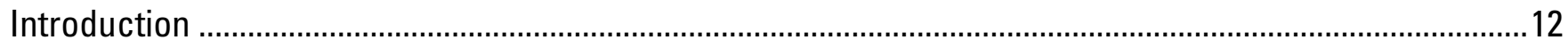

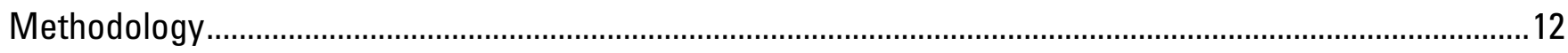

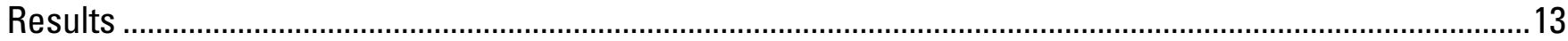

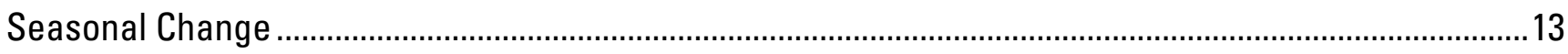

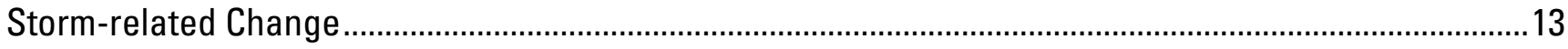

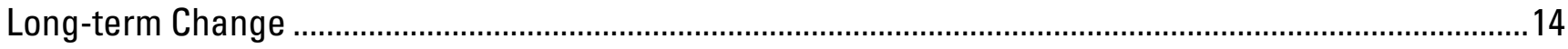

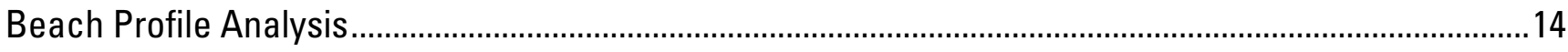

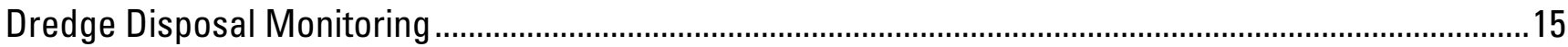

Empirical Model Development ………………………………………………………………..... 15

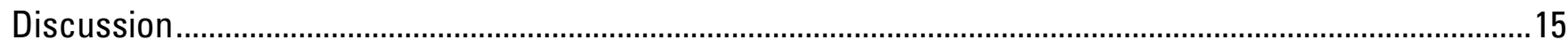

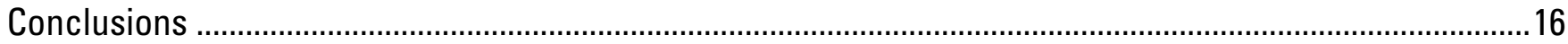

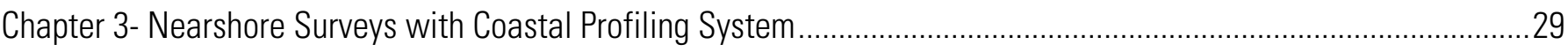

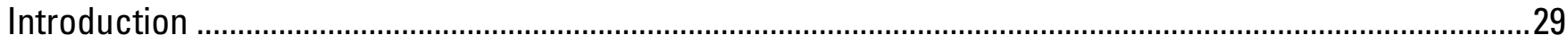

Methodology

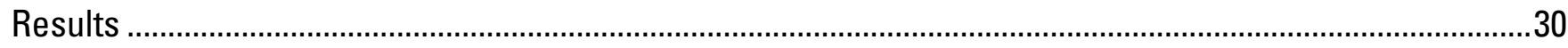

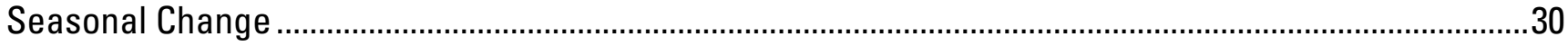

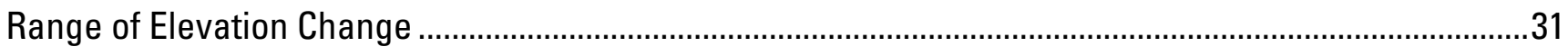

Nearshore Bar Growth and Trough Erosion …………………………………………………….......

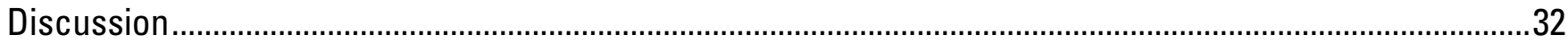

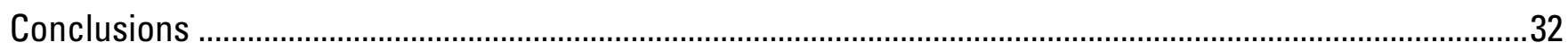

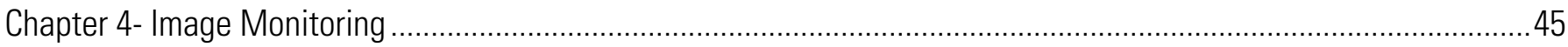

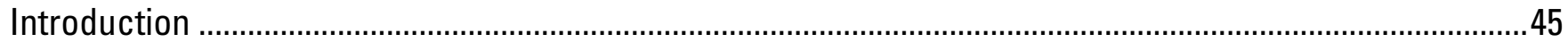

Methods 


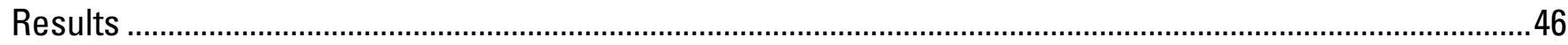

Time-averaged Images ………………………………………………………………………. 46

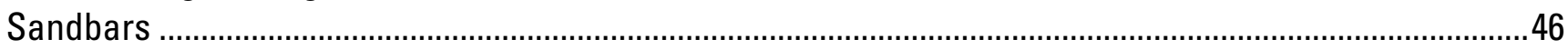

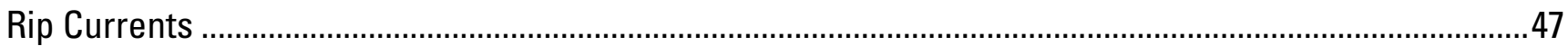

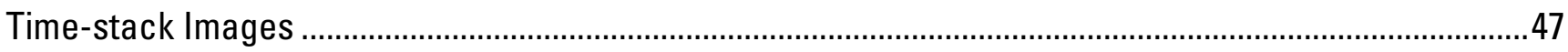

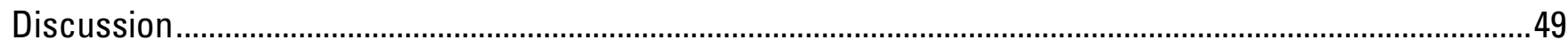

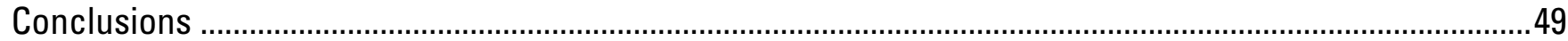

Chapter 5-Offshore Instrument Deployments .......................................................................................................5

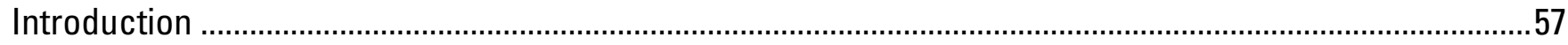

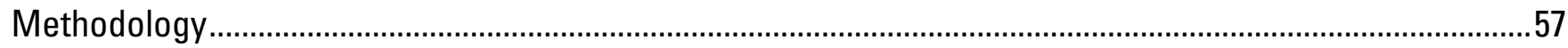

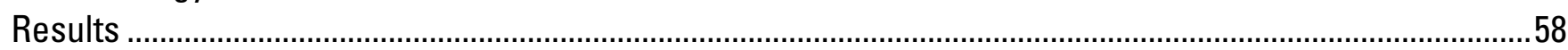

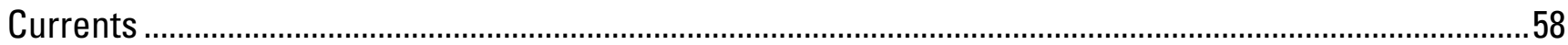

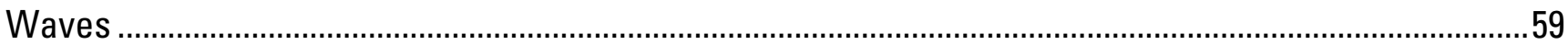

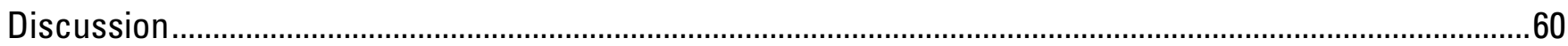

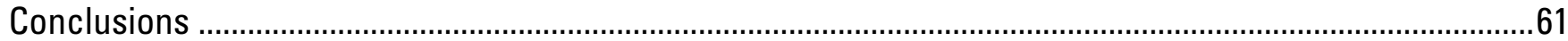

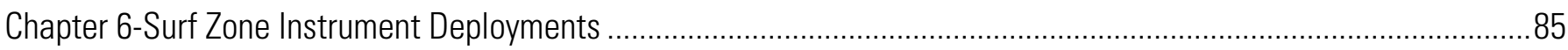

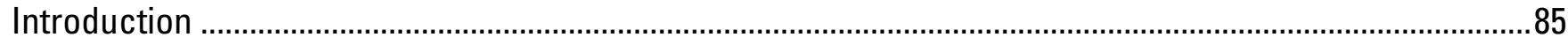

Methods

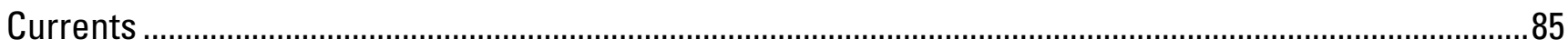

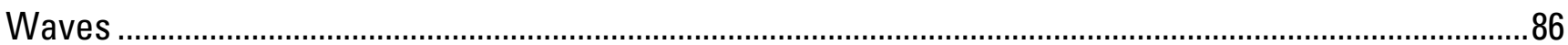

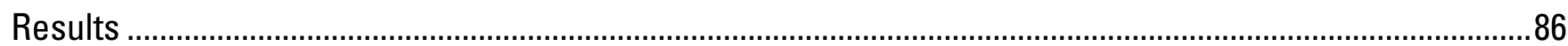

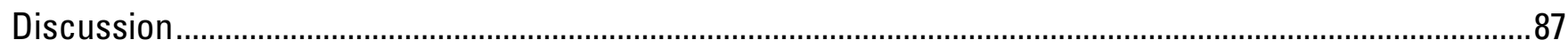

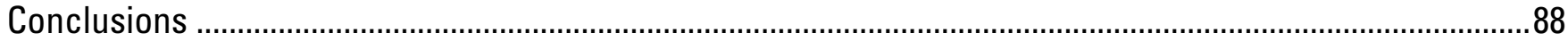

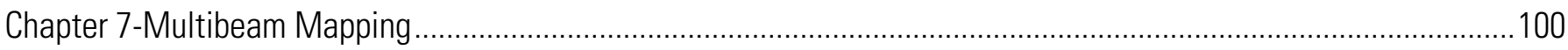

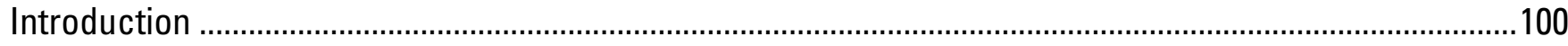

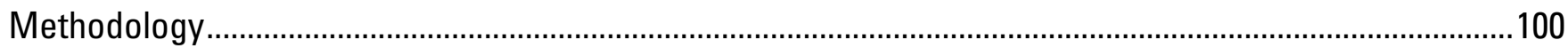

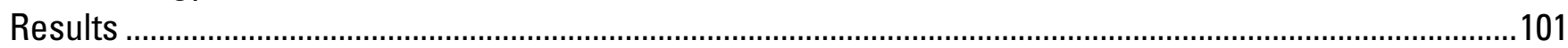

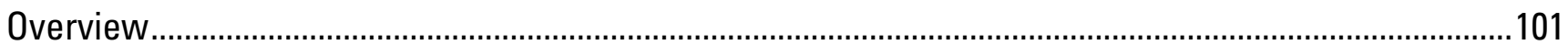

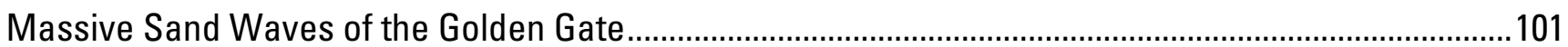

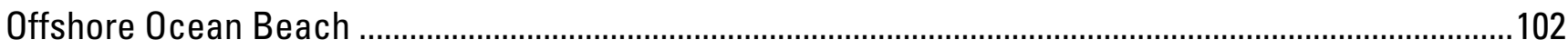

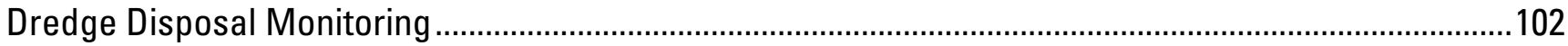

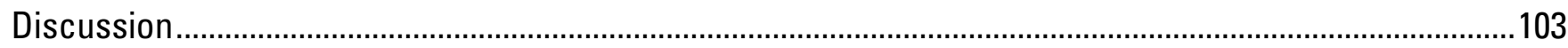

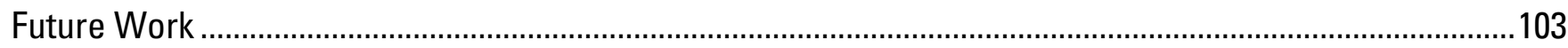

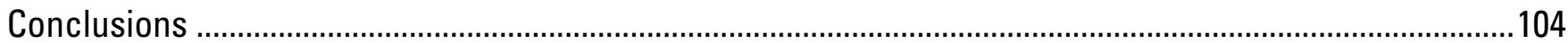

Chapter 8-Grain Size Mapping ........................................................................................................................ 116

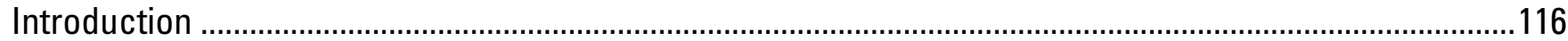

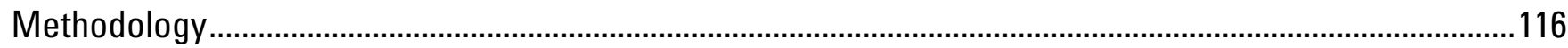

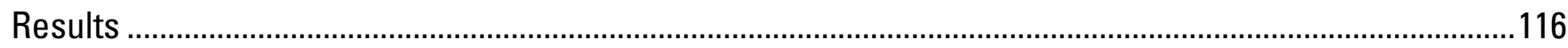

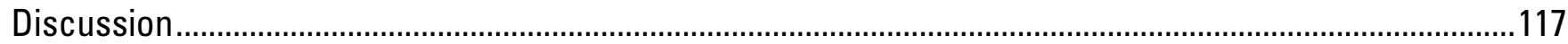

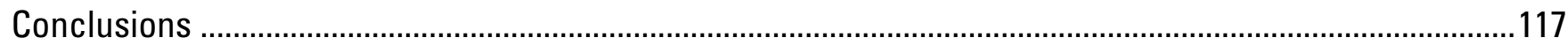

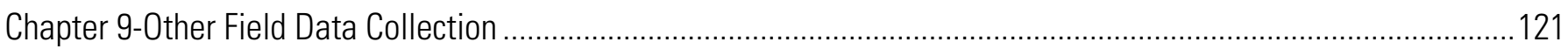

High-resolution Subbottom Profiles of Active Faults and Sediment on the Golden Gate Platform.............121

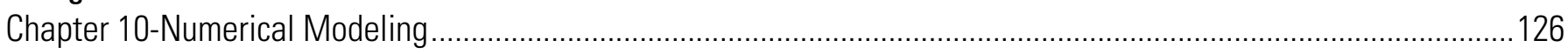

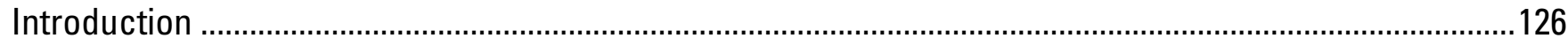

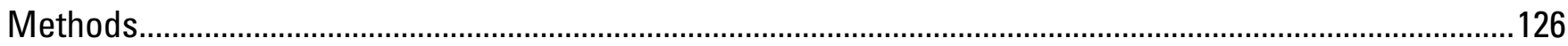




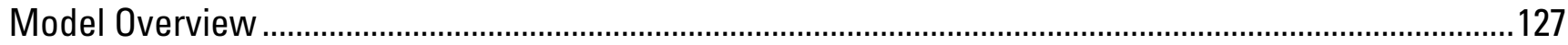

Grid and Boundary Conditions...................................................................................................... 127

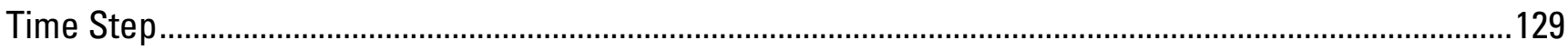

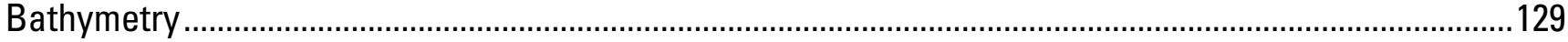

Calibrations and Parameter Settings ..............................................................................................129

Tide Constituent Calibrations ................................................................................................129

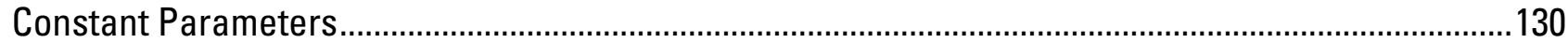

Comparison of Model Results with Field Data............................................................................. 130

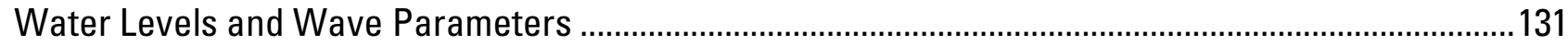

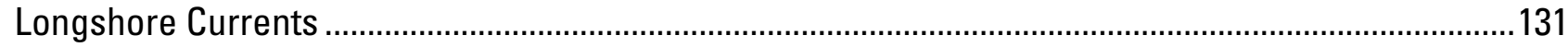

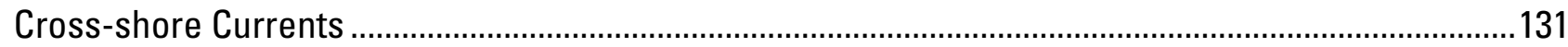

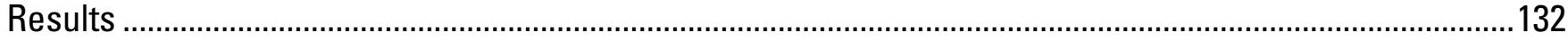

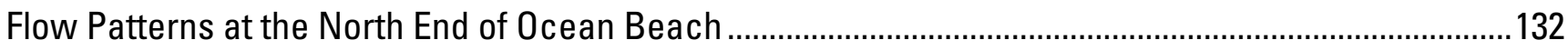

Variable Wave Impact Along the Beach …………………………………………………………...... 132

Influence of Offshore Wave Direction .............................................................................................133

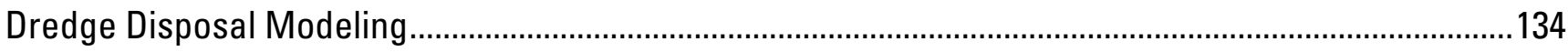

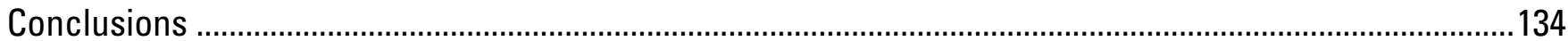

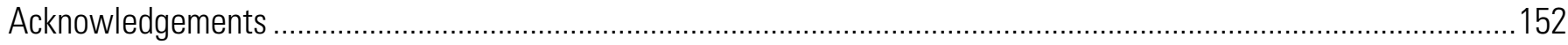

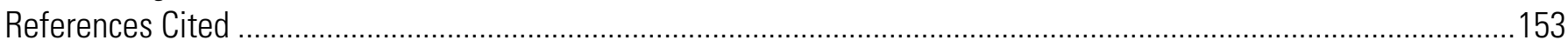

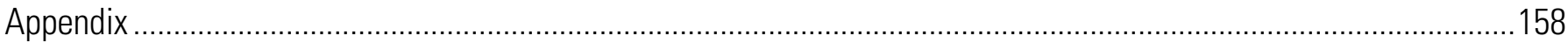

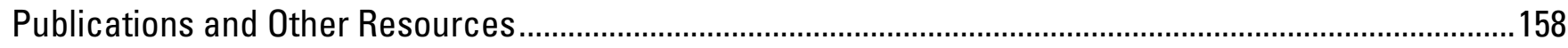

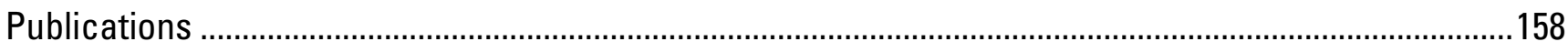

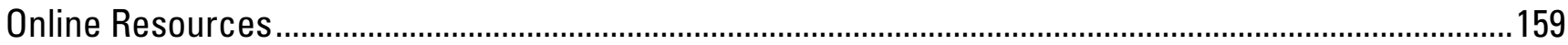

Research Featured in the News.................................................................................................159

Field Activity IDs and Web Links........................................................................................................... 


\section{Figures}

Figure 1.1. Map of the study area included in the San Francisco Bight Coastal Processes

Study, and the focus site for the Ocean Beach Coastal Processes Study (green box). .....10

Figure 1.2. Map showing the 0 cean Beach Coastal Processes study area, including the

locations of the existing dredge disposal site (SF-8) and test dredge disposal site (0cean

Beach Disposal Site).

Figure 1.3. Erosion south of Sloat Blvd. at Ocean Beach during 1997-98 El Niño winter (image

courtesy of Surfrider). The Great Highway is to the left.....................................................11

Figure 2.1. ATV set up for conducting topographic beach surveys using Differential GPS.......16

Figure 2.2. Typical data coverage (middle panel) and resulting grid (right panel) at the northern

end (Reach 1) of Ocean Beach, from the November 15, 2004 survey.

Figure 2.3. Map of the reach locations referenced in the analysis of beach topographic data.

The area of chronic erosion is labeled.

Figure 2.4. Beach volumetric fluctuations above $0.5 \mathrm{~m}$ (NAVD88) from

April 2004 to June 2006 18

Figure 2.5. Cumulative beach change above $0.5 \mathrm{~m}$ (NAVD88) from April 2004 to June 2006......19

Figure 2.6. Winter change (MHW line) during the 1997-98 El Niño compared to the winters of

2004-05. Profiles are spaced $50 \mathrm{~m}$ apart and numbering increases from north to south....19

Figure 2.7. Beach change in the Sloat Blvd. (main east-west street pictured) region between

December 2004 and January 2005.

Figure 2.8. Short-term beach change associated with a significant wave event (offshore wave

heights reached six meters) at Ocean Beach in March 2005 as compared to the month

prior. A) Northern Ocean Beach (Reach 1). B) Southern Ocean Beach (Reach 7).............21

Figure 2.9. Alongshore shoreline change from two storms in 2005. Gaps in the data indicate no

data and/or no MHW shoreline accessible. .23

Figure 2.10. Shoreline change since LIDAR data was collected in 1997-98. The red line

represents the rate as determined from the fall beach (October 1997 - October 2004). The

blue line represents the rate as determined from the spring beach

(April 1997 - April 2006)

Figure 2.11. Average values of a) swash beach width, $\mathrm{m} \mathrm{b}$ ) swash sediment storage $\mathrm{m} 2$ and $\mathrm{c}$ )

swash beach slope averaged over the profile for each individual profile and also by reach

plotted on local bathymetry. .24

Figure 2.12. Seasonal averages of beach slope for each profile at Ocean Beach.......................25

Figure 2.13. Beach change during the dredge disposal monitoring period, as compared to

2004. A) Northern Ocean Beach (Reaches 1-2. B) Southern Ocean Beach (Reaches 5-7)

and average vertical change totals for entire beach study area.

Figure 2.14. Empirical relationship between the wave direction $\left(D_{p}\right)$ and beach volume change

at Reach five during the storm surveys of winter 2005-06. The blue line represents a

horizontal line that goes through the mean of the mean volume change data. The solid red line is the best fit to the data based on the multiple regression equation. The dashed red curves are the $95 \%$ confidence interval curves. The correlation variance $r^{2}=0.687 \ldots \ldots \ldots . .28$

Figure 3.1. Third generation Coastal Profiling System in action. ..................................................33

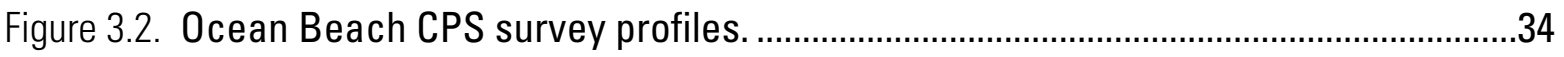

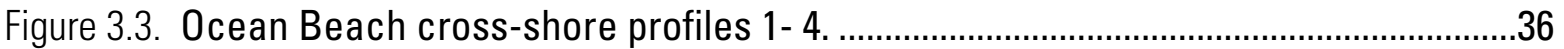


Figure 3.4. Ocean Beach cross-shore profiles 5 - 8 ...............................................................3

Figure 3.5. Ocean Beach cross-shore profiles 9 - 12..............................................................38

Figure 3.6. Ocean Beach cross-shore profiles 13 - 16. ..........................................................39

Figure 3.7. Ocean Beach cross-shore profiles $17-18$.............................................................40

Figure 3.8. Grid difference plots showing elevation change between surveys a) February,

2006- November, 2005 b) May, 2006 - February, 2006 c) November, 2006 - May, 2006 d)

December, 2006 - November, 2006.

Figure 3.9. Calculations from all survey data available of a) standard deviation of elevation

with mean elevation contours b) mean elevation (dredge disposal site and erosion hotspot in magenta)

Figure 3.10. Definition sketch for volume of bar growth and trough erosion calculations using

profile five. The blue section shows the calculated volume of bar growth and the red section shows the volume of trough erosion.

Figure 3.11. Variation in a) volume of bar growth and trough erosion and b) volume of bar growth and trough erosion per meter profile length for profiles 1-16, 18 along 0cean Beach. .44

Figure 4.1. Digital camera and video system on the top of the Cliff House Restaurant..............50 Figure 4.2. Aerial image showing camera's field of view, in situ instrument locations (ADCP as

a red square and Aquadopps as circles), CPS survey profiles (blue east-west oriented lines), and time-stack transects (yellow lines). Aerial image pt_bonita_se.tif, 08/25/1993.51 Figure 4.3 Typical images used for analysis: (a) unrectified time-averaged image, (b) rectified time-averaged image, and (c) time-stack image. .52

Figure 4.4. Break points observed in time-averaged images plotted on cross-shore profile

measured with the CPS.

Figure 4.5. Locations of dominant rip currents at the north end of Ocean Beach.......................53

Figure 4.6. Seasonal distribution of observed rip current occurrence at any of the four

locations at the north end of Ocean Beach. 54

Figure 4.7. Typical 17 min tide detrended time-series illustrating the dominant infragravity component (transect T3 on 06/24/05, 10:09 to 10:23 am) .54

Figure 4.8. Total energy density, averaged over ten subsequent 17 minute time-periods, measured at each cross-shore transect. The heavy solid line is the best linear fit through T3 over 0.03 to $0.1 \mathrm{~Hz}$. Dashed vertical line is cutoff between infragravity and sea swell frequencies.

Figure 4.9. Measured runup statistics versus (a) Hunt's significant runup formula (1959), and

(b) $2 \%$ exceedance using Ruggiero and others (2004) formulation. Both are shown with $T=T_{\text {mo2 }}$ .56

Figure 5.1. Instrument deployment sites at Ocean Beach......................................................64

Figure 5.2. Photographs of typical instrumented tripods deployed at a) Sites 1-3 and b)

Sites $4-5$. 6.65

Figure 5.3. Water density calculated for Site 3 during winter 2006 deployment. .65

Figure 5.4. Principal axis calculations for depth-averaged current measurements at a) Site 1 summer 2005 b) Site 2 summer 2005 c) Site 3 summer 2005 d) Site 4 summer 2005 e) Site 3 winter 2006 f) Site 5 winter 2006 
Figure 5.5. Flow patterns measured at Ocean Beach throughout a tidal cycle on 06/25/05 during the summer 2005 deployment. Plot a) shows the measured tide at Site 1; points and text refer to measured currents in plots b) through i). Depth values are shown by colored contours and currents at different vertical locations have colored arrows.

Figure 5.6. Flow patterns measured at Ocean Beach throughout a tidal cycle on 01/28/06 during the winter 2006 deployment. Plot a) shows the measured tide at Site 3; points and text refer to measured currents in plots b) through i). Depth values are shown by colored contours and currents at different vertical locations have colored arrows. .72

Figure 5.7. Current profile plots through time for summer deployment at Site 1 a) eastward velocity b) northward velocity. (Note that this is a different time period than the other plots and only 4 days since the instrument was buried.)

Figure 5.8. Current profile plots through time for summer deployment at Site 2 a) eastward velocity b) northward velocity.

Figure 5.9. Current profile plots through time for summer deployment at Site 3 a) eastward

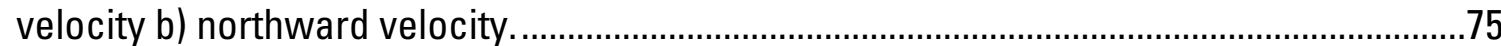

Figure 5.10 Current profile plots through time for summer deployment at Site 4 a) eastward velocity b) northward velocity. (Note the different scale on both axes from previous plots because of more onshore directed flow at Site 4). .76

Figure 5.11. Current profile plots through time for winter deployment at Site 3 a) eastward velocity b) northward velocity.

Figure 5.12. Current profile plots through time for winter deployment at Site 5 a) eastward velocity b) northward velocity (Note the different scale on both axes from previous plots because of more onshore directed flow at Site 5).

Figure 5.13. Direction histograms for Point Reyes CDIP buoy \#029 by month for all available wave data measured from 1996 through 2006 ( $N$ is number of observations out of a total 156,828 , the percentage is for the total data that occurred in that month, and $h_{m}$ is the maximum wave height for the month which came from a direction marked by the solid black line) (SCRIPPS Institution of Oceanography, 2006).

Figure 5.14. Wave parameters calculated from measurements during summer 2005 deployment at Sites $1-4$ a) significant wave height b) peak wave period c) peak wave direction.

Figure 5.15. Wave parameters calculated from measurements during winter 2006 deployment

at Sites 3 and 5 a) significant wave height b) peak wave period c) peak wave direction. .81

Figure 5.16. Polar plots of wave direction and height for the a) summer 2005 deployment and

b) the winter 2006 deployment. (Note the different radial axis due to larger wave heights

in the winter).

Figure 5.17. 1-D Spectral evolution through time from measurements during summer 2005

deployment for a) Site 1 b) Site 2 c) Site 3 d) Site 4.

Figure 5.18. Spectral evolution through time from measurements during winter 2006

deployment for a) Site 3 b) Site 5.

Figure 5.19. Estimated longshore transport (0) from CERC equation for Sites 1-3 along Ocean

Beach (Note the difference in units along the $y$-axis).

Figure 6.1. Overview of Aquadopp instrument deployments (01/23/06- 01/27/06). Data was not

recorded at sz 9 and the northern ADCP (Site1). 
Figure 6.2. Aquadopp frame setup and surf zone deployment scheme: (a) deployment schematic, and (b) photo of instrument and frame.

Figure 6.3. Measured water depth and vertical current structure measured with Nortek Aquadopps during the surf zone field study. Data shown are for complete tide cycles (depending on data availability) for measurement sites from north to south (sz1 through sz8); u-directed: east-west with east positive, v-directed: north-south, with north positive.

Figure 6.4 Maximum depth averaged currents measured in the surf zone at the north end of

Ocean Beach during a complete tide cycle (Jan 24-25, 2006). .98

Figure 6.5. Variations of the breaking parameter with tide level at the north end of 0 cean Beach. Upper plot (a) shows concurrently measured offshore wave conditions at ADCP Site 5. Lower plot (b) shows calculated breaking parameters for surf zone measurements at sz1 through sz4 and measured water depth at sz1. Dashed horizontal line is the 0.78 breaking ratio.

Figure 7.1. Shaded relief image showing the multibeam coverage area from the 2004-2005

survey and the location of sand wave migration surveys in the Golden Gate....................105

Figure 7.2. Change between bathymetric surveys conducted in 1956 and 2005......................106

Figure 7.3. A) Bedform orientation based on sand wave orientation, and B) dominant sediment

transport direction as inferred from bedform shape asymmetry... .107

Figure 7.4. Map of bedform A) wavelength and B) height, gridded to $50 \mathrm{~m}$ cell resolution......109

Figure 7.5. View of the giant sand waves at the mouth of San Francisco Bay (from Barnard and others, 2006a). View is to the east toward San Francisco Bay. The Golden Gate Bridge is approximately $2 \mathrm{~km}(1.2 \mathrm{mi})$ long. Shaded relief image created with a $2-\mathrm{m}$ grid, $4 \mathrm{x}$ vertical exaggeration, sun azimuth of 240 degrees, and sun angle of 66 degrees. The land topography was generated by overlaying digital orthophoto quadrangles (D00s) on USGS digital elevation models (DEMs), with a $2 x$ vertical exaggeration. Bathymetry data inside the Bay (that is east of Golden Gate Bridge) is from Dartnell and Gardner (1999). Golden Gate Bridge model courtesy of Interactive Visualization Systems.

Figure 7.6. Oblique view of the giant sand waves at the mouth of San Francisco Bay (from Barnard and others, 2006a). View is south across the Golden Gate toward Baker Beach and the city of San Francisco. See Figure 7.5 for more image information.

Figure 7.7. Diverse sand waves at the mouth of San Francisco Bay, seaward of the Golden Gate Bridge. Shaded relief image created with $5 x$ vertical exaggeration, sun elevation of 45 degrees, and sun azimuth of 45 degrees. (A) Irregular sand waves seaward of the main sand wave field. (B) Ebb-dominated sand waves with wavelengths as great as $150 \mathrm{~m}$ with superimposed sand waves of $5 \mathrm{~m}$ to $10 \mathrm{~m}$ wavelength. (C) Linguoid sand waves, $20 \mathrm{~m}$ to 30 $\mathrm{m}$ in wavelength. (D) Flood-dominated sand waves, $15 \mathrm{~m}$ to $20 \mathrm{~m}$ in wavelength, just offshore of Baker Beach.

Figure 7.8. Overview of large sand wave field and high resolution difference map of two surveys approximately 21 hours apart illustrating both large-scale and small-scale sand wave migration and orientation. Migration is from right to left. 114

Figure 7.9. Multibeam survey from 2004 showing A) alongshore migrating bedforms, B) onshore-directed bedform morphologies north of the disposal site, and C) intense scour associated with the outfall pipe, the approximate site of the June 2005 dredge disposal (from Barnard and others, 2006b). 
Figure 8.1. Location of beach sediment samples along 0cean Beach, from the May 2004 survey. The profile locations are labeled.

Figure 8.2. Sediment sample locations at the mouth of San Francisco Bay in summer 2005, along with Oceanside Biology Laboratory (OBL) sample stations. ..................................119

Figure 8.3. Median grain size of swash samples from 3 surveys along Ocean Beach..............119

Figure 8.4. Median grain size along five profiles from the May 2004 survey.............................120

Figure 8.5. Grid of grain size class at the mouth of San Francisco Bay, using the both OBL and

USGS samples.

Figure 9.1. Trackline map of subbottom data collected on the Lakota in late September 2006

(for more cruise information: http://walrus.wr.usgs.gov/infobank///106sf/html//-1-06-

sf.meta.html). Thin black lines correspond to CHIRP profiles; wider gray lines to mini-

sparker profiles. Locations of Figures 9.2 and 9.3 are shown by bold black line. B-

Bolinas, GG - Golden Gate, FF - Fort Funston.

Figure 9.2. Mini-sparker profile GG-30 collected offshore of Fort Funston showing folded and disrupted reflectors associated with the San Andreas Fault (SAF). M - water bottom multiple; TWTT- two-way travel time. 124

Figure 9.3. Mini-sparker profile GG-9b collected across a fault-bounded graben located southwest of Bolinas. The dots show the base of the graben, which contains over $50 \mathrm{~m}$ of sediment. M - water bottom multiple; TWTT- two-way travel time; SGF - San Gregorio Fault; SAF - San Andreas Fault; GGF - Golden Gate Fault. 124

Figure 9.4. Map of the Golden Gate platform that shows thicknesses of acoustically

transparent sediment of inferred Holocene age. These sediments are interpreted to be primarily composed of ebb-tidal delta deposits. The contour lines delineate sediment thicknesses that are greater than $10 \mathrm{~m}$. The red lines show offshore fault traces. The gray lines show the locations of profiles used to map the acoustically transparent unit.125

Figure 10.1. Curvilinear grids used for the FLOW and WAVE modules (a) and FLOW grid with

boundaries (b). 136

Figure 10.2. Final gridded bathymetry (positive depth in meters relative to mean sea level)...137

Figure 10.3. Measured and modeled water levels: (a) Site 2; (b) Site 3. Blue circles are

residuals (measured - modeled). .138

Figure 10.4. Comparison of measured and modeled significant wave heights $\left(H_{s}\right)$. Note the

residual (blue diamonds) $y$-axis on the right.

Figure 10.5. Comparison of measured and modeled longshore currents $(a, b)$ and cross-shore currents (c, d) at Sites 2 and 3 . 140

Figure 10.6. Flow patterns at the north end of Ocean Beach. Plot (a) shows the measured tide at Site 2; points and text refer to snap shots of model results in plots (b) through (m). Open circle is Site 1 sampling station. Flow directions are shown with arrows while current speeds $(\mathrm{m} / \mathrm{s})$ are shown with the color scheme. White horizontal lines in plots $\mathrm{g}, \mathrm{h}$, and $\mathrm{i}$ indicate rip current observations from time-averaged images (Chapter 4).......143 
Figure 10.7. Eddy position as a function to tide stage. Based on analysis of model simulation slightly shorter than one month, the southern most point of the eddies reach to about $\mathrm{N}$ 4.179E6, which coincides with PWC transect 5 (a). Approximate eddy center locations are plotted against the tidal stage in (b) and (c) (note that the axis of the Eastings and Northings are switched ease of geographic considerations). Central Easting position only moves slightly with positive tide levels, while at negative tides (corresponding to the spring cycle), the position moves as much as $1 \mathrm{~km}$ in the east-west direction. With respect to the right-hand Figure, the eddies appear to move about $1 \mathrm{~km}$ in the north-south direction with the tide, such that the eddies appear further south with lower tide stage.

Figure 10.8. Evidence of rip currents at $\mathbf{N} 4180.63 \mathrm{~km}$, which coincides with 'rip 3' as seen with time-averaged images (see Chapter 4). Plot (a) shows model predicted flow patterns along 0 cean Beach; plot (b) shows measured tide at Site 1 and, with the red circle, the time-step of (a).

Variation in line density is due to grid cell spacing.

Figure 10.11. Along-shore variation of estimated long-shore sediment transport $\left(\mathrm{m}^{3} / \mathrm{day}\right.$ per along-shore unit width). The thick red lines bound the erosion 'hot spot'.

Figure 10.12. Modeled significant wave height values at 0 cean Beach with parameterized forcing of $H_{\mathrm{s}}=4 \mathrm{~m}$ and a) $\left.\left.T_{\mathrm{p}}=10 \mathrm{sec}, D_{\mathrm{p}}=330 \mathrm{deg} \mathrm{b}\right) T_{\mathrm{p}}=10 \mathrm{sec}, D_{\mathrm{p}}=280 \mathrm{deg} \mathrm{c}\right) T_{\mathrm{p}}=20 \mathrm{sec}, D_{\mathrm{p}}=$ 330 deg d) $T_{\mathrm{p}}=20 \mathrm{sec}, D_{\mathrm{p}}=280 \mathrm{deg}$.

Figure 10.13. Modeled peak wave direction values at 0 cean Beach with parameterized forcing of $\mathrm{Hs}=4 \mathrm{~m}$ and a) $\mathrm{Tp}=10 \mathrm{sec}, \mathrm{Dp}=330 \mathrm{deg}$ b) $\mathrm{Tp}=10 \mathrm{sec}, \mathrm{Dp}=280 \mathrm{deg}$ c)Tp=20 sec, $D p=330$ deg $d) T p=20$ sec, $D p=280$ deg. 150

Figure 10.14. Residual transport of the dredge disposal mound with tidal forcing only (a)

Residual transport of the dredge disposal mound with tidal and wave forcing, illustrating the importance of wave shoaling in the onshore migration of the disposal material(b). 


\title{
Coastal Processes Study at Ocean Beach, San Francisco, CA: Summary of Data Collection 2004- 2006
}

\author{
By Patrick L. Barnard', Jodi Eshleman², Li Erikson ${ }^{3}$, and Daniel M. Hanes ${ }^{4}$
}

\section{Executive Summary of Major Findings}

Chapter 2 - Beach Topographic Mapping

- Beach volume at Ocean Beach varies seasonally over a maximum envelope of $400,000 \mathrm{~m}^{3}$.

- The El Niño winter of 1997-98 caused double the average shoreline retreat than the more typical 2004-05 winter at Ocean Beach.

- Shoreline retreat can exceed $20 \mathrm{~m}$ during severe winters, with localized retreat over $70 \mathrm{~m}$.

- Single storm events can cause an average shoreline retreat of over ten meters and remove over $100,000 \mathrm{~m}^{3}$ of sediment from the beach.

- Since the 1997-98 airborne LIDAR surveys, there has been a trend of accretion at the north end of Ocean Beach (Reach 1 shoreline change rate $=+2.1 \mathrm{~m} / \mathrm{yr}$ ) and continued erosion at the south end (Reach 5-6 shoreline change rate $=-1.1 \mathrm{~m} / \mathrm{yr}$ ).

- Preliminary findings from storm response surveys indicate a potentially strong correlation between wave height and direction with beach response.

- The shape of the ebb tidal delta exerts a first order control on decadal scale morphology changes at Ocean Beach.

Chapter 3 - Nearshore Surveys with Coastal Profiling System

- Comparisons of bathymetric profiles show patterns of seasonal bar migration onshore in the summer and offshore in the winter. Bars can be as high as two meters and move several hundred meters in the cross-shore.

- A shorter-term survey after one month suggests that a few winter storms can force offshore bar migration on the order of $100 \mathrm{~m}$.

- Comparisons of elevation change throughout all surveys suggest a range in depth of closure from $15 \mathrm{~m}$ at the north end to a shallower $10 \mathrm{~m}$ at the south end. This

\footnotetext{
${ }^{1}$ Research Geologist, Coastal and Marine Geology Team, Santa Cruz, CA, pbarnard@usgs.gov

${ }^{2}$ Coastal Engineer, Coastal and Marine Geology Team, Santa Cruz, CA, jeshleman@usgs.gov

${ }^{3}$ Coastal Engineer, Coastal and Marine Geology Team, Santa Cruz, CA, lerikson@usgs.gov

${ }^{4}$ Research Oceanographer and Project Chief, Coastal and Marine Geology Team, Santa Cruz, CA, dhanes@usgs.gov
} 
analysis suggests that the dredge disposal site is too deep for significant crossshore transport of sand to occur.

- An order of magnitude estimate of offshore bar growth from measured bathymetric profiles suggests 2 million $\mathrm{m}^{3}$ (2.6 million cubic yards) of sand is moving in the cross-shore to form nearshore bars.

\section{Chapter 4 - Image Monitoring}

- Wave-breaking locations deduced from time-averaged images agree with those from bathymetric data obtained with the CPS.

- Time-averaged images show that multiple breaking locations are common along Ocean Beach. It is not clear if both of the breaker locations were associated with bars, or if the inner location was simply due to depth-limited breaking.

- Four rip currents occurred seasonally at the north end of Ocean Beach with a spacing of $150 \mathrm{~m}$ to $200 \mathrm{~m}$.

- Analysis of time-stack runup data shows that the beach was dissipative under typical summer conditions with infragravity conditions dominating and swash periods on the order of a minute.

\section{Chapter 5 - Offshore Instrument Deployments}

- Current magnitudes are much greater along the northern portion of Ocean Beach due to the proximity of the mouth of the bay (root mean square values of depthaveraged currents were $50 \%$ greater at Site 1 than at Site 3), but wave energy is much greater along the southern portion (mean wave height was $15 \%$ greater at Site 3 than at Site 1) where erosion problems are greatest.

- The gradients in current speed along Ocean Beach varied with the tide, where northern currents speeds were greater on the flooding and high tides and southern current speeds began to dominate on the ebbing and low tides.

- Current directions along Ocean Beach were shore-parallel, whereas the offshore sites show principal axes shifted more east-west, with an increasing eastward magnitude of flow with increased northing and proximity to the mouth of the bay.

- In the along-shore direction, vertical gradients in current magnitude of northsouth directed currents increased with increasing distance from the inlet; variation in current magnitude throughout the water column was greatest at Site 3. Eastwest currents show a relatively stronger vertical decay due to the influence of wave-induced currents. At the offshore sites (Sites 4 and 5) vertical gradients were apparent for both the north-south and east-west currents, and Site 4 had current reversal with a changing tide.

- Refraction patterns across the delta oriented waves with an onshore direction around $270^{\circ}$ in a more southwest direction as they propagated into shallower water.

- Calculations of alongshore transport using wave measurements at Sites 1-3 and the CERC equation indicate the direction of transport was north in the winter at Site 3 and suggest that a nodal point existed somewhere between Site 2 and Site 3 during the summer. 


\section{Chapter 6 - Surf Zone Instrument Deployments}

- Analysis of surf-zone current data shows that instantaneous flows $(O(50 \mathrm{~cm} / \mathrm{s}))$ occur in both the cross-shore and along-shore directions.

- Simultaneous cross-shore current data show that flow direction and variation of relative speeds were correlated in time, suggesting that there was strong uniformity in cross-shore currents, but that the speeds were greater in the outer surf zone.

- Simultaneous along-shore current data suggest that the maximum northward oriented tidal currents are stronger than southward currents but also that there is a cross-shore variation of the longshore currents such that the southward oriented currents are stronger further inshore.

- There is little vertical current structure in the surf zone except near the bottom during high tide in east-west directed currents.

- North-south currents within the surf zone reversed from a southerly directed 50 $\mathrm{cm} / \mathrm{s}$ flow during ebb-tide to an equally strong northward flow at low tide. Eastwest currents were also tidally driven but were slightly slower $(35 \mathrm{~cm} / \mathrm{s}$ to 45 $\mathrm{cm} / \mathrm{s})$.

- With varying tide levels and offshore wave conditions on the order of $H_{\mathrm{s}}=1.5 \mathrm{~m}$, the outer limit of the surf zone moved more than $40 \mathrm{~m}$ in the cross-shore direction with energy dissipation widths exceeding $20 \mathrm{~m}$.

\section{Chapter 7 - Multibeam Mapping}

- The ebb-tidal delta at the mouth of San Francisco Bay has experienced a large scale erosion trend over the last 50 years.

- Erosion of the shoals offshore of southern Ocean Beach has made the adjacent beach more susceptible to wave attack.

- Large, dynamic sand waves are located in the Golden Gate and off Point Lobos.

- Dominant sediment transport patterns outside the surf zone are controlled by tidal forcing, evident by the presence of alongshore migrating bedforms.

- Bedload sediment transport is seaward through the center of the inlet and toward the bay adjacent to Baker Beach.

\section{Chapter 8 - Grain Size Mapping}

- Median grain size varies minimally along Ocean Beach during the summer with a $\mathrm{d}_{50}=0.28 \mathrm{~mm}$.

- Sediment placed in the nearshore disposal site $\left(\mathrm{d}_{50}=0.18 \mathrm{~mm}\right)$ is finer than swash samples $\left(\mathrm{d}_{50}=0.28 \mathrm{~mm}\right)$ collected at Ocean Beach, and thus it is not likely to be stable on the beach.

- Large bodies of beach quality sand likely exist on the inner parts of the ebb-tidal delta at depths that could be dredged. Chapter 9 shows that a total volume of just over $1 \mathrm{~km}^{3}$ of acoustically transparent sediment is present. 


\section{Chapter 9 - High-resolution Subbottom Profiles}

- The maximum sediment thickness of the ebb tidal delta is $16 \mathrm{~m}$, with an overall volume of over $1 \mathrm{~km}^{3}$ of sediment.

\section{Chapter 10 - Numerical Modeling}

- Comparisons between measurements and model results show that the calibrated Delft3D model is capable of predicting hydrodynamics at Ocean Beach for summer conditions.

- Model simulations predict that currents along Ocean Beach are strongest prior to flow reversal at both flood and ebb tides, and are strongly influenced by the Golden Gate entrance.

- Along- and cross-shore currents are strongly modulated by the tide. The influence of the tidal inlet at the Golden Gate decreases significantly with distance such that the currents are about 30\% stronger at the north end compared to the southern end of Ocean Beach.

- The Pt. Lobos headland provides a shadow zone to the south so that nearshore tidal flows are weaker at ebb tide compared to areas further offshore.

- Model results suggest that rip currents are related to tidal flows and occur near times of flow reversal (high and low tide).

- Model results suggest that the longshore sediment transport is to the south during typical summer conditions and that the section stretching from the north part of Ocean Beach to immediately south of the erosion hot-spot undergoes strong longshore transport rates under high wave conditions $\left(\mathrm{H}_{\mathrm{s}}>2.5 \mathrm{~m}\right)$. Model results also suggest that the erosion hot-spot is directly impacted from shore-normal incident waves during storm conditions. Furthermore, the erosion hot-spot appears to be a result of wave focusing caused by the shape of the southern ebb tidal delta.

- Long-period, shore-normal incident large waves at Ocean Beach will likely have the largest erosional capacity, as waves coming from the northwest tend to be dissipated by the northern lobe of the ebb tidal delta. Preliminary modeling suggests that offshore waves originating from the west undergo less energy loss compared to offshore waves originating from the northwest, whose wave height reduces by about $50 \%$ as a result of refraction over the northern lobe of the ebb tidal delta.

- Numerical modeling suggests that despite the strong tidal currents in the region, wave forcing is the dominant factor moving the sediment slowly toward shore, and placing sediment at a depth of about $8 \mathrm{~m}$ will provide indirect beach nourishment. 


\section{Chapter 1- Introduction}

\section{Project Summary}

Ocean Beach in San Francisco, California, contains a persistent erosional section in the shadow of the San Francisco ebb tidal delta and south of Sloat Boulevard that threatens valuable public infrastructure as well as the safe recreational use of the beach. Coastal managers have been discussing potential mediation measures for over a decade, with little scientific research available to aid in decision making. The United States Geological Survey (USGS) initiated the Ocean Beach Coastal Processes Study in April 2004 to provide the scientific knowledge necessary for coastal managers to make informed management decisions. This study integrates a wide range of field data collection and numerical modeling techniques to document nearshore sediment transport processes at the mouth of San Francisco Bay, with emphasis on how these processes relate to erosion at Ocean Beach. The Ocean Beach Coastal Processes Study is the first comprehensive study of coastal processes at the mouth of San Francisco Bay.

\section{Objectives}

The objectives of this report are the following:

- Provide a thorough summary of the data collection efforts conducted as part of the USGS Ocean Beach Coastal Processes Study, initiated in April 2004.

- Present key findings, particularly as they may relate to pending management decisions.

- Outline future research directions at the mouth of San Francisco Bay- the San Francisco Bight Coastal Processes Study.

\section{Background}

Ocean Beach is a seven kilometer long north-south trending sandy beach that stretches south from a rocky headland at Point Lobos to the bluffs at Fort Funston (Figures 1.1-1.2). It is strongly affected by tidal currents from the adjacent Golden Gate, as well as wave refraction around the ebb-tidal delta. Ocean Beach has undergone numerous significant anthropogenic alterations since the late $19^{\text {th }}$ century: highway construction, seawall construction, dune stabilization, dune removal, rip-rap emplacement, beach nourishment, inlet fill, etc. (United States Army Corps of Engineers, 1996). The most significant manmade feature is the $1.5 \mathrm{~km}$ long O'Shaughnessy Seawall at the northern end of the beach. It was built between 1915 and 1929 to protect the Great Highway and is arguably one of the more successful seawalls in the country (Wiegel, 2001). The beach has maintained a healthy volume of sand in front of the seawall and no significant end-around erosion has been noted. The seawall's success can be attributed to several factors: it traps and prevents wind-blown sediment from leaving the beach system and Point Lobos acts as a natural jetty to trap the 
dominant northerly littoral drift, as well as return tidal flow from a strong eddy that spins off Pt. Lobos during the ebbing tide.

Varying portions of the shoreline at Ocean Beach have experienced periods of erosion over the last century, with recent (since mid-1990) severe effects focused south of Sloat Blvd, in front of the San Francisco Zoo, which has destroyed and continues to threaten important local infrastructure (Figure 1.3). The greatest concern is the structural integrity of a $3.6 \mathrm{~m}(12 \mathrm{ft})$ diameter sewage transport box that lies underneath the Great Highway. This approximately ten million dollar piece of infrastructure was exposed during the 1997-98 El Niño winter, and carries one third of the City of San Francisco's treated sewage out to sea. Emergency rip-rap was placed in front the exposed pipe that winter, but that protection has steadily degraded. The City of San Francisco and the United States Army Corps of Engineers (USACE), San Francisco (SF) District have been formally investigating shoreline protection strategies since the mid-1990s (Moffatt and Nichol Engineers, 1995; United States Army Corps of Engineers, 1996).

In 2004, the USGS instituted a state-of-the-art coastal monitoring program at Ocean Beach to provide coastal managers with scientific data to help mitigate the erosion problem. This program includes repeated topographic beach surveys using All-Terrain Vehicles (ATVs), cliff surveys using ground-based light detection and ranging (LIDAR), nearshore bathymetric surveys using the Coastal Profiling System (CPS), sediment surveys using a digital bed sediment "eyeball" camera, continuous video camera monitoring, and numerical modeling using Delft3D and the Nearshore Community Model (NearCoM). This program was further augmented by extensive field operations on the ebb-tidal delta culminating in winter 2006, that included over 50 days of bathymetric surveys using a multibeam side scan system, summer and winter physical process measurements of waves and tidal currents, and nearly 200 surface sediment samples. This project supports the long-term research goals of the USGS National Program priorities of understanding, modeling and forecasting coastal evolution and systems.

\section{Preliminary Findings}

Regular topographic beach surveys, sediment analysis, nearshore bathymetric surveys, and numerical modeling have begun to quantify the processes controlling this dynamic system. The fall 2004 multibeam survey (see Chapter 4) indicated that the ebb-tidal delta has been contracting since the 1950s and there has been extensive accretion on the southern lobe of the ebb-tidal delta at the existing dredge disposal site. Sediment dumped at this site has not been dispersing and may have become relatively immobile due to the steady reduction in tidal influence along the outer reaches of the ebb-tidal delta. This shoaling has made dredging operations increasingly dangerous in recent years. The constriction of the ebb-tidal delta is possibly due to a reduction in tidal prism from San Francisco Bay, and has resulted in new wave focusing patterns over the past few decades. The delta retreat has eroded shoals that once protected the Sloat region from direct wave attack from west and southwest swells. It may have also served to shift a littoral drift nodal point from Ft. Funston north to the Sloat Region.

As a result of the new findings, the USACE implemented a new dredge disposal program in June 2005 to both reduce the strain on the existing disposal site and possibly feed sediment onto the eroding portion of Ocean Beach. Approximately 230,000 $\mathrm{m}^{3}\left(300,000 \mathrm{yd}^{3}\right)$ of sediment was placed in a nearshore disposal site - numerical modeling suggests possible shoreward transport from this region (Figure 1.2; Barnard and Hanes, 2006). The California 
State University Monterey Bay Sea Floor Mapping Lab (SFML) and USGS are currently monitoring and modeling the fate of the dredge disposal to help USACE determine if this new dredge disposal practice should be implemented permanently. This technique is a lowimpact form of shoreline protection that has been a successful form of beach nourishment in The Netherlands for years (e.g. van Duin and others, 2004), but has rarely been implemented in the United States. The cost of dredge disposal at the offshore site is approximately $\$ 9 / \mathrm{m}^{3}$ $\left(\$ 7 / \mathrm{yd}^{3}\right)$, whereas direct beach nourishment costs upwards of $\$ 33 / \mathrm{m}^{3}\left(\$ 25 / \mathrm{yd}^{3}\right)$.

\section{Prior Work}

Battalio and Trivedi (1996) estimated a sediment budget for Ocean Beach based on historical data summarized by Moffatt and Nichol Engineers (1994; 1995). The former estimated a net surplus of sediment between 1971 and 1992, which they believed to be caused by dredge material dumped on the southern lobe of the ebb-tidal delta migrating shoreward, and possibly, minor input from sea-cliff erosion to the south of Ocean Beach. Battalio and Trivedi (1996) estimated the potential shoreward transport of sediment from the ebb-tidal delta to range between 80,000 and 210,000 $\mathrm{m}^{3} / \mathrm{yr}$ during this time. An average of 403,000 $\mathrm{m}^{3} / \mathrm{yr}$ of sediment was dredged from the San Francisco Ship Channel between 1931 and 1994 (United States Army Corps of Engineers, 1996). Major losses of sediment to the Ocean Beach system are thought to occur as littoral transport moves sediment north past Point Lobos and by aeolian transport of sediment across the Great Highway driven by prevailing westerly and northwesterly winds (Domurat and others, 1979). A significant study was completed in 2000 on the ebb-tidal delta to identify a major potential borrow site for the San Francisco Airport Expansion (ADEC, 2000). The study focused primarily in the region located within and adjacent to the ship channel. Field work included $104 \mathrm{~km}$ (56 nautical miles) of geophysical surveys, 12 grab samples, and seven marine borings. A suite of other reference, while largely limited in scope, when taken as a whole provide a good knowledge base for the region (Battalio and Trivedi, 1996; Domurat and others, 1979; Galvin, 1980; Johnson, 1977; Moffatt and Nichol Engineers, 1995; Street and others, 1969; Trask, 1954; United States Army Corps of Engineers, 1996; Wiegel, 2001; Woodward-Clyde Consultants, 1978). The USGS has published some summaries of work to date in this region (Barnard, 2005; Barnard and Hanes, 2005, 2006; Barnard and others, 2006a; Barnard and others, 2006b; Barnard and others, 2006c; Dartnell and others, 2006; Erikson and others, 2006).

\section{Future Work}

Beginning in Fiscal Year (FY) 2007, the Ocean Beach Coastal Processes Study officially transitioned to the San Francisco Bight Coastal Processes Study, in recognition of the impact of regional coastal processes within this massive interconnected coastal environment. This system includes the San Francisco littoral cell, extending $75 \mathrm{~km}$ from Pt. Reyes in the north to Pt. San Pedro in the south, and San Francisco Bay, covering an area of $4100 \mathrm{~km}^{2}$ and draining over $40 \%$ of the land of California (Figure 1.1; Chin and others, 2004; Friends of the Estuary, 1997). 


\section{Report Outline}

This report is set up to provide a broad summary of each major data collection effort at the mouth of San Francisco Bay from 2004-2006:

- Chapter 2-Beach Topographic Mapping

- Chapter 3-Nearshore Surveys with Personal Watercraft

- Chapter 4-Video Monitoring

- Chapter 5-Offshore Instrument Deployments

- Chapter 6-Surf Zone Instrument Deployments

- Chapter 7-Multibeam Mapping

- Chapter 8-Grain Size Mapping

- Chapter 9-Numerical Modeling

- Delft3d

- NearCoM

- Chapter 10-Other Data Collection

At the end of each chapter there are bullet points to emphasize the key findings- these are also listed in the Executive summary at the beginning of this report. A comprehensive list of all field data collection efforts is contained in the appendix.

\section{Project Support and Collaboration}

The Ocean Beach Coastal Processes Study has benefited greatly from internal support at the USGS as well as its interactions with a number of other agencies and groups. A list of the primary collaborators is outlined below:

- USGS Support:

- Mendenhall Post-doctoral Fellowship (Patrick Barnard)

- Coastal Evolution: Process-based, Multi-scale Modeling Project (Dan Hanes)

- Delft Hydraulics Cooperative (Giles Lesser, Edwin Elias)

- USGS Collaborators: Jeff List

- Academic Partners

- Cal State Monterey Bay (Rikk Kvitek, Seafloor Mapping Lab)

- San Francisco State (Toby Garfield, Karen Grove, Jeffrey Hansen)

- University of Delaware (Fengyan Shi)

- University of California, Santa Cruz (Gary Griggs)

- Oregon State University (Peter Ruggiero)

- Government Agencies:

- U.S. Army Corps of Engineers, San Francisco District (Peter Mull, Stephen Chesser, Tom Kendall)

- City of San Francisco (Frank Filice) 
- California Department of Boating and Waterways (Kim Sterrett)

- National Park Service, Golden Gate National Recreation (Tamara Williams, Steve Ortega, Daphne Hatch, Rebecca Beavers)

- Private Sector:

- Phillip Williams and Associates (Bob Battalio)

- Moffatt \& Nichol Engineers (Dilip Trivedi) 


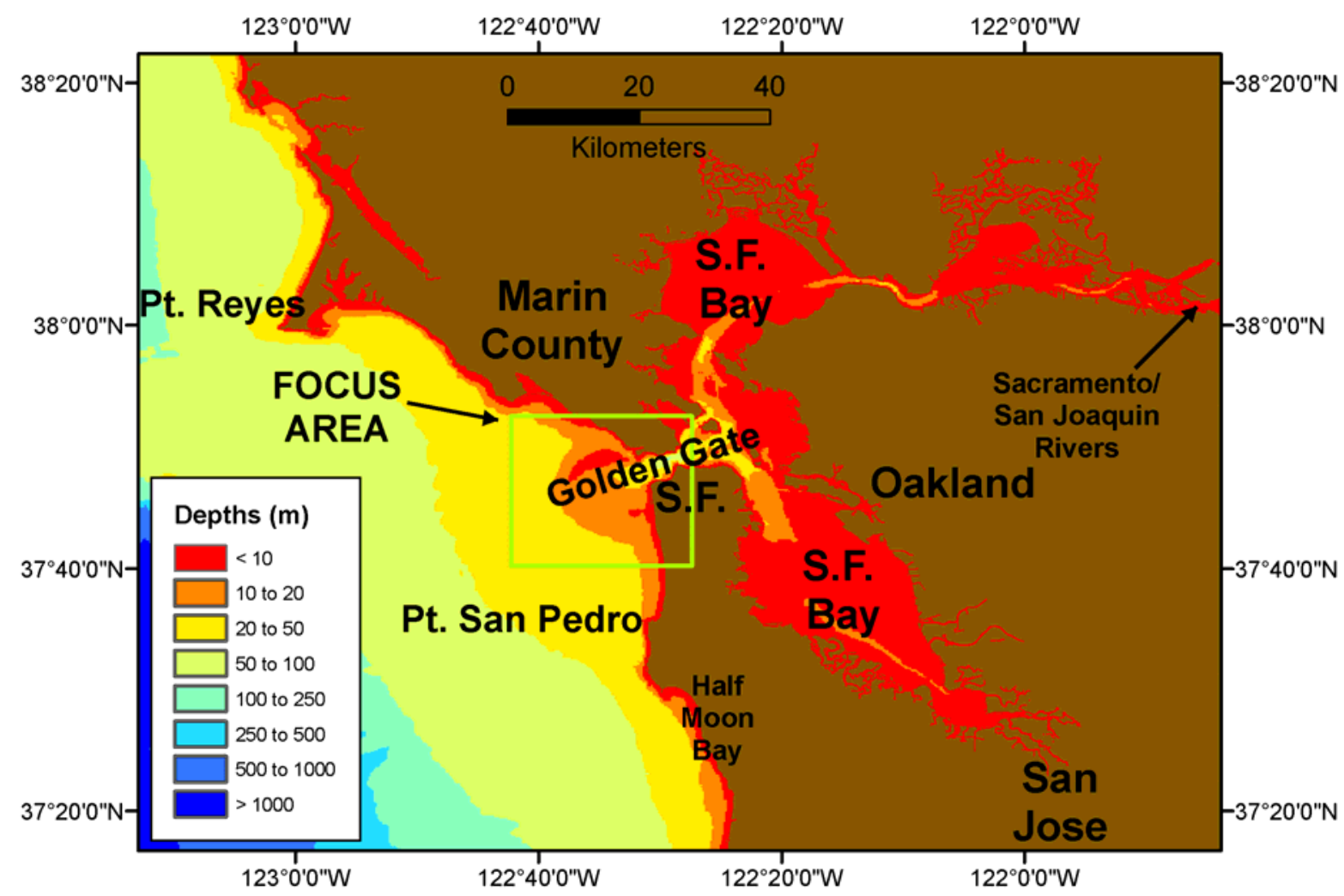

Figure 1.1. Map of the study area included in the San Francisco Bight Coastal Processes Study, and the focus site for the Ocean Beach Coastal Processes Study (green box). 


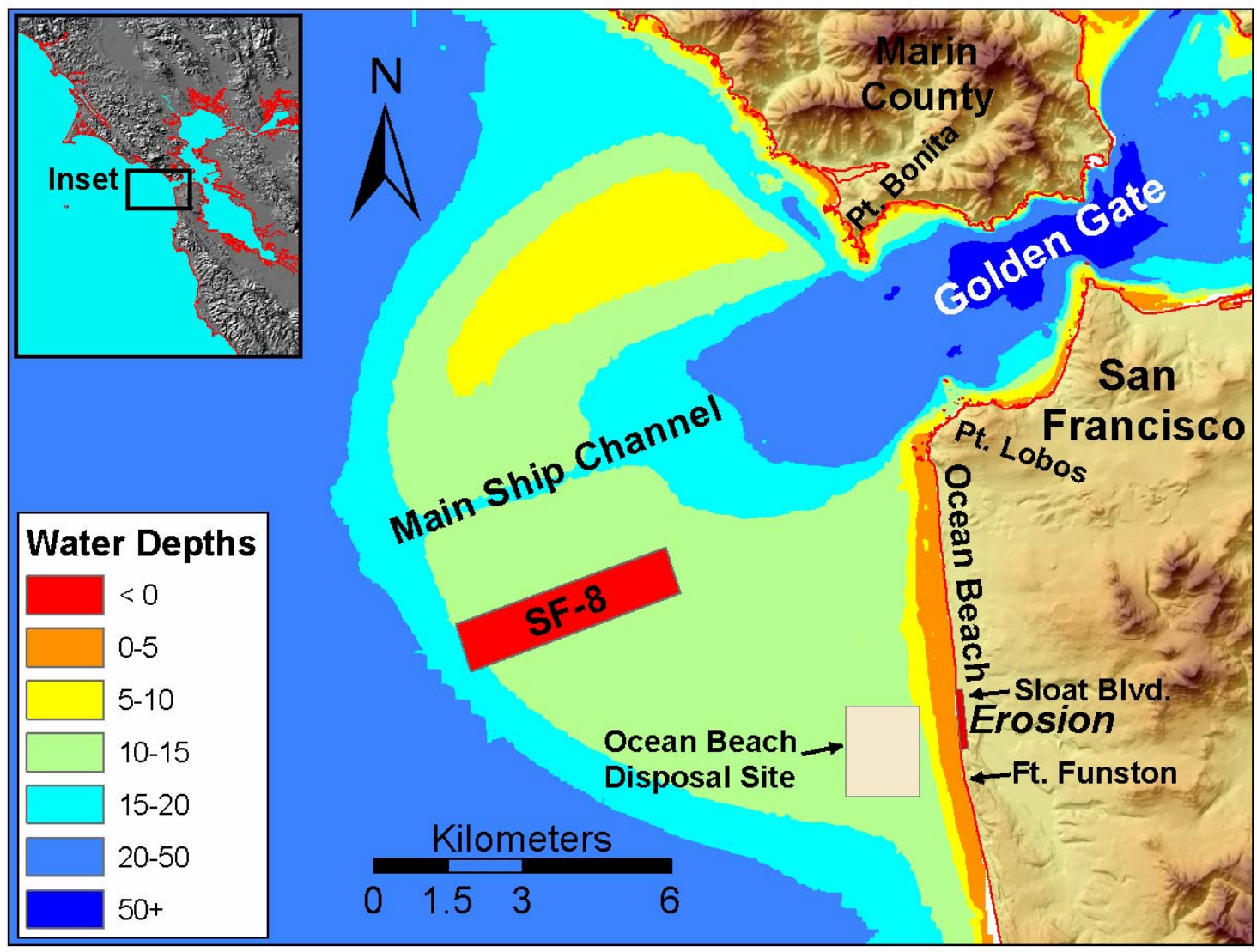

Figure 1.2. Map showing the 0 cean Beach Coastal Processes study area, including the locations of the existing dredge disposal site (SF-8) and test dredge disposal site (Ocean Beach Disposal Site).

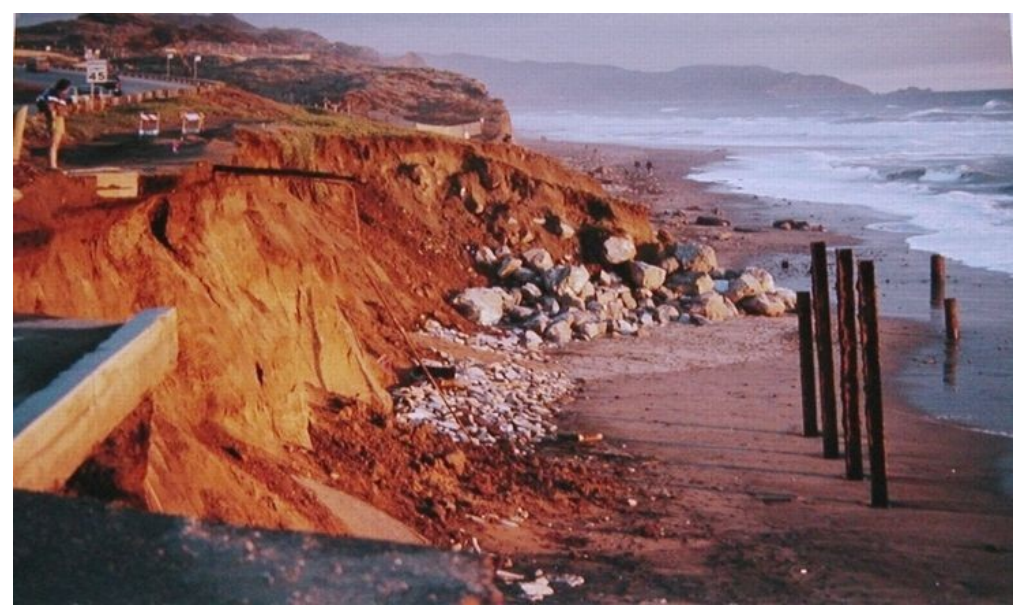

Figure 1.3. Erosion south of Sloat Blvd. at Ocean Beach during 1997-98 El Niño winter (image courtesy of Surfrider). The Great Highway is to the left. 


\title{
Chapter 2- Beach Topographic Mapping
}

\author{
By Patrick L. Barnard
}

\section{Introduction}

Forty-five topographic beach surveys have been conducted at Ocean Beach from April, 2004, through the end of 2006. The purpose of these surveys is to:

- quantify seasonal changes in beach volume, shoreline position, and profile change

- determine the impact of winter storms on beach morphology

- determine beach response to nearshore dredge disposal

- develop an empirical model for relating offshore wave conditions to beach response

\section{Methodology}

The surveys were conducted with all terrain vehicles (ATVs) that use Ashtech $^{(}$ equipment to collect data with the Differential Global Positioning System (DGPS; Figure 2.1). The data collected on the ATV was post-processed using data recorded at a base station, which was set up on a USGS benchmark at the Oceanside Water Pollution Control Plant, located at the southern end of Ocean Beach. All surveys were collected in the Universal Transverse Mercator (UTM) projection, using NAD83, Zone 10 as the horizontal coordinate system. All elevations are relative to NAVD 88, which is approximately $2 \mathrm{~cm}$ below MLLW at the Ft. Point Tide Station (National Oceanic and Atmospheric Association, 2006b), located just inside the Golden Gate in San Francisco Bay. Based on repeated surveys of the sidewalk behind the O'Shaugnessy Sea Wall before and after each topographic survey, the horizontal and vertical accuracy of this system is approximately $+/-3 \mathrm{~cm}$. Each survey consisted of from 15,000 to 35,000 points covering the entire seven kilometer stretch of Ocean Beach, with coverage often reaching below the MLLW line. This is far more efficient than traditional land surveying techniques, where only approximately one percent of the number of survey points could be gathered in the same amount of time. Triangular irregular networks (TINs) are created from post-processed $\mathrm{x}-\mathrm{y}-\mathrm{z}$ data, and then gridded to $2 \mathrm{~m}$ cells to be analyzed in ArcGIS and MATLAB to identify seasonal trends, storm effects, areas of chronic erosion, shoreline position and beach volume changes (Figure 2.2). A list of the surveys to date is included in the appendix. Airborne light detection and ranging (LIDAR) data surveys collected by the National Oceanic and Atmospheric and Atmospheric Association (NOAA), USGS, and NASA in the Fall of 1997 and Spring of 1998 (National Oceanic and Atmospheric Association, 2007) is also used here to look at longer-term beach change and seasonal change during an El Niño winter. Of the 45 ATV topographic surveys performed thus far, 20 have been conducted in response to large winter storms.

For analytical purposes, the beach has been divided into seven reaches based on beach morphology, observed morphologic response and physical structures. Shore normal profiles have been generated along Ocean Beach; 138 total with numbering increasing from north to south with $50 \mathrm{~m}$ alongshore spacing. The reaches and associated profiles have been assigned according to the profile ranges included in Table 2.1. 
Table 2.1 Reach designations at Ocean Beach.

\begin{tabular}{|c|c|c|c|c|}
\hline & \multirow[b]{2}{*}{ Name } & \multicolumn{3}{|c|}{ Profile Range } \\
\hline & & $\frac{\text { Length }}{(\mathrm{m})}$ & $\underline{\text { Start }}$ & \\
\hline Reach 1 & 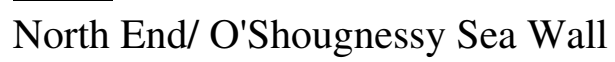 & $\overline{1477}$ & $\overline{1}$ & \\
\hline Reach 2 & Dune Field- S of Lincoln & 1282 & 31 & \\
\hline Reach 3 & New Sea Wall & 925 & 57 & \\
\hline Reach 4 & Dune Field- $\mathrm{N}$ of Sloat & 684 & 75 & \\
\hline Reach 5 & North of pinch point (N Sloat) & 574 & 89 & 100 \\
\hline Reach 6 & South of pinch point (S Sloat) & 467 & 101 & 109 \\
\hline Reach 7 & Ft. Funston & 1442 & 110 & $13 \xi$ \\
\hline
\end{tabular}

See Fig. 2.3 for a map of these locations. Reaches 5 through 6 cover the erosion hot spot. Cross-sections were extracted along the profile lines for each of the processed topographic surveys to analyze beach parameters such as beach width, beach slope, and sediment storage.

\section{Results}

\section{Seasonal Change}

Results from the ATV surveys show typical seasonal patterns of beach erosion during the winter months and accretion during the summer/early fall, with beach volume maximum in September/ October and beach minimum in January (Figures 2.4-2.5). Over the course of the surveys to date the beach volume has fluctuated within an envelope of approximately $+/-$ $200,000 \mathrm{~m}^{3}$ of sediment on the subaerial beach (here defined as elevations above $0.5 \mathrm{~m}$ relative to NAVD88). Between October 2004 and May 2005, a fairly typical winter in terms of wave climate, the mean high water (MHW) shoreline position retreated an average of ten meters, with localized retreat up to $40 \mathrm{~m}$ (Figure 2.6). However, between October 1997 and April 1998, an intense El Niño winter with a more southerly wave approach, shoreline retreat was twice as great, with an average of $22 \mathrm{~m}$ of erosion for the entire beach, and localized pockets of shoreline retreat of over $70 \mathrm{~m}$. The most vulnerable part of Ocean Beach (Reaches five and six) was significantly eroded during the1997-98 winter, with an already narrow beach eroding over $20 \mathrm{~m}$ on average. Reaches one and two both lost over $30 \mathrm{~m}$ of shoreline during this period, showing its vulnerability to more southerly swell. During the 1997-98 winter, the northern end of most beaches in California accreted (Storlazzi and Griggs, 2000), due to the more southerly wave approach. However, due to the large ebb tidal delta at the mouth of San Francisco Bay, even waves from a more southerly direction will be refracted to near shore normal, and thus offshore transport dominates the beach morphology.

\section{Storm-related Change}

Superimposed on the seasonal trends, there is a quasi-systematic alongshore alternating erosion/accretion trend at the same wavelengths as the rip spacing at Ocean Beach, approximately 200-400 m (Figure 2.7). In the vicinity of the erosion hot spot at Ocean 
Beach, winter storms cause dramatic and immediate beach response, with localized monthly shoreline retreat approaching as much $20 \mathrm{~m}$.

Looking at event-scale change, large storms can erode the beach at the same scale as the seasonal trends. A single storm in March 2005 removed over 40,000 $\mathrm{m}^{3}$ of sediment from the beach and resulted in as much as $20 \mathrm{~m}$ of local shoreline retreat (Figures 2.8-2.9). A series of winter storms can result in more significant beach response, such as during the week of December 22-29, 2005, when over 100,000 $\mathrm{m}^{3}$ of sediment was removed from the beach, with an average shoreline retreat of ten meters, and localized retreat of over $22 \mathrm{~m}$.

\section{Long-term Change}

Decadal scale change has been calculated using the LIDAR data collected in 1997-98, as the first datum based topographic survey, and recent USGS surveys (Figure 2.10). Although there are local anomalies based on large-scale horn and cusp location, there is a pronounced trend since 1997-98 of accretion in the northern and central portions of Ocean Beach (i.e. profiles 1-80) and erosion in the vicinity of Sloat in the southern portion of Ocean Beach (i.e. profiles 80-120). Overall, the entire beach Mean High Water (MHW) line accreted an average of $5.8 \mathrm{~m}$ (maximum erosion $=18.8 \mathrm{~m}$, maximum accretion $=41.8 \mathrm{~m}$ ) from October 1997 to October 2004, and $2.7 \mathrm{~m}$ from April 1998 to April 2006 (maximum erosion $=49.4 \mathrm{~m}$, maximum accretion $=42.1 \mathrm{~m}$ ). Reach five showed the highest amount of erosion along the entire beach, with $15.1 \mathrm{~m}$ of shoreline retreat since fall 1997.

Rates of shoreline accretion at Reach one at the northern end of Ocean Beach average $2.1 \mathrm{~m} / \mathrm{yr}$ since the 1997-98 LIDAR surveys, and retreat at reaches five and six (erosion hot spot) average $1.1 \mathrm{~m} / \mathrm{yr}$. However, erosion along some profiles in Reach six has become so severe that the MHW line on the planar beach no longer exists with water reaching the shoreline protection structures, and therefore cannot be mapped with the ATV system, and no rate calculated.

The USGS National Assessment study (Hapke and others, 2006) for the Ocean Beach area indicate that the long- (mid to late 1800's - 1998) and short term (1950's - 1998) rates of shoreline change are stable at the northern end $(\sim 0 \mathrm{~m} / \mathrm{yr})$, but become strongly erosional to the south $(\sim 1-2 \mathrm{~m} / \mathrm{yr})$. For the $56 \mathrm{~km}$ of coastline south of the Golden Gate, the long term average is $-0.2 \mathrm{~m} / \mathrm{yr}$ and the short term average is $-0.5 \mathrm{~m} / \mathrm{yr}$.

\section{Beach Profile Analysis}

Beach profile calculations along the 138 profiles at Ocean Beach show significant spatial variation. Average values of beach width and sediment storage decrease with distance south along Ocean Beach (Figure 2.11). There is a sharp drop in both beach width and storage at reach 6 . The slope is steeper in the southern portion of the beach and there is a distinct change in beach slope that corresponds precisely with the offshore location of the crest of the southern lobe of the ebb tidal delta. There is a sharp peak in maximum beach slope values at reach 4 , however, this is approximately 1 kilometer north of the location where beach width and storage are at a minimum. There are also seasonal fluctuations in beach slope, although this also varies alongshore- during the winter the beach slope increases in the northern reaches and decreases in the southern reaches (Figure 2.12). 


\section{Dredge Disposal Monitoring}

In May 2005 the USACE, placed 230,000 $\mathrm{m}^{3}$ of sediment dredged from the main shipping channel at a nearshore disposal site approximately $500 \mathrm{~m}$ offshore of the erosion hot spot at Ocean Beach (see Figure 1.2). A comparison of topographic beach surveys during the May-August period in both 2004 and 2005 indicate a higher rate of beach accretion, particularly along the northern half of Ocean Beach (Figure 2.13). However, this higher rate of accretion could be attributed to a number of variables (e.g. dominant wave direction), and without a longer term data set it is not possible to isolate the dredge disposal as the direct cause of this accretion (Barnard and Hanes, 2006).

\section{Empirical Model Development}

Preliminary analysis of the winter storm surveys indicates a strong correlation $\left(\mathrm{r}^{2}=\right.$ $0.65)$ between winter significant wave height $\left(\mathrm{H}_{\mathrm{s}}\right)$ and direction with beach response at Reach 5 (Fig. 2.14). Large waves $\left(\mathrm{H}_{\mathrm{s}}>5 \mathrm{~m}\right)$ from azimuths of less than $300^{\circ}$ cause more erosion than from azimuths greater than $300^{\circ}$. This is likely due to the sheltering effects of the massive ebb tidal delta at the mouth of San Francisco Bay. Waves become increasingly less impeded as they approach Ocean Beach from more southerly directions. See Hansen (2007) for more information.

\section{Discussion}

The trend of erosion at the southern end of Ocean Beach has continued since the last airborne LIDAR surveys were conducted in the late 1990s, putting increased pressure on already threatened infrastructure. Conversely, the northern end of Ocean Beach has accreted significantly, with rates of over five meters per year measured at some profile locations. This accretion could be the result of onshore sediment transport from SF-8 (see Figure 1.2), as postulated by Battalio and Trivedi (1996). In 1971, the USACE began disposing of ship channel dredge material south of the Main Shipping Channel on the ebb tidal delta, as opposed to seaward of the ebb tidal delta. This beach accretion could represent transport from this disposal site. The rate of accretion at the northern end is much greater than that eroded from the southern end of Ocean Beach, and therefore a significant amount of sediment must be transported from offshore or from the north, potentially from the strong tidal currents carrying sediment around Point Lobos from the Golden Gate. This issue will be discussed further in upcoming chapters.

The crest of the ebb tidal delta corresponds precisely with the location of increased beach slopes at Ocean Beach (Figure 2.11), as well as a shift from a decadal accretional to erosional trend (Figure 2.10). Therefore, it appears that the shape of the ebb tidal delta, and specifically the location of the crest of the ebb tidal delta, exerts a first order control on longer-term beach morphology changes at Ocean Beach. This control likely results due to wave focusing on the crest of the bar, which in turn produces variations in littoral drift magnitude and direction through this area (see Chapters 5 and 10). If the current trend of ebb tidal delta constriction continues (see Chapters 1 and 7), then it's likely that the erosional trend in the southern portion of Ocean Beach will migrate further north. 


\section{Conclusions}

- Beach volume at Ocean Beach varies seasonally over a maximum envelope of $400,000 \mathrm{~m}^{3}$.

- The El Niño winter of 1997-98 caused double the average shoreline retreat than the more typical 2004-05 winter at Ocean Beach.

- Shoreline retreat can exceed $20 \mathrm{~m}$ during severe winters, with localized retreat over $70 \mathrm{~m}$.

- Single storm events can cause an average shoreline retreat of over ten meters and remove over $100,000 \mathrm{~m}^{3}$ of sediment from the beach.

- Since the 1997-98 airborne LIDAR surveys, there has been a trend of accretion at the north end of Ocean Beach (Reach 1 shoreline change rate $=$ $+2.1 \mathrm{~m} / \mathrm{yr}$ ) and continued erosion at the south end (Reach 5-6 shoreline change rate $=-1.1 \mathrm{~m} / \mathrm{yr}$ ).

- Preliminary findings from storm response surveys indicate a potentially strong correlation between wave height and direction with beach response.

- The shape of the ebb tidal delta exerts a first order control on decadal scale morphology changes at Ocean Beach.

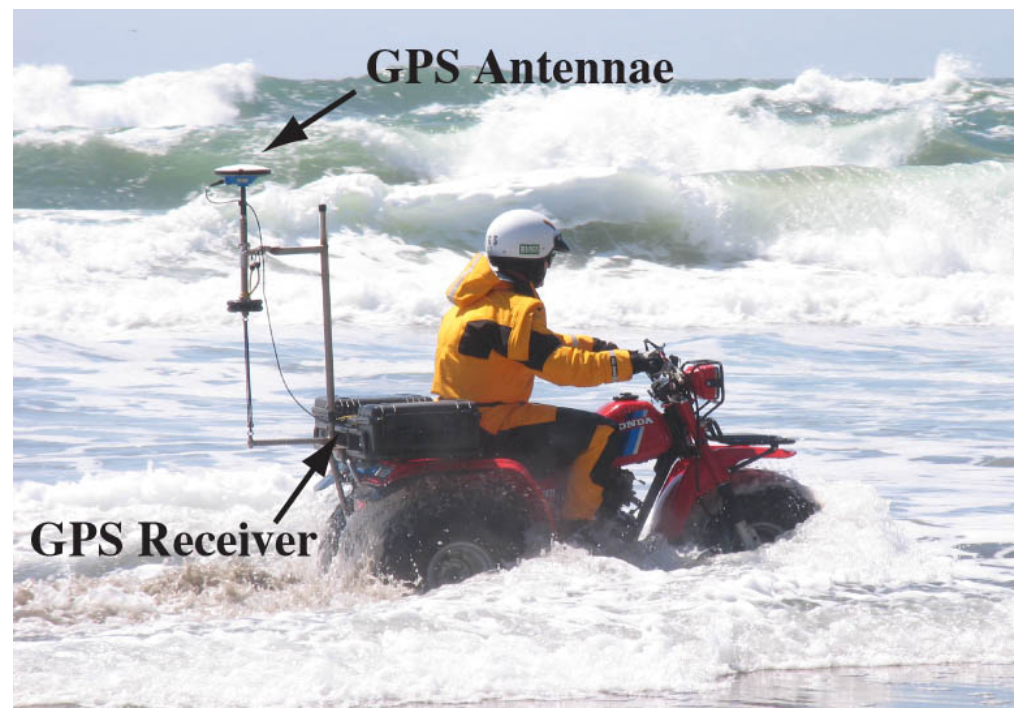

Figure 2.1. ATV set up for conducting topographic beach surveys using Differential GPS. 

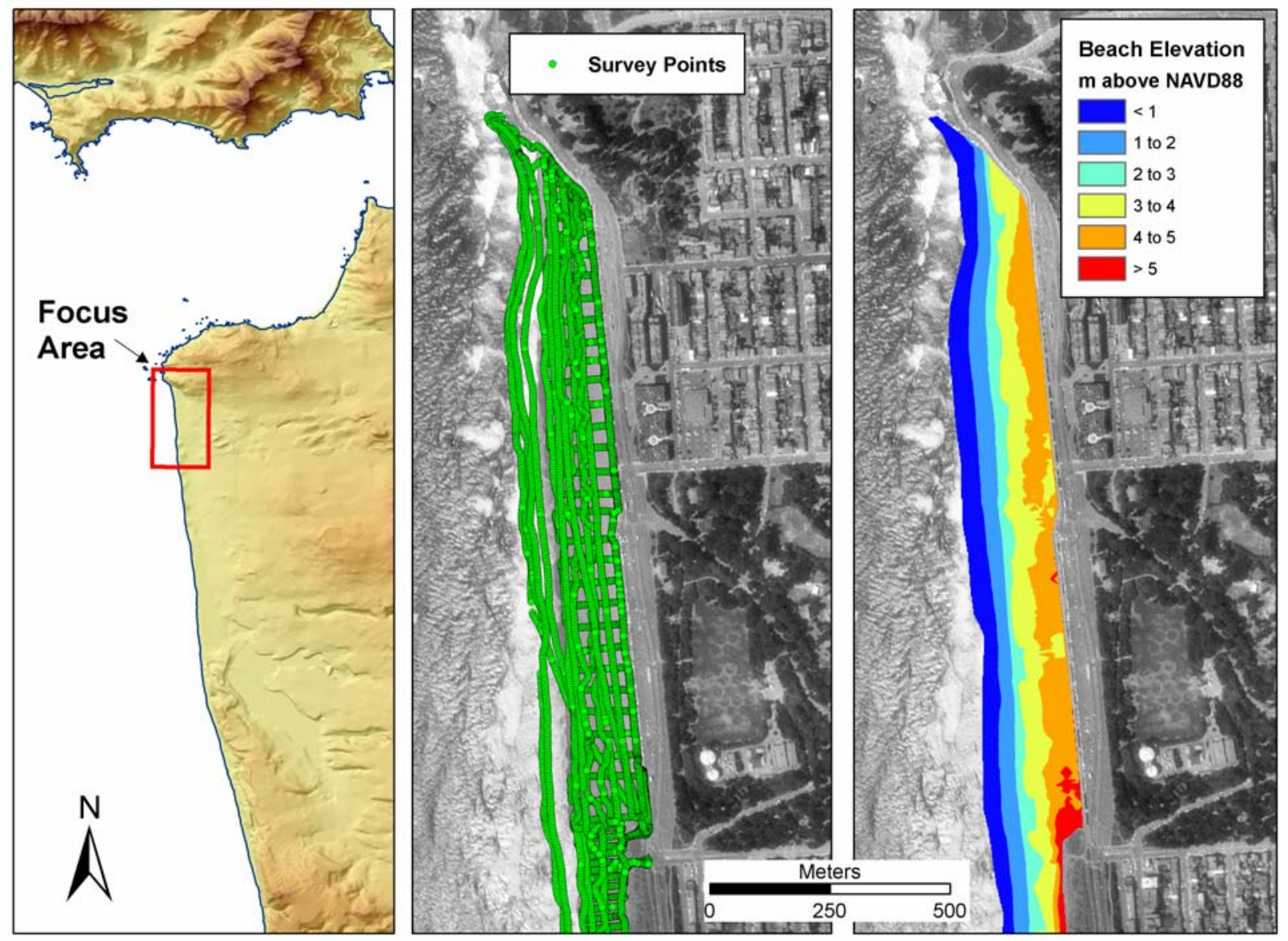

Figure 2.2. Typical data coverage (middle panel) and resulting grid (right panel) at the northern end (Reach 1) of Ocean Beach, from the November 15, 2004 survey. 


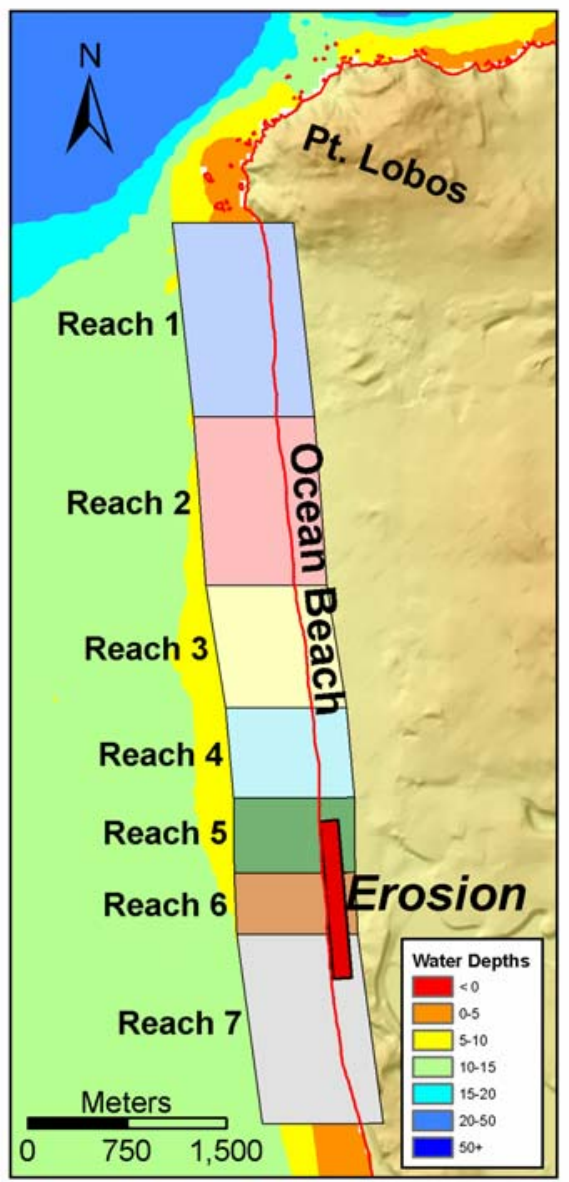

Figure 2.3. Map of the reach locations referenced in the analysis of beach topographic data. The area of chronic erosion is labeled.

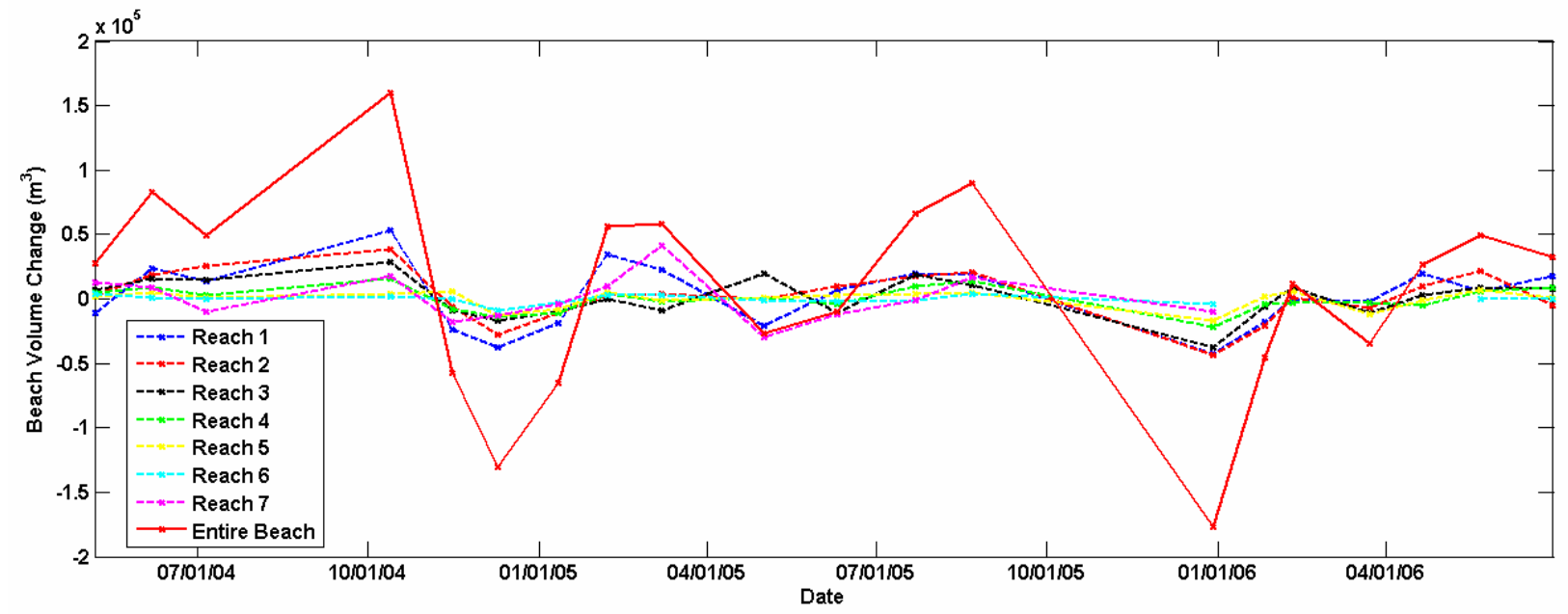

Figure 2.4. Beach volumetric fluctuations above $0.5 \mathrm{~m}$ (NAVD88) from April 2004 to June 2006. 


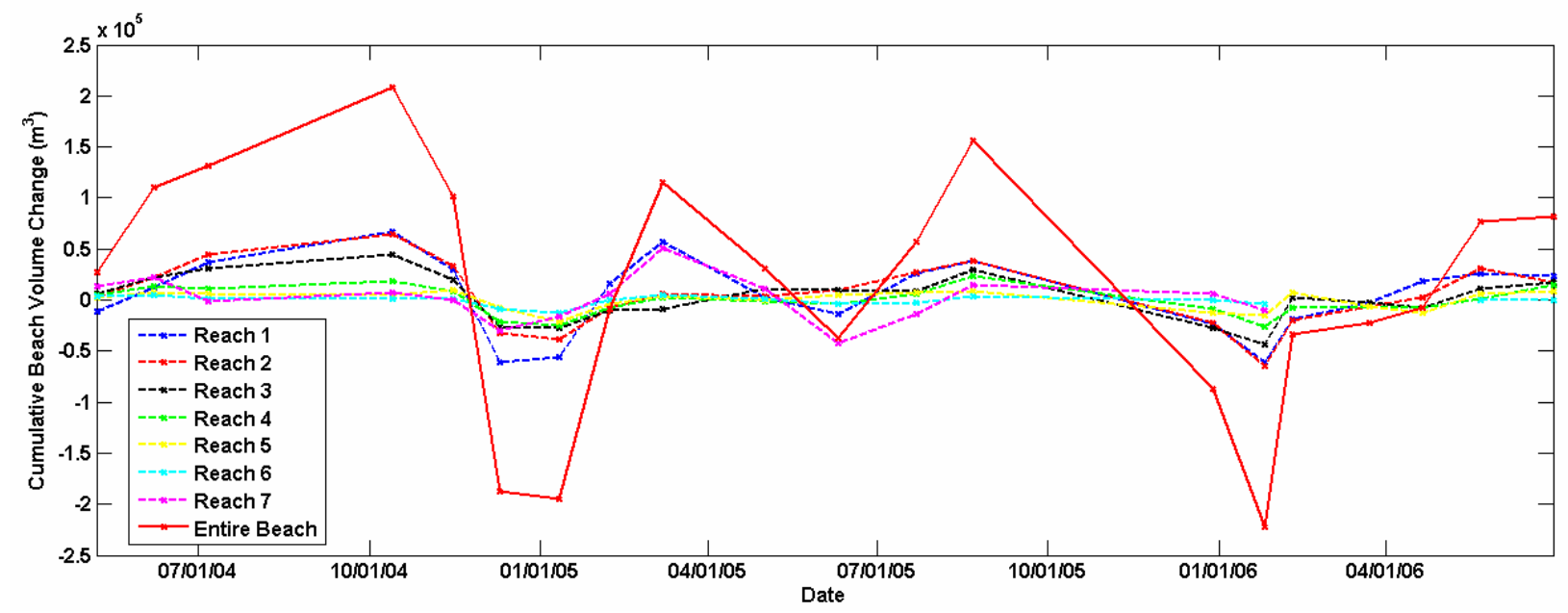

Figure 2.5. Cumulative beach change above $0.5 \mathrm{~m}$ (NAVD88) from April 2004 to June 2006.

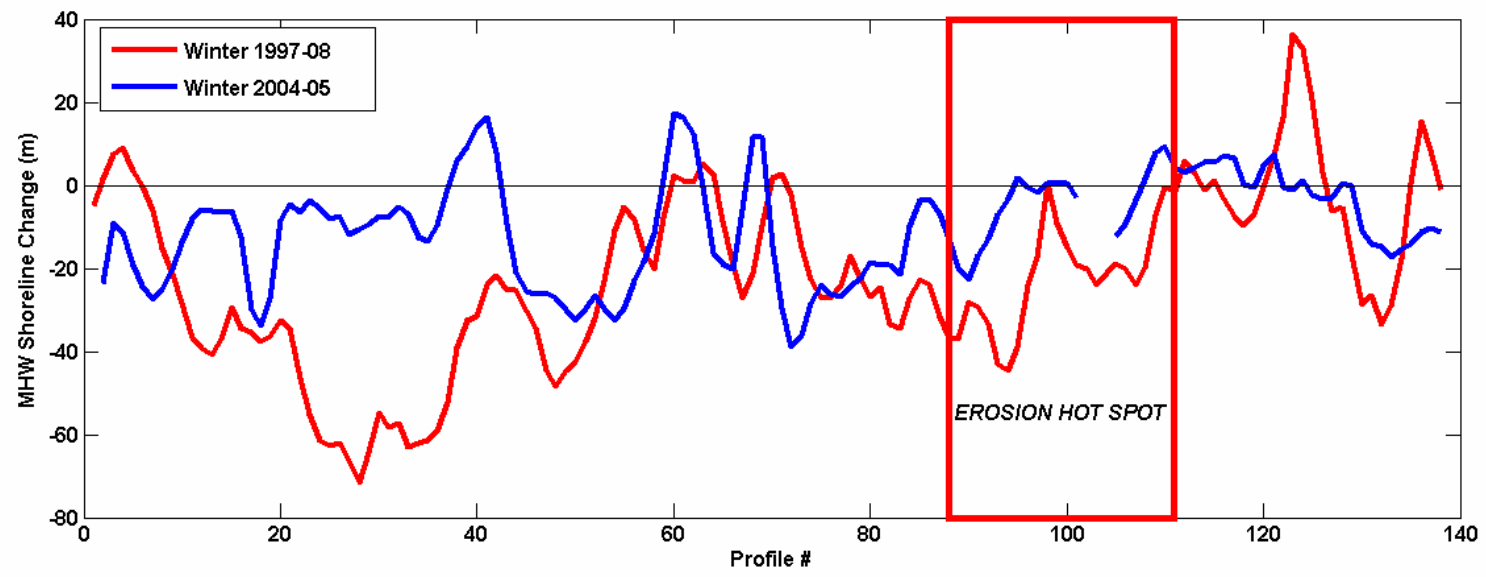

Figure 2.6. Winter change (MHW line) during the 1997-98 El Niño compared to the winters of 2004-05. Profiles are spaced $50 \mathrm{~m}$ apart and numbering increases from north to south. 

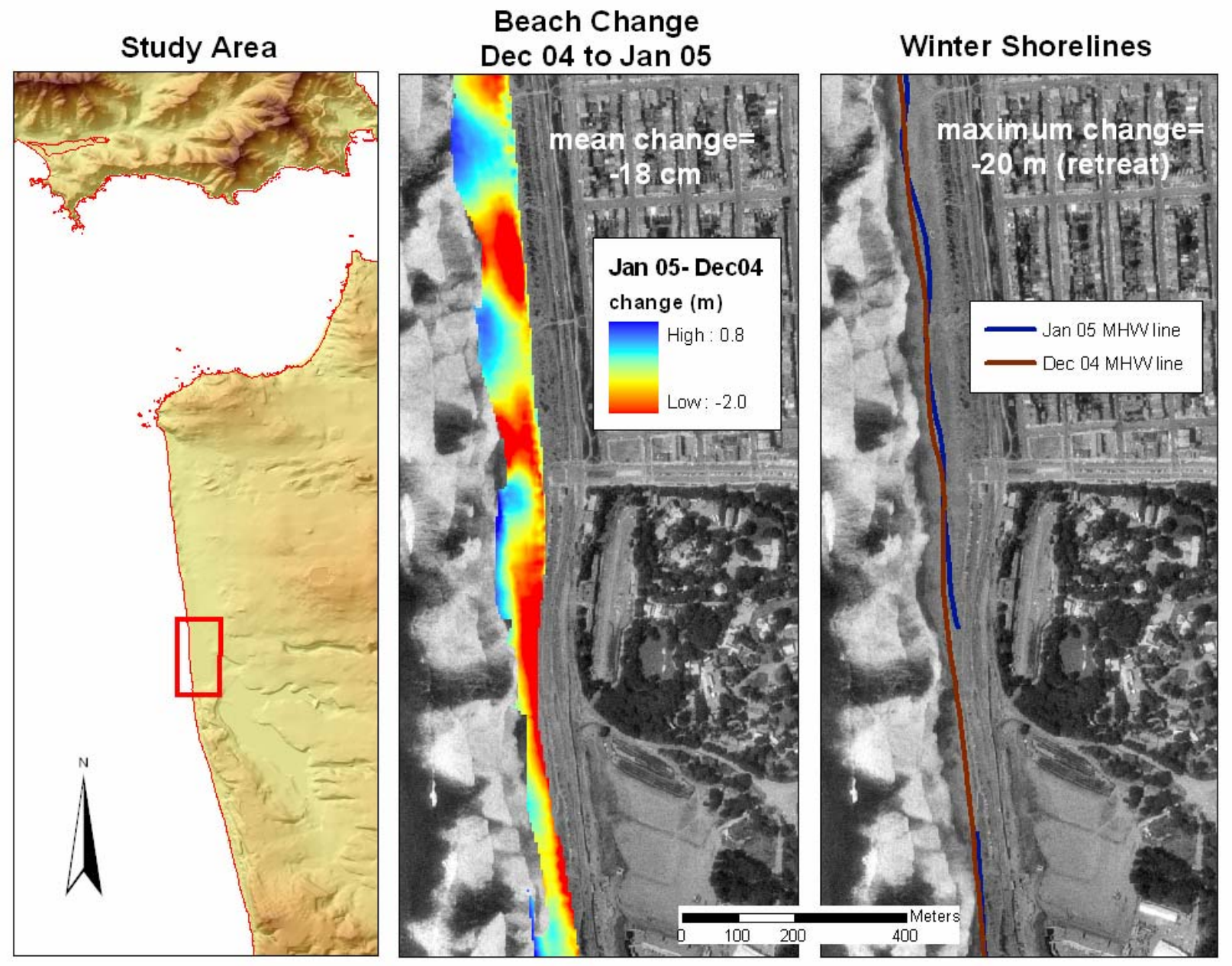

Figure 2.7. Beach change in the Sloat Blvd. (main east-west street pictured) region between December 2004 and January 2005. 
Figure 2.8. Short-term beach change associated with a significant wave event (offshore wave heights reached six meters) at Ocean Beach in March 2005 as compared to the month prior. A) Northern Ocean Beach (Reach 1). B) Southern Ocean Beach (Reach 7).

A

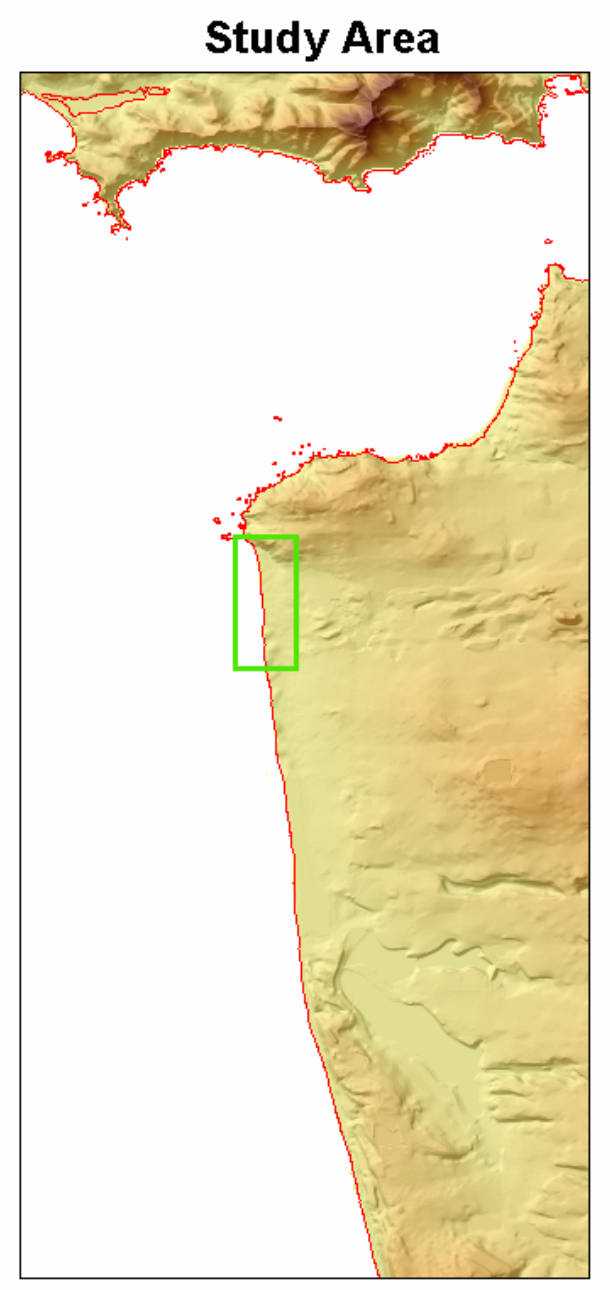
Beach Change, Feb. 7 Beach Change, to March 8, 2005 March 8-11, 2005

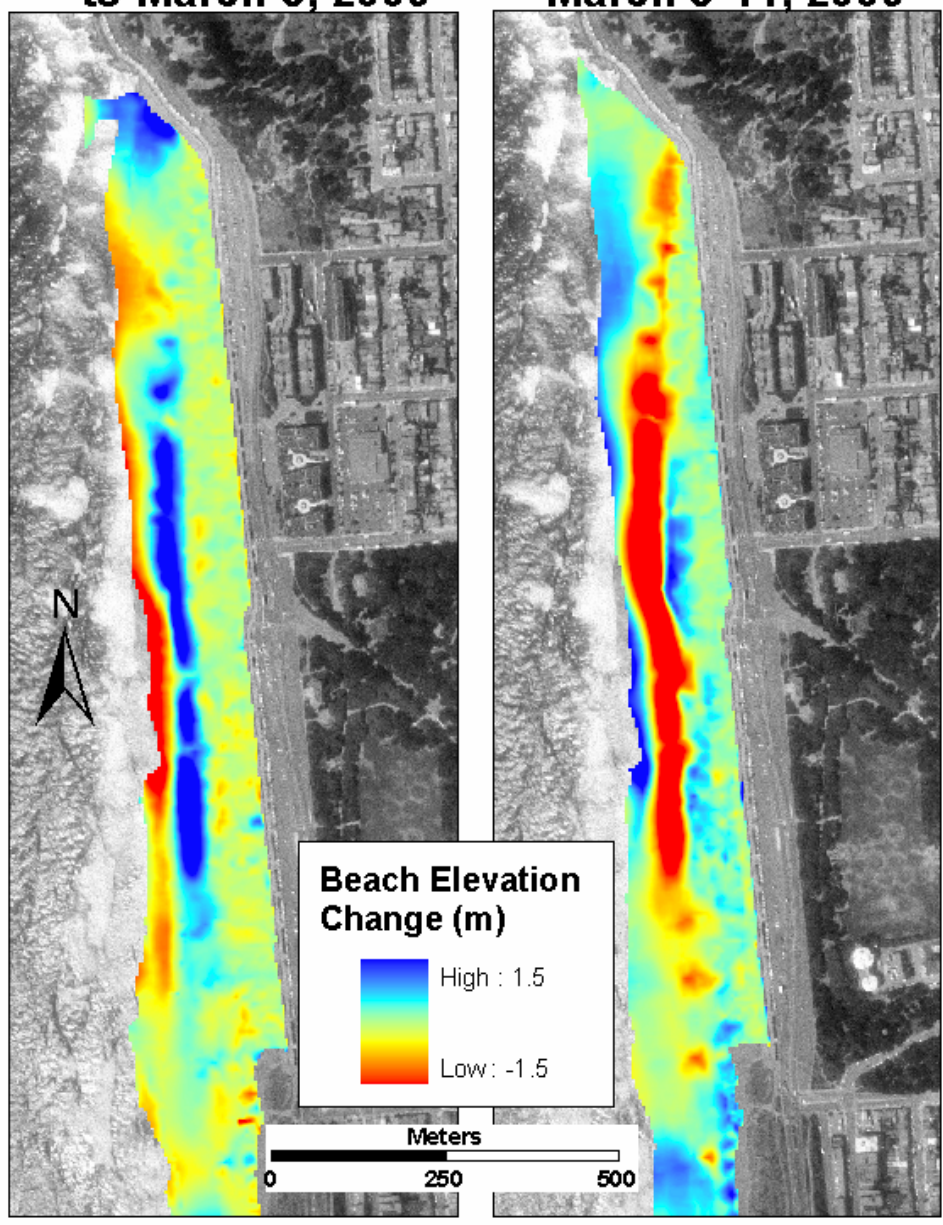


B

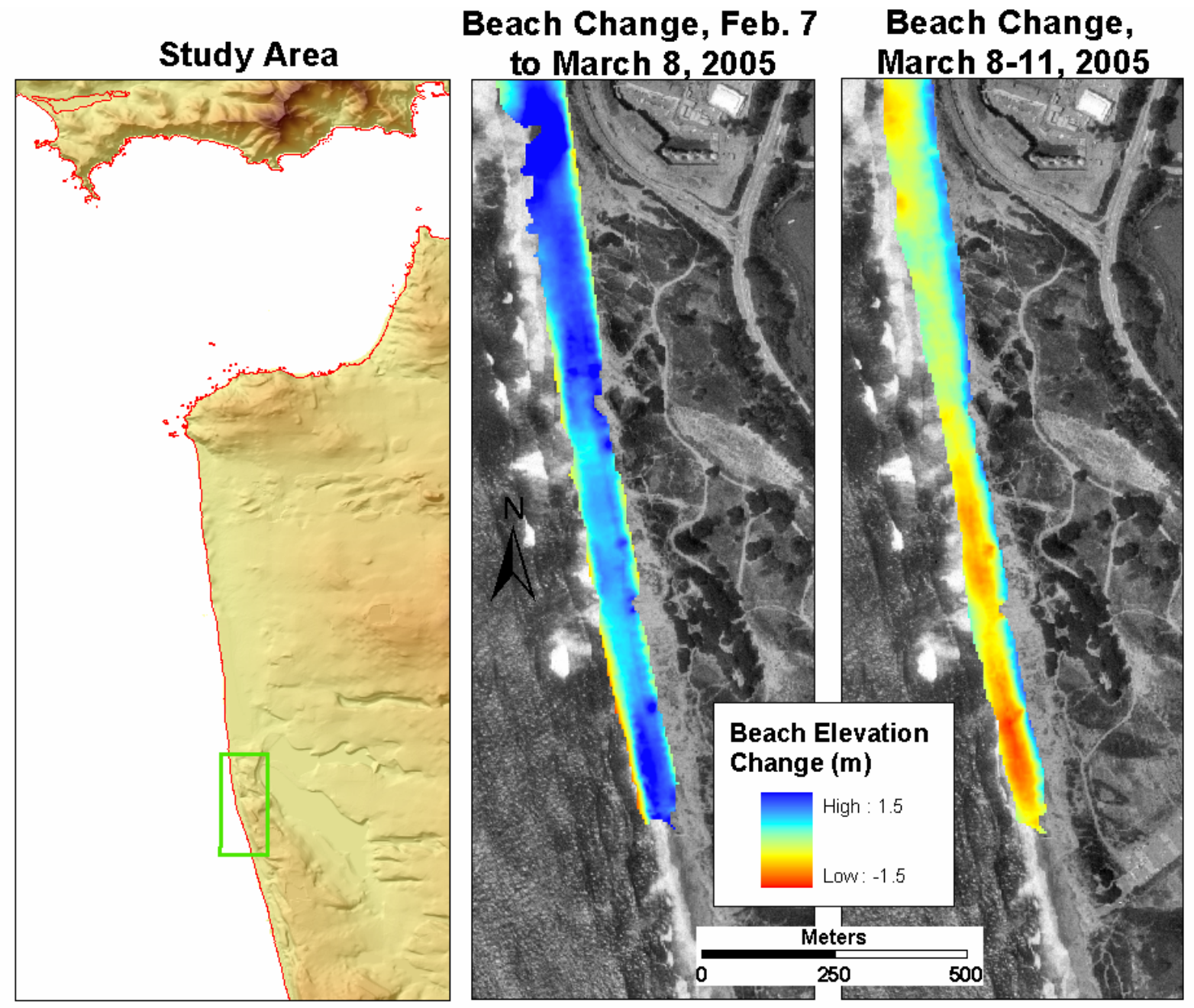




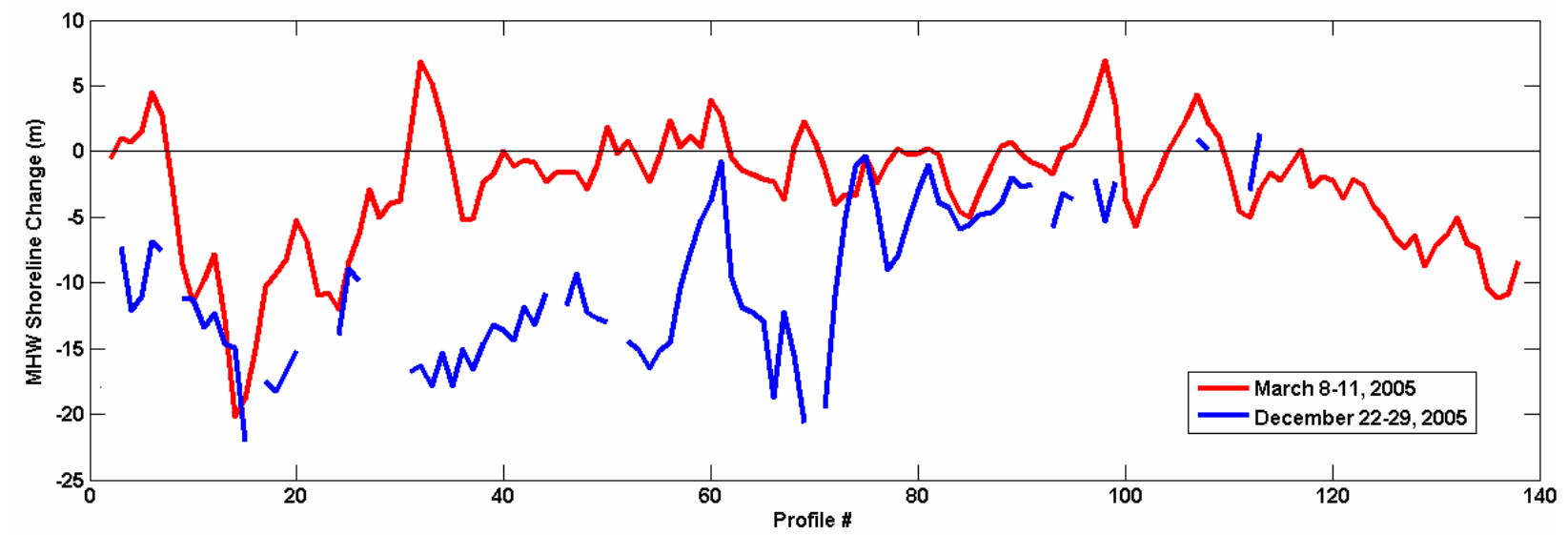

Figure 2.9. Alongshore shoreline change from two storms in 2005. Gaps in the data indicate no data and/or no MHW shoreline accessible.
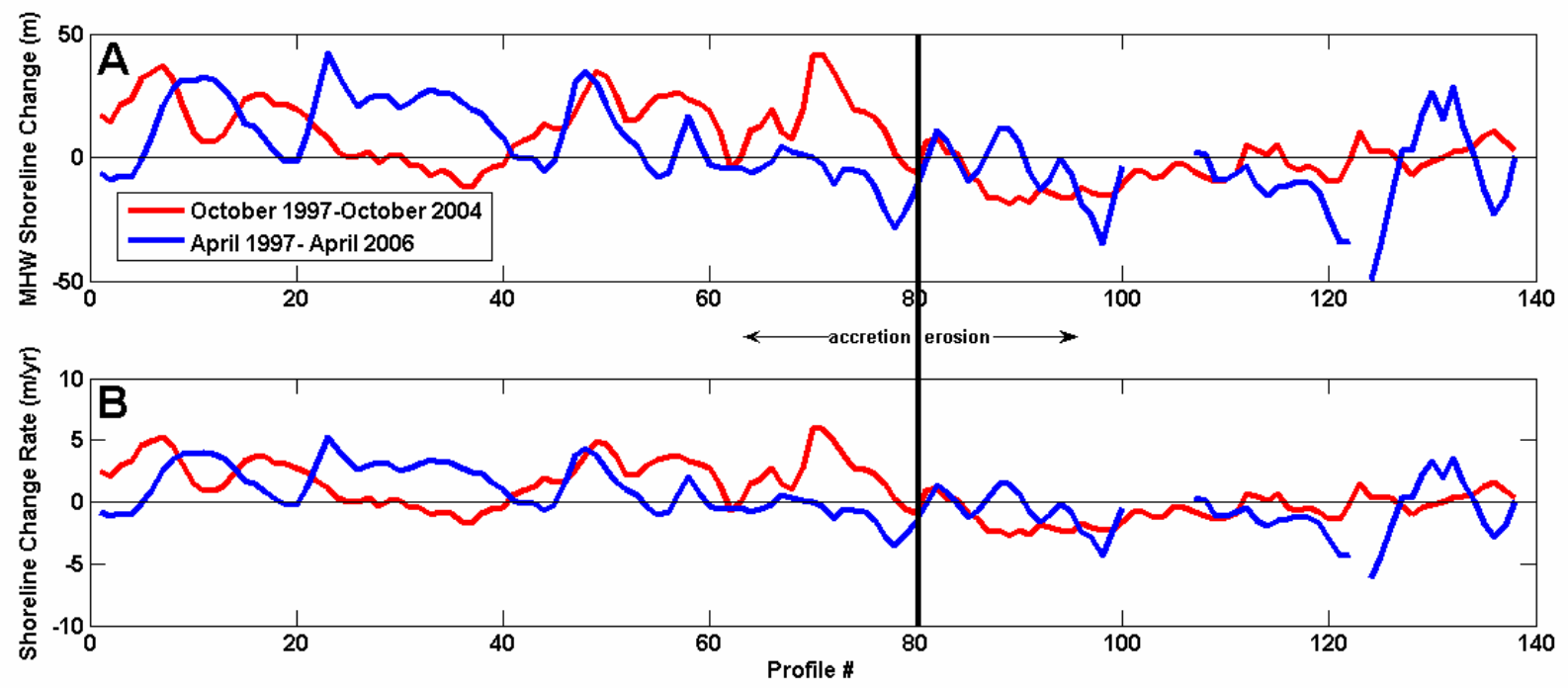

Figure 2.10. Shoreline change since LIDAR data was collected in 1997-98. The red line represents the rate as determined from the fall beach (October 1997 - October 2004). The blue line represents the rate as determined from the spring beach (April 1997 - April 2006). 

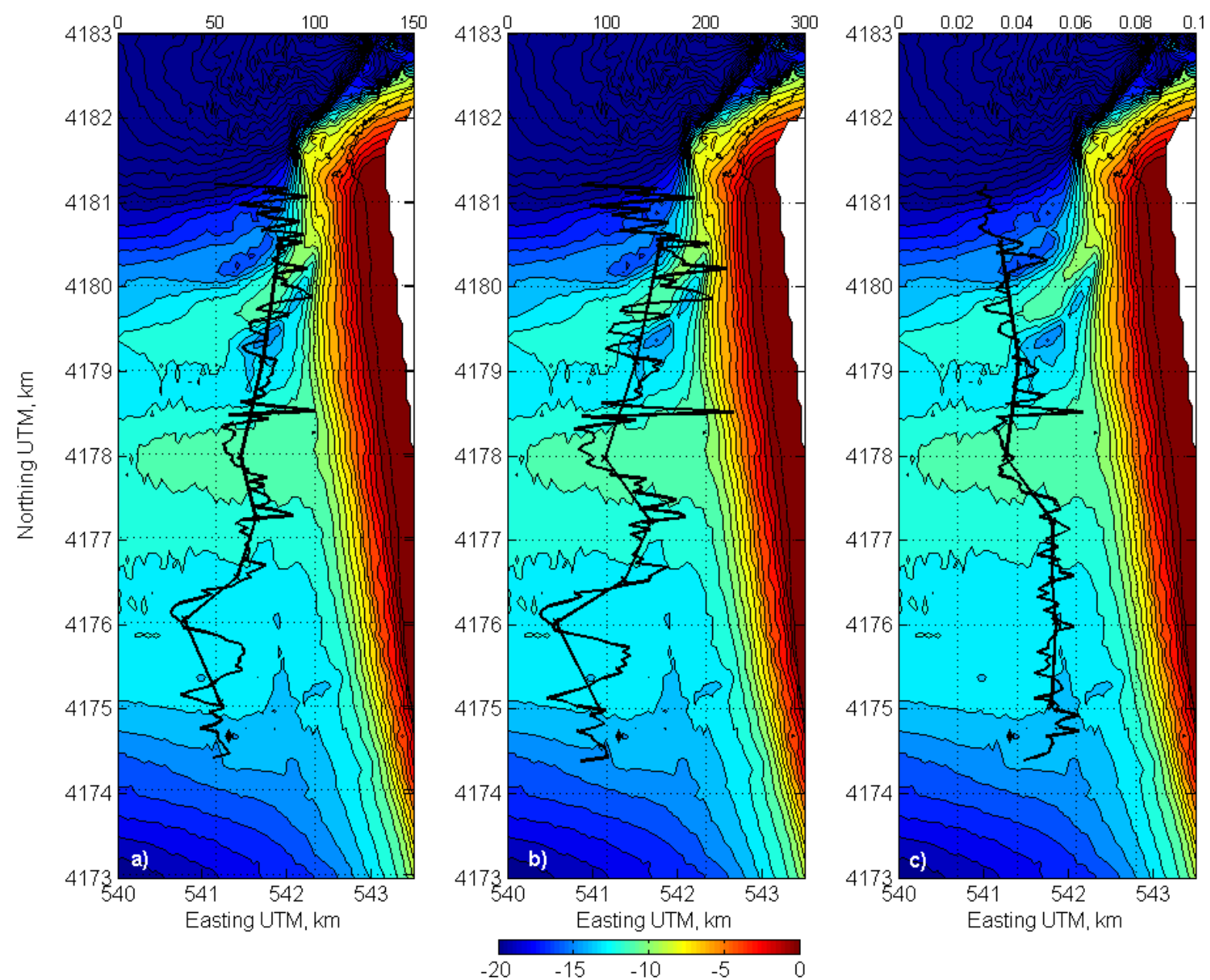

Figure 2.11. Average values of a) swash beach width, $\mathrm{m} \mathrm{b}$ ) swash sediment storage $\mathrm{m} 2$ and $\mathrm{c}$ ) swash beach slope averaged over the profile for each individual profile and also by reach plotted on local bathymetry. 


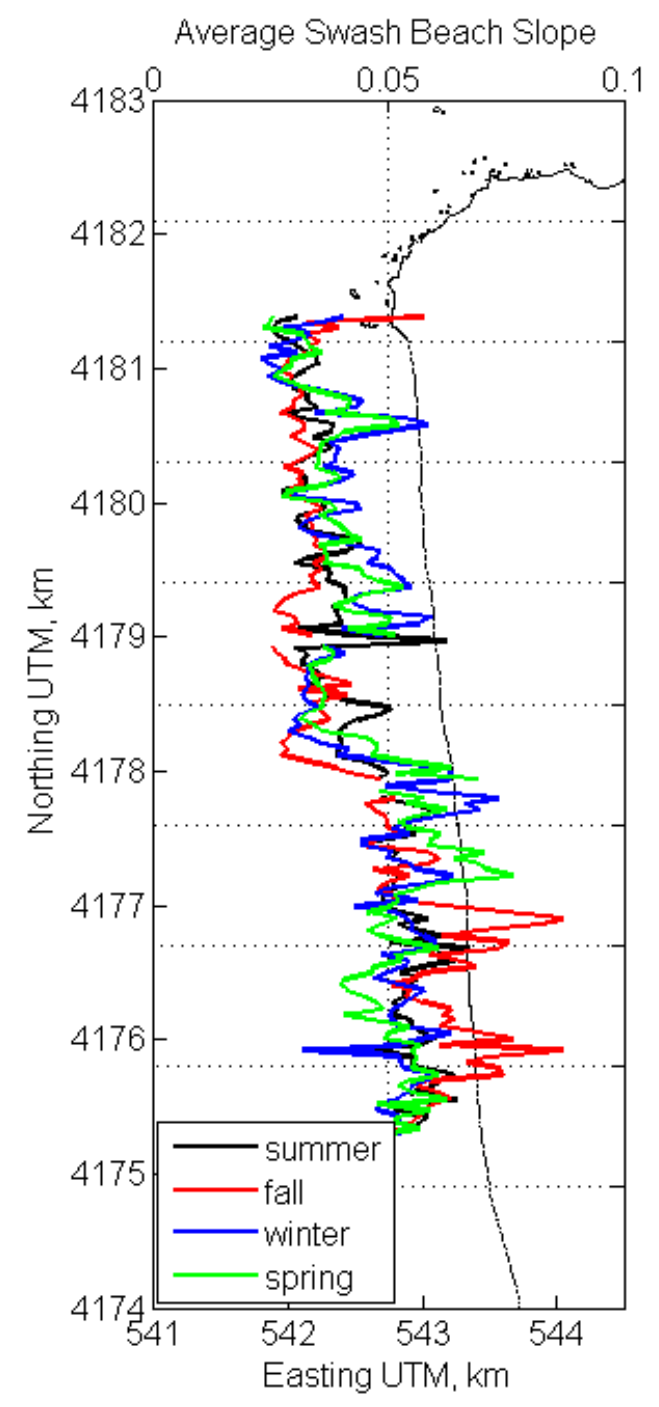

Figure 2.12. Seasonal averages of beach slope for each profile at Ocean Beach. 
Figure 2.13. Beach change during the dredge disposal monitoring period, as compared to 2004. A) Northern Ocean Beach (Reaches 1-2. B) Southern Ocean Beach (Reaches 5-7) and average vertical change totals for entire beach study area.

A
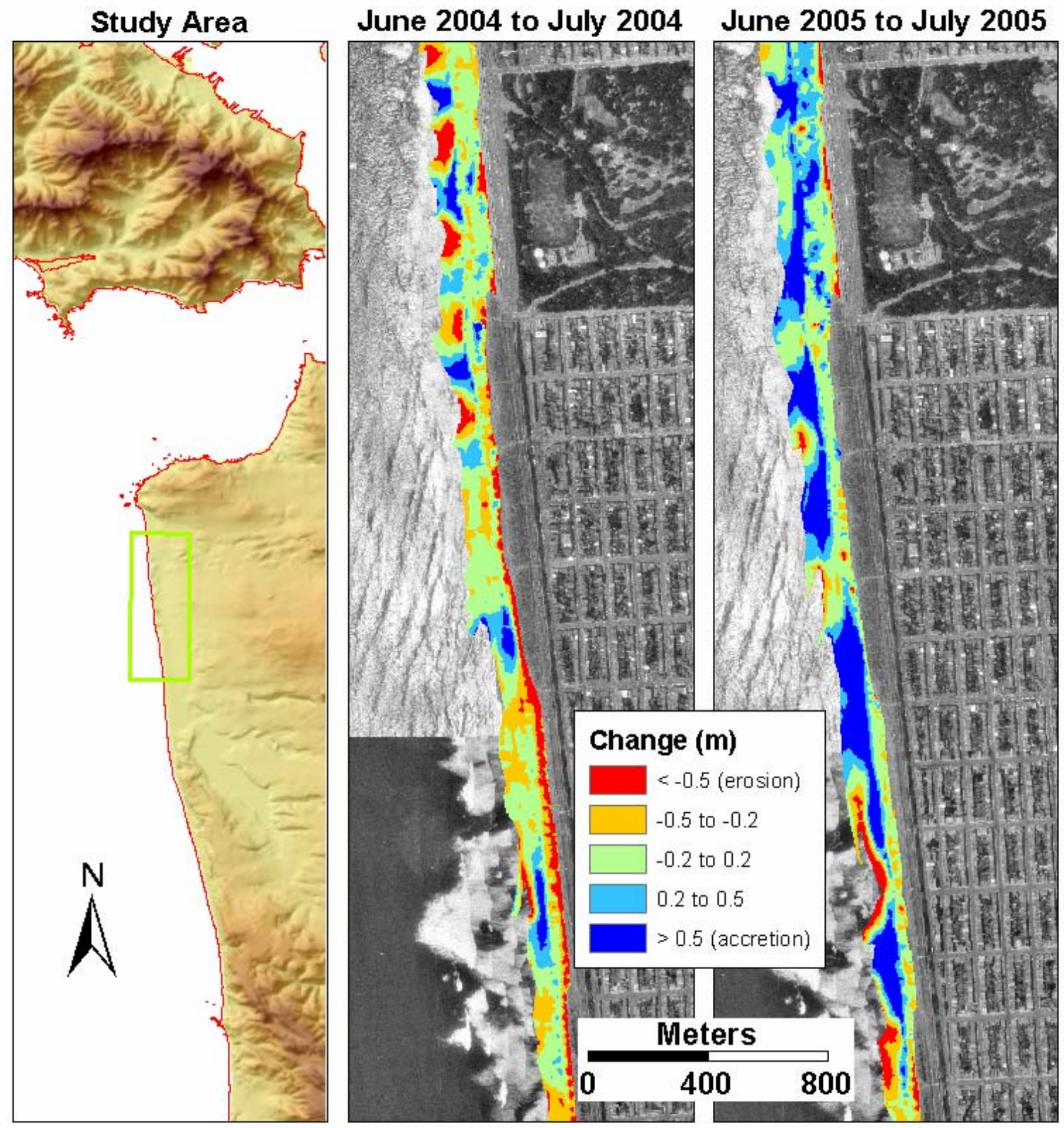
B

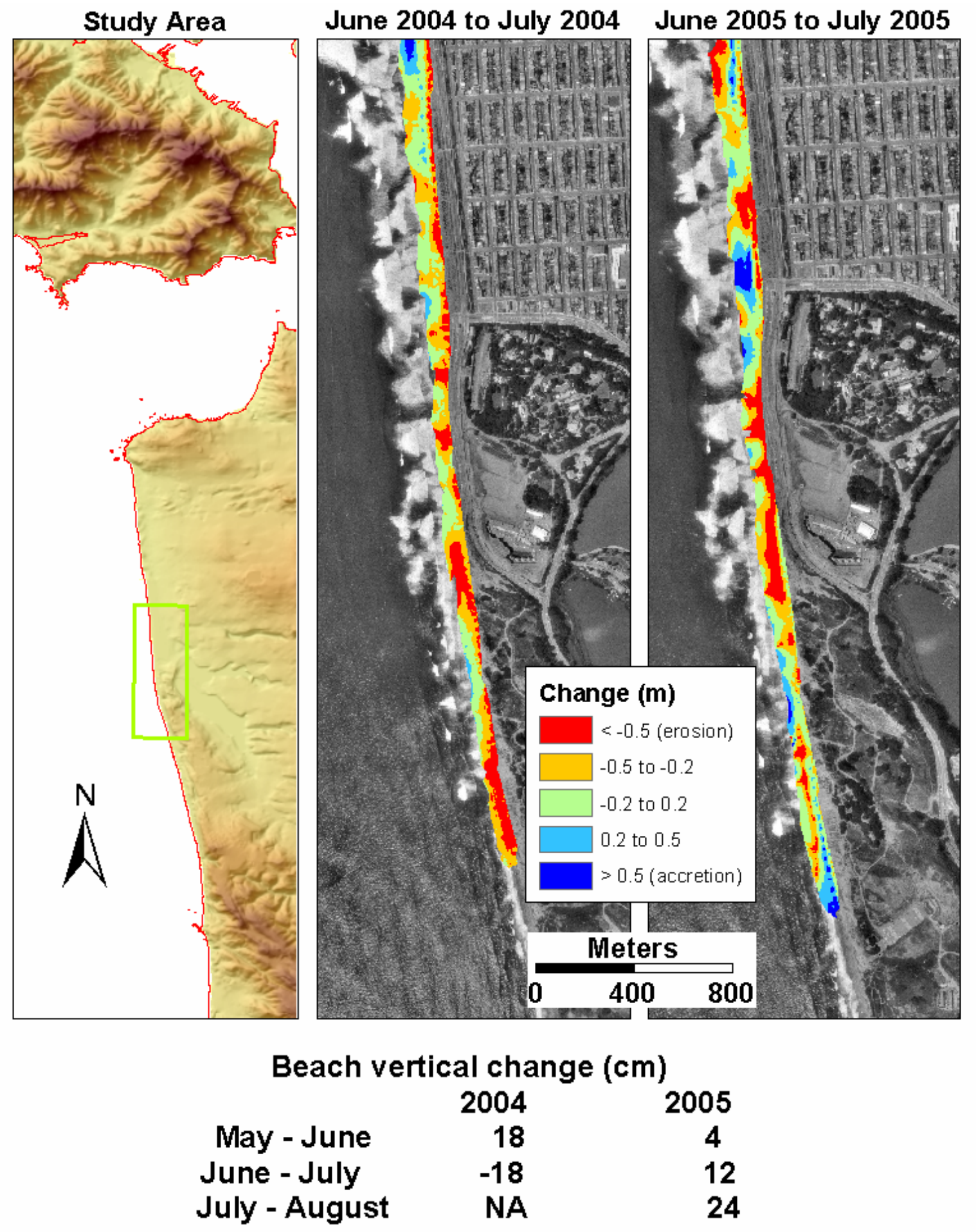




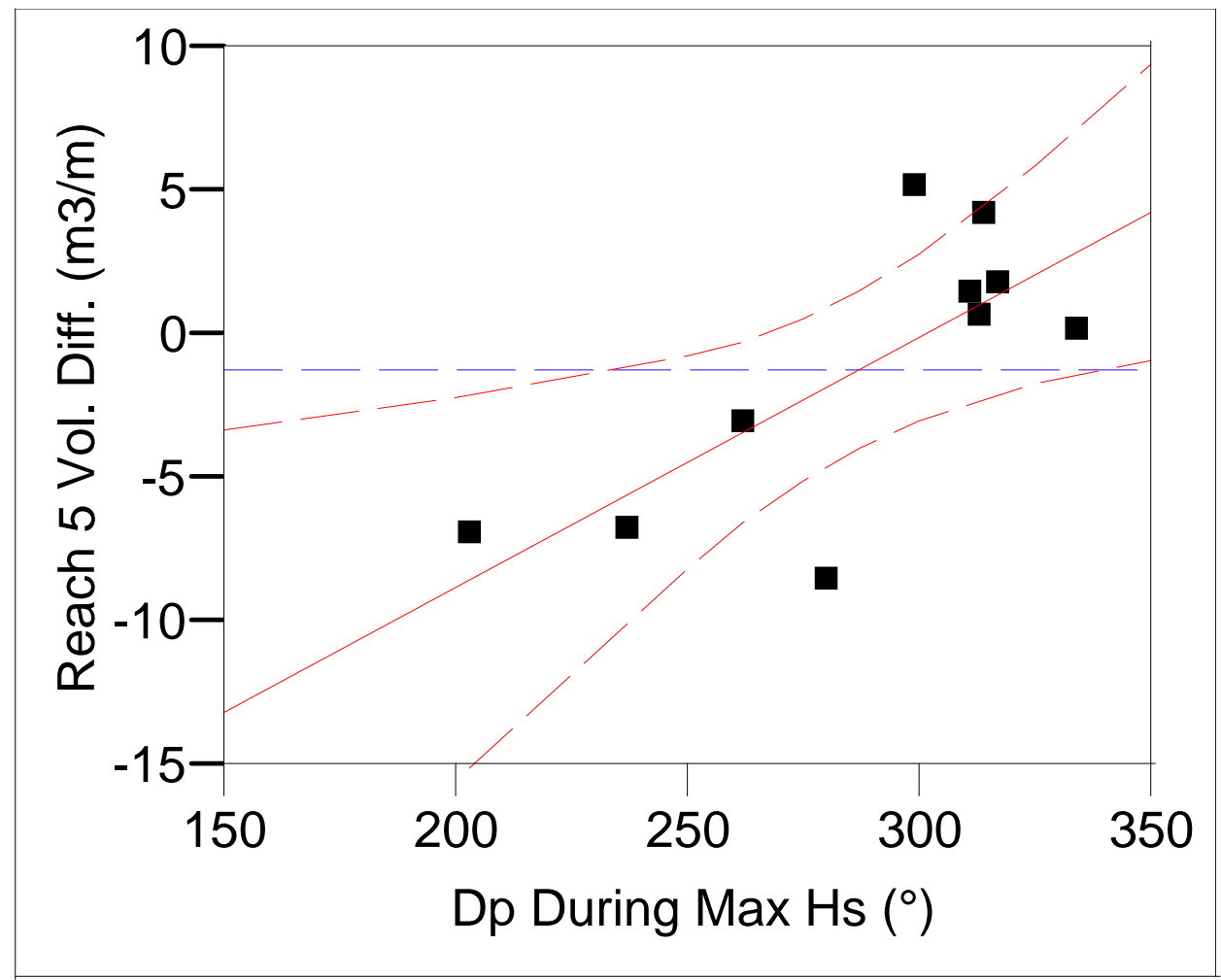

Figure 2.14. Empirical relationship between the wave direction $\left(D_{\mathrm{p}}\right)$ and beach volume change at Reach five during the storm surveys of winter 2005-06. The blue line represents a horizontal line that goes through the mean of the mean volume change data. The solid red line is the best fit to the data based on the multiple regression equation. The dashed red curves are the $95 \%$ confidence interval curves. The correlation variance $r^{2}=0.687$. 


\title{
Chapter 3- Nearshore Surveys with Coastal Profiling System
}

\author{
By Jodi Eshleman
}

\section{Introduction}

In May, 2004, the USGS began a seasonal shallow-water bathymetric surveying campaign at Ocean Beach. Since then, bathymetric data has been collected bi-annually, with additional surveys scheduled to coincide with instrument deployments and to help capture inter-seasonal change. This nearshore mapping initiative provides data to monitor seasonal trends, identify areas of chronic erosion, and create detailed bathymetric grids for enhanced numerical modeling capabilities. Recent innovations in field techniques have made it possible to quickly collect high-quality survey data in an area where extreme conditions were prohibitive in the past.

\section{Methodology}

The Coastal Profiling System (CPS), a hydrographic surveying system mounted on a Personal Watercraft (PWC), is used to collect bathymetric data for a seven kilometer stretch within the Golden Gate National Recreation Area in San Francisco, CA (Figure 3.1). The CPS combines the high accuracy positioning of a DGPS and the mobility of a personal watercraft to collect rapid and precise bathymetric profiles. The CPS has traditionally been used to survey cross-shore profiles perpendicular to a shoreline from approximately $15 \mathrm{~m}$ depth to one meter depth (NAVD 88), depending on weather and tide conditions. The survey setup for this site consists of 18 cross-shore profiles running from $1.8 \mathrm{~km}$ offshore through the surf zone and two alongshore profiles parallel to the coastline (Figure 3.2).

The bathymetric data has been collected using two different versions of the CPS. The first survey in May, 2004 was completed using the second generation CPS (CPS II), which was designed in cooperation with the University of Florida (MacMahan, 2001). All subsequent surveys were completed with the third generation CPS (CPS III), which is similar to the second generation version, but is mounted on a newer PWC model and includes updated hardware (Figure 3.2). A more complete discussion of specifics regarding the CPS can be found in Ruggiero and others (2005) and MacMahan (2001). This bathymetric surveying technique has been shown to achieve sub-decimeter accuracy (MacMahan, 2001); however reasonable variations in water temperature can affect depth estimates by as much as two percent of the total water depth. All data are corrected to adjust the vertical coordinate for the actual speed of sound in post-processing using the average of the surface water temperature measured at the San Francisco National Data Buoy Center (NDBC) Buoy, Station \#46026 during the survey period (National Oceanic and Atmospheric Administration, 2006a).

There were two different types of GPS equipment used to collect bathymetric data. For all surveys completed after the fall of 2005, the Trimble ${ }^{\circledR}$ survey gear was replaced with Ashtech $^{\odot}$. All survey data was collected in the UTM horizontal coordinate system, Zone 10 and referenced to NAVD 88. Table 3.1 includes a list of the bathymetric surveys, which profiles were completed, and which survey equipment and CPS version was used. The CPS collects data at $5 \mathrm{~Hz}$ and while traveling at $3 \mathrm{~m} / \mathrm{s}$ generates a depth sounding every 0.6 meters along the sea floor. All surveys were completed using Real Time Kinematic (RTK) GPS, 
where rovers receive information by radio signal from a base station while in the field, minimizing post-processing requirements. HYPACK ${ }^{\circledR}$ (Coastal Oceanographics, Inc.) hydrographic surveying software was the platform used for navigation and data collection in the field.

Trimble ${ }^{\circledR} 4000$ series receivers were used and have manufacturer reported root mean square (RMS) accuracies of approximately $\pm 3 \mathrm{~cm}+2 \mathrm{ppm}$ (parts per million) of baseline length (typically $10 \mathrm{~km}$ or less) in the horizontal and approximately $\pm 5 \mathrm{~cm}+2 \mathrm{ppm}$ in the vertical while operating in Real Time Kinematic surveying mode (Trimble Navigation Limited, 1998). Ashtech ${ }^{\circledR} \mathrm{Z}$-Extreme receivers were used for all subsequent surveys and have manufacturer reported accuracies of approximately $\pm 1 \mathrm{~cm}+1 \mathrm{ppm}$ in the horizontal and approximately $\pm 2 \mathrm{~cm}+2 \mathrm{ppm}$ in the vertical while operating in RTK surveying mode (Magellan Navigation, Inc., 2006). These reported accuracies are, however, additionally subject to multi-path, satellite obstructions, poor satellite geometry, and atmospheric conditions. While the horizontal uncertainty of individual data points is approximately $0.05 \mathrm{~m}$, the CPS operators cannot stay 'on line', in waves and currents, to this level of accuracy. Typically, mean offsets are less than $2.0 \mathrm{~m}$ from the preprogrammed track lines and maximum offsets along the approximately $2 \mathrm{~km}$ long transects are typically less than $10.0 \mathrm{~m}$.

The geodetic benchmark used to set up a base station was located at the Oceanside Water Pollution Control Plant located on the opposite side of the Great Highway from Ocean Beach in the central portion of the survey area. The horizontal coordinates in NAD83 were $37^{\circ} 43^{\prime} 39.89423^{\prime}$ ' $\mathrm{W}$ and $122^{\circ} 30^{\prime} 20.62585^{\prime}$ ' $\mathrm{N}$, with an ellipsoid height of $-10.902 \mathrm{~m}$ and NAVD88 elevation of $21.853 \mathrm{~m}$. When necessary, a radio repeater was set up on the roof of the Cliff House restaurant to help extend radio coverage to southern portions of the beach where cliffs block the radio signal.

\section{Results}

\section{Seasonal Change}

Figures 3.3 through 3.7 show cross-shore profiles at each of the 18 locations identified in Figure 3.2. Profiles 2-4 show a pronounced change in slope between the 10 and $15 \mathrm{~m}$ depth contours, with a slightly shallower section beyond this break (Figure 3.3). For the rest of the profiles, the slope is much smoother and depth change flattens out offshore with little variation below $10 \mathrm{~m}$ depth. Figures 3.3 to 3.7 show cross-shore seasonal bar migration in all profiles over a profile section of approximately $300-600 \mathrm{~m}$, with sand moving offshore in the winter and onshore in the summer. To allow for comparisons between individual surveys, alongshore profiles 19 and 20 were combined with the crossshore profile data to create 2-dimensional gridded surfaces in Matlab ${ }^{\circledR}$ using triangle-based, weighted linear interpolation. Figure 3.8 shows difference grids determined by subtracting the gridded surface of the more recent survey from the older survey to help identify trends in bar migration and beach volume change over time. The grid difference plots display offshore bar migration in the winter (Figure $3.3 \mathrm{a}$ ), and continued onshore bar migration over the summer and early fall (Figure $3.3 \mathrm{~b}, \mathrm{c}$ ). In Figure $3.3 \mathrm{~d}$, a one month grid difference plot captures offshore bar migration resulting from a few winter storm events. 


\section{Range of Elevation Change}

Figure 3.9 highlights the range of elevations that have been measured over the survey area throughout the entire sampling campaign. The mean and standard deviation of each grid cell were calculated by generating a grid over the same data range for each survey and then combining all grids for statistical analysis. Figure 3.9a shows that most changes in bathymetry offshore of Ocean Beach occurred in water depths less than $10 \mathrm{~m}$. In the northern and central portions of the beach, two shallower sections exist. The shallow section in the center of the beach around northing $4178 \mathrm{~km}$ appears to be fairly stable, as the standard deviation in that region is very small, if not zero. The shallow section at the northern part of the beach (northing 4179-4181 km) is highly variable, with standard deviation values reaching $1.2 \mathrm{~m}$ in localized spots. Here, bathymetric change extended outside of the $15 \mathrm{~m}$ contour.

\section{Nearshore Bar Growth and Trough Erosion}

An estimation of the volume of bar growth and trough erosion at Ocean Beach using the measured bathymetric profiles was attempted. The goal of this analysis is to get an estimate of the amount of sand that moves in the cross-shore seasonally to form offshore bars. This was done using the surveys conducted in November, 2005, and February, 2006, because these surveys captured the winter offshore bar migration better than any other time. Unfortunately, beach topography data was not available for both of these surveys, so a total volume of profile change could not be calculated to determine if sediment was conserved in the cross-shore or evaluate the component from alongshore transport. For this analysis, a volume of bar growth was calculated for profiles one through eighteen by calculating a crossshore area for portions of the profile where the elevation in February, 2006 was greater than that in November, 2005. The trough erosion was estimated by calculating a similar crossshore area for sections when the November, 2005 elevation was greater than the February, 2006 elevation. Both volumes were constrained between the two and ten meter depth contours to be consistent between different profiles, although there is change outside of this region. A schematic of this technique is presented in Figure 3.10.

A value of volume change in $\mathrm{m}^{3} / \mathrm{m}$ for each profile was computed since this was an areal difference at one location in the alongshore (Figure $3.11 \mathrm{a}$ ). These values were normalized by the profile length, which is the cross-shore distance over which we have data from both surveys. This quantity helps to facilitate comparisons between different profiles, giving a volume estimate of $\mathrm{m}^{3} / \mathrm{m} / \mathrm{m}$ (Figure $3.11 \mathrm{~b}$ ). Profiles one and seventeen were removed from the analysis since the bar migration was not within the constrained depth contours. This simplified technique captures fluctuations in sand throughout the entire profile, but the assumption is that the volume of sand included in the bar is significantly larger, therefore it can give order of magnitude estimation. Another assumption here is that

all sand accumulating in the offshore bar comes from offshore cross-shore transport, which is likely not the case at Ocean Beach where very strong shore-parallel tidal currents exist. By comparing winter and fall bathymetric surveys, an estimated volume of offshore bar growth of roughly $300 \mathrm{~m}^{3} / \mathrm{m}$ on and a trough erosion of $200 \mathrm{~m}^{3} / \mathrm{m}$ occurred on average for a single cross-shore profile (Figure $3.11 \mathrm{a}$ ). It is likely that the trough erosion is less than the bar growth because the sand moving off of the beach is not included in this calculation. When normalized by profile length, this results in approximately $0.6 \mathrm{~m}^{3} / \mathrm{m}$ bar growth and $0.4 \mathrm{~m} / \mathrm{m}$ trough erosion on average. 


\section{Discussion}

Comparisons of bathymetric survey data collected at Ocean Beach show seasonal patterns of bar migration. Figure 3.8 maps this movement in 2006. Figure 3.8a shows a very pronounced offshore bar migration in the winter of 2006, with a three meter trough developing in the northern portion of the beach. This was the largest change observed during the period of study, in part because it is very difficult to collect survey data in winter months due to the frequency and duration of storms. By May, 2006 the bar had partially migrated onshore and the deep trough had started to fill in (Figure $3.8 \mathrm{~b}$ ). The onshore bar migration continued throughout the calm summer months, as shown in elevation difference plots from November 2006 (Figure $3.8 \mathrm{c}$ ). A survey completed one month later to look at shorter-term storm response identified offshore bar migration on the order of $100 \mathrm{~m}$ in the cross-shore (Figure $3.8 \mathrm{~d}$, Figure 3.5) in response to a few storm events. During this one month period, there were six storm events (defined by periods when significant wave heights were greater than $2 \mathrm{~m}$ ) based on measurements recorded at the Coastal Data Information Program (CDIP) Point Reyes buoy \#029 (SCRIPPS Institution of Oceanography, 2006).

Calculations of the range of elevations collected throughout the survey campaign at each grid cell suggest that the offshore extent of significant vertical profile change, or depth of closure (Hallermeier, 1978), varies alongshore at Ocean Beach. Using very small values of the standard deviation of elevation as a proxy for the depth of closure, Figure 3.9a suggests that this depth is much shallower in the southern and central sections than at the north end. The depth of closure ranges from $10 \mathrm{~m}$ in the central and southern portions of the beach to a depth of $15 \mathrm{~m}$ or greater at the northern end. Figure 3.9 also includes the dredge disposal site (magenta box), disposal mound peak (magenta star), and erosion hotspot (magenta box). The location of the disposal mound peak appears to be outside of the estimated depth of closure, suggesting that cross-shore transport of sand from this site is limited. Future attempts to dispose of this sand in shallower water may produce improved results.

If the volume of bar growth estimate per profile of $300 \mathrm{~m}^{3} / \mathrm{m}$ is multiplied by seven kilometers for the stretch of shoreline along Ocean Beach, the result is an approximate volume of 2.1 million $\mathrm{m}^{3}$ (2.7 million cubic yards), giving a rough order of magnitude estimate of the amount of sand moving in the cross-shore to generate bars in this region.

\section{Conclusions}

- Comparisons of bathymetric profiles show patterns of seasonal bar migration onshore in the summer and offshore in the winter. Bars can be as high as two meters and move several hundred meters in the cross-shore.

- A shorter-term survey after one month suggests that a few winter storms can force offshore bar migration on the order of $100 \mathrm{~m}$.

- Comparisons of elevation change throughout all surveys suggest a range in depth of closure from $15 \mathrm{~m}$ at the north end to a shallower $10 \mathrm{~m}$ at the south end. This analysis suggests that the dredge disposal site is too deep for significant cross-shore transport of sand to occur.

- An order of magnitude estimate of offshore bar growth from measured bathymetric profiles suggests 2 million $\mathrm{m}^{3}$ (2.6 million cubic yards) of sand is moving in the cross-shore to form nearshore bars. 


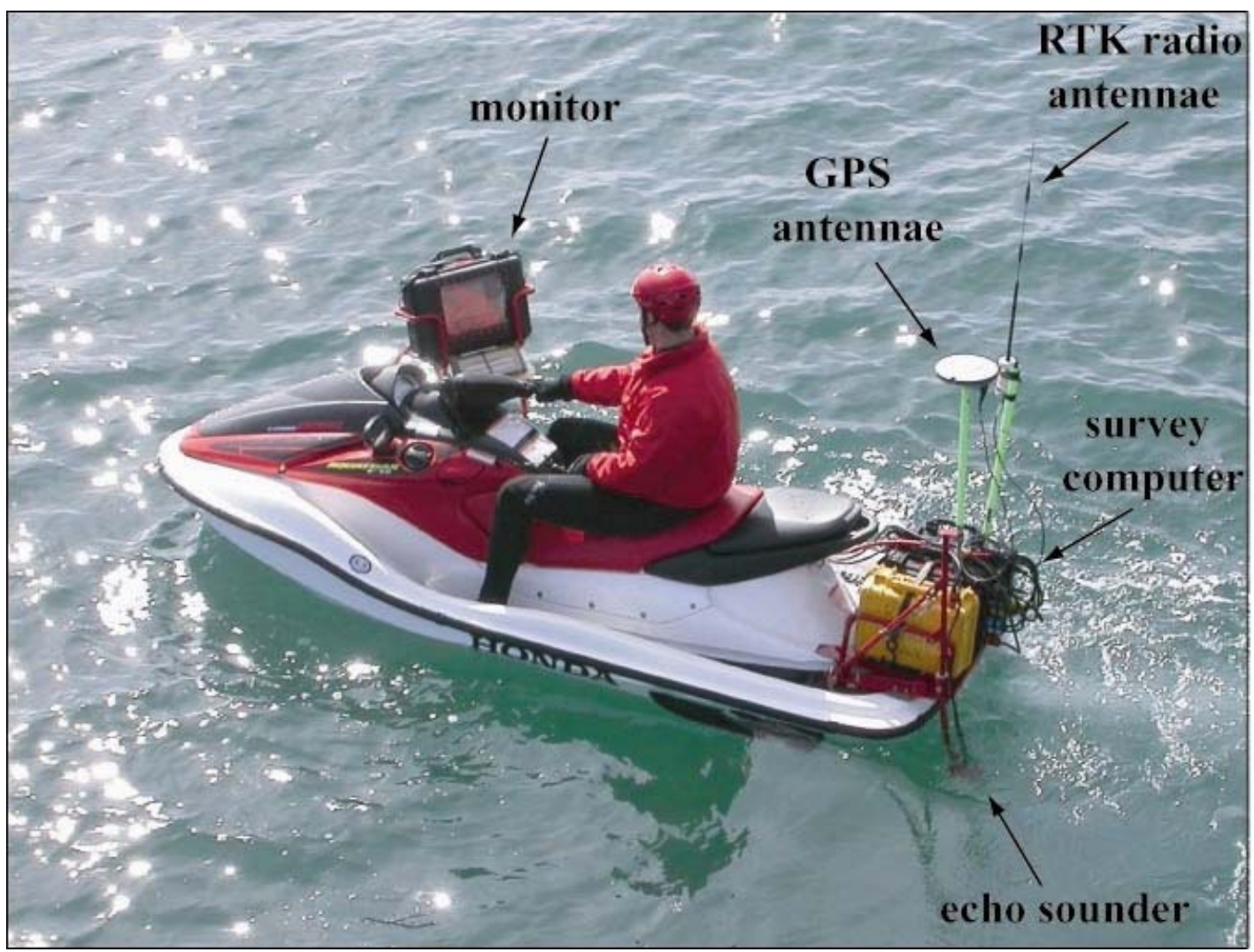

Figure 3.1. Third generation Coastal Profiling System in action. 


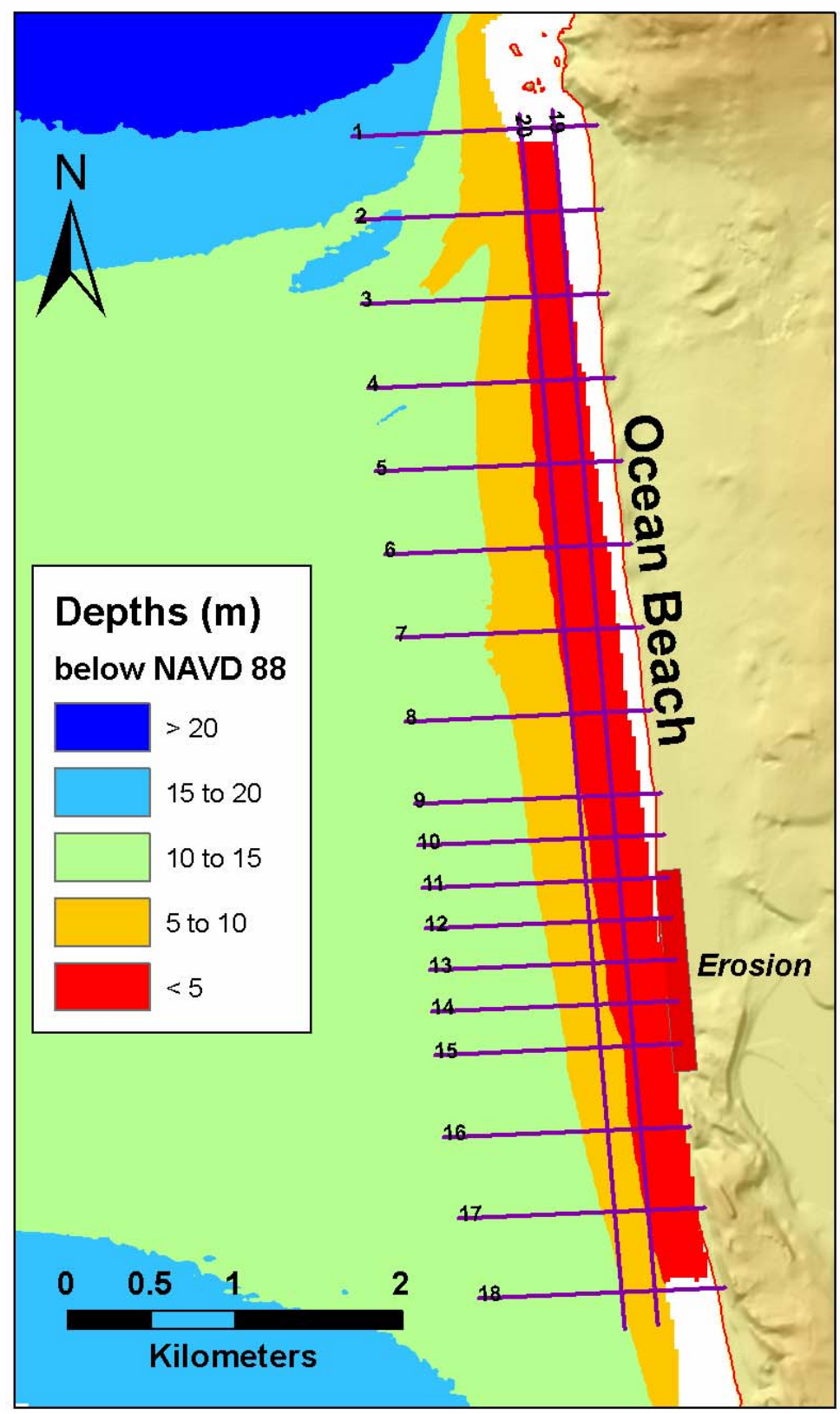

Figure 3.2. Ocean Beach CPS survey profiles. 
Table 3.1. Nearshore bathymetry survey coverage and equipment.

\begin{tabular}{|c|c|c|c|c|}
\hline Date & Profiles & Survey Equipment & CPS System & Notes \\
\hline $5 / 4 / 2004$ & $2-14$ & Trimble $^{\circledR}$ & CPS II & \\
\hline $7 / 20 / 2004$ & $1-20$ & Trimble $^{\circledR}$ & CPS III & \\
\hline $11 / 12 / 2004$ & $1-18$ & Trimble $^{\circledR}$ & CPS III & \\
\hline $5 / 3 / 2005$ & $1,3,5,7-18$ & Trimble $^{\circledR}$ & CPS III & $\begin{array}{l}* \text { Survey completed just before } \\
\text { summer instrument campaign. }\end{array}$ \\
\hline $11 / 17 / 2005$ & $1-18$ & Ashtech $^{\odot}$ & CPS III & \\
\hline $2 / 10 / 2006$ & $1-20$ & Ashtech $^{\odot}$ & CPS III & $\begin{array}{l}\text { *Coincided with winter } \\
\text { instrument campaign. }\end{array}$ \\
\hline $5 / 23 / 2006$ & $1-20$ & Ashtech $^{\odot}$ & CPS III & \\
\hline $11 / 6 / 2006$ & $1-20$ & Ashtech $^{\odot}$ & CPS III & \\
\hline $12 / 5 / 2006$ & $1-20$ & Ashtech $^{\odot}$ & CPS III & *inter-seasonal storm response \\
survey.
\end{tabular}



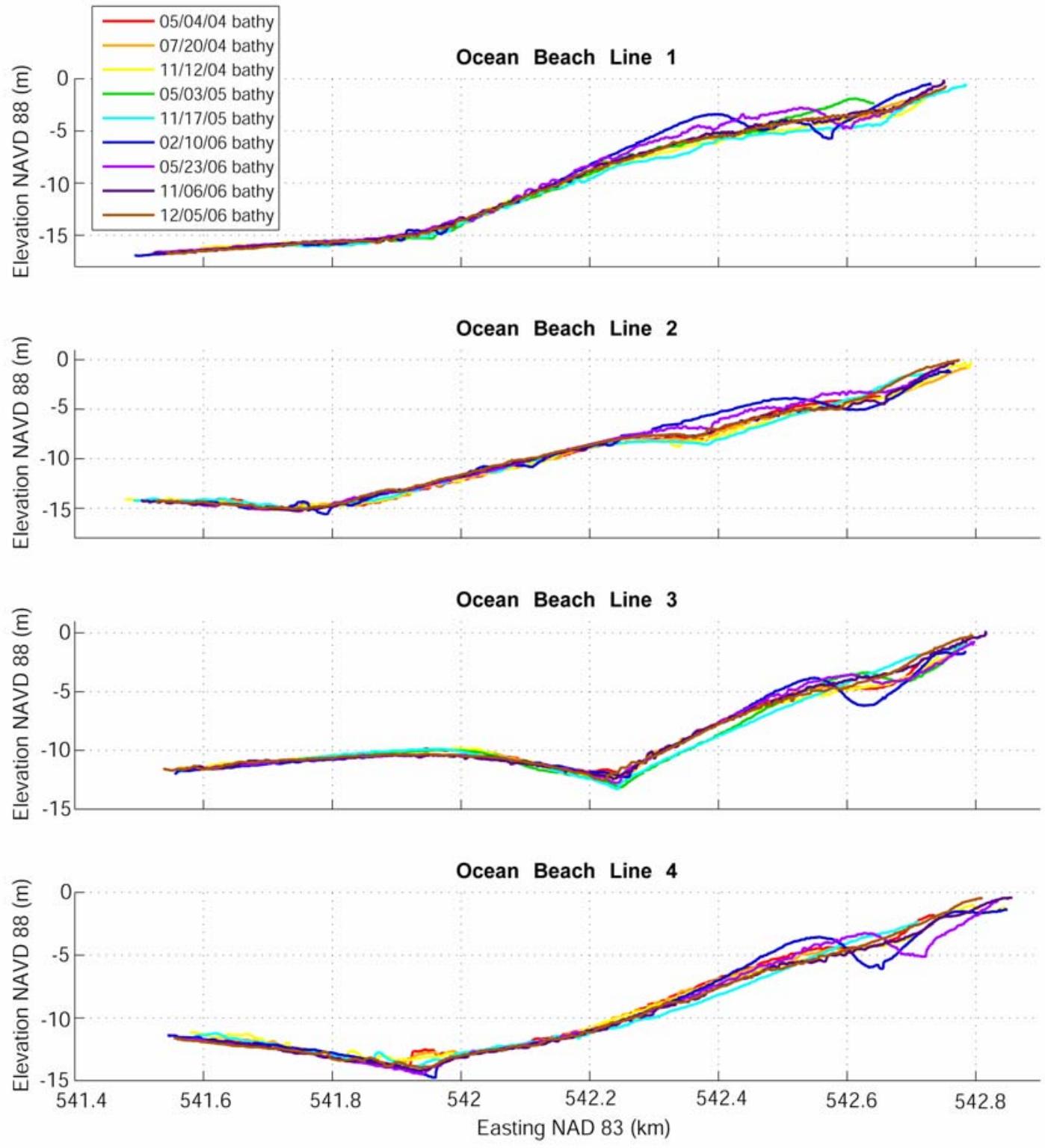

Figure 3.3. Ocean Beach cross-shore profiles 1- 4. 

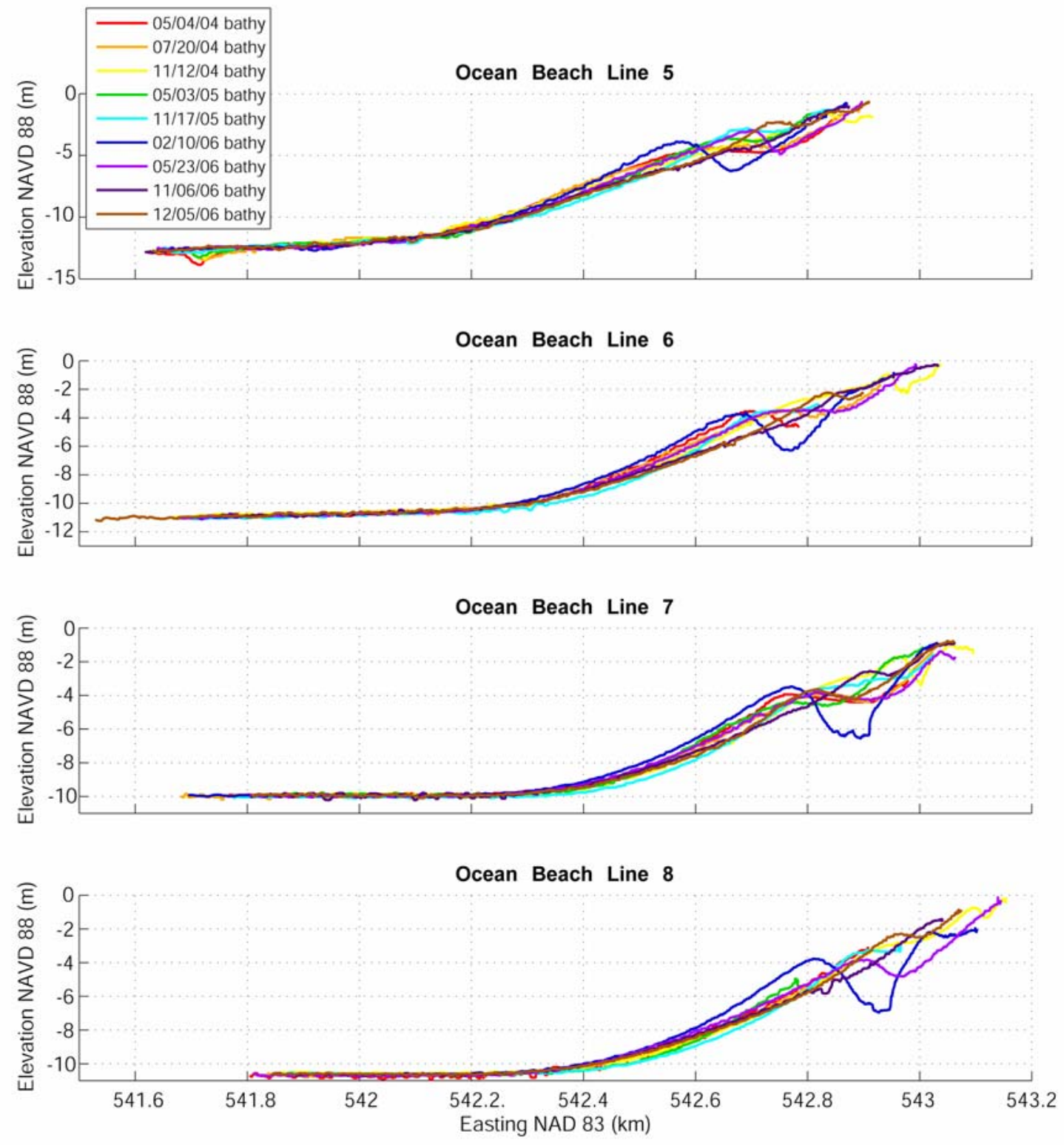

Figure 3.4. Ocean Beach cross-shore profiles 5 - 8. 

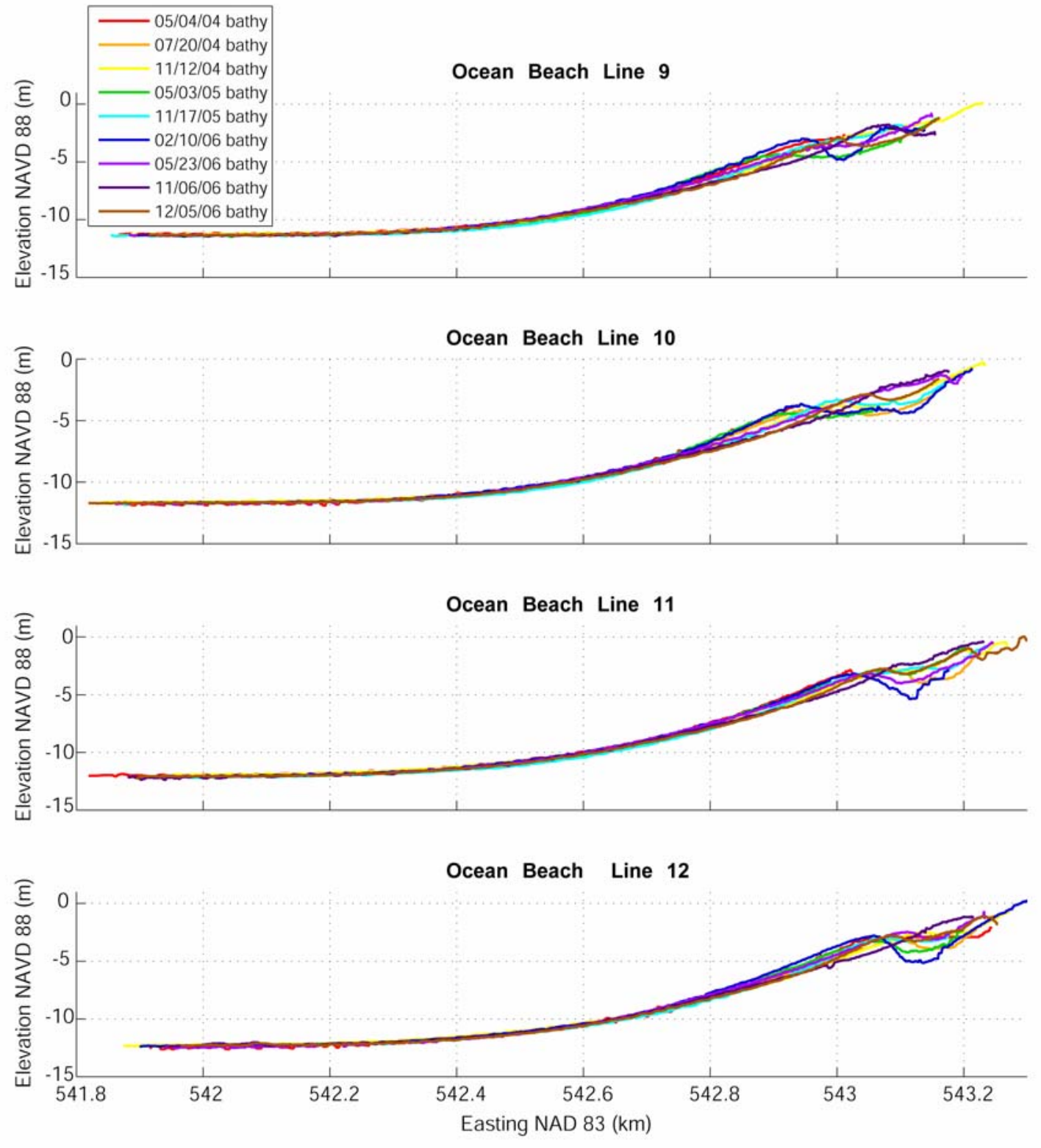

Figure 3.5. Ocean Beach cross-shore profiles 9 - 12 . 

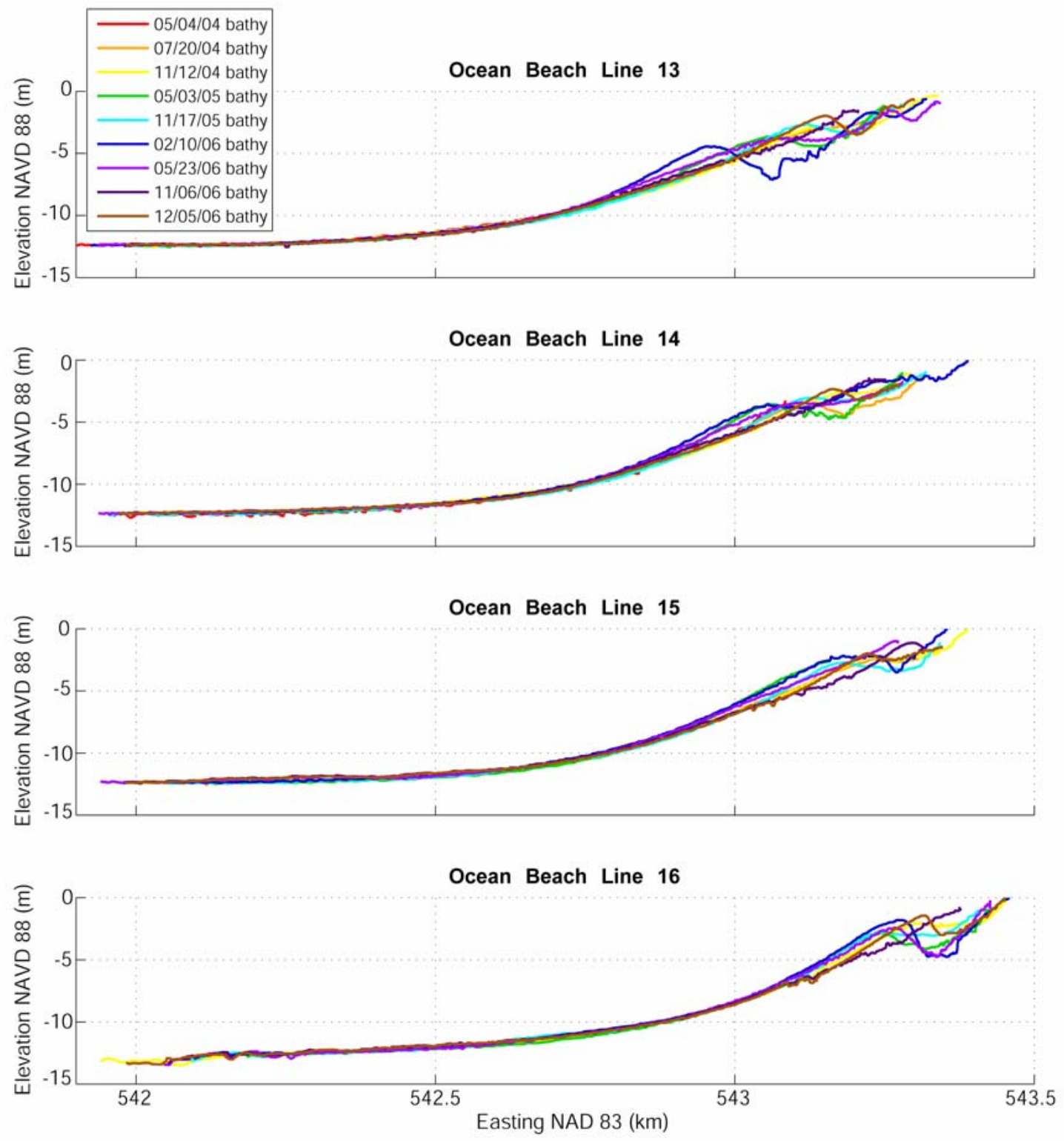

Figure 3.6. Ocean Beach cross-shore profiles 13 - 16 . 

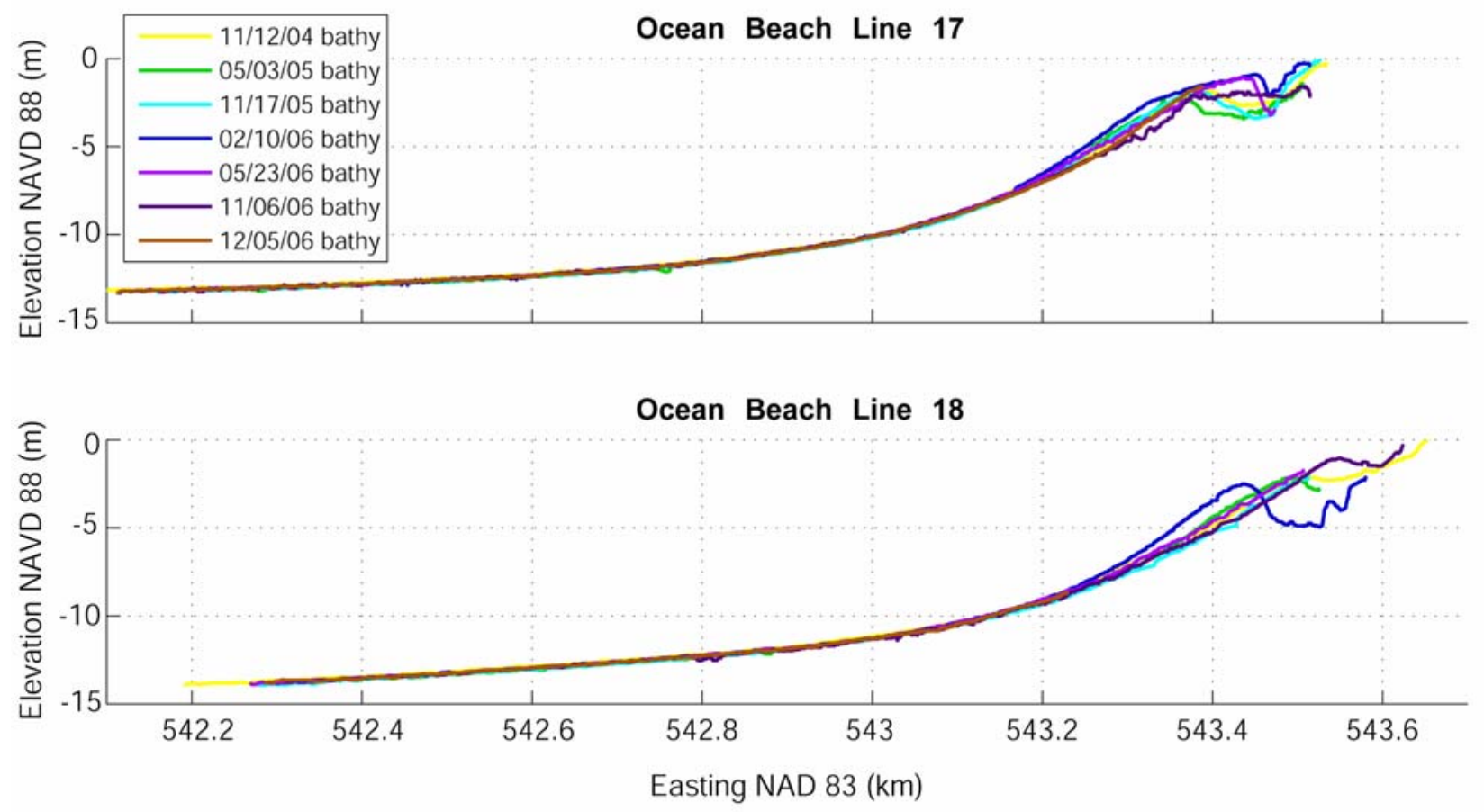

Figure 3.7. Ocean Beach cross-shore profiles 17 - 18. 


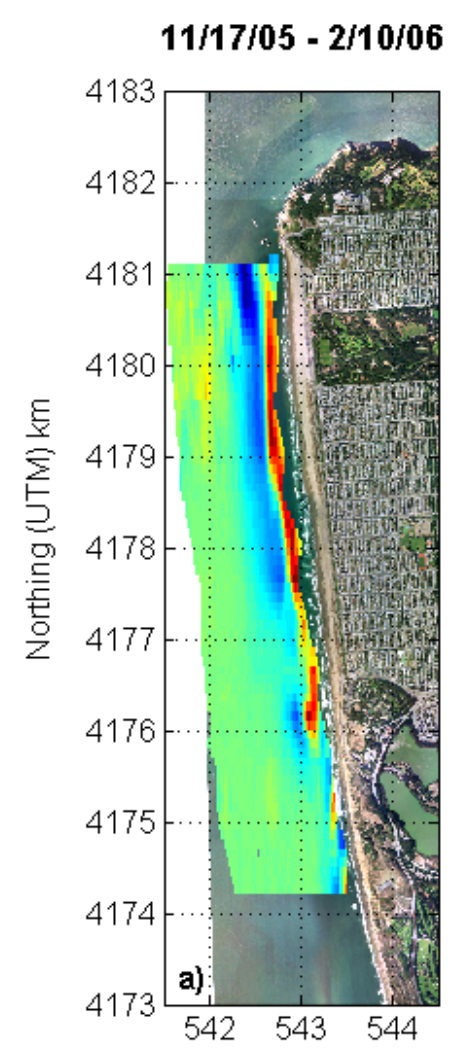

Easting (UTM) km
$2 / 10 / 06-5 / 23 / 06$

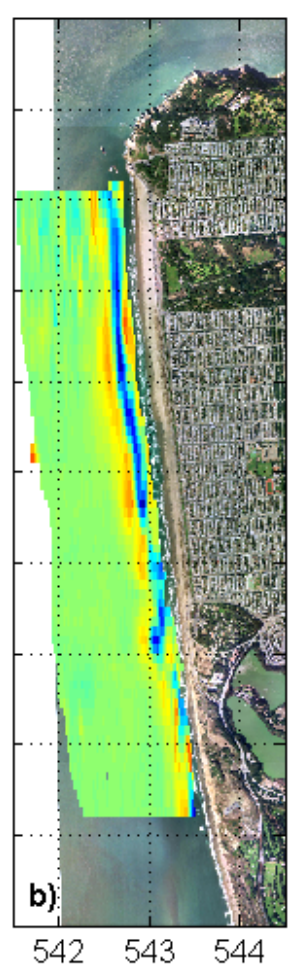

Easting (UTM) km
$5 / 23 / 06-11 / 6 / 06$

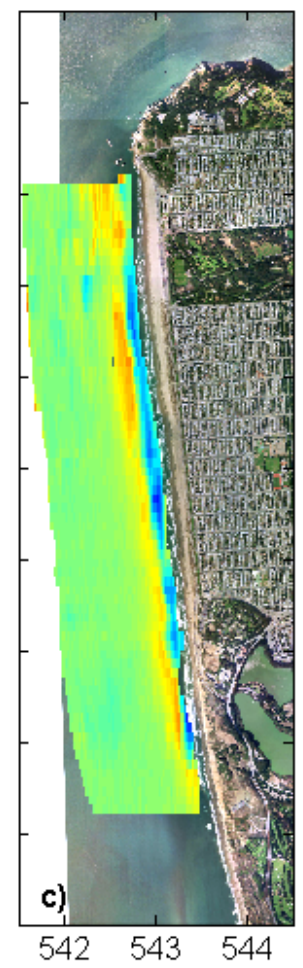

Easting (UTM) km
$11 / 6 / 06-12 / 5 / 06$

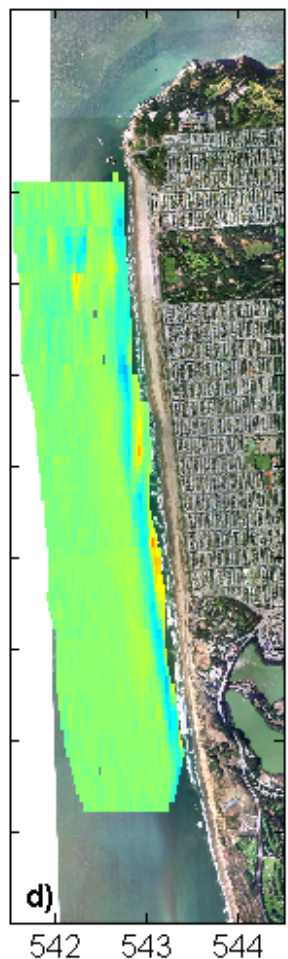

Easting (UTM) km

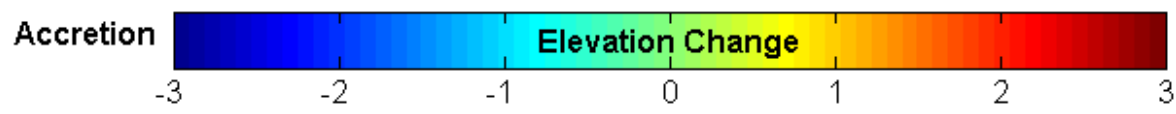

Erosion

Figure 3.8. Grid difference plots showing elevation change between surveys a) February, 2006- November, 2005 b) May, 2006 - February, 2006 c) November, 2006 - May, 2006 d) December, 2006 - November, 2006. 

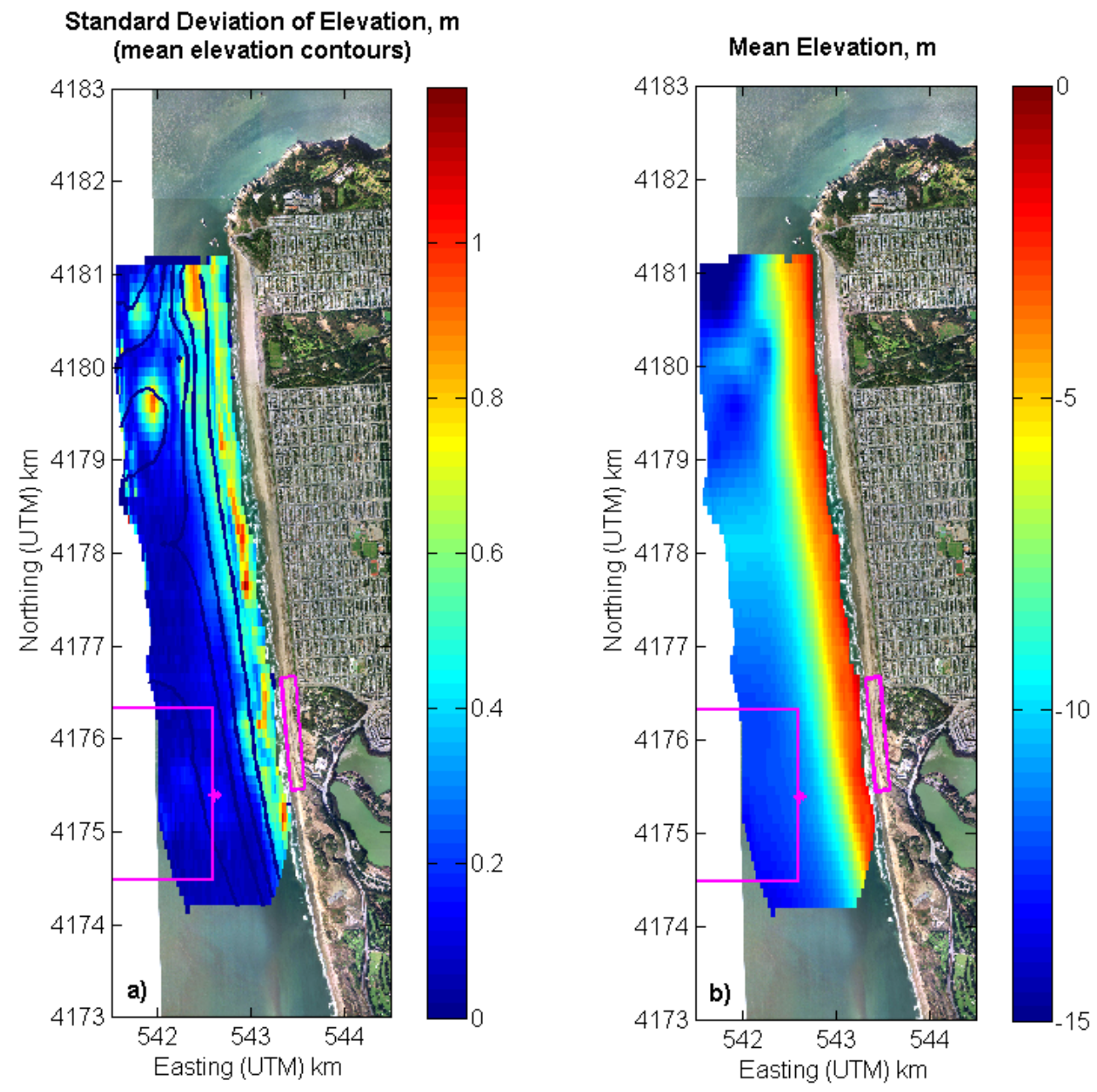

Figure 3.9. Calculations from all survey data available of a) standard deviation of elevation with mean elevation contours b) mean elevation (dredge disposal site and erosion hotspot in magenta). 


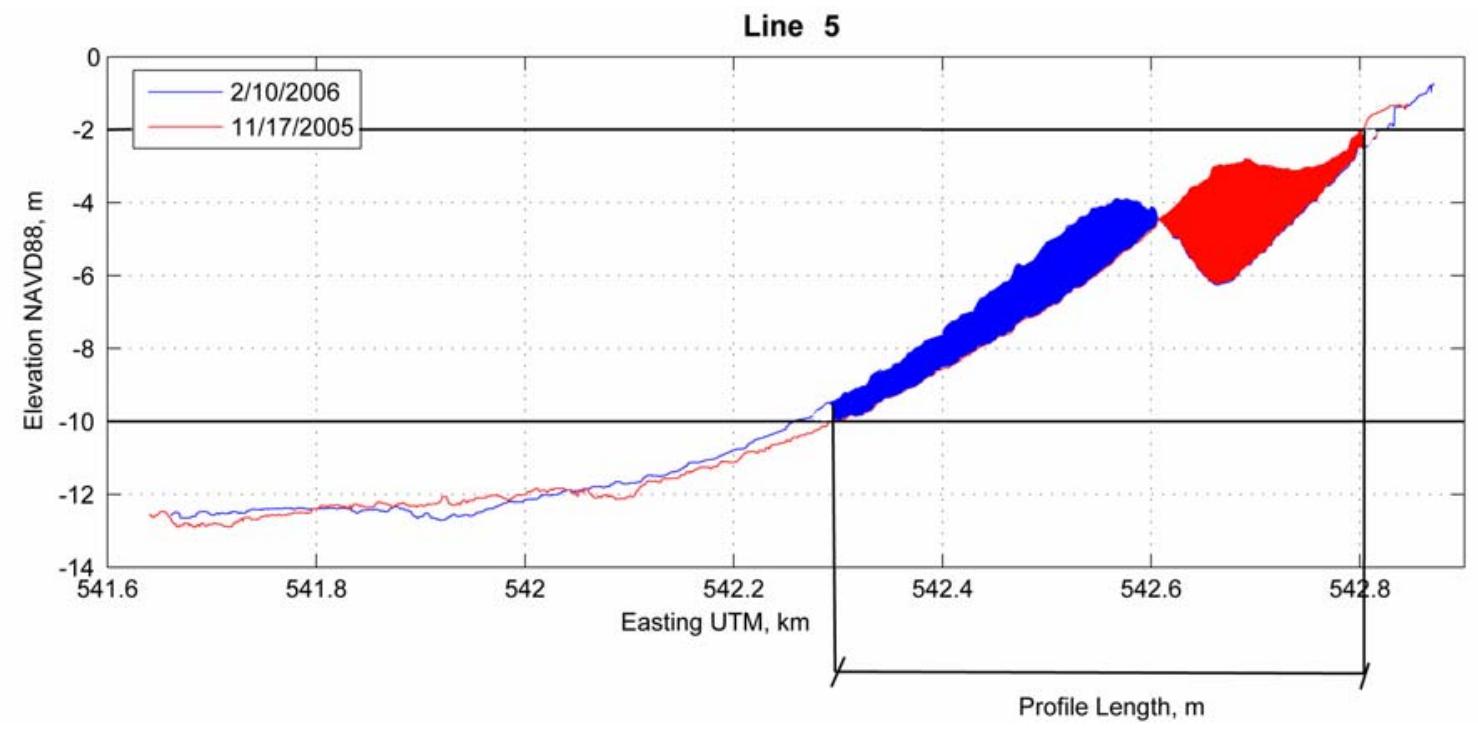

Figure 3.10. Definition sketch for volume of bar growth and trough erosion calculations using profile five. The blue section shows the calculated volume of bar growth and the red section shows the volume of trough erosion. 

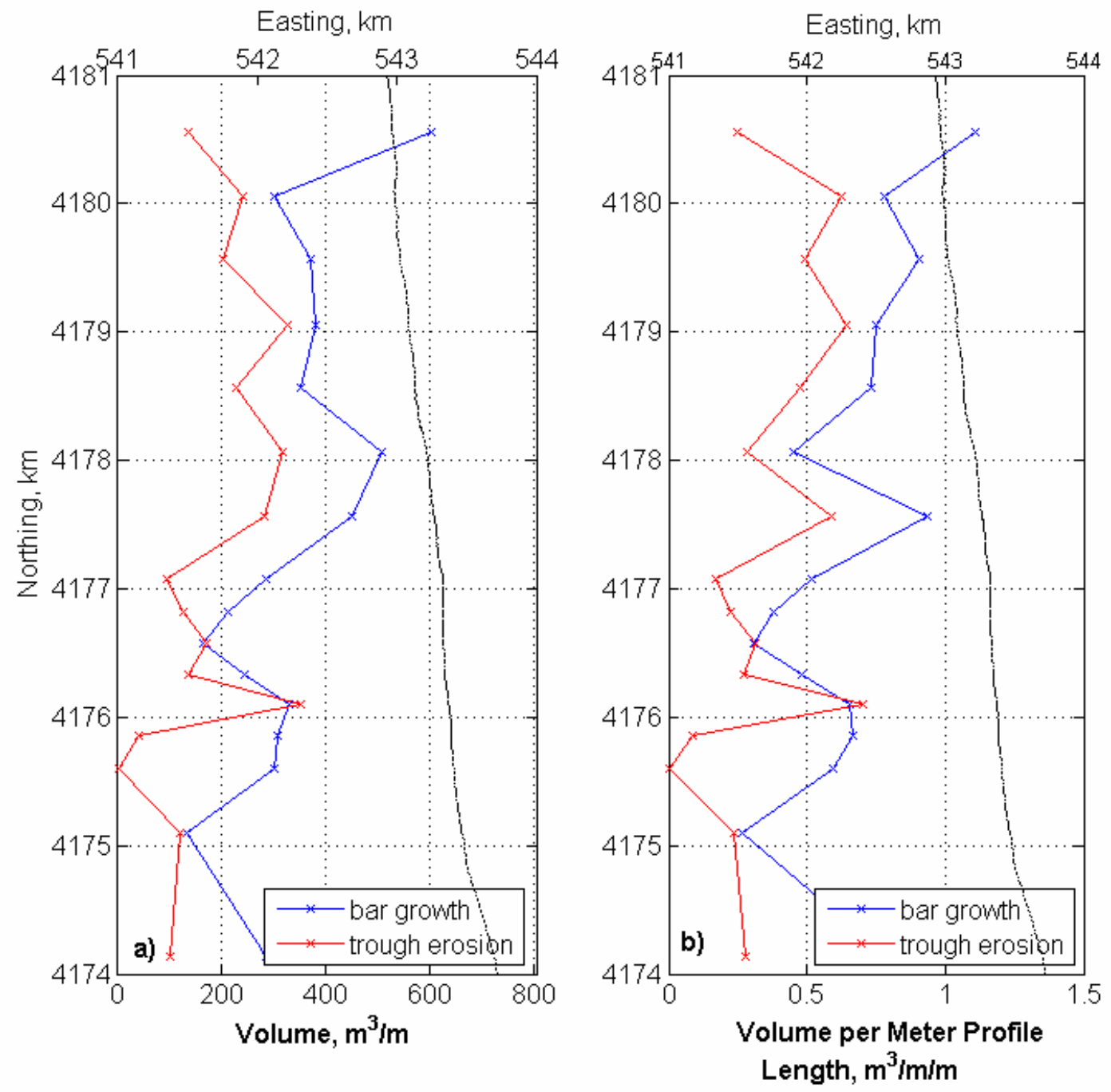

Figure 3.11. Variation in a) volume of bar growth and trough erosion and $b$ ) volume of bar growth and trough erosion per meter profile length for profiles 1-16, 18 along 0 cean Beach. 


\title{
Chapter 4- Image Monitoring
}

\author{
By Li Erikson
}

\section{Introduction}

Digital still camera and video imagery provided continuous monitoring of the inshore region at the north end of Ocean Beach (http://www.evsboca.com/usgs/default.htm). Due to the shallow depth and the highly dynamic and energetic surf zone, the inshore region is typically off limits to traditional methods of measurement. The image monitoring system, on the other hand, supplemented the other field operations undertaken for this study in addition to providing continuous, long-term monitoring of coastal and shoreline dynamics. To this end, the main objectives of deploying the image monitoring system were to locate the shoreline and bathymetric features (e.g., bars and rip currents), and provide data on surf and swash hydrodynamics.

\section{Methods}

Since September 2004, digital video and still cameras with high precision pan and tilt capabilities, encased in a protective housing, were mounted on the roof of the Cliff House Restaurant (Figure 4.1), approximately 30 m above MSL (Erdman Video Systems, Inc., 1996-2006). The approximate region of the camera's field of view is shown in Figure 4.2, along with locations of temporary in situ current meters (Chapters 5 and 6) and cross-shore bathymetric sampling transects (Chapter 3). Still images provide snapshots of the nearshore region, but the majority of the data analysis was done with images obtained by the video camera. Two variations of video images were generated: first, a series of video images averaged over ten minutes; and second, "time-stacks" along the five cross-shore transects (T1 through T5, spaced $\sim 50 \mathrm{~m}$ apart) shown in yellow in Figure 4.2. As of June 2005, timestacks were obtained between 10 am and $1 \mathrm{pm}$ on a daily basis and time-averaged images were recorded at ten minute intervals during remaining daylight times. Due to increased capabilities of the monitoring hardware, the time-stack sampling scheme was increased to nine cross-shore and two along-shore transects in February 2006 (compared to five transects shown in Figure 4.2).

Select time-averaged images have been analyzed for spatial determination of sandbar dynamics and the presence of rip currents. By averaging thousands of images over a ten minute time period, fluctuations due to incident waves breaking at different locations are averaged, yielding a more stable image of the wave breaking region, and thus illuminating shallows of offshore bars or shoaling regions. A typical time-averaged image is shown in Figure $4.3 \mathrm{a}-\mathrm{b}$, where the bar location is evidenced by the lighter band in the image.

In contrast to time-averaged images, time-stacks plot transects of image pixels (sampled at $1 \mathrm{~Hz}$ ) and stack them in the vertical direction resulting in an image with time on the vertical axis and distance on the horizontal axis, as shown in Figure 4.3c. Time-stacks obtained during the surf zone experiment (January 2006) are shown in Figure $4.3 \mathrm{c}$ for the five cross-shore transects (T1 through T5 in Figure 4.2). Select time-stack images have been analyzed for maximum runup height/length (i.e., maximum height/distance of the leading edge of the waves on the beach face) and swash period. 
Prior to extracting data from the images, rectification and geo-referencing were necessary to account for image distortion caused by the oblique field of view (other distortions such as those caused by lens irregularities are considered to be relatively small and have not been directly accounted for). Image rectification is the process of transforming a distorted image so that it is parallel to the baseline and so that a physical length unit anywhere on the image represents an equal real-world distance throughout the image (i.e., the image geometry is recovered). Geo-referencing is the process of assigning real-world coordinates to image pixels. Image rectification and geo-referencing were performed with transformation matrices determined from known ground control points, associated pixels, the assumption of a plane beach for the time-stack evaluations (Holland and others, 1997) and by constraining the vertical elevation to mean sea level, as was done by Lippman and Holman (1989) to determine bar and rip current positions. Based on comparisons with ground control points not used in the image rectification process, the error associated with bar and rip current positions was found to be $14 \mathrm{~m} \pm 11 \mathrm{~m}$ in the north-south direction and $19 \mathrm{~m} \pm 13 \mathrm{~m}$ in the east-west direction.

\section{Results}

\section{Time-averaged Images}

Time-averaged images were evaluated for bar and rip current positions. This section begins with a comparison of bar positions observed with the images as compared to those measured with the CPS (Chapter 3). Time-averaged images were then used to infer which storms and wave energy levels caused an offshore bar to develop during the winter of 2005/2006.

\section{Sandbars}

Although there are two CPS survey profiles that fell within the camera's field of view (Figure 4.2), most of the northern one (profile 1) is lost during the image rectification process. Hence, image breaking locations were compared to CPS survey profile 2. Because the location of breaking is not only dependent on the bathymetry but also on wave conditions, the most noticeable bars in a cross-shore profile may not be visible in the timeaveraged images on a given day. The CPS surveys were intentionally completed on days with low wave energy (for safety and data quality requirements), while time-averaged images only show offshore bars on days with coincident low tide and relatively high wave conditions. As such, wave breaking positions were determined from time-averaged images taken within five days following the CPS surveys and when offshore significant wave heights measured at the CDIP buoy \#029 (Scripps, 2006) exceeded $2.5 \mathrm{~m}$. The breaking locations, as determined from the images, are shown with filled circles in Figure 4.4. These breaking locations concur with the inshore bar, near the depth-limited range of the CPS measurements. The second bar at about E542.55 km on 05/23/06 is not evident in the images because the wave conditions were too small. Not evidenced by the bathymetry however, is a second breaking location clearly evident in the images from 02/10/06 and 05/23/06 at $37 \mathrm{~m}$ and $64 \mathrm{~m}$ shoreward of the Eastern most CPS measurement, respectively (not shown in the Figure).

The cross-shore profiles along profile 2 (Figure 4.4) show that a significant bar developed at a depth of approximately four meters sometime between 11/17/05 and 02/10/06. The depth at which the bar was situated suggests that it was generated by rather large wave events, with breaking wave heights on the order of $3+\mathrm{m}$. There were nearly 20 Pacific 
storms whose swell $\left(H_{\mathrm{s}}>2.5 \mathrm{~m}\right)$ reached the CDIP buoy and Ocean Beach between 11/17/05 and $2 / 10 / 06$. The offshore bar is not visible in the time-averaged images until the swell on $12 / 21 / 05\left(H_{\mathrm{s}}>6.5 \mathrm{~m}\right.$ and $\left.T_{\mathrm{P}}=15 \mathrm{~s}\right)$, as shown with the triangle in Figure 4.4. By 01/04/06, a storm swell of similar magnitude $\left(H_{\mathrm{s}}=6.11 \mathrm{~m}\right.$ and $\left.T_{\mathrm{p}}=16.7 \mathrm{~s}\right)$ shows that the bar moved slightly further offshore (solid square in Figure 4.4). Following the swell of 01/04/06, large swell conditions were a meter or more lower than those measured at the CDIP buoy during the previous large swells. Time-averaged images from the remaining large swell events all showed breaking shoreward of the bar, indicating that the storms of 12/21/05 and 01/04/06 generated the offshore bar.

\section{Rip Currents}

Rip current locations were manually digitized from time-averaged images spanning the entire data set from September 2004 through August 2006. The data showed that there were four primary rip current locations within the camera's field of view (Figure 4.5). The rip currents were spaced on the order of $150 \mathrm{~m}$ to $200 \mathrm{~m}( \pm 41 \mathrm{~m})$. Based on available data, the rip current located furthest south of the Cliff House Restaurant (rip 4 in Figure 4.5) was most prevalent (37\% of total number of observations) and appeared to occur at any time during the year, followed in decreasing frequency by rips 1,3 , and $2(27 \%, 23 \%$, and $13 \%)$. Rip current occurrence appeared to follow a cyclical seasonal distribution with the greatest number of observations occurring in April and August (Figure 4.6). The seasonal occurrence of rip currents is likely related to variations in wave conditions, bathymetry and beach topography. Previous studies suggest that rip currents most frequently occur when waves approach at near normal incidence, where there are alongshore variations in bathymetry and an alongshore sandbar is present. Variations in local bathymetry in the context of rip current generation have not yet been analyzed. However, a preliminary assessment suggests that the inshore bathymetric variance was not sufficient to fully describe the occurrence and location of rip currents. This suggests that refraction over varying offshore bathymetry and tidal currents affected by the inlet might provide a disturbance in the wave field resulting in alongshore wave height variation that could generate rip currents. This hypothesis could be tested with the numerical model described in Chapter 10 (e.g., Long and Ozkan-Haller, 2005).

\section{Time-stack Images}

Swash hydrodynamics were investigated by closely analyzing time-stack images obtained along the five cross-shore transects (Figure 4.2) during a four hour sampling period on 06/24/05. Beach slopes were determined from topographic data collected with ATVs (Chapter 2) and were mild, ranging from 0.01 to 0.05 .

Neglecting set-up due to radiation stresses caused by breaking waves, total runup is often considered to consist of two components: first, incident waves producing runup and run-down (backwash) on a beach, and second, oscillations at infragravity frequencies, generating swash periods greater than $20 \mathrm{~s}$, beyond the usual range of incident wave periods. In order to assess the relative contributions of each, the runup time-series were band-pass filtered to the sea and swell incident component, $\left(R_{i n c}, 0.05 \mathrm{~Hz}<f<0.2 \mathrm{~Hz}\right)$ and infragravity $\left(R_{i g}\right.$, $f<0.05 \mathrm{~Hz}$ ) component. The relative contribution of runup in the infragravity band to total 
runup $\left(R_{i g} / R\right)$ was 0.83 , similar to what Ruessink and others (1998) found $\left(R_{i g} / R=0.85\right)$, but less than the Oregon data set presented by Ruggiero and others (2001 and 2004). A typical time-series showing the dominant infragravity component is shown in Figure 4.7.

Runup energy density spectra were calculated using Welch's averaging method and a bandwidth of $9 \mathrm{E}^{-4} \mathrm{~Hz}$ for each transect and are shown in Figure 4.8. The dashed vertical line depicts the cutoff between infragravity and incident runup frequencies, and it is clear that the peak energy lies within the infragravity band. The peak periods $\left(1 / f_{p}\right)$ range from 41 to 68 $\mathrm{s}$, with the longer periods ( $56 \mathrm{~s}-68 \mathrm{~s}$ ) observed at the three middle cross-shore transects.

The steep drop-offs in Figure 4.8 suggest saturated surf and swash zones. Miche (1951) theorized that monochromatic incident waves consist of both a progressive and a standing wave component and that runup is proportional to the amount of shoreline reflection from the standing wave amplitude. The amplitude of the standing wave is depth-limited as an increase in incident wave heights causes the breaking to occur further offshore, allowing energy dissipation through wave breaking and less energy for swash. As such, saturation implies that the incident band runup height does not increase with increased offshore wave height.

Swash hydrodynamics have many consequences, including defining the landward extent of shoreline change. Numerical process-based models are invaluable tools for simulating hydro- and morphodynamcis across large complex regions such as the San Francisco Bight and Ocean Beach, but are often limited in their ability to simulate detailed shoreline change. As a complement to the numerical modeling for shoreline evolution undertaken as part of this study, the use of analytical models to predict runup at Ocean Beach was assessed. Although numerous factors influence the extent of runup (e.g., grain size, friction, turbulence, swash interaction, and infiltration), three parameters are generally considered to be strongly linked to observed runup statistics: offshore wave height, deepwater wave length and beach slope. Various combinations of these three parameters have been proposed, and in particular, there have been some recent developments in the prediction of runup on dissipative beaches.

Comparison of predicted runup values from six different semi-empirically-based analytical models showed that the significant runup, $R_{s}$ (mean of the one-third highest runup elevations) is well predicted with the classic Hunt formula $\left(R^{2}=0.70\right.$, Figure $\left.4.9 \mathrm{a}\right)$ and the $2 \%$ runup height $\left(R_{2}\right.$, runup height that is exceeded $2 \%$ of the time $)$ is well predicted with a recent formulation proposed by Ruggiero et al. (2001, $R^{2}=0.70$, Figure $\left.4.9 \mathrm{~b}\right)$. Offshore wave heights employed in the models were measured with the offshore RD Instruments Acoustic Doppler Current Profiler (RDI ADCP) shown in Figure $4.2\left(0.9 \mathrm{~m}<H_{s}<1.5 \mathrm{~m} ; 9 \mathrm{~s}<T_{p l}<\right.$ 13.5s). As mentioned previously, bimodal conditions dominated the wave spectra during the summer months, and as such the sensitivity of the models to the choice of bulk parameters obtained from the bimodal velocity spectra were compared using the two peak periods $\left(T_{\mathrm{p} 1}\right.$ and $\left.T_{\mathrm{p} 2}\right)$ and mean representations $\left(T_{\mathrm{mol}}\right.$ and $\left.T_{\mathrm{mo} 2}\right)$. Using peak wave periods increased the root-mean-square-error ( $r m s e$ ) in all cases, while the mean period, in particular $T_{\operatorname{mo2} 2}$, which is theoretically similar to the wave period obtained through zero-down crossing, gave results with the smallest rmse. In all, the analytical runup formulations did quite well considering that Ocean Beach, and in particular the northern part of Ocean Beach, is strongly influenced by tidal currents (approximately $1 \mathrm{~m} / \mathrm{s}$ during the field study) and associated wave-current interactions. The relatively mild conditions of the summer may be partially responsible for this positive performance. 


\section{Discussion}

Although the time-averaged images can fill some of the time-series data gaps of locating the bars and break points in time and space, they are limited by daylight, tidal elevation, and weather and wave conditions (waves need to be large enough so that breaking occurs over the deeper situated bars). Even so, the analyses presented herein provide a means to determine multiple break points with a high resolution time-scale and a means to associate swell conditions with bar generation. As such, the images provided complementary information about the inner bar often not captured with the CPS surveys.

A causal relationship between rip current occurrence and location was not determined. At this time it is thought that refraction over irregular bathymetry and complex flow patters associated with the tidal inlet may be the driving mechanism for rip currents at the north end of Ocean Beach. Implementation of the numerical model Delft3D might provide a means to test the hypothesis.

Summer swash conditions were analyzed with time-stack images and were shown to be highly dissipative. Detailed analyses of winter runup conditions are expected to show a dominance of incident frequency swash oscillations, related to a steeper foreshore slope. This has yet to be determined with topographic data obtained with the ATV surveys and from validated profiles obtained with time-averaged images. Coupling between the surf and swash zones will need to be done with additional analysis of the time-stack images. Surf zone currents will be calibrated and validated with in situ measurements (Chapter 6) during the winter field campaign in 2006. This should provide additional data for the assessment of rip currents, as well as cross- and long-shore sediment transport.

\section{Conclusions}

- Wave-breaking locations deduced from time-averaged images agree with those from bathymetric data obtained with the CPS.

- Time-averaged images show that multiple breaking locations are common along Ocean Beach. It is not clear if both of the breaker locations were associated with bars, or if the inner location was simply due to depth-limited breaking.

- Four rip currents occurred seasonally at the north end of Ocean Beach with a spacing of $150 \mathrm{~m}$ to $200 \mathrm{~m}$.

- Analysis of time-stack runup data shows that the beach was dissipative under typical summer conditions with infragravity conditions dominating and swash periods on the order of a minute. 


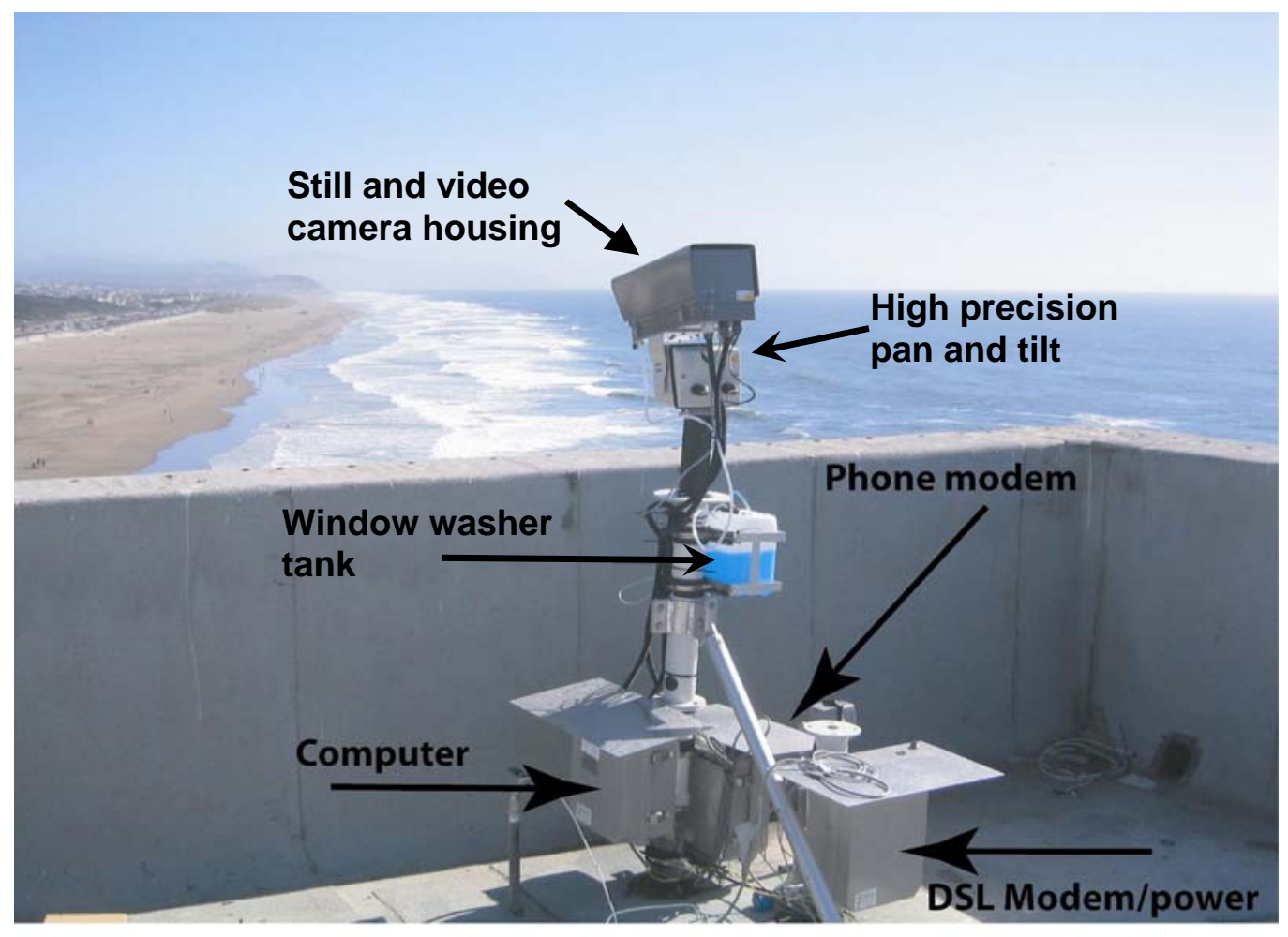

Figure 4.1. Digital camera and video system on the top of the Cliff House Restaurant. 


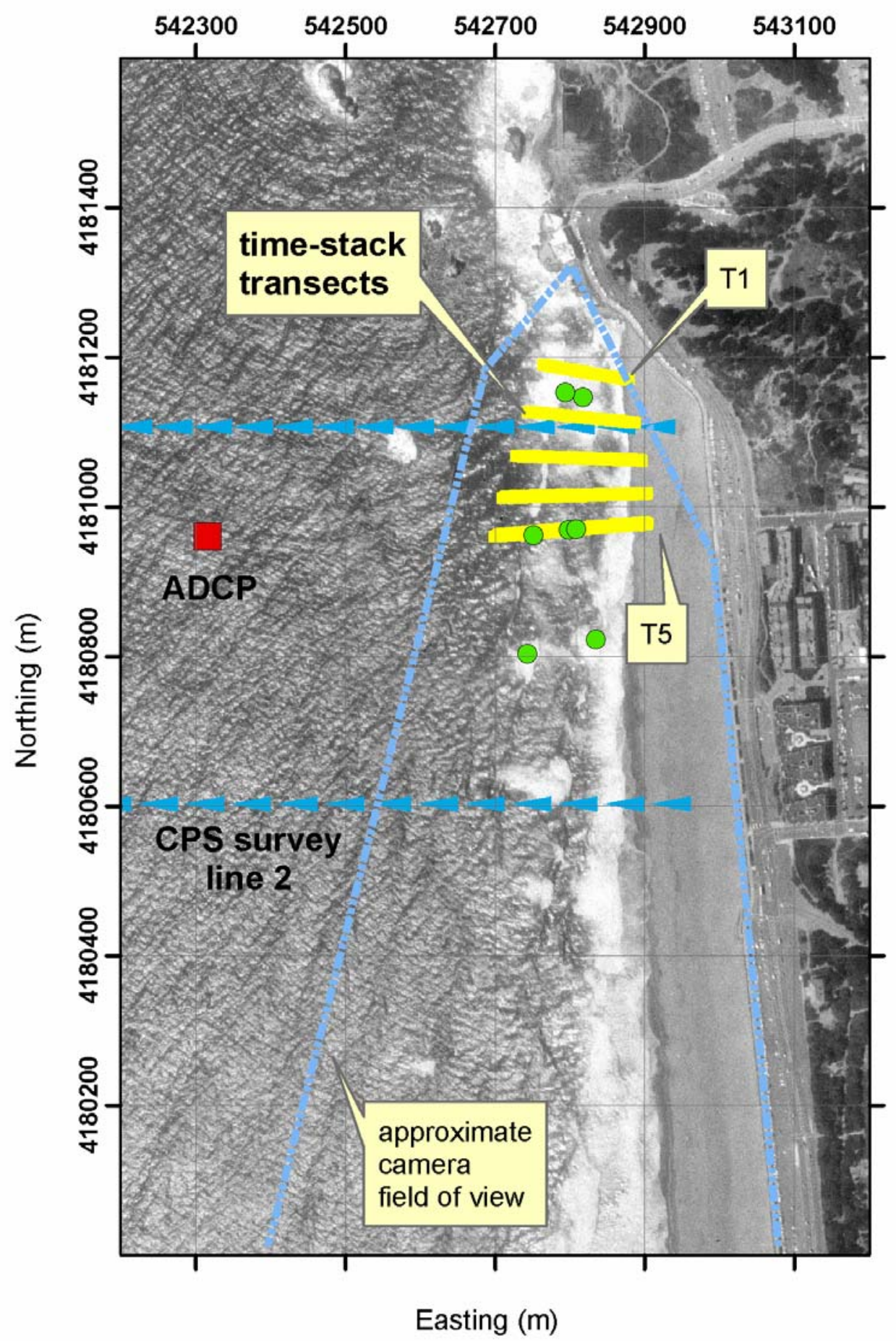

Figure 4.2. Aerial image showing camera's field of view, in situ instrument locations (ADCP as a red square and Aquadopps as circles), CPS survey profiles (blue east-west oriented lines), and time-stack transects (yellow lines). Aerial image pt_bonita_se.tif, 08/25/1993. 

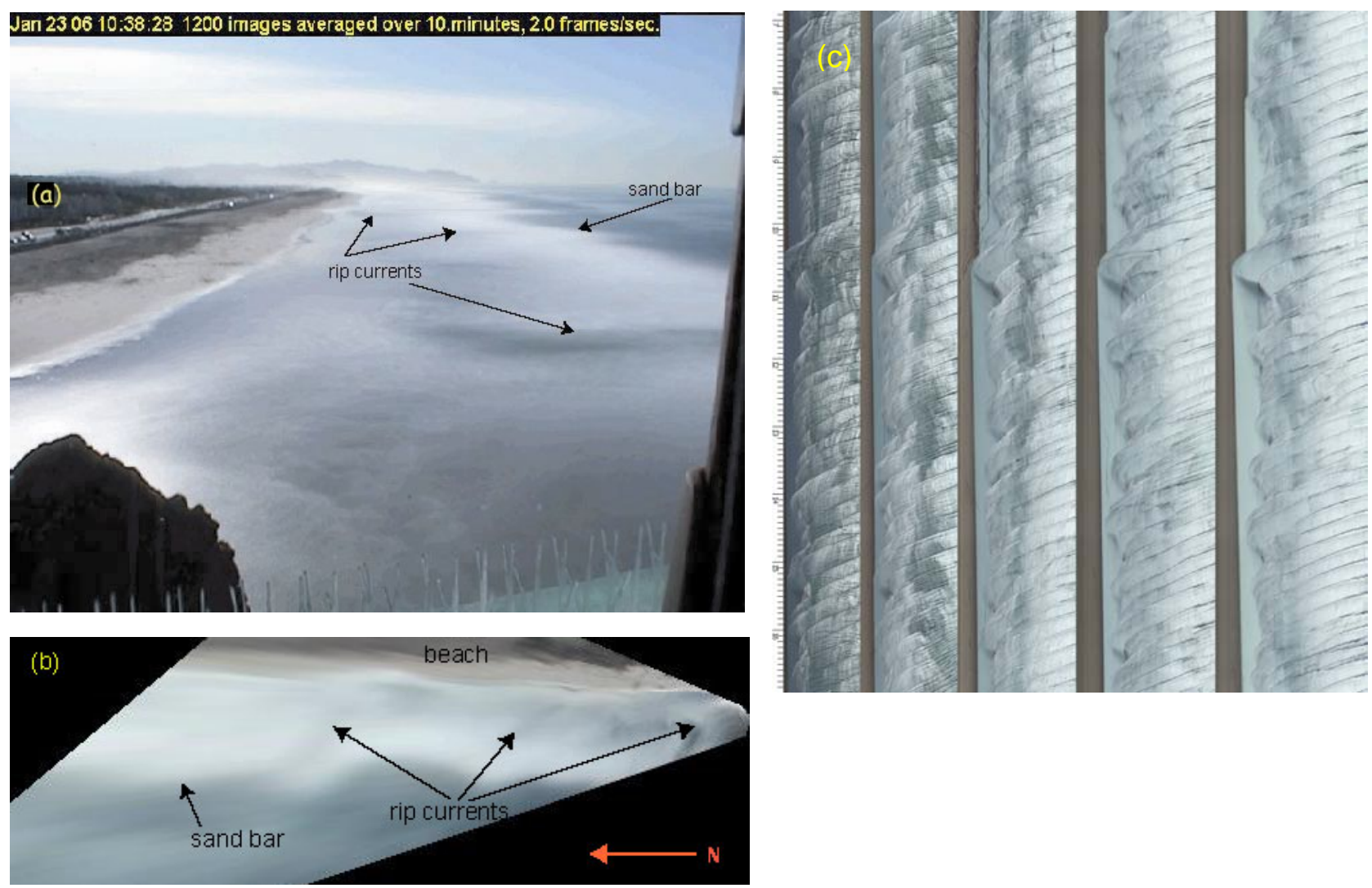

Figure 4.3 Typical images used for analysis: (a) unrectified time-averaged image, (b) rectified time-averaged image, and (c) time-stack image.

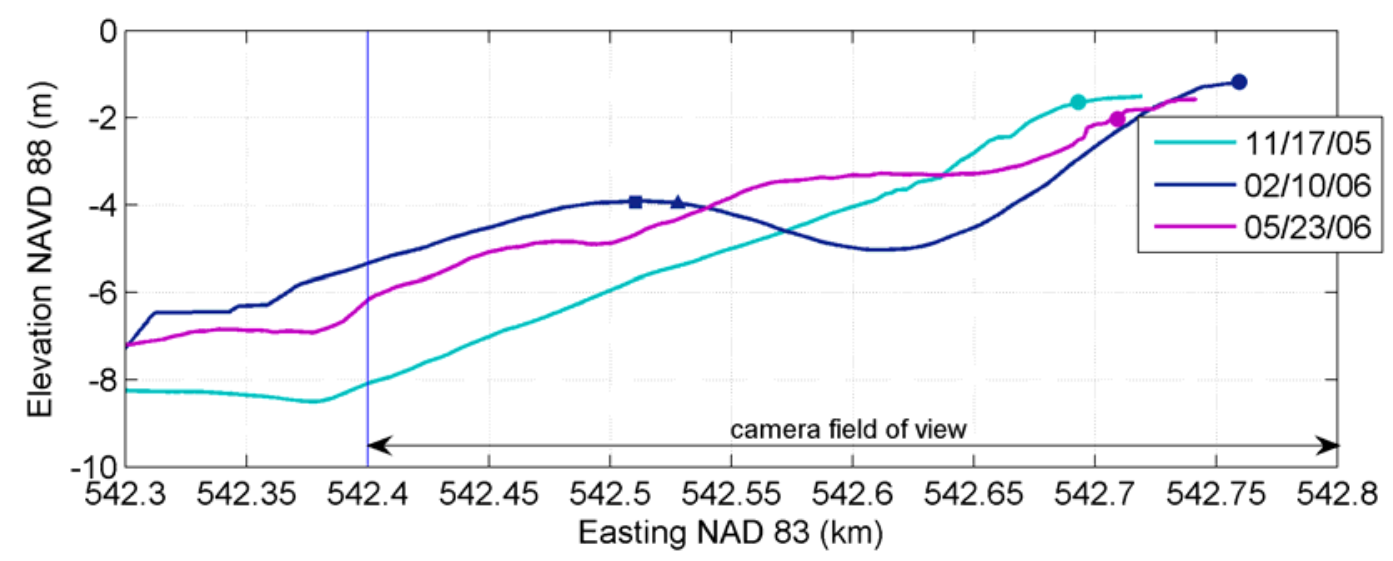

Figure 4.4. Break points observed in time-averaged images plotted on cross-shore profile measured with the CPS. 


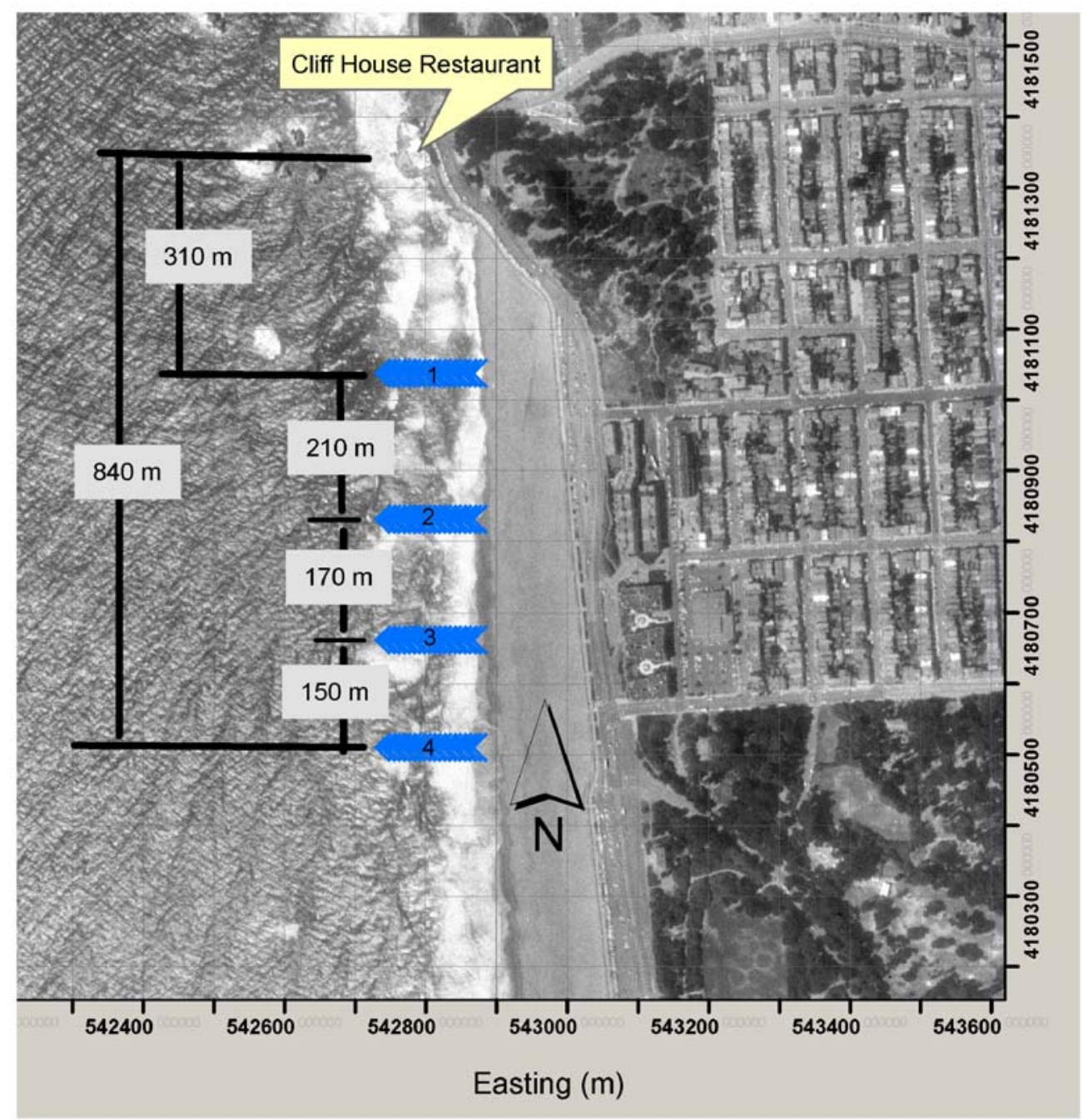

Figure 4.5. Locations of dominant rip currents at the north end of Ocean Beach. 


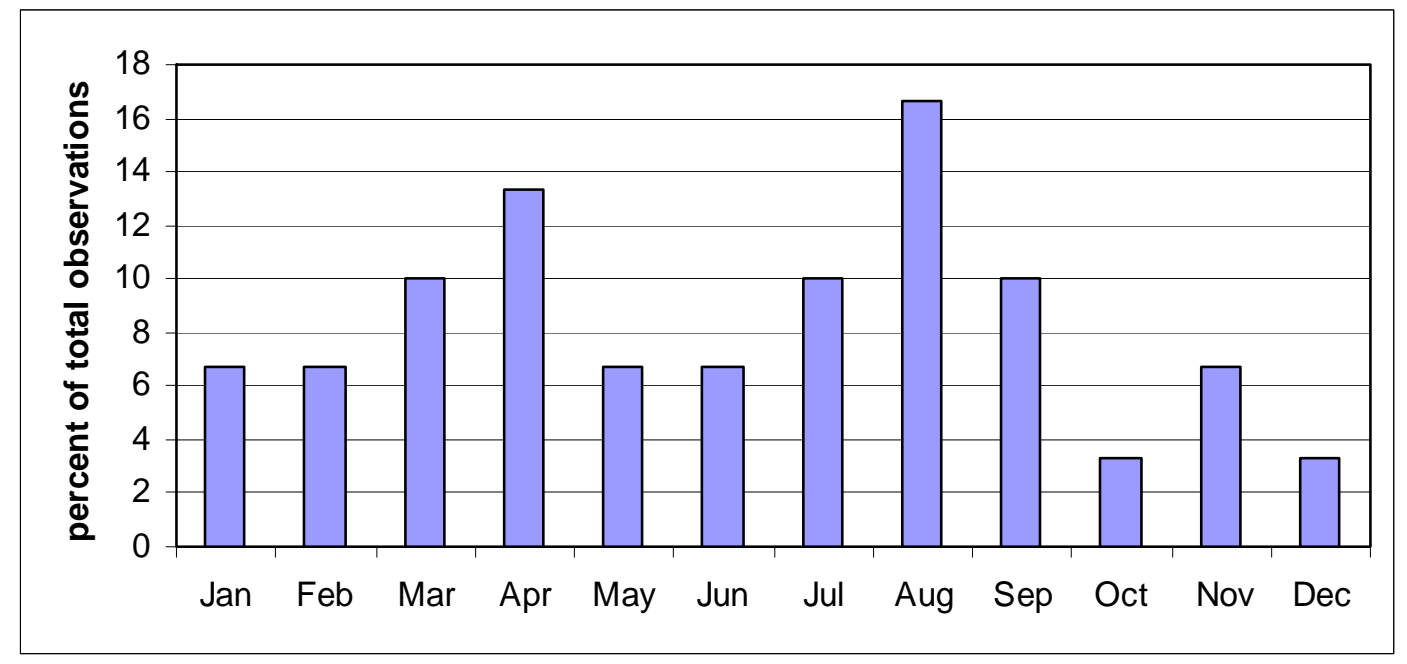

Figure 4.6. Seasonal distribution of observed rip current occurrence at any of the four locations at the north end of Ocean Beach.

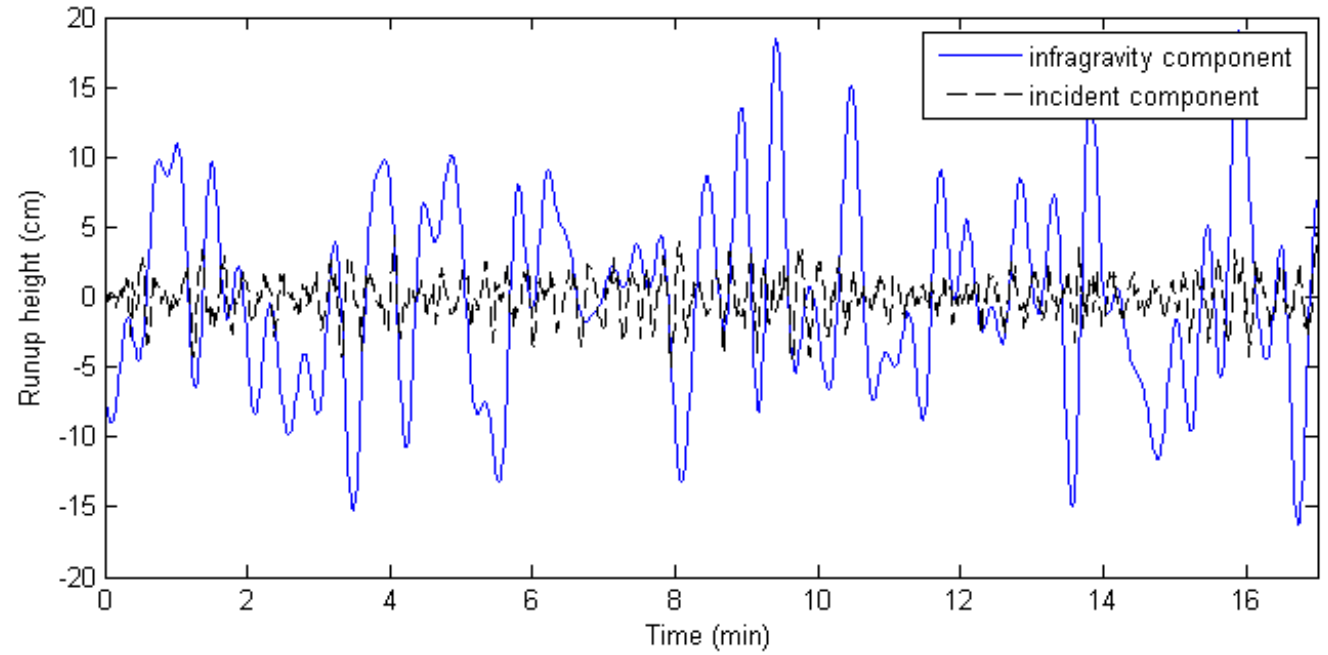

Figure 4.7. Typical 17 min tide detrended time-series illustrating the dominant infragravity component (transect T3 on 06/24/05, 10:09 to 10:23 am). 


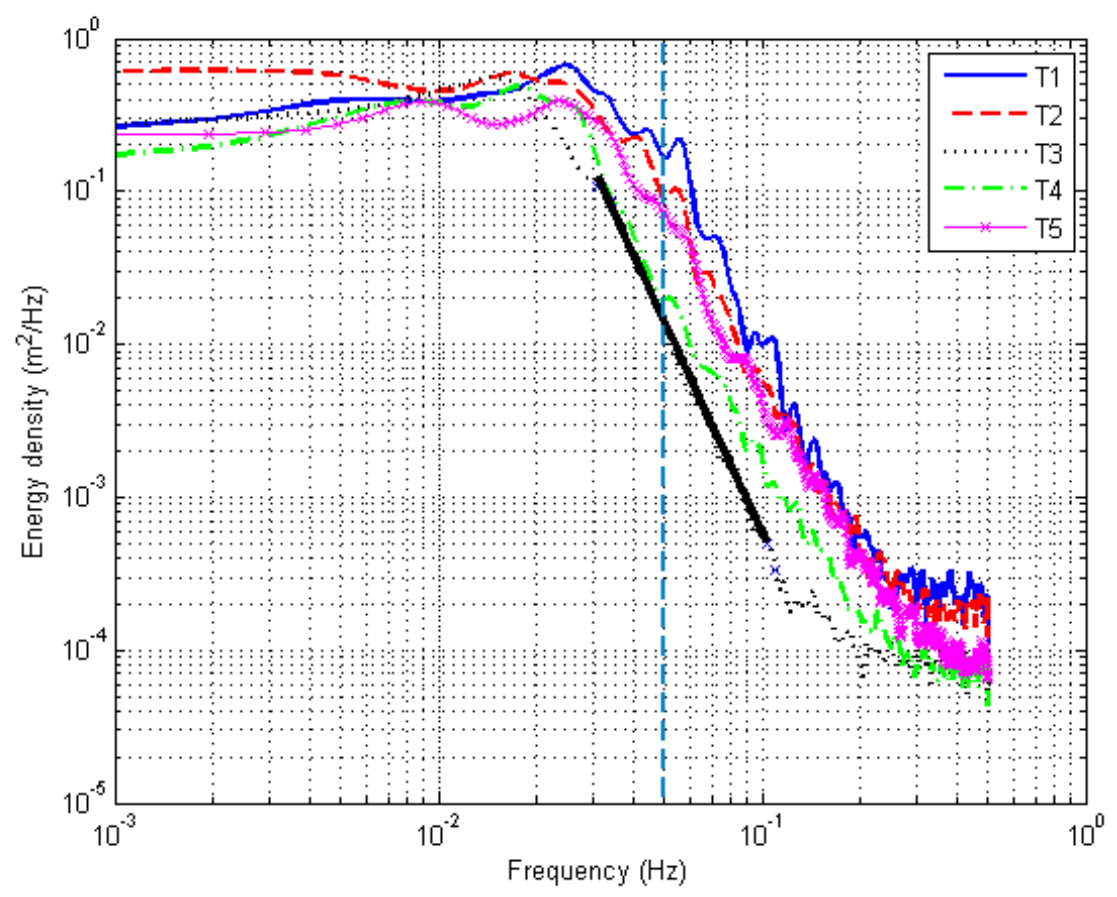

Figure 4.8. Total energy density, averaged over ten subsequent 17 minute time-periods, measured at each cross-shore transect. The heavy solid line is the best linear fit through T3 over 0.03 to $0.1 \mathrm{~Hz}$. Dashed vertical line is cutoff between infragravity and sea swell frequencies. 
(a)
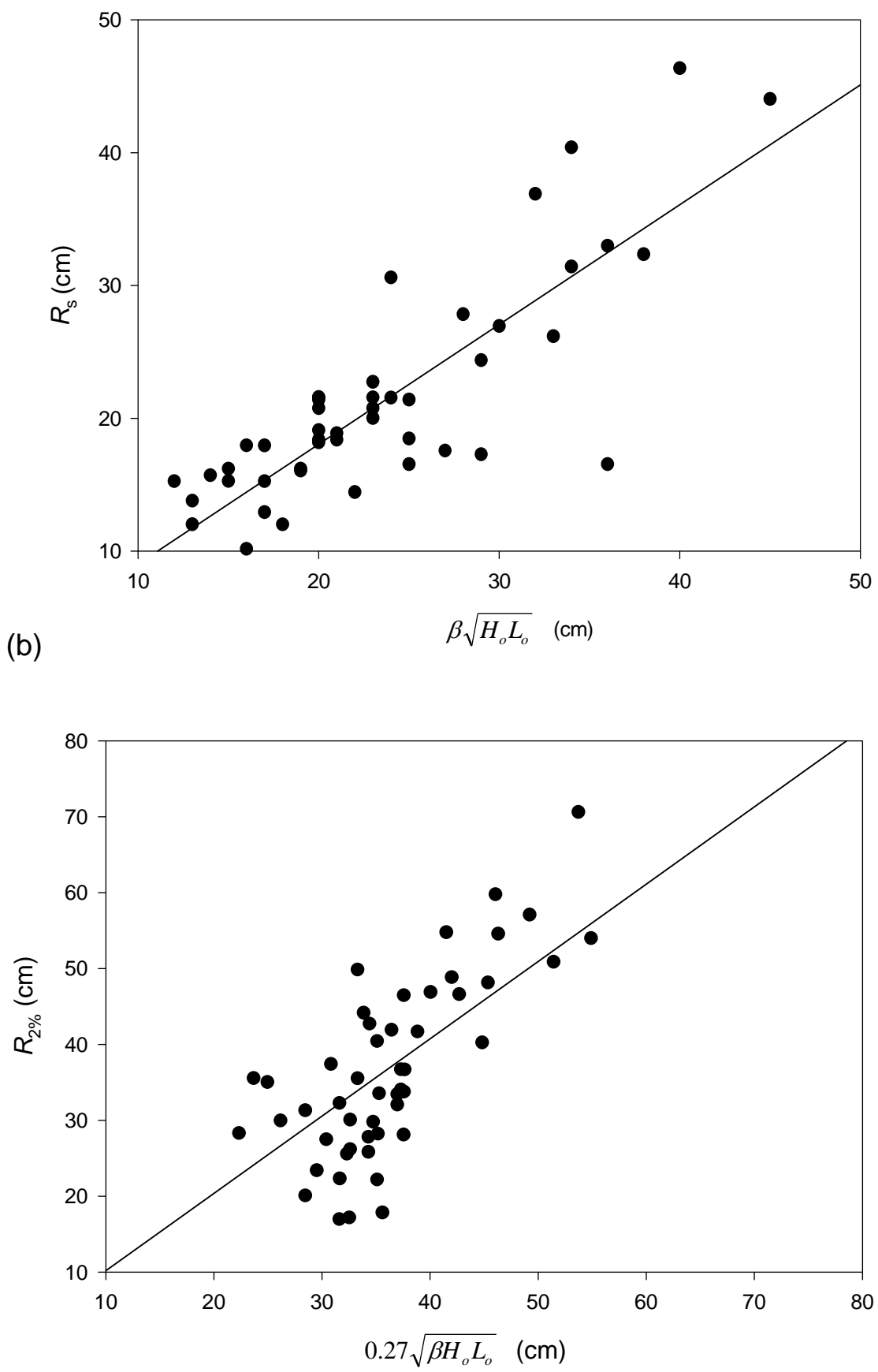

Figure 4.9. Measured runup statistics versus (a) Hunt's significant runup formula (1959), and (b) $2 \%$ exceedance using Ruggiero and others (2004) formulation. Both are shown with $T=T_{\text {mo2* }}$ 


\title{
Chapter 5-Offshore Instrument Deployments
}

\author{
By Jodi Eshleman
}

\section{Introduction}

Two oceanographic instrument deployment campaigns were conducted between June 21, 2005 and February 11, 2006. The instrument deployment campaigns were designed to achieve two goals: 1) to provide data to calibrate a numerical model for the region, and 2) to characterize the wave and current climate in the surf zone and offshore of Ocean Beach. These goals are essential to aid in understanding coastal change in the area and in generation of a predictive numerical model to help coastal managers make more informed decisions to preserve and maintain local infrastructure and resources.

\section{Methodology}

In summer, 2005, current profilers were deployed at four locations offshore of Ocean Beach (Figure 5.1). RD Instruments Acoustic Doppler Current Profilers (RDI ADCP) were placed at Sites 1-3, which were located in the nearshore region in water depths ranging from seven to $15 \mathrm{~m}$ and were spread out in the alongshore to highlight spatial differences in wave and current patterns (Figure 5.1). The fourth instrument was a Nortek Acoustic Wave and Current Meter (AWAC), which was deployed offshore in $20 \mathrm{~m}$ of water to help understand wave transformation across the ebb-tidal delta. Pictures of typical instrumented frames deployed at these sites are shown in Figure 5.2. This deployment was designed for a two month duration, therefore sampling intervals for waves and currents were chosen to maximize battery life (Table 5.1).

For the winter, 2006 deployment, several sites were revisited to help quantify seasonal changes in wave and current patterns. RDI ADCPs were deployed at Sites 1 and 3 and the Nortek AWAC was moved to a new location offshore in $12 \mathrm{~m}$ of water on the outer ebb-tidal delta (Site 5). In this campaign, a Seabird SBE-37 Microcat was included on the frames deployed at Sites 3 and 5 to gain some insight into changes in temperature, density, and salinity values. The instrument included on the frame at Site 3 (S/N 2538) measured conductivity, temperature and pressure with a range of $0-350 \mathrm{~m}$ on the pressure sensor. The instrument included on the frame at Site 5 (S/N 3013) measured conductivity and temperature with an internal pump, but did not include pressure. The sampling setup for the winter deployment was identical to that of the summer (Table 5.1), except the AWAC at Site 5 collected data at $2 \mathrm{~Hz}$ and had a wave bin size of $1.56 \mathrm{~m}$ and the blanking distance on the $\mathrm{ADCP}$ at Site 3 was changed to $0.20 \mathrm{~m}$.

Table 5.2 includes descriptions of locations and instrumentation for both the summer and winter deployments. The instrument located at Site 1 for the summer 2005 campaign (S/N 2054) was buried by $2.5 \mathrm{ft}$ of sediment upon recovery and measurements show that data collection at this site stopped after six days. The ADCP deployed at this same site for the winter 2006 deployment (S/N 6363) was not recovered, likely because burial prevented the dive pinger required to locate the frame from working properly. The head of the ADCP from Site 3 during the winter deployment (S/N 2054) was cracked upon recovery, but this did not appear to affect the saved data files in any way. The Microcat at Site 3 (S/N 2538) also logged pressure, which is used as a backup to validate pressure measurements from the ADCP. The sampling tube on the Microcat that was deployed at Site 5 (S/N 3013) filled 
with sand after nine days and did not collect valid conductivity data after that time; the temperature sensor still logged data. Water density was calculated from measurements of salinity, temperature, and pressure and the average water density of $1025 \mathrm{~kg} / \mathrm{m}^{3}$ was used to calculate water depths from pressure measured by the current profilers (Figure 5.3).

The current profilers deployed at all sites provided detailed measurements of current magnitude and direction throughout the water column. In addition, this current data was used with an array processing technique to determine directional wave information. The details of these calculations are different for both the ADCP and the AWAC. The Wavesmon software package from RD Instruments and Quickwave from Nortek were used to generate power and directional spectra from pressure, surface track, and current profile measurements at each site and determine bulk statistics. The RDI ADCP current data was processed using the ADCP Data Processing System, a Matlab ${ }^{\circledR}$ toolbox developed at the USGS Woods Hole Field Center and detailed information about this toolbox can be found in the ADCP Data Processing System Manual (Cote, 2003). Measurements were compared at all sites, but since there were two types of instrumentation and software packages used, spectral output and wave parameters were not all determined using the same algorithm. It is possible that some differences in output could be a result of different methods used to measure waves by the different systems.

\section{Results}

Waves and currents were measured at five sites in the nearshore region off of Ocean Beach. These measurements show spatial gradients in current magnitude and direction and wave height and direction along the seven kilometer stretch of Ocean Beach, as well as across the ebb-tidal delta.

\section{Currents}

Table 5.3 includes basic statistics for depth-averaged current measurements. The principal axis was calculated for each site based on the covariance between the measured $u$ and $v$ depth-averaged velocities. Figure 5.4 includes plots of the principal axis and depthaveraged current data for each site. This highlights the differences in current magnitude and principal direction at different sites. Current magnitudes at the north end of the Ocean Beach (Sites 1 and 2) are almost twice as strong as those measured at the southern end (Site 3) or offshore (Sites 4 and 5). For the sites located in shallower water (7-13 m) just off the beach, the principal current axis follows the shoreline, with northward velocities dominating. At offshore sites, the eastward component becomes more important, especially at Site 4 where the greater influence of the mouth of San Francisco Bay becomes apparent.

Figures 5.5 and 5.6 show the variation in measured currents throughout a tidal cycle for the summer and winter deployments. These include vectors of currents measured at the surface, middle, and bottom bin at each site to help identify vertical stratification as well as spatial differences in current speed and direction. During a summer tidal cycle, current speeds decay with distance from the inlet during the flooding and slack high tides (Figure 5.5 $\mathrm{d}, \mathrm{e}, \mathrm{h}, \mathrm{i}$ ). However, currents measured at Site 3 (especially on the bottom) can be as great or greater than Site 1 on the ebbing and low slack tides (Figure 5.5 b, c, f, g). In addition, Site 3 seems to have a stronger onshore component throughout the entire tidal cycle than Sites 1 and 2, which are located further north along Ocean Beach. During a winter tidal cycle 
(Figure 5.6), Site 3 has less of an onshore component of flow and less stratification. Currents measured at Site 5 are often on the same order of magnitude as Site 3.

Plots of eastward and northward current velocity variation with depth are shown in Figures 5.7 through 5.12 for all sites for both the summer and winter deployments. These plots show only one week of data at each site so trends corresponding to tidal cycles and daily changes are visible, and they suggest that comparing depth averages of current velocity is not always a good representation of the data. At all sites gradients of current magnitude throughout the water column were observed, commonly on the order of 50 to $100 \mathrm{~cm} / \mathrm{s}$. Sites 2 and 3 had very strong surface currents, which decay with depth, especially in the eastward velocity component for the summer and the northward velocity component for the winter (Figures 5.8, 5.9, and 5.11). At Site 4, there are not only gradients in current magnitude, but reversal throughout the water column (Figure 5.10). For the eastward velocity component this occurred on the ebbing tide and for the northward component, on the flooding tide.

\section{Waves}

Valuable information about wave forcing for this region is available by reviewing historical data from the Point Reyes Coastal Data Information Program (CDIP) buoy \#029 located approximately 20 miles west of Point Reyes in 550 m water depth (SCRIPPS Institution of Oceanography, 2006). Figure 5.13 displays wave direction histograms calculated by month from the time series of bulk wave parameters calculated from data measured at the CDIP buoy. Of particular interest is the strong dominance of waves coming from the northwest direction. From April through October, most waves come from directions ranging from 300 to 330 degrees. During the winter months, a much greater occurrence of waves are directed more onshore, from directions ranging from 270 to 300 degrees. Figure 5.13 shows the maximum wave height and direction measured in each month, and during the winter (October through January) these maximum wave heights come from an onshore directed angle. Figure 5.13 also shows a greater occurrence of waves in the four to six meter range from November through March, as would be expected during winter storms.

Bulk wave statistics determined from wave spectra show similar trends at all sites, lending some confidence to the wave output determined from multiple algorithms. Table 5.4 includes basic statistics of these bulk parameters. Significant wave heights at Site 3 are larger than at Sites 1 and 2 in the northern stretch along Ocean Beach (Figure 5.14). For the component of waves coming from onshore directed angles, directions measured for the summer at Site 4 had a higher angle by approximately 30 degrees than directions measured at the inshore sites during the summer (Figure 5.14, 5.16). Similarly, wave directions determined for the winter deployment show approximately a 40 degree difference from Site 3 in the same direction, originating more from the west than southwest (Figure 5.15, 5.16). Measurements at Site 3 for the winter show longer peak periods than offshore at Site 5, encompassing a ten degree spread rather than five degree spread, but similar trends are evident in both time series.

Figures 5.17 and 5.18 show the full 1-D spectrum at each site through time. Figure 5.17 indicates that there were bi-modal spectra most of the time during the summer, so bulk wave statistics of peak period and peak direction would not do a very good job of describing the wave climate. It is evident in Figure 5.17 that Site 3 has the most energy in the summer months. Some tidal modulation of waves is reflected in these plots for both winter and 
summer conditions by the streaky energy in the spectral plots. Note that the winter plots have a different scale, and these plots show much more energy in the winter at both sites.

\section{Discussion}

Current and wave measurements spanning different seasonal conditions show spatial gradients in wave power and current magnitude in the region offshore of Ocean Beach, likely due to the proximity of the mouth of San Francisco Bay. The northern and central sections of the beach experienced very strong tidal currents on the order of $1 \mathrm{~m} / \mathrm{s}$, whereas the southern stretch had current magnitudes that were almost half as strong. However, plots throughout a tidal cycle showed that this relationship occurs on the flooding tide, but on the ebbing tide current speeds at Site 3 can equal or exceed those measured in the northern section of the beach. These currents flowed in an axis along the coast, were dominated by tidal forcing, and had a very small eastward component of flow. The strongest currents were at the surface, and vertical gradients in current magnitude showed velocities varying by as much as $1 \mathrm{~m} / \mathrm{s}$ throughout the water column, with an average range of velocities on the order of 25 $\mathrm{cm} / \mathrm{s}$. At the outer sites, the influence of the mouth of the bay skewed the principal axis to be angled further east and the eastward component of flow began to dominate at Site 4 on the ebb-tidal delta. Measurements of current profiles on the delta also showed flow reversal within the water column, which occurred on the ebbing tide for eastward flow and on the flooding tide for northward flow.

While the northern portion of the beach experienced stronger currents overall, wave energy was much greater in the southern portion near the erosion hotspot. This is reflected in the larger energy spectrum values for Site 3 and increased estimates of significant wave height at that location compared to Sites 1 and 2. The summer months were dominated by bimodal spectra with two peaks in energy representing local seas ( 8 second range) and swell (15 second range). For this reason, the peak direction jumps between the two values at different frequencies, and bulk parameters do not do a good job of representing the direction and frequency of energy, because they only include information for one peak. During the winter months, there was a more consistent dominant wave direction because the spectrum was usually unimodal, and dominated by long period energy. For both seasons, waves measured around $270^{\circ}$ offshore have lower measured angles at the inshore sites (Figure 5.16). This suggests that complicated refraction patterns over the ebb-tidal delta caused the waves to be oriented more from the southwest as they propagated into shallower water. In addition, Figure 5.14 displays more southerly dominant wave angles at Site 2 than 3 during the summer, and a closer look at the spectral plot (Figure 5.17) shows that the lower frequency peak dominated more often at Site 2 than at Site 3. In reality, both sites were seeing two different peaks in energy coming from different directions, but the bulk parameter plot is misleading.

Figure 5.19 shows calculated magnitudes of alongshore transport (Q) using the CERC formula (ERDC, 1984) and a gamma value of $0.78, \mathrm{~K}$ of $0.60, \mathrm{n}$ of 0.4 , and a breaking wave height at the instrument location determined through conservation of energy. This formulation is very dependent on wave direction, and shows increased wave energy at Site 3 during the winter (Figure 5.17) and more southwest directions at Site 2 in the summer (Figure 5.14). This longshore transport calculation is based on wave parameters and shoreline angle, and therefore does not include a lot of important components at Ocean Beach, where tidally-forced currents are very strong. Figure 5.19 does not identify a clear nodal point, although Figure 5.19 a shows times when the direction of transport was to the 
north at Site 2 and to the south at Site 3 (07/5/05-7/10/05, 07/17/05-07/20/05, 07/25/05-

07/30/05). Most of the beach change occurred during the winter months, and magnitudes of transport were greater in Figure $5.19 \mathrm{~b}$ due to increased wave energy. For the summer, most transport was south at Site 3, but in the winter the direction of transport was almost always directed north due to the more onshore directed wave climate. As a result of instrument loss at Site 1, there is no data from the northern portion of the beach to compare this transport direction with for the winter deployment, when magnitudes of sediment transport are likely highest.

\section{Conclusions}

- Current magnitudes are much greater along the northern portion of Ocean Beach due to the proximity of the mouth of the bay (root mean square values of depthaveraged currents were $50 \%$ greater at Site 1 than at Site 3), but wave energy is much greater along the southern portion (mean wave height was $15 \%$ greater at Site 3 than at Site 1) where erosion problems are greatest.

- The gradients in current speed along Ocean Beach varied with the tide, where northern currents speeds were greater on the flooding and high tides and southern current speeds began to dominate on the ebbing and low tides.

- Current directions along Ocean Beach were shore-parallel, whereas the offshore sites show principal axes shifted more east-west, with an increasing eastward magnitude of flow with increased northing and proximity to the mouth of the bay.

- In the along-shore direction, vertical gradients in current magnitude of northsouth directed currents increased with increasing distance from the inlet; variation in current magnitude throughout the water column was greatest at Site 3. Eastwest currents show a relatively stronger vertical decay due to the influence of wave-induced currents. At the offshore sites (Sites 4 and 5) vertical gradients were apparent for both the north-south and east-west currents, and Site 4 had current reversal with a changing tide.

- Refraction patterns across the delta oriented waves with an onshore direction around $270^{\circ}$ in a more southwest direction as they propagated into shallower water.

- Calculations of alongshore transport using wave measurements at Sites 1-3 and the CERC equation indicate the direction of transport was north in the winter at Site 3 and suggest that a nodal point existed somewhere between Site 2 and Site 3 during the summer. 
Table 5.1. Summer 2005 current profiler sampling design.

\begin{tabular}{|c|c|c|c|c|}
\hline Parameters & Site 1 & Site 2 & Site 3 & Site 4 \\
\hline Instrument Type & RDI ADCP & RDI ADCP & RDI ADCP & Nortek AWAC \\
\hline Instrument Serial Number & 2054 & 5620 & 3796 & WAV 5179 \\
\hline Frequency $(\mathrm{kHz})$ & 1200 & 1200 & 1200 & 1000 \\
\hline Coordinate System & BEAM & BEAM & BEAM & ENU \\
\hline Blanking distance (m) & 0.44 & 0.44 & 0.44 & 0.50 \\
\hline \multicolumn{5}{|l|}{ Current Sampling: } \\
\hline Cell size (m) & 1 & 1 & 1 & 1 \\
\hline Ensemble interval (min) & 10 & 10 & 10 & 20 \\
\hline $\begin{array}{l}\text { Ensemble Averaging Length } \\
\text { (min) }\end{array}$ & 1 & 1 & 1 & 1.5 \\
\hline Sampling Rate (Hz) & 1 & 1 & 1 & $6^{1}$ \\
\hline \multicolumn{5}{|l|}{ Wave Sampling: } \\
\hline Cell size (m) & 1 & 1 & 1 & 2.52 \\
\hline Burst interval (min) & 120 & 120 & 120 & 20 \\
\hline Sampling rate $(\mathrm{Hz})$ & 2 & 2 & 2 & 1 \\
\hline Samples per burst & 8192 & 8192 & 8192 & 1024 \\
\hline
\end{tabular}

${ }^{1}$ Internal sampling rate is $6 \mathrm{~Hz}$ but the fastest the instrument can write out data is $1 \mathrm{~Hz}$ (Nortek 2004).

Table 5.2. Instrumented Frames Deployed at Ocean Beach in 2005 / 2006.

\begin{tabular}{|l|c|c|c|c|l|}
\hline $\begin{array}{c}\text { Deployment } \\
\text { Campaign }\end{array}$ & Location & $\begin{array}{c}\text { Deployment } \\
\text { Dates }\end{array}$ & Latitude & Longitude & \multicolumn{1}{|c|}{ Instruments } \\
\hline Summer 2005 & Site 1 & $\begin{array}{c}06 / 21 / 05- \\
08 / 16 / 05\end{array}$ & $\begin{array}{c}37.775 \\
\mathrm{~N}\end{array}$ & $122.519 \mathrm{~W}$ & RD I 1200 kHz ADCP S/N 2054 \\
\hline & Site 2 & $\begin{array}{c}06 / 21 / 05- \\
08 / 16 / 05\end{array}$ & $\begin{array}{c}37.756 \\
\mathrm{~N}\end{array}$ & $122.520 \mathrm{~W}$ & RD I 1200 kHz ADCP S/N 5620 \\
\hline & Site 3 & $\begin{array}{c}06 / 21 / 05- \\
08 / 16 / 05\end{array}$ & $\begin{array}{c}37.726 \\
\mathrm{~N}\end{array}$ & $122.518 \mathrm{~W}$ & RD I 1200 kHz ADCP S/N 3796 \\
\hline & Site 4 & $\begin{array}{c}06 / 21 / 05- \\
07 / 26 / 05\end{array}$ & $\begin{array}{c}37.789 \\
\mathrm{~N}\end{array}$ & $122.643 \mathrm{~W}$ & Nortek AWAC S/N WAV 5179 \\
\hline Winter 2006 & Site 1 & $\begin{array}{c}01 / 12 / 06- \\
\text { present }\end{array}$ & $\begin{array}{c}37.775 \\
\mathrm{~N}\end{array}$ & $122.520 \mathrm{~W}$ & RD I 1200 kHz ADCP S/N 6363 \\
\hline & Site 3 & $\begin{array}{c}01 / 12 / 06- \\
02 / 10 / 06\end{array}$ & $\begin{array}{c}37.726 \\
\mathrm{~N}\end{array}$ & $122.518 \mathrm{~W}$ & $\begin{array}{l}\text { RD I 1200 kHz ADCP S/N } \\
\text { 2054, Microcat CTD S/N 2538 }\end{array}$ \\
\hline & Site 5 & $\begin{array}{c}01 / 12 / 06- \\
02 / 11 / 06\end{array}$ & $\begin{array}{c}37.747 \\
\mathrm{~N}\end{array}$ & $122.609 \mathrm{~W}$ & $\begin{array}{l}\text { Nortek AWAC S/N WAV 5179, } \\
\text { Microcat CTD S/N 3013 }\end{array}$ \\
\hline
\end{tabular}


Table 5.3. Basic Statistics for Depth-Averaged Currents.

\begin{tabular}{|c|c|c|c|c|c|c|c|c|c|}
\hline & & \multicolumn{3}{|c|}{ Eastward Velocity (m/s) } & \multicolumn{4}{c|}{ Northward Velocity (m/s) } \\
\hline Deployment & Location & mean & min & max & rms & mean & min & max & rms \\
\hline $\begin{array}{c}\text { Summer } \\
\mathbf{2 0 0 5}\end{array}$ & Site 1 & -0.05 & -0.44 & 0.21 & 0.09 & 0.29 & -0.94 & 1.35 & 0.60 \\
\hline & Site 2 & -0.00 & -0.23 & 0.33 & 0.07 & 0.14 & -1.02 & 1.09 & 0.48 \\
\hline & Site 3 & 0.01 & -0.11 & 0.16 & 0.04 & 0.07 & -0.86 & 0.70 & 0.31 \\
\hline & Site 4 & -0.07 & -0.44 & 0.28 & 0.16 & 0.04 & -0.47 & 0.56 & 0.15 \\
\hline $\begin{array}{c}\text { Winter } \\
\mathbf{2 0 0 6}\end{array}$ & Site 3 & -0.03 & -0.43 & 0.17 & 0.06 & 0.04 & -0.79 & 0.74 & 0.31 \\
\hline & Site 5 & -0.03 & -0.56 & 0.43 & 0.18 & -0.07 & -0.78 & 0.67 & 0.31 \\
\hline
\end{tabular}

Table 5.4. Basic Statistics for Wave Parameters.

\begin{tabular}{|c|c|c|c|c|c|c|c|c|c|c|}
\hline & & \multicolumn{3}{|c|}{ Hs } & \multicolumn{3}{c|}{ Tp } & \multicolumn{3}{c|}{ Dp } \\
\hline Deployment & Location & mean & min & max & mean & min & max & mean & min & max \\
\hline $\begin{array}{c}\text { Summer } \\
\mathbf{2 0 0 5}\end{array}$ & Site 1 & 1.2 & 0.9 & 1.7 & 15.5 & 8.5 & 18.2 & 238 & 206 & 290 \\
\hline & Site 2 & 1.1 & 0.6 & 2.0 & 12.6 & 4.1 & 21.3 & 252 & 198 & 309 \\
\hline & Site 3 & 1.4 & 0.7 & 2.4 & 10.1 & 3.3 & 18.2 & 270 & 178 & 324 \\
\hline & Site 4 & 1.2 & 0.6 & 2.2 & 10.1 & 4.5 & 16.6 & 273 & 224 & 304 \\
\hline $\begin{array}{c}\text { Winter } \\
\mathbf{2 0 0 6}\end{array}$ & Site 3 & 2.1 & 0.8 & 4.1 & 14.6 & 9.8 & 21.3 & 245 & 226 & 306 \\
\hline & Site 5 & 2.6 & 1.1 & 5.6 & 12.0 & 9.1 & 18.3 & 276 & 256 & 294 \\
\hline
\end{tabular}




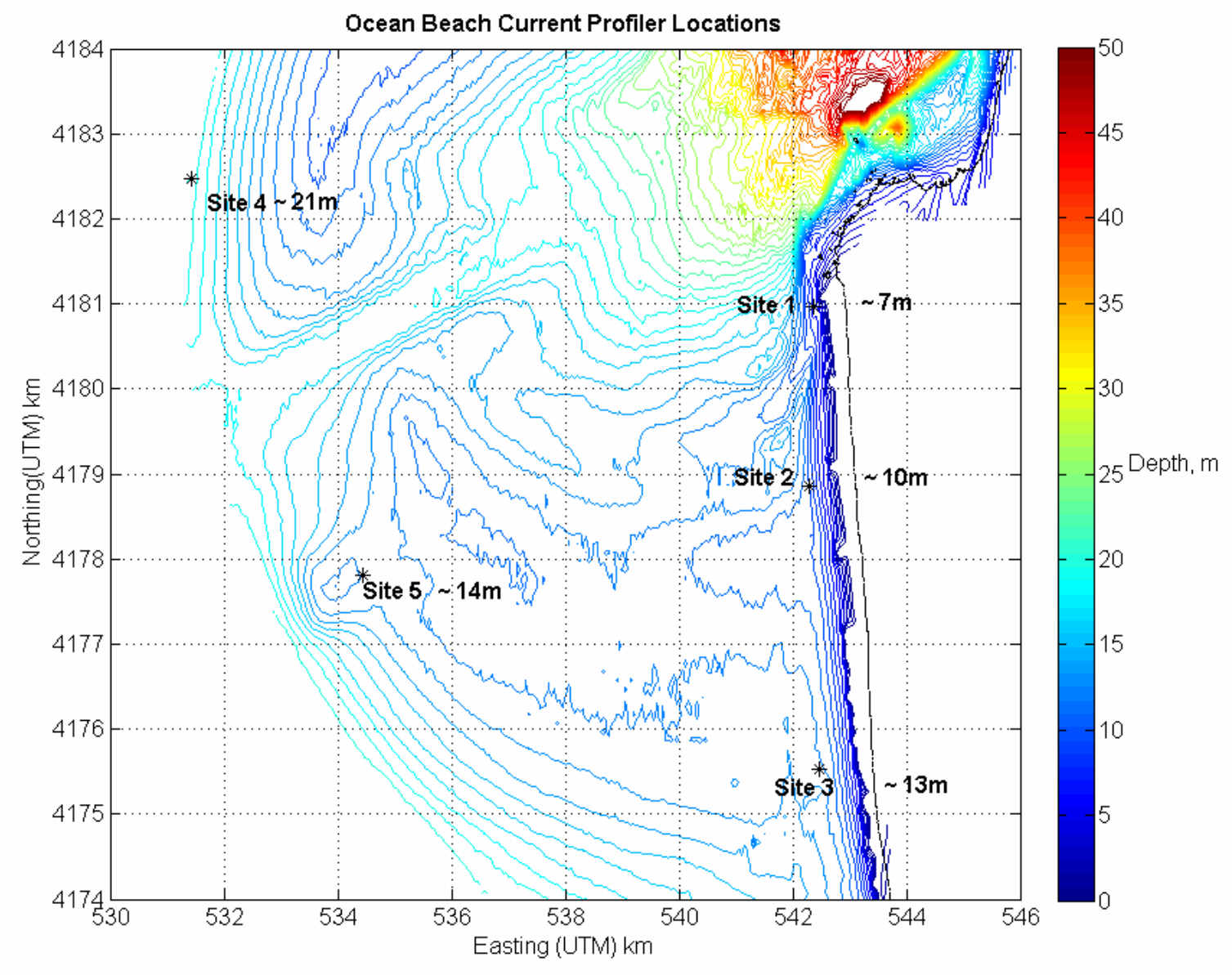

Figure 5.1. Instrument deployment sites at 0cean Beach.

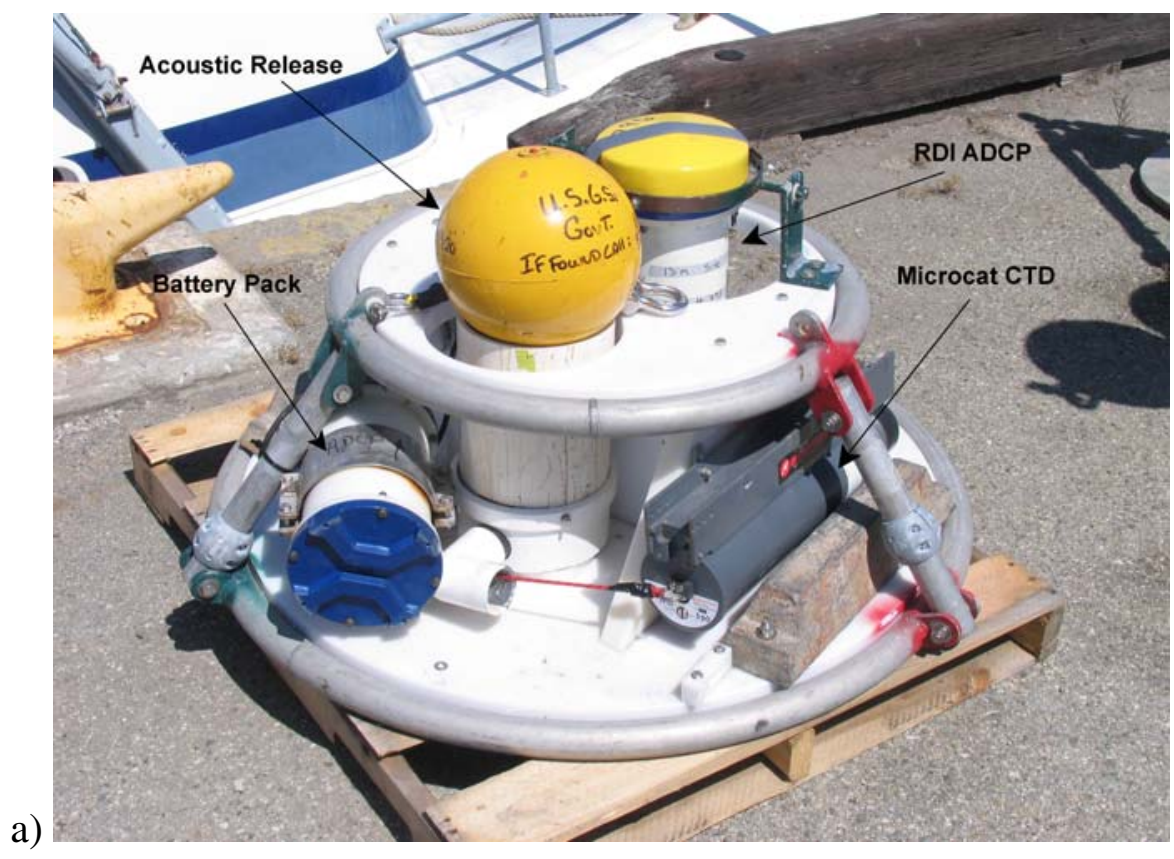




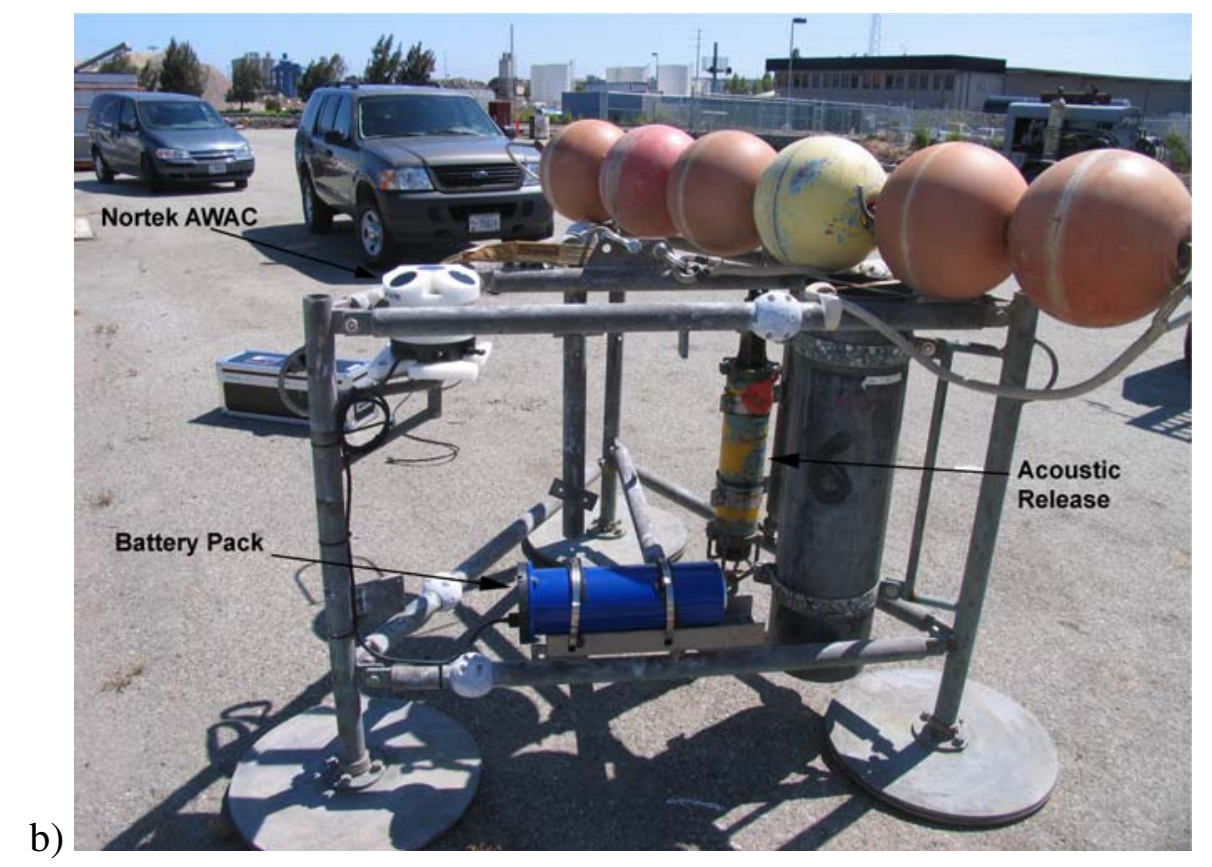

Figure 5.2. Photographs of typical instrumented tripods deployed at a) Sites 1-3 and b) Sites $4-5$.

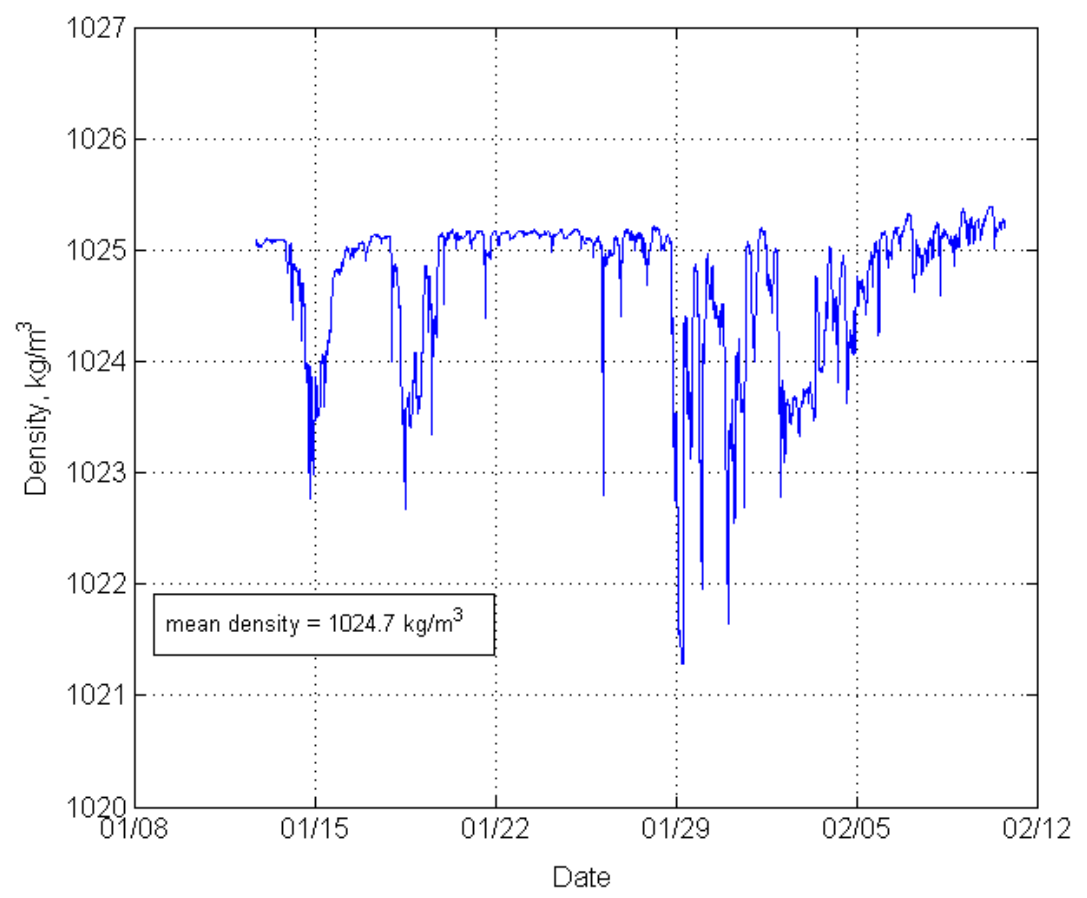

Figure 5.3. Water density calculated for Site 3 during winter 2006 deployment. 

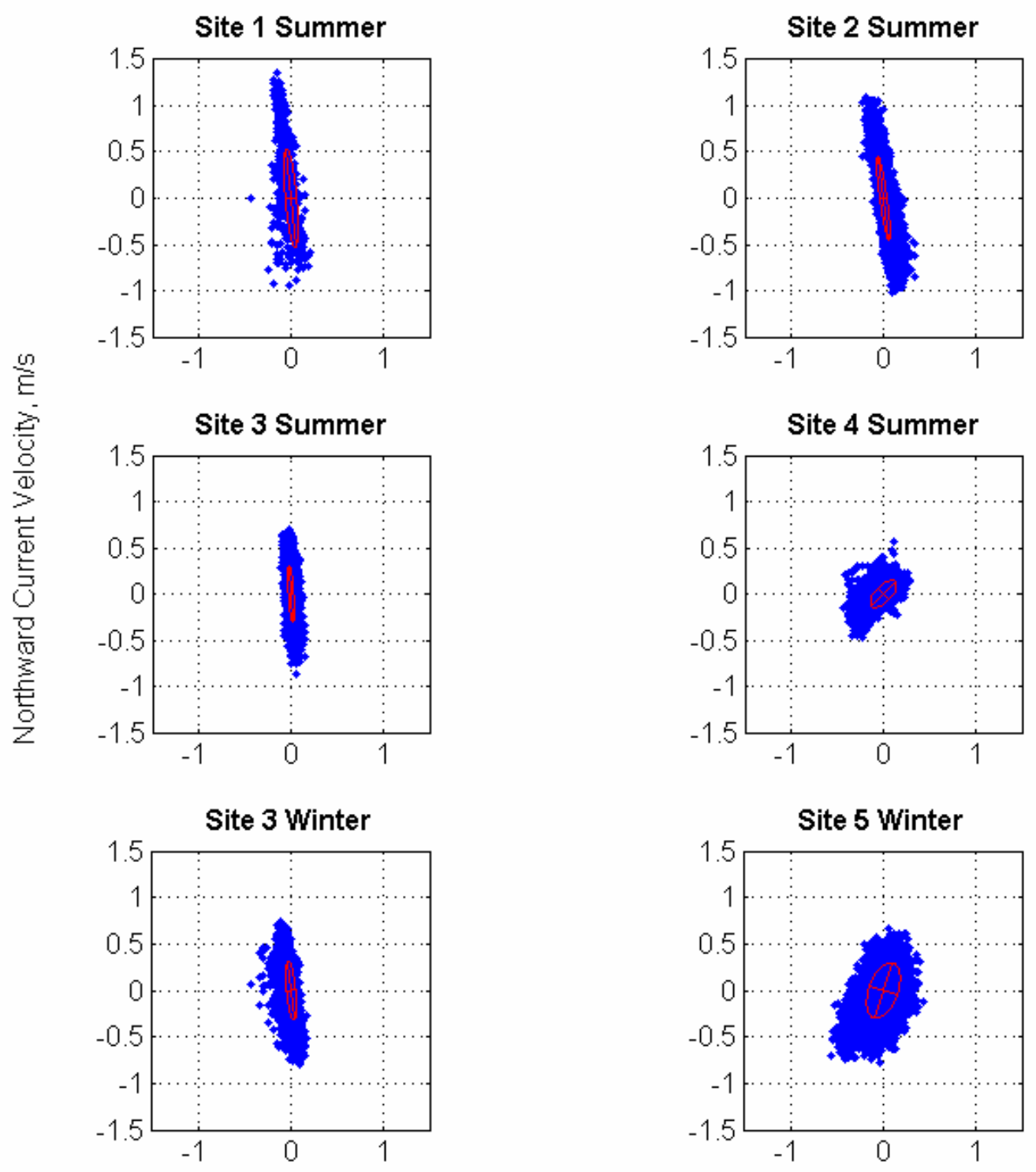

Eastward Current Velocity, m/s

Figure 5.4. Principal axis calculations for depth-averaged current measurements at a) Site 1 summer 2005 b) Site 2 summer 2005 c) Site 3 summer 2005 d) Site 4 summer 2005 e) Site 3 winter 2006 f) Site 5 winter 2006. 


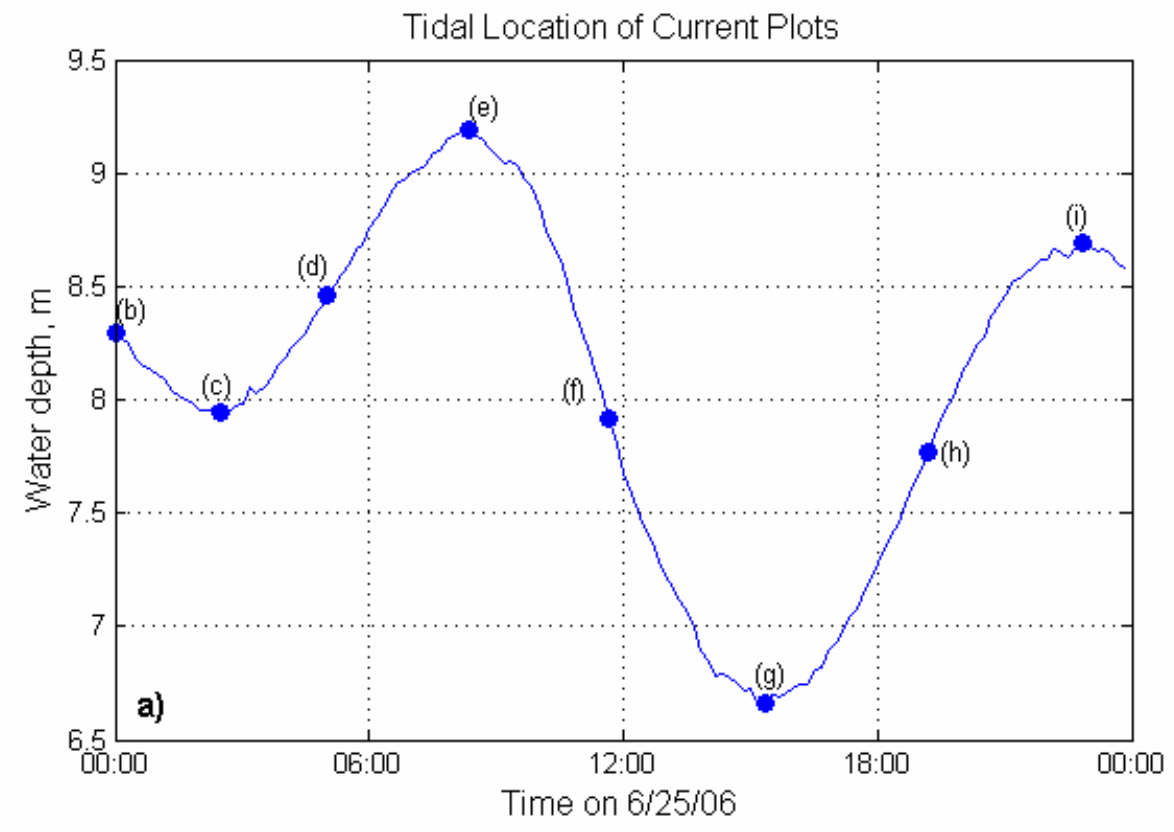



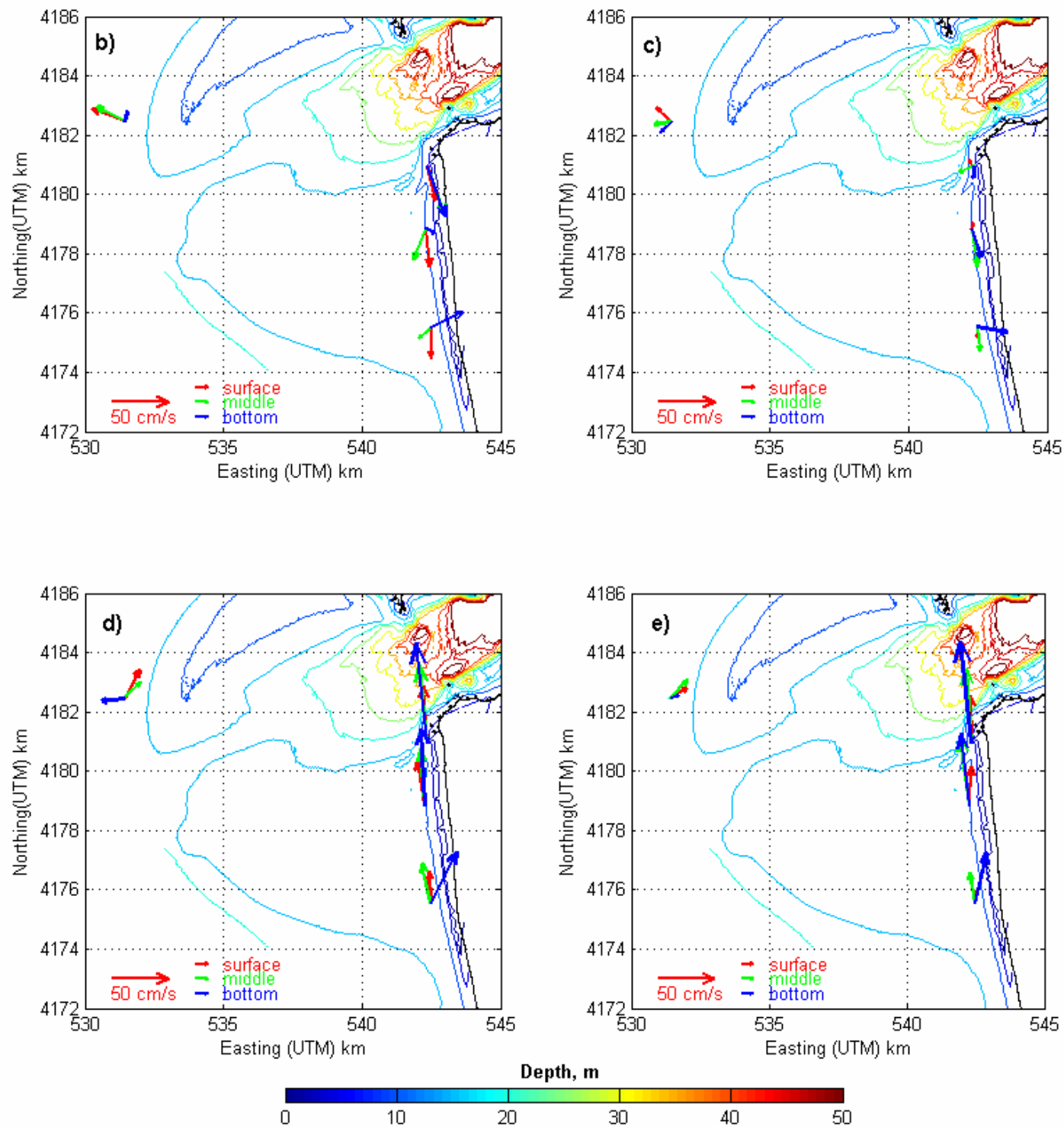

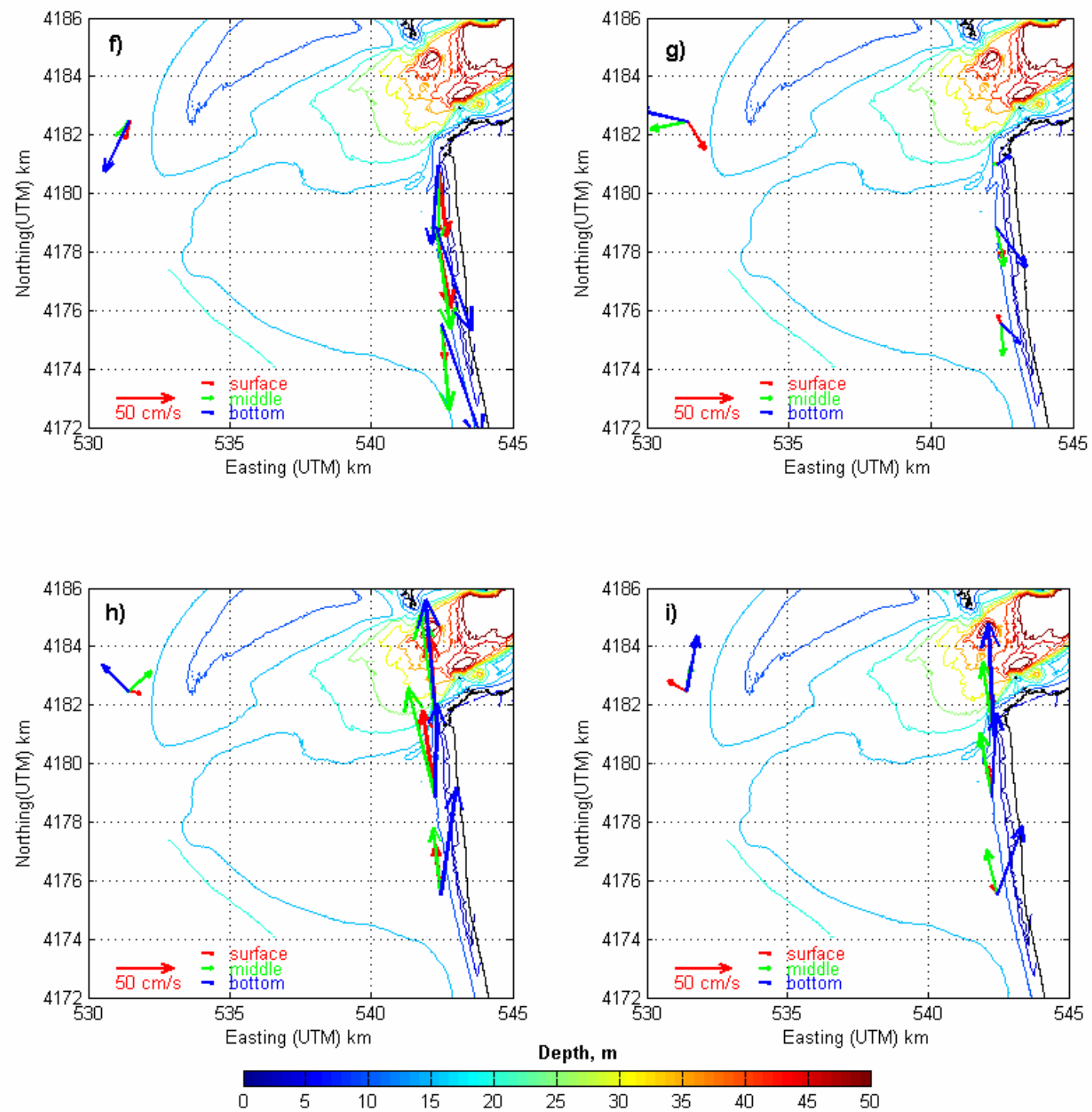

Figure 5.5. Flow patterns measured at 0 cean Beach throughout a tidal cycle on 06/25/05 during the summer 2005 deployment. Plot a) shows the measured tide at Site 1; points and text refer to measured currents in plots b) through i). Depth values are shown by colored contours and currents at different vertical locations have colored arrows. 


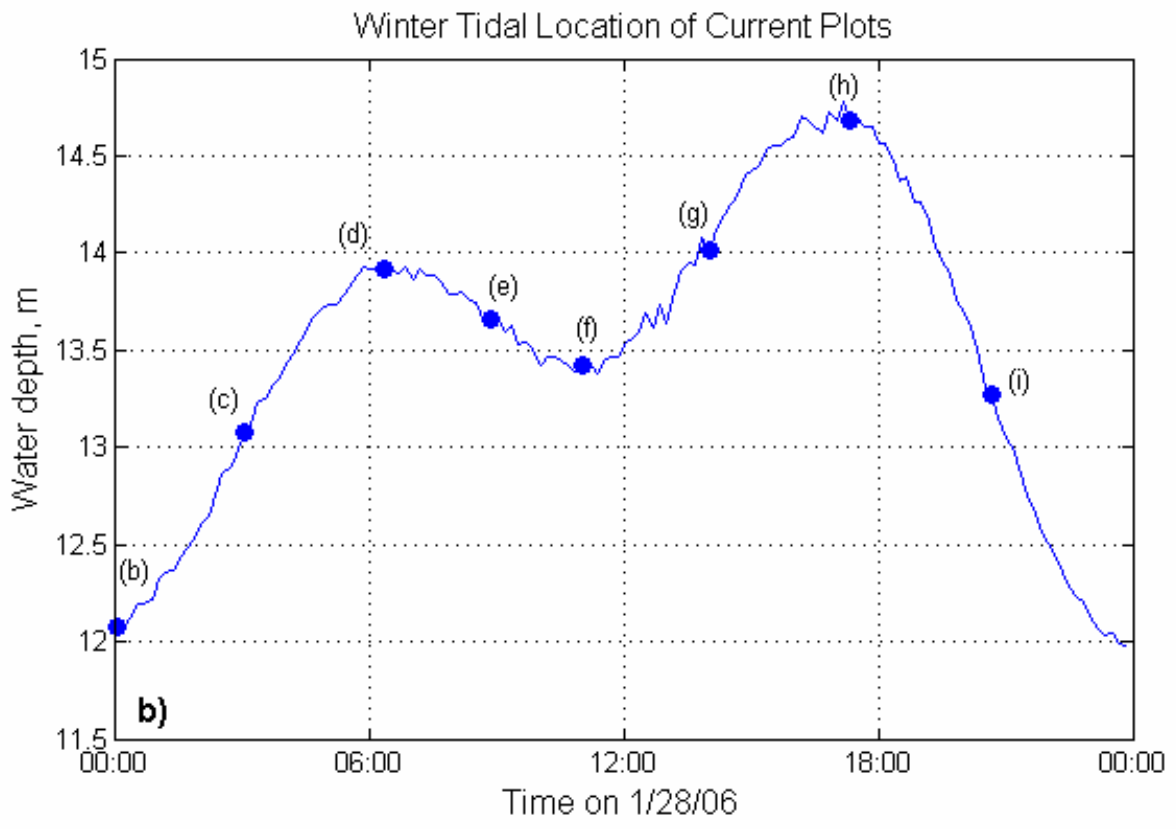



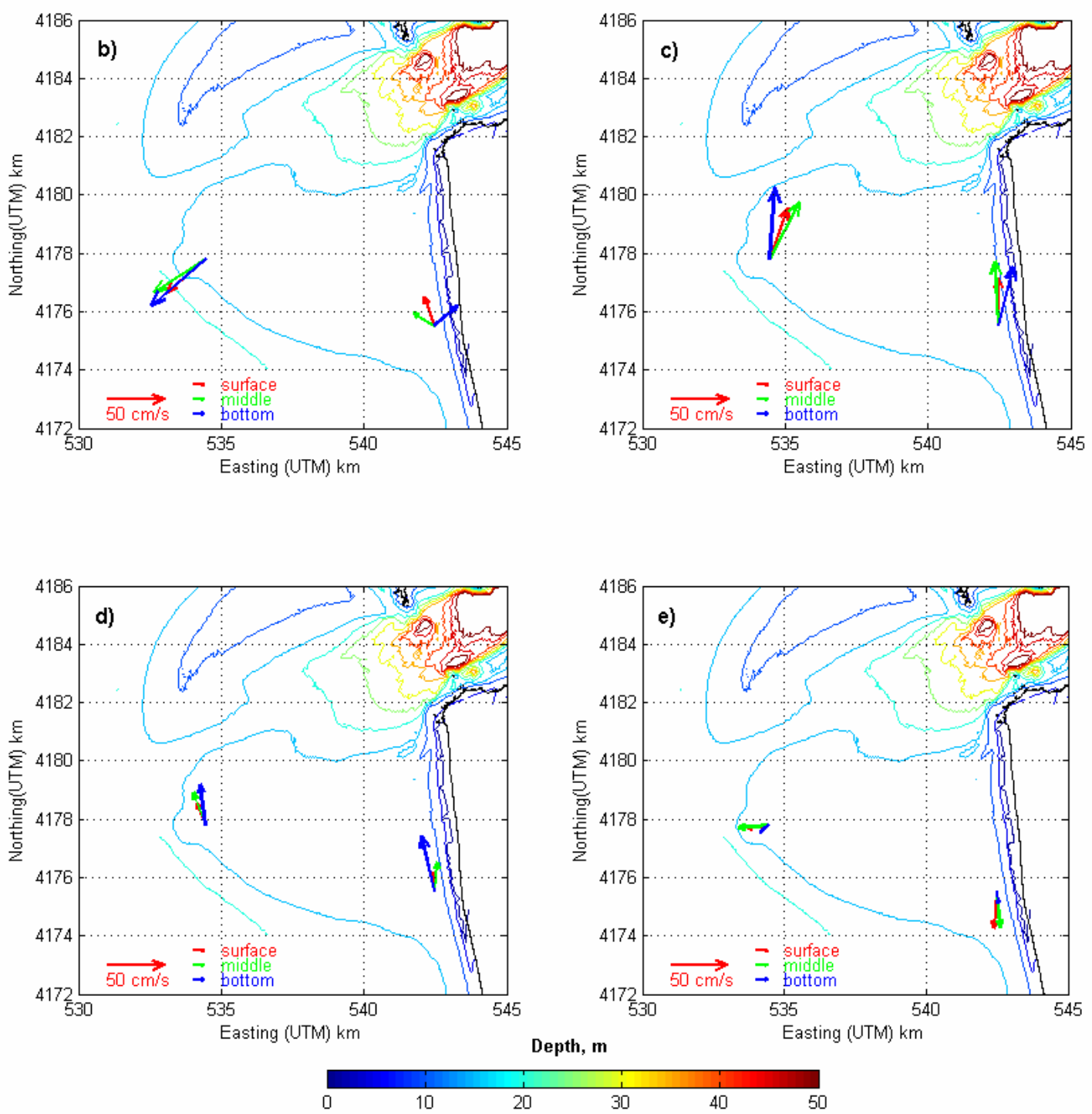

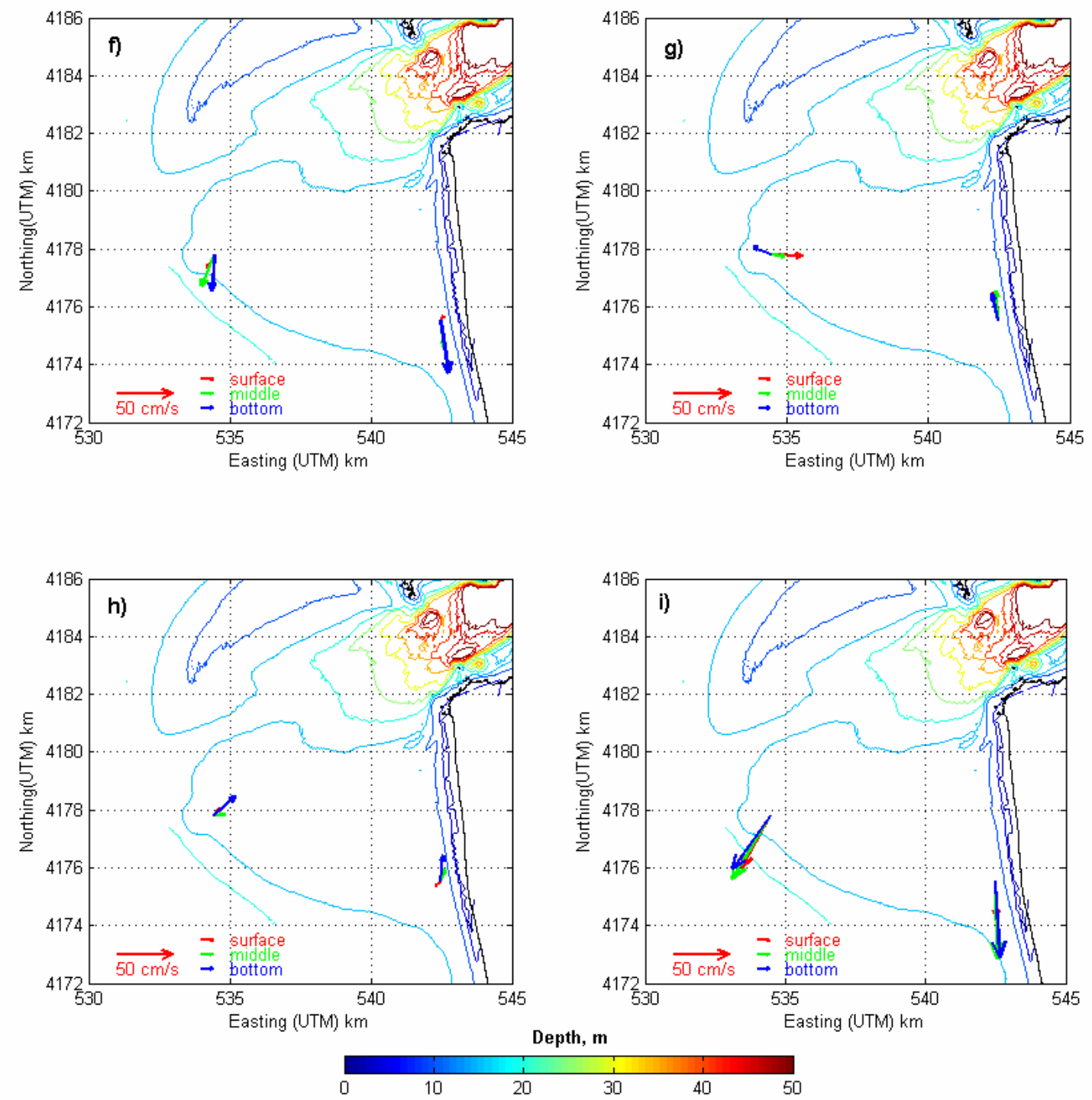

Figure 5.6. Flow patterns measured at 0 cean Beach throughout a tidal cycle on 01/28/06 during the winter 2006 deployment. Plot a) shows the measured tide at Site 3; points and text refer to measured currents in plots b) through i). Depth values are shown by colored contours and currents at different vertical locations have colored arrows. 

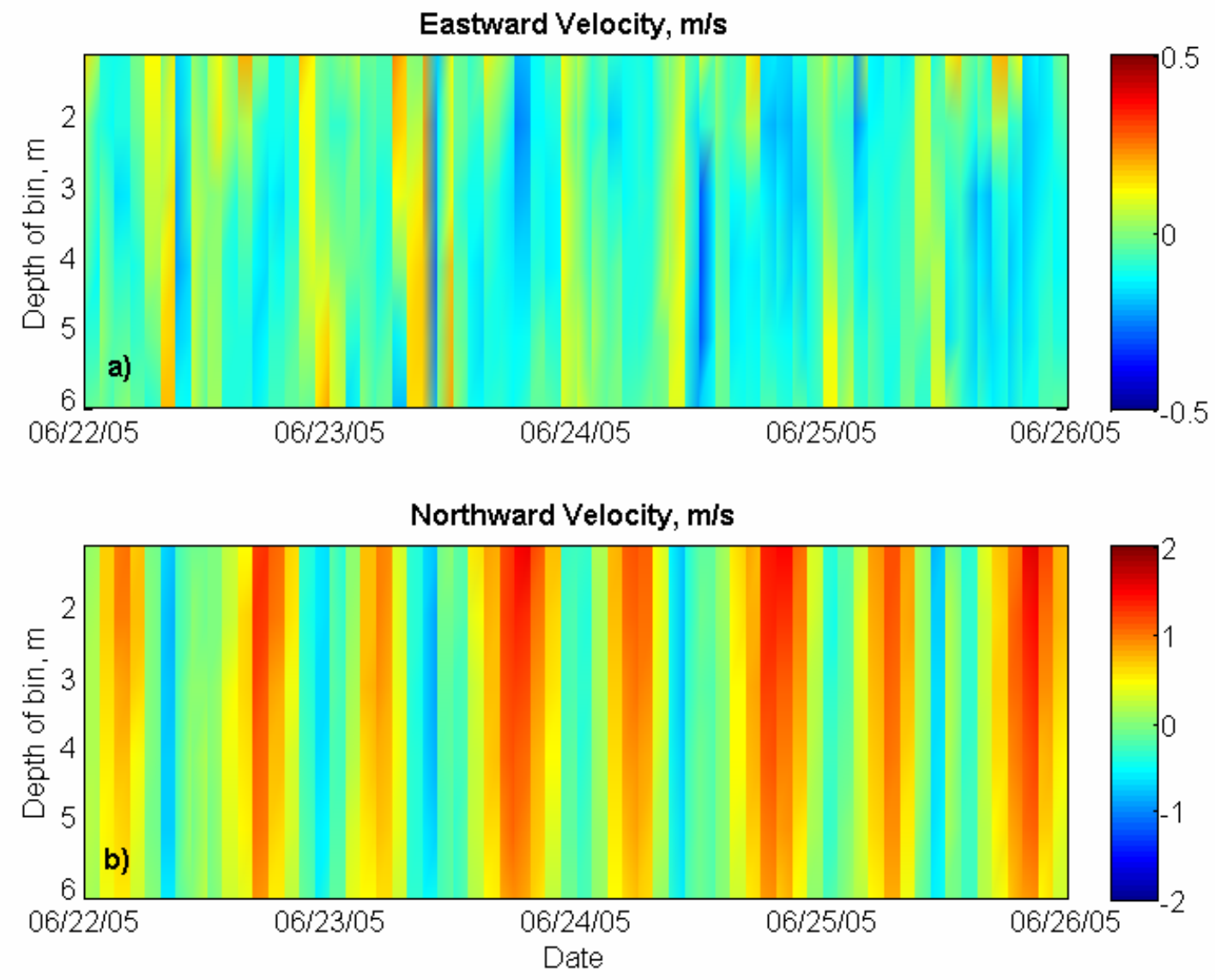

Figure 5.7. Current profile plots through time for summer deployment at Site 1 a) eastward velocity b) northward velocity. (Note that this is a different time period than the other plots and only 4 days since the instrument was buried.) 

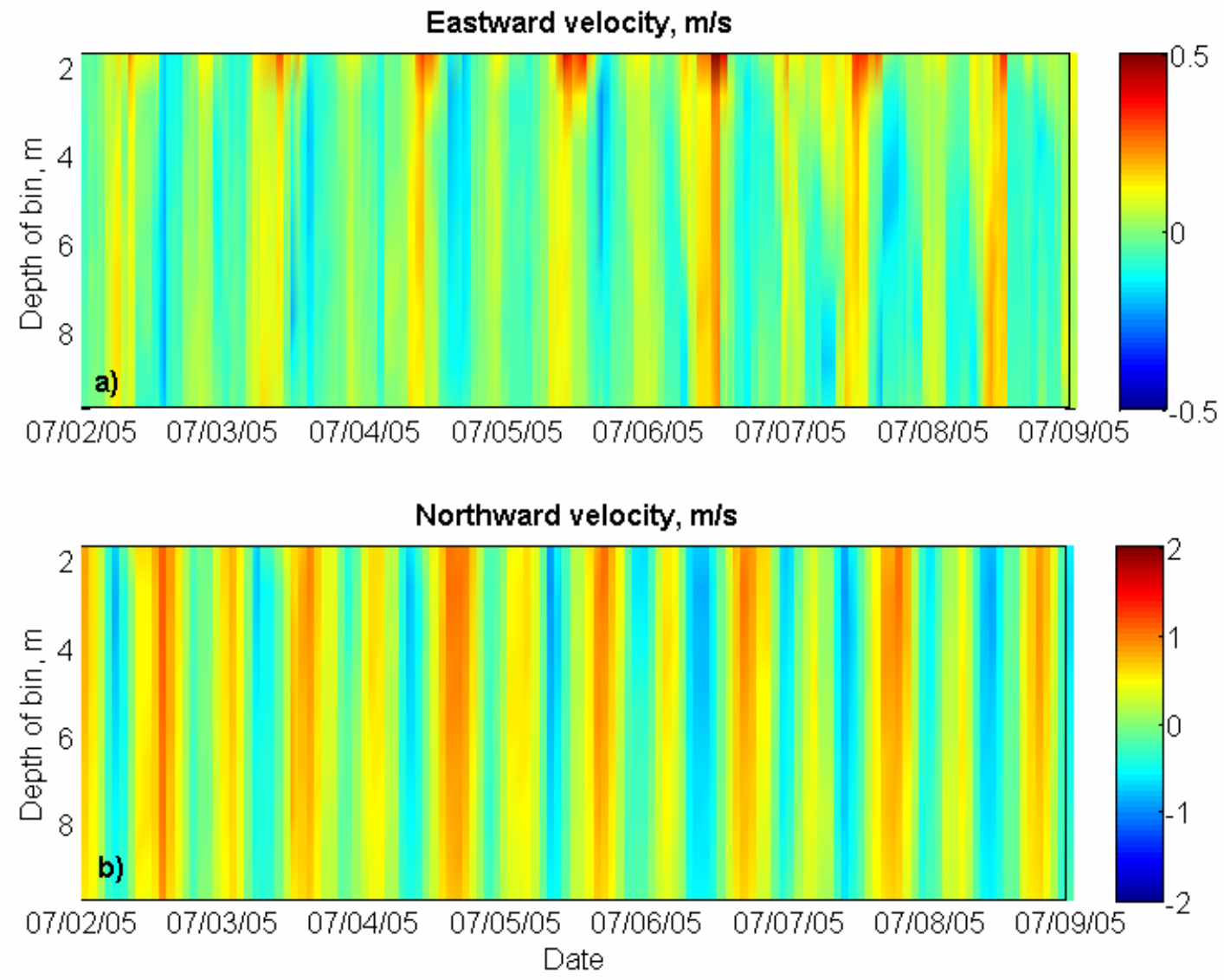

Figure 5.8. Current profile plots through time for summer deployment at Site 2 a) eastward velocity b) northward velocity. 

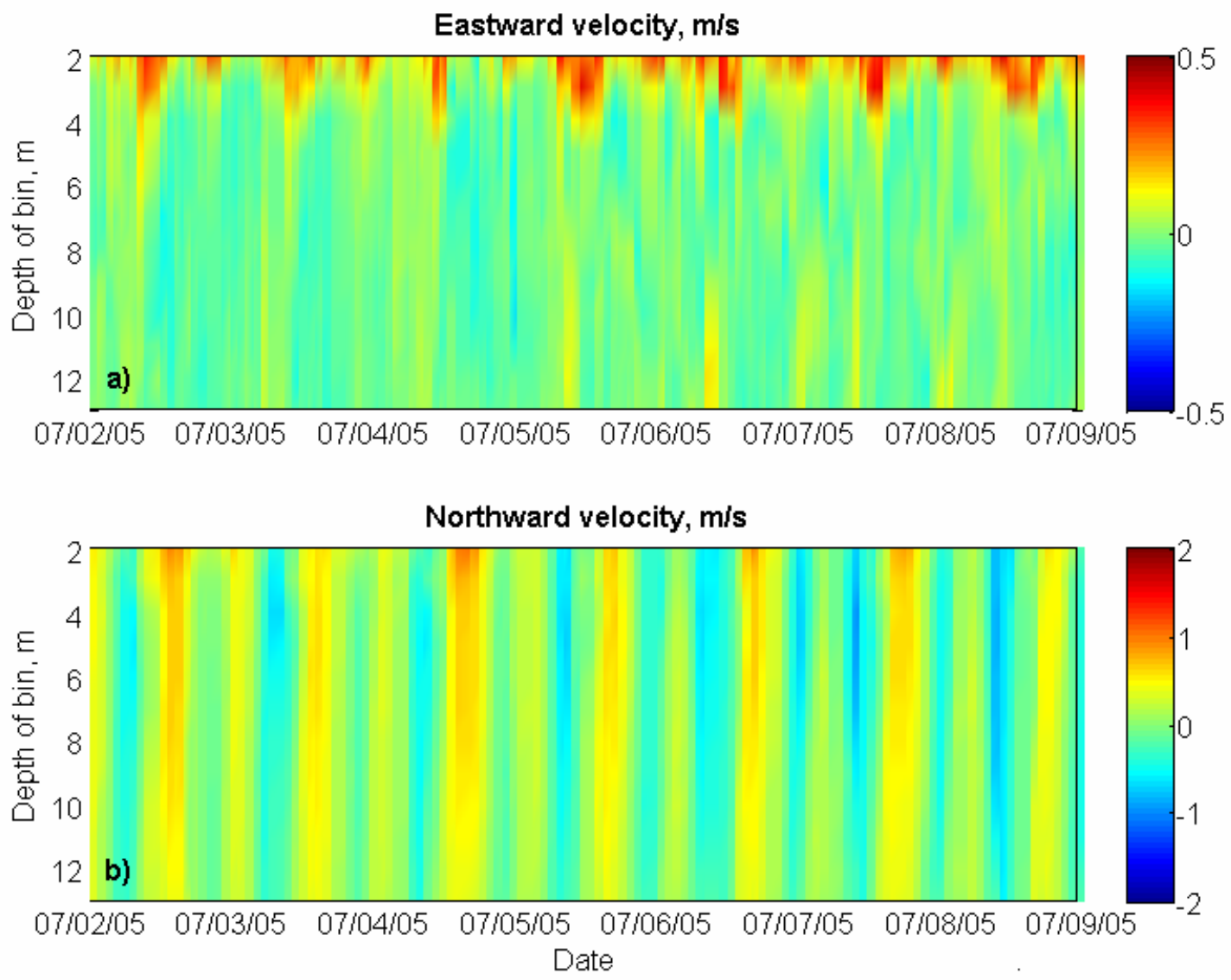

Figure 5.9. Current profile plots through time for summer deployment at Site 3 a) eastward velocity b) northward velocity. 

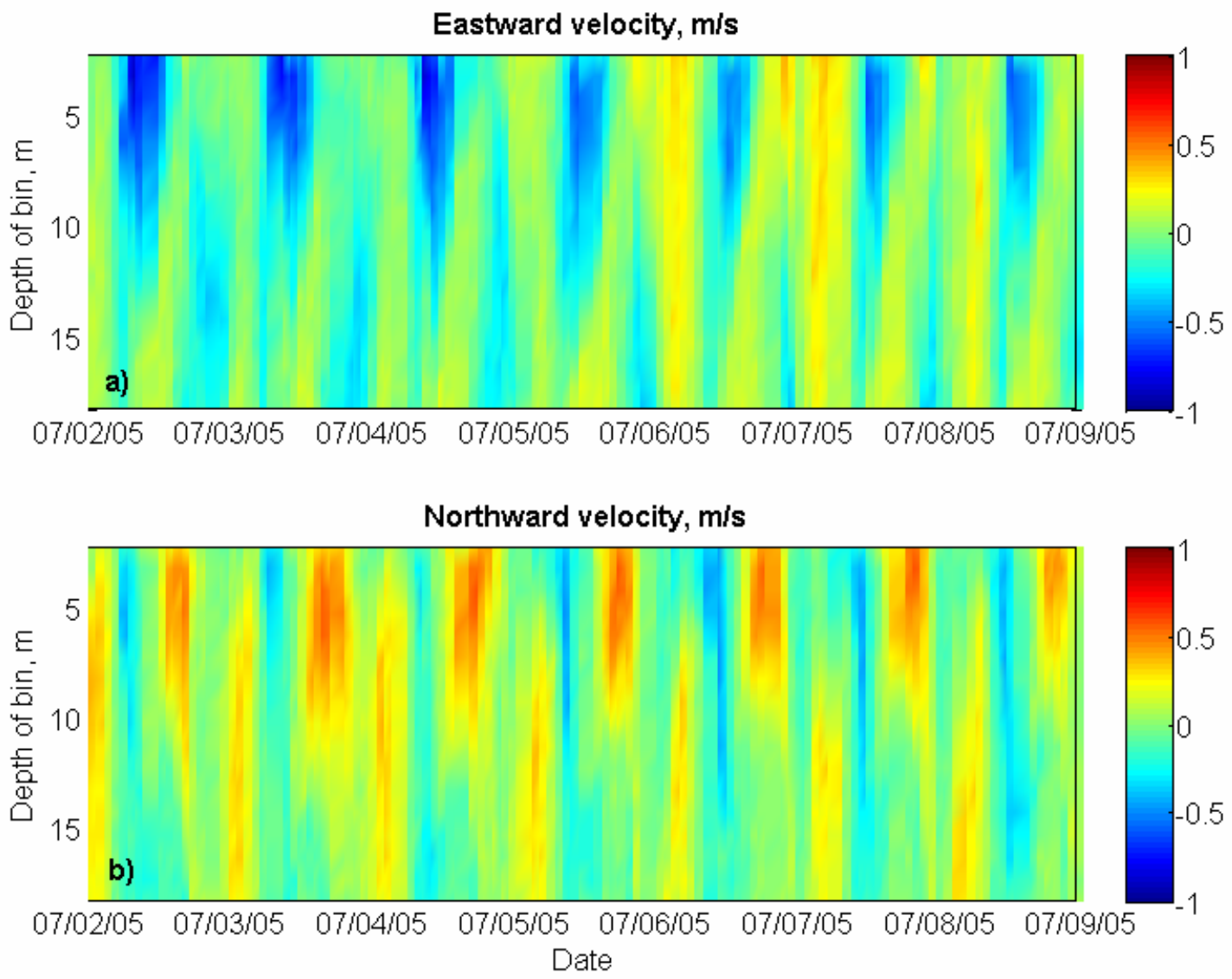

Figure 5.10 Current profile plots through time for summer deployment at Site 4 a) eastward velocity b) northward velocity. (Note the different scale on both axes from previous plots because of more onshore directed flow at Site 4). 

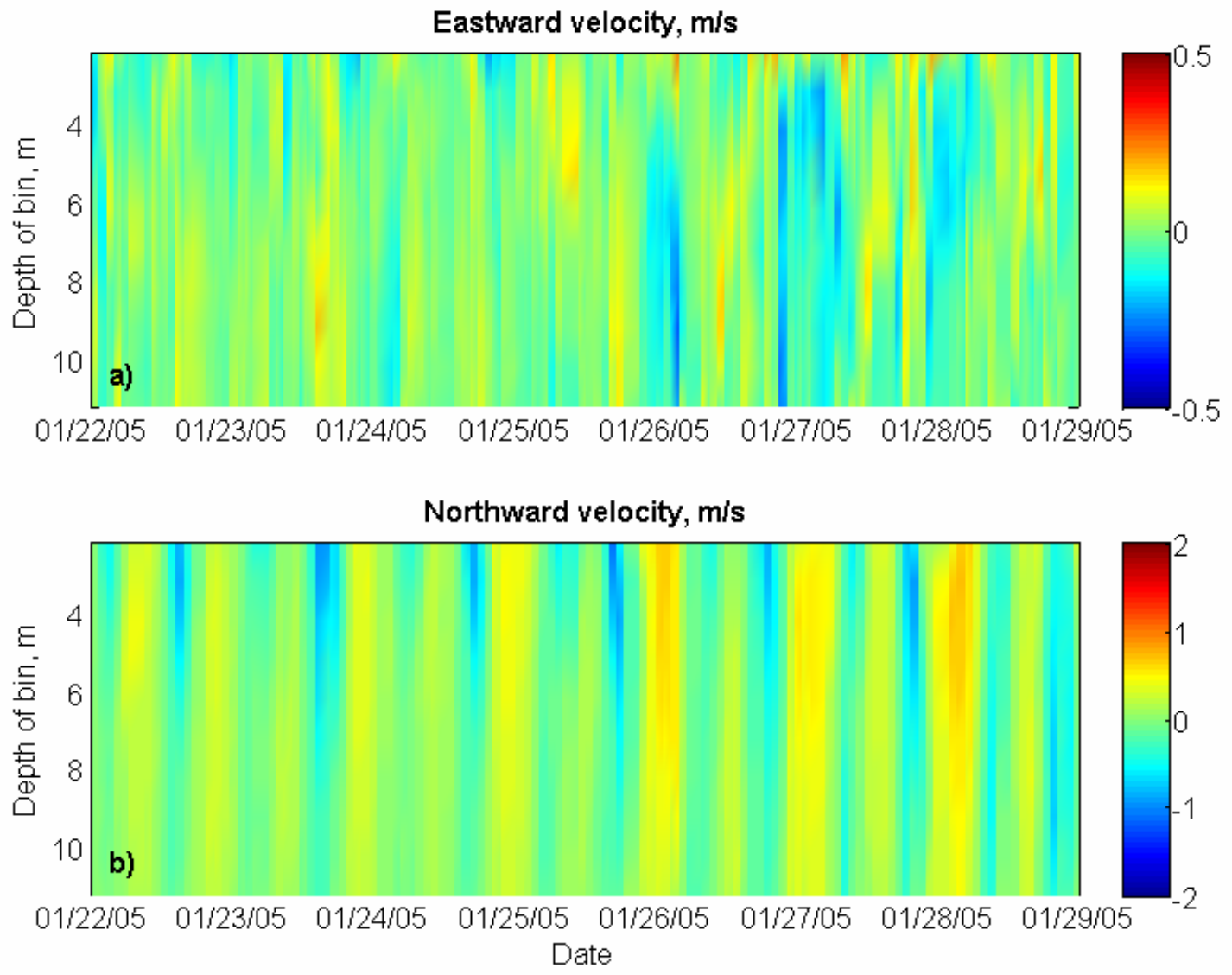

Figure 5.11. Current profile plots through time for winter deployment at Site 3 a) eastward velocity b) northward velocity. 

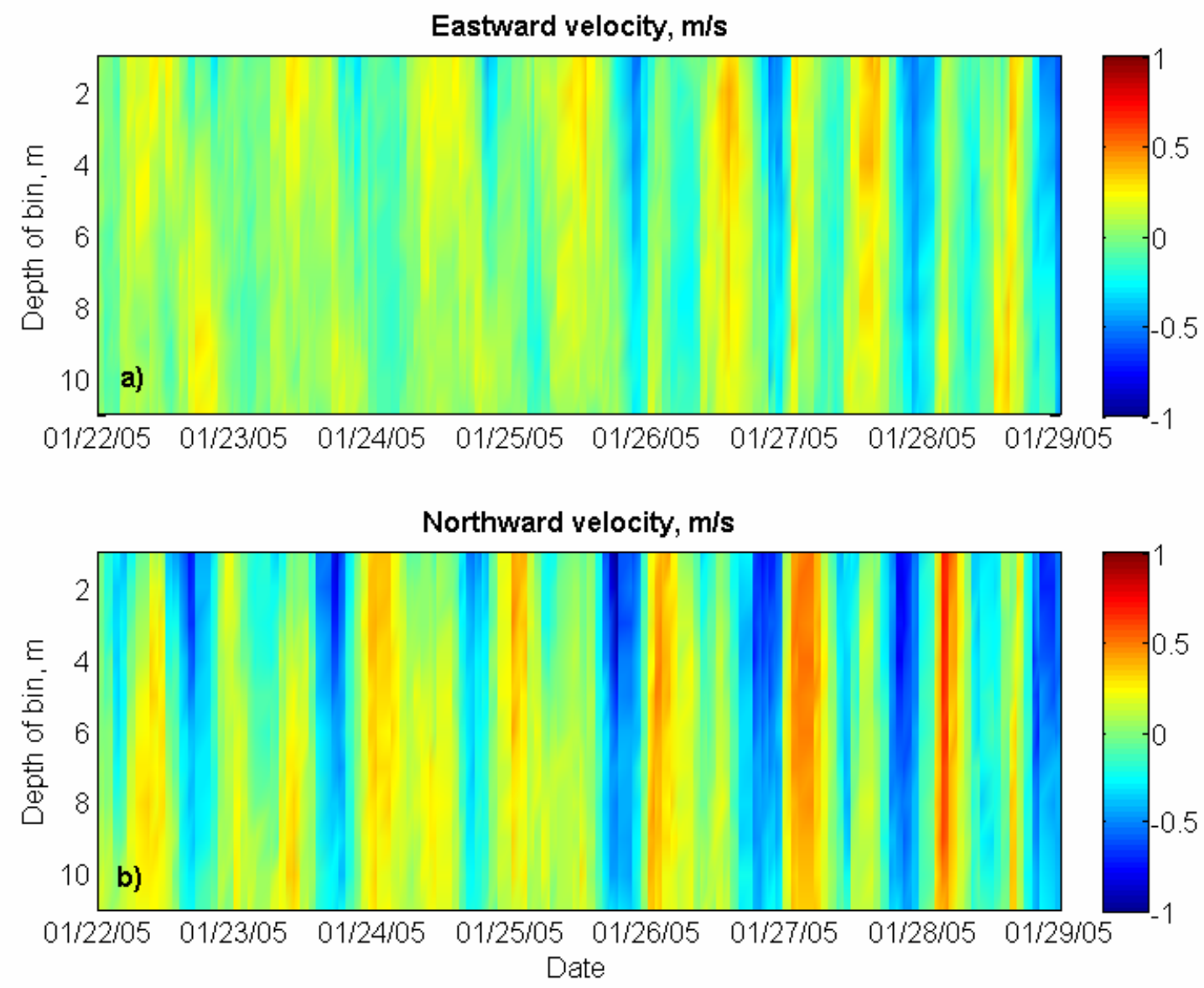

Figure 5.12. Current profile plots through time for winter deployment at Site 5 a) eastward velocity b) northward velocity (Note the different scale on both axes from previous plots because of more onshore directed flow at Site 5). 

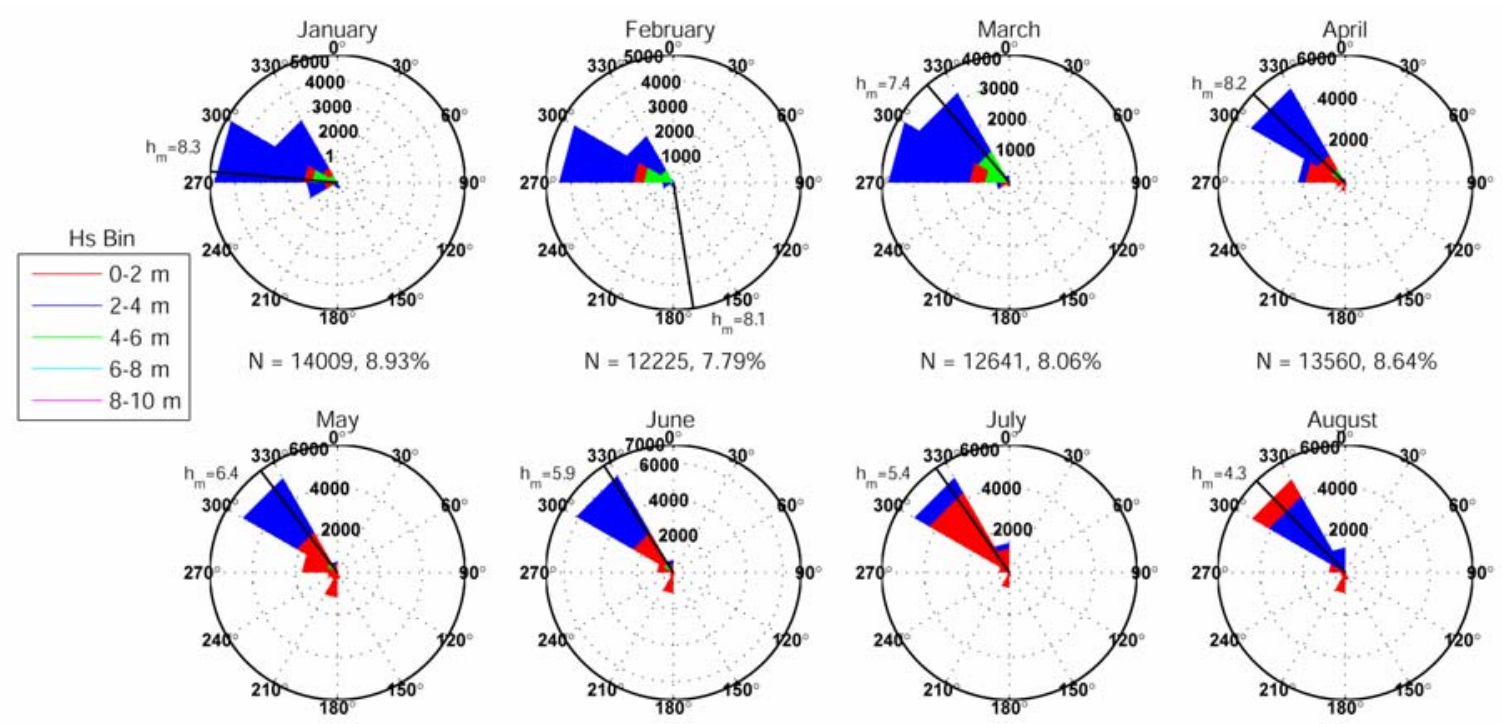

$N=14643,9.33 \%$

$N=14051,8.95 \%$

$N=13982,8.91 \%$

$N=14202,9.05 \%$

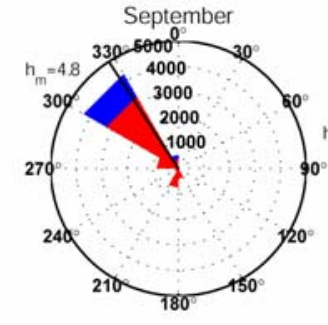

$N=11355,7.24 \%$

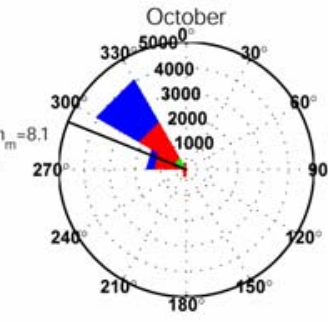

$\mathrm{N}=11122,7.09 \%$

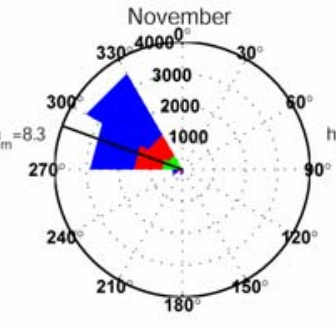

$N=11666,7.43 \%$

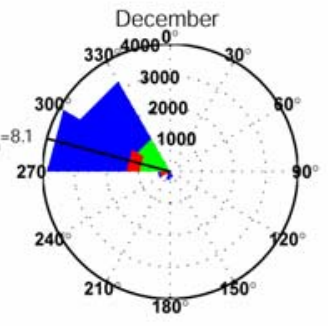

$\mathrm{N}=13372,8.52 \%$

Figure 5.13. Direction histograms for Point Reyes CDIP buoy \#029 by month for all available wave data measured from 1996 through 2006 ( $N$ is number of observations out of a total 156,828 , the percentage is for the total data that occurred in that month, and $h_{m}$ is the maximum wave height for the month which came from a direction marked by the solid black line) (SCRIPPS Institution of Oceanography, 2006). 

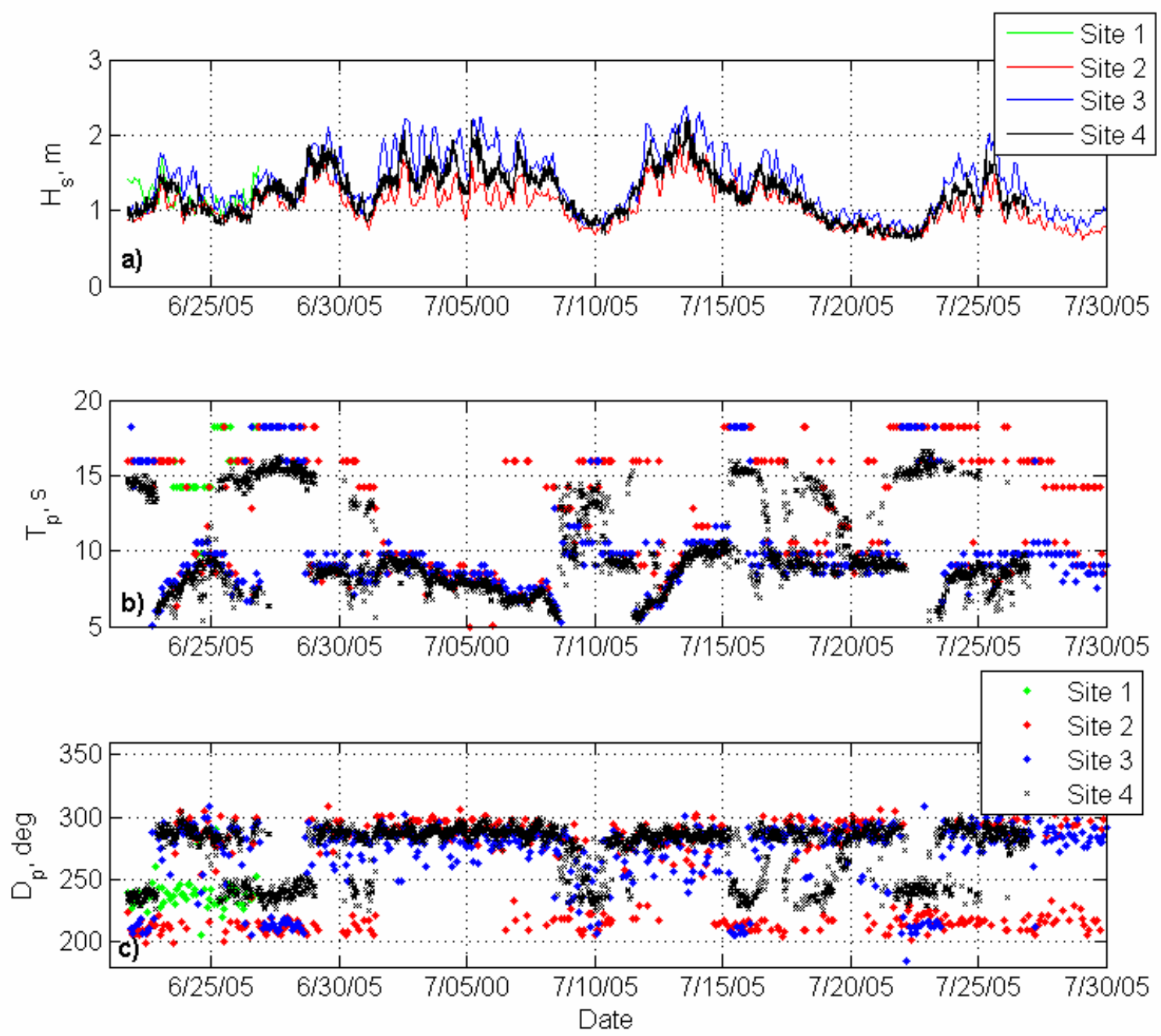

Figure 5.14. Wave parameters calculated from measurements during summer 2005 deployment at Sites $1-4$ a) significant wave height b) peak wave period c) peak wave direction. 

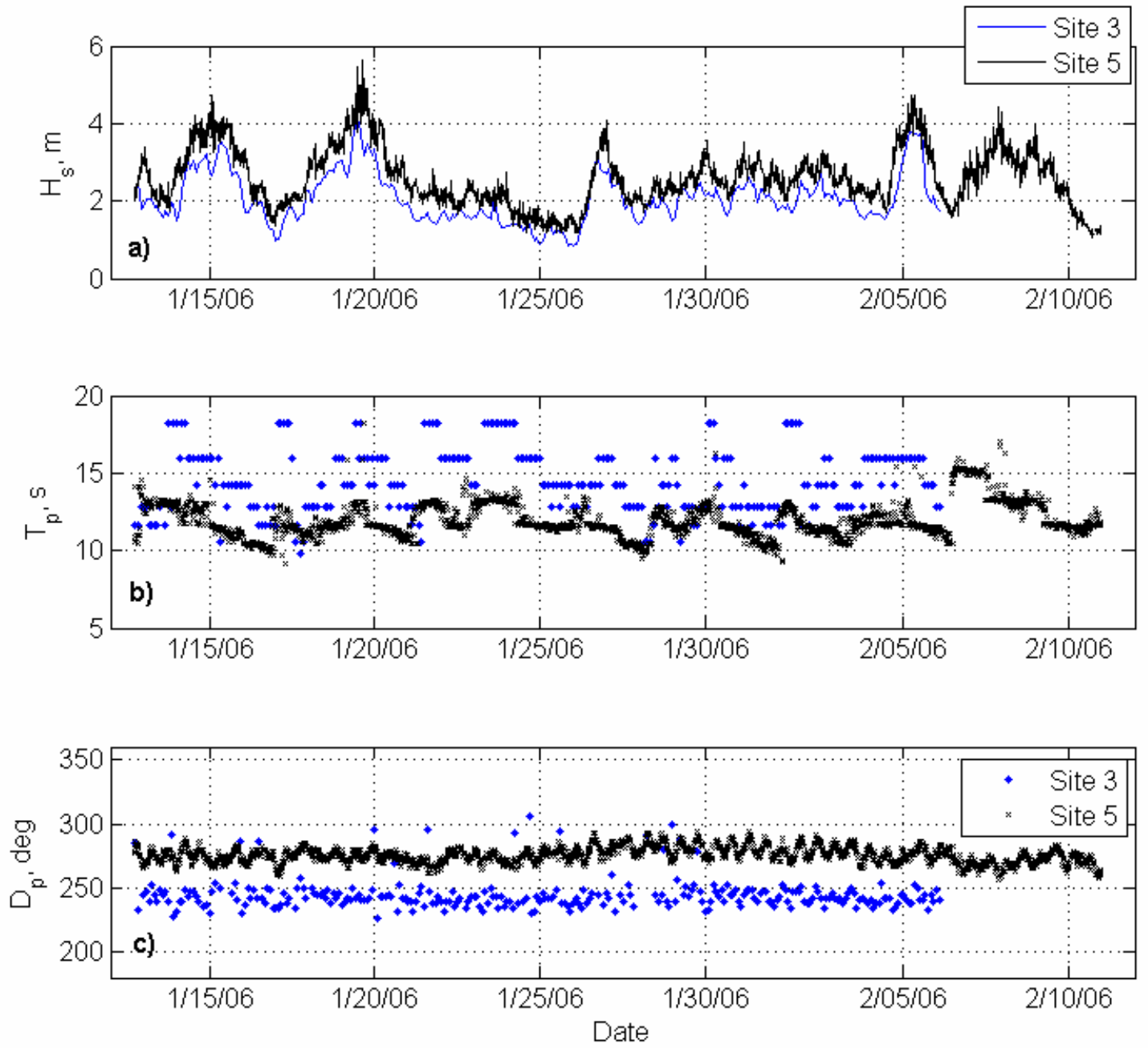

Figure 5.15. Wave parameters calculated from measurements during winter 2006 deployment at Sites 3 and 5 a) significant wave height b) peak wave period c) peak wave direction. 

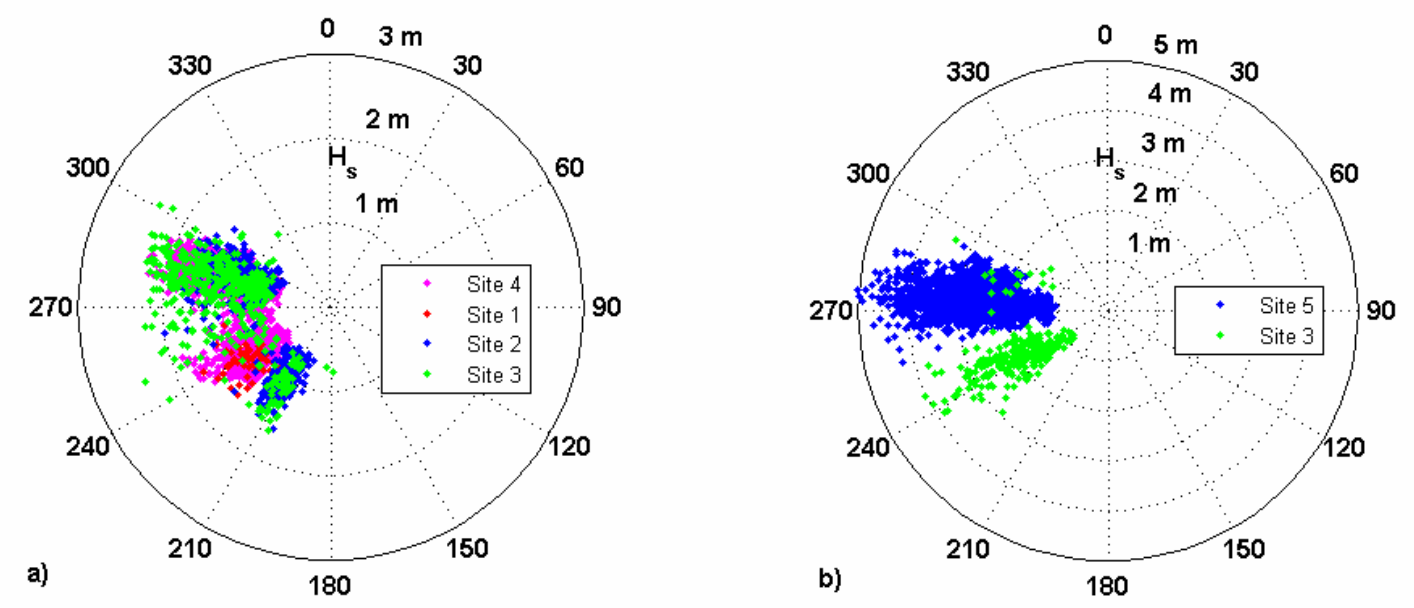

Figure 5.16. Polar plots of wave direction and height for the a) summer 2005 deployment and b) the winter 2006 deployment. (Note the different radial axis due to larger wave heights in the winter). 
Site 1
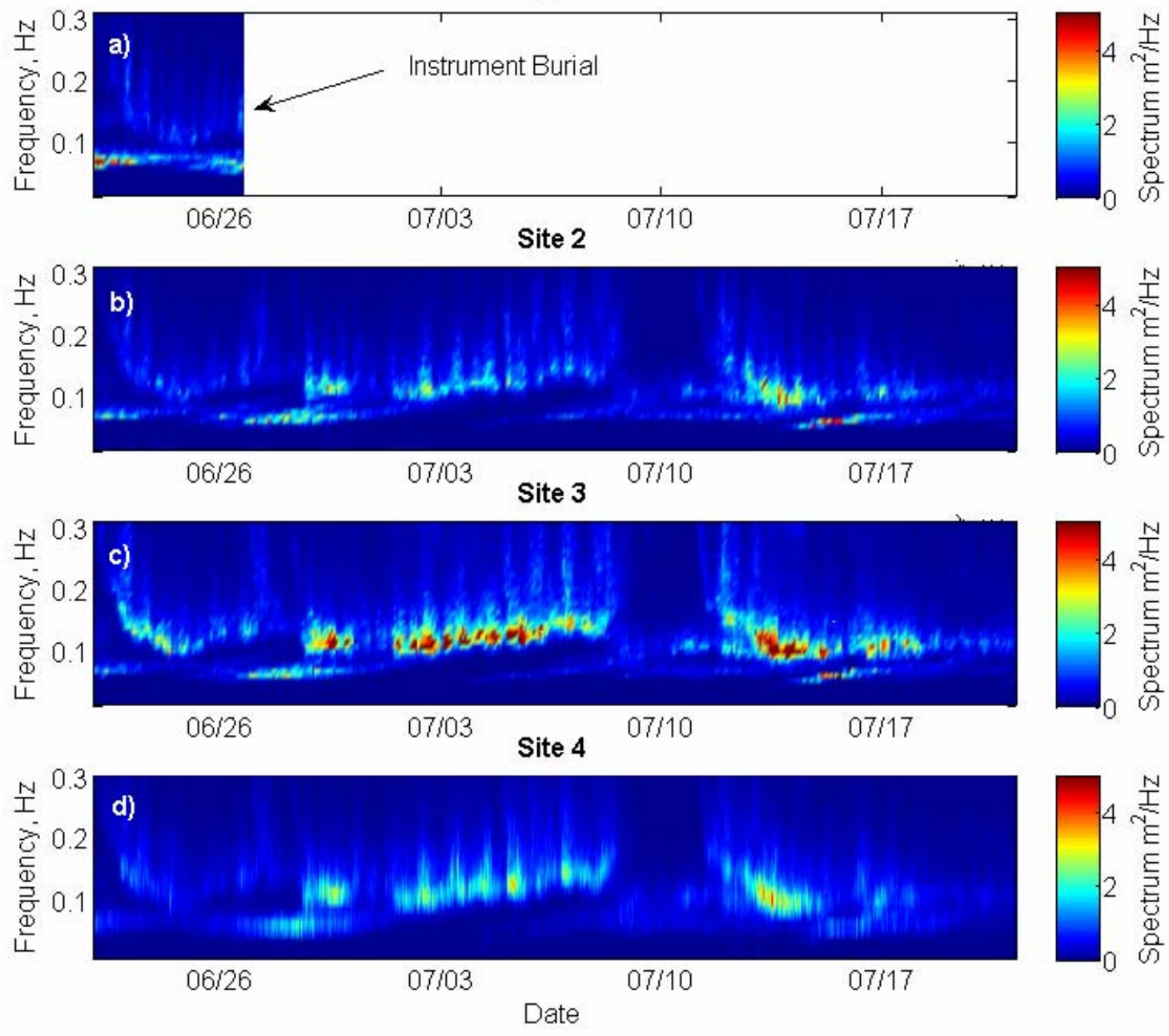

Figure 5.17. 1-D Spectral evolution through time from measurements during summer 2005 deployment for a) Site 1 b) Site 2 c) Site 3 d) Site 4. 
Site 3

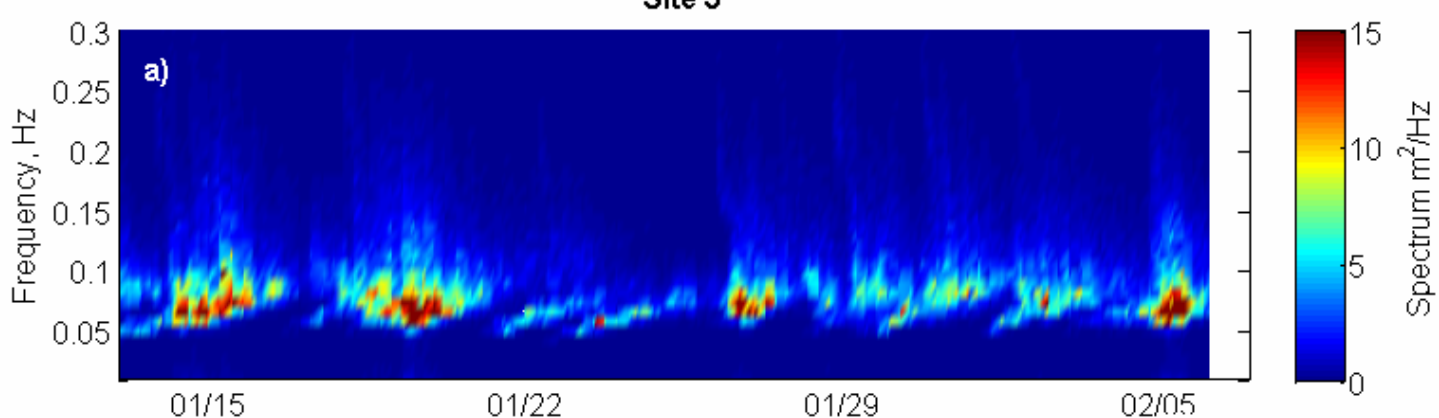

Site 5

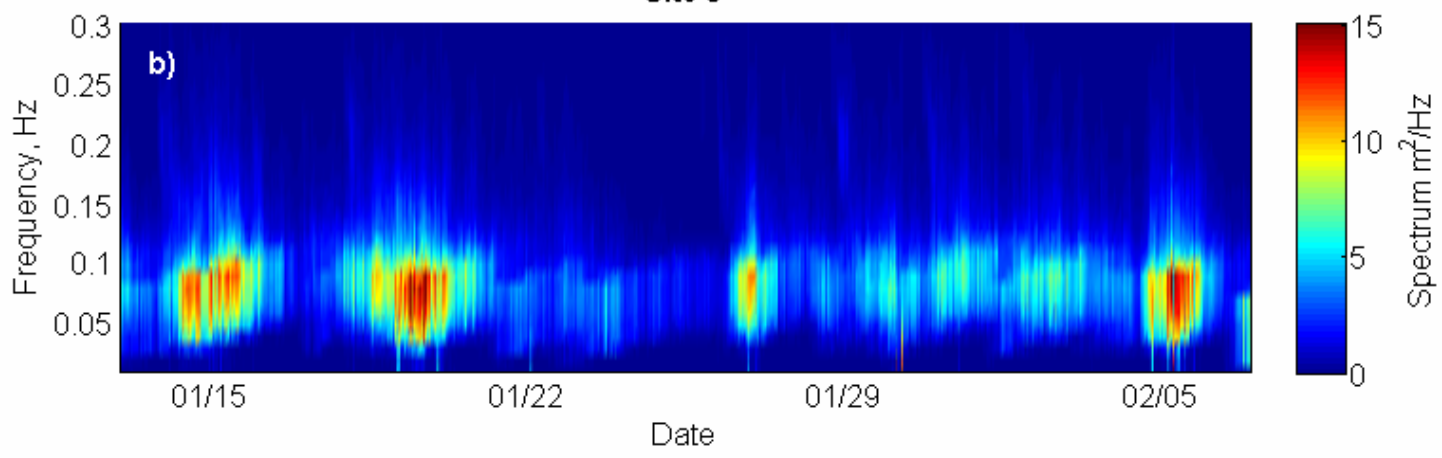

Figure 5.18. Spectral evolution through time from measurements during winter 2006 deployment for a) Site 3 b) Site 5.
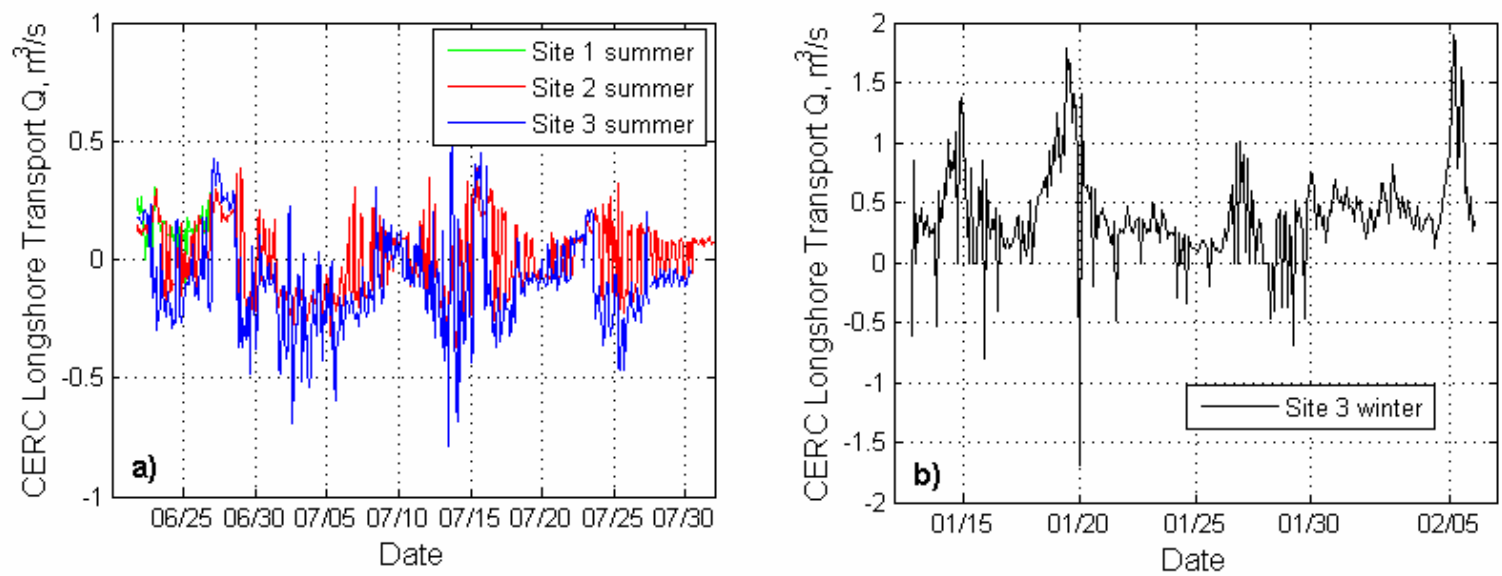

Figure 5.19. Estimated longshore transport ( 0 ) from CERC equation for Sites 1-3 along 0cean Beach (Note the difference in units along the $y$-axis). 


\title{
Chapter 6-Surf Zone Instrument Deployments
}

\author{
By Li Erikson and Jodi Eshleman
}

\section{Introduction}

A surf zone study was conducted over five days (1/23/2006 - 1/27/2006) approaching spring tides (maximum measured tide range was 2.2 meters). A total of five upward looking $2 \mathrm{MHz}$ Nortek Aquadopp ${ }^{\mathrm{TM}}$ (http://www.nortek-as.com/) current profilers were deployed at nine select locations along Ocean Beach (Figure 6.1, Table 6.1). The measurements were used to investigate surf zone hydrodynamics and sediment transport in the breaking region along the beach, calibrate and validate the numerical models Delft3D and NearCoM, and support the development and validation of models describing swash hydrodynamics and runup statistics at Ocean Beach. Concurrent with the Aquadopp measurements, time-stack and time-averaged images of the surf zone were collected (see Chapter 4), as well as sediment grain size, beach topography, and bathymetric profiles (Chapter 3). At the time of writing this report, the beach topography and bathymetry data have not been post-processed and so are not included in the Figures.

The Aquadopp profilers were mounted on aluminum frames that were deployed at low tide, and secured with sand anchors. Total water depths ranged from $2.7 \mathrm{~m}$ to complete exposure during times of negative tide. Due to the fluctuating tide and relatively constant wave climate $\left(1.19<H_{s}<1.87 \mathrm{~m}\right)$, the break points moved so that the instruments were well within or outside the surf zone at different times during the measurement period. The frames were partially buried in the sand and stabilized with weights and two sand anchors on either side of the frame along the direction of breaking waves (Figure 6.2) so as to keep the instruments in place on the seabed and within the high-energy surf zone.

The Aquadopps measured depth (pressure), heading, pitch, and roll and recorded velocity data in east, north and up coordinates in 40 ten centimeter vertical bins. Data was collected continuously at $1 \mathrm{~Hz}$ (Table 6.2), which allowed for flexibility in post-processing. This setup was chosen over added deployment length because the dynamic surf zone environment contains air bubbles and turbulence that make data-screening and manipulation more challenging than in deeper areas. By maximizing the amount of data saved, it was possible to assess a variety of averaging intervals and data screening techniques to get the best possible characterization of surf zone activity from the measurements.

\section{Methods}

\section{Currents}

Data was saved internally in the Aquadopp profilers and extracted to binary format using the Nortek proprietary AquaPro software and subsequently converted to Matlab binary format. In order to eliminate 'bad' velocity data and account for times when the instruments were out of the water, several steps were undertaken as part of data post-processing, Timeseries endpoints associated with before and after instrument deployments were removed as were data spikes, defined as data values equal to three times the standard deviation of the entire time-series. Measurement points with low signal-to-noise ratio (SNR<120 counts) were removed (Nortek AS, TN-020), as were date in upper bins where sidelobe interference 
was predicted to occur. Lastly, the current data was time-averaged with a running mean over six wave cycles (estimated to be $6 \times 15=90$ s) to remove additional noise.

\section{Waves}

Bulk wave parameters were calculated with the well known PUV technique where pressure (P) was used to estimate wave heights and peak periods (http://www.nortekusa.com/software/QuickWave.html, 2006). Although less reliable in the surf zone, the east-west and north-south velocities (UV) in the bin closest to the bed were used to estimate wave directions. Significant wave heights were calculated with the classical

approach of $H_{s}=4 \sqrt{C_{\eta \eta p}}$ where $C_{\eta \eta p}$ is the surface elevation energy spectra after accounting for non-linear transfer from the near bottom to the surface. Measurements were binned to 17 minute segments (1024 sampling points at $1 \mathrm{~Hz})$ with a low frequency cutoff set at $0.035 \mathrm{~Hz}$. A series of 'reality checks', such as the maximum wave steepness and maximum ratio of wave height to water depth, were used to infer erroneous wave height estimates.

\section{Results}

Figure 6.3 presents 24 hour time-series of post-processed depth and current measurements obtained at sz1 through sz6 at the north end of Ocean Beach, and at sz8 at the south end of Ocean Beach. No data was recorded at sz9, just south of sz8 (Fig. 6.1) due to instrument failure. Plots 6.3a through $6.3 \mathrm{~d}$ and $6.3 \mathrm{~h}$ show concurrent measurements at sites sz1 through sz4 at the north end of Ocean Beach and at sz8 at the south end of the beach. The remaining plots span subsequent full tide cycles. The measurements shown here are only a subset of the available dataset; the total length of the experiment was more than three days.

Sampling sites sz1 and sz2 were aligned in the cross-shore direction with sz2 located closer to the shore. The instrument at sz 2 was out of the water during low tide as evidenced by the pressure signal at the beginning of the time-series (Fig. 6.3b). A second cross-shore array, slightly further south, was also deployed during the same time-interval. A comparison of plots 6.3ai with $6.3 \mathrm{bi}$ and $6.3 \mathrm{ci}$ with $6.3 \mathrm{di}$ show that the flow direction and variation of relative magnitude are correlated in time, suggesting that there was strong uniformity in cross-shore currents. However, the magnitude was greater and more complex at the offshore sites as compared to the inshore sites.

Disregarding the lack of data near the bed due to instrument blanking distance, there does not appear to be much vertical structure except during high tide. This was particularly noticeable at sz4 (Fig. 6.4di) where the velocities decayed from $40 \mathrm{~cm} / \mathrm{s}$ to near zero at $25 \mathrm{~cm}$ above the bed. Also, at sz4, the cross-shore flow direction switched drastically from about $35 \mathrm{~cm} / \mathrm{s}$ shoreward to $45 \mathrm{~cm} / \mathrm{s}$ seaward halfway through ebbing tide. Flow reversal is apparent at all the sites along the north end of Ocean Beach and may be at least partially related to the eddies that form from tidally driven flows around Pt. Lobos just to the north (see the modeling chapter for further discussion). The intermittent pattern of very low flow velocities to rather strong currents during the flood at sz1 and sz2 are likely related to the complex hydrodynamics such as reflection and diffraction around the outcrop at the north end of Ocean Beach. 
With respect to the north-south direction (v-directed velocities), the currents were quite strong reversing from a southerly directed average $50 \mathrm{~cm} / \mathrm{s}$ current during ebb-tide to an equally strong current northward near low tide. In Figure 6.4, the measurements have been rotated to the along- and cross-shore directions, and the maximum measured depth-averaged currents over the same tide cycle shown with vectors for sites sz1 through sz4. Maximum currents were on the order of $0.63 \mathrm{~m} / \mathrm{s}$ in the cross-shore direction and $0.73 \mathrm{~m} / \mathrm{s}$ in the alongshore direction. The along-shore currents were greater when heading north, except at sampling station sz2, located furthest inshore ( 85) where the southward directed alongshore currents were $10 \mathrm{~cm} / \mathrm{s}$ greater than the northward bound currents. This apparent crossshore distribution of the along-shore current can have a significant impact on longshore sediment transport patterns.

Time-series of breaking parameters $\left(H_{s} / h\right)$ are shown for sites sz1 through sz4 at the north end of Ocean Beach in Figure 6.5b. The horizontal dashed line at $H s / h=0.78$ is the proxy to breaking conditions. Recalling that sz1/sz2 and sz3/sz4 were in cross-shore arrays, it is clear that the instruments along the northern array at sz1/sz2 were under changing surf zone conditions, while the array formed by sz3/sz4 was situated either at the inner or outer part of the surf zone. The fact that little shoaling occurred at sz3/sz4, even during the lower stages of the tide, suggests that the instruments were in the inner part of the surf zone and that the shoal associated with the ebb-tidal delta caused the waves to break offshore of sz3/sz4. For the sz $2 / s z 3$ array, it is apparent that breaking occurred at the offshore instrument, sz1, at the beginning of the time series during lower tide and higher offshore wave conditions. Offshore wave conditions measured with an ADCP at Site5 (see chapter on 'offshore instrument deployments') are shown in the upper plot of Figure 6.4. Although an ADCP was placed just outside the surf zone (Site 1, square in Fig. 6.1) specifically for this study, data was not retrievable and hence Site 5 is used to assess the offshore conditions. Following the start of the shown time-series (Fig. 6.4), the offshore wave heights decreased and remained fairly constant with the exception of similar conditions around 06:00 hrs. The increased signal is apparent in the breaking parameter at sz1/sz2. During the lower high tide and higher low tide (between 03:00 and 09:00 hours), the break point moved shoreward from sz1 toward sz2. At high tide there was a drop-off of the breaking parameter, and breaking appears to have occurred landward of sz 2 but then back out to sz2 during ebbing tide. This cycle is expected to repeat itself with the tide cycle and vary depending on offshore conditions. With these few select point measurements, the entire surf zone, and variations along shore, were measured and are expected to be of great value in furthering the understanding of surf zone processes at Ocean Beach.

\section{Discussion}

Assessment of the data suggests that the measurements obtained with the Aquadopps in the surf zone are reasonable and representative of the conditions at the time of the field study. A series of checks and evaluations of the pressure and velocity spectra, vertical current structure, predicted breaking, wave steepness, and correlation between offshore wave parameters and surf zone conditions indicate that the resulting current measurements and calculated wave parameters are within reason. Air bubbles during breaking and stronger than normal pressure attenuation due to highly non-linear effects of near breaking waves may have introduced errors in the measurements that were not explicitly accounted for however. In shallow water, nonlinearly forced high frequency components are strongly amplified and 
significantly change the local wave kinematics. Constantian (1999) and Herbers and others (2002) showed that the observed vertical attenuation of horizontal velocity spectra at high frequencies in eight and four meter depths was much weaker than predicted using linear theory, whereas at two meter depths there was little difference. To resolve this issue, they suggest to include a Boussinesq term in the transfer function. Because the measurements obtained for this study were all in water depths less than $3 \mathrm{~m}$, the Boussinesq term was not included in the calculations, but may provide increased accuracy if accounted for.

\section{Conclusions}

- Analysis of surf-zone current data shows that instantaneous flows $(O(50 \mathrm{~cm} / \mathrm{s}))$ occur in both the cross-shore and along-shore directions.

- Simultaneous cross-shore current data show that flow direction and variation of relative speeds were correlated in time, suggesting that there was strong uniformity in cross-shore currents, but that the speeds were greater in the outer surf zone.

- Simultaneous along-shore current data suggest that the maximum northward oriented tidal currents are stronger than southward currents but also that there is a cross-shore variation of the longshore currents such that the southward oriented currents are stronger further inshore.

- There is little vertical current structure in the surf zone except near the bottom during high tide in east-west directed currents.

- North-south currents within the surf zone reversed from a southerly directed $50 \mathrm{~cm} / \mathrm{s}$ flow during ebb-tide to an equally strong northward flow at low tide. East-west currents were also tidally driven but were slightly slower $(35 \mathrm{~cm} / \mathrm{s}$ to $45 \mathrm{~cm} / \mathrm{s})$.

- With varying tide levels and offshore wave conditions on the order of $H_{\mathrm{s}}=1.5 \mathrm{~m}$, the outer limit of the surf zone moved more than $40 \mathrm{~m}$ in the cross-shore direction with energy dissipation widths exceeding $20 \mathrm{~m}$. 
Table 6.1 Nortek Aquadopp profiler locations and sampling times at Ocean Beach.

\begin{tabular}{|c|c|c|c|c|c|}
\hline Site & Dates & Lat & Long & $\begin{array}{c}\text { Distance to } \\
\text { shore }(\mathrm{m})\end{array}$ & $\begin{array}{c}\text { Instrument } \\
\text { ID }\end{array}$ \\
\hline sz1 & $01 / 23 / 06-01 / 25 / 06$ & $37.777 \mathrm{~N}$ & $122.514 \mathrm{~W}$ & 104 & S/N Y06 \\
\hline sz2 & $01 / 23 / 06-01 / 25 / 06$ & $37.777 \mathrm{~N}$ & $122.514 \mathrm{~W}$ & 85 & S/N W5 \\
\hline sz3 & $01 / 22 / 06-01 / 25 / 06$ & $37.775 \mathrm{~N}$ & $122.514 \mathrm{~W}$ & 120 & S/N Y4 \\
\hline sz4 & $01 / 23 / 06-01 / 27 / 06$ & $37.775 \mathrm{~N}$ & $122.514 \mathrm{~W}$ & 139 & S/N BY3 \\
\hline sz5 & $01 / 25 / 06-01 / 28 / 06$ & $37.775 \mathrm{~N}$ & $122.515 \mathrm{~W}$ & 180 & S/N Y4 \\
\hline sz6 & $01 / 26 / 06-01 / 27 / 06$ & $37.774 \mathrm{~N}$ & $122.514 \mathrm{~W}$ & 111 & S/N Y06 \\
\hline sz7 & $01 / 25 / 06-01 / 28 / 06$ & $37.774 \mathrm{~N}$ & $122.515 \mathrm{~W}$ & 210 & S/N W5 \\
\hline sz8 & $01 / 24 / 06-01 / 26 / 06$ & $37.736 \mathrm{~N}$ & $122.509 \mathrm{~W}$ & 95 & S/N O2 \\
\hline sz9 & $01 / 24 / 06-01 / 26 / 06$ & $37.735 \mathrm{~N}$ & $122.509 \mathrm{~W}$ & 86 & S/N B1 \\
\hline
\end{tabular}

Table 6.2 Aquadopp profiler setup.

\begin{tabular}{|l|c|}
\hline \multicolumn{1}{|c|}{ Parameters } & Value \\
\hline Instrument Type & $\begin{array}{c}\text { Nortek Aquadopp } \\
\text { Profiler }\end{array}$ \\
\hline Corrected Magnetic Declination & +14.77 \\
\hline Cell size - Currents (m) & 0.1 \\
\hline Number of Cells & 40 \\
\hline Sampling Rate $(\mathrm{Hz})$ & 1 \\
\hline Blanking distance $(\mathrm{m})$ & 0.1 \\
\hline
\end{tabular}




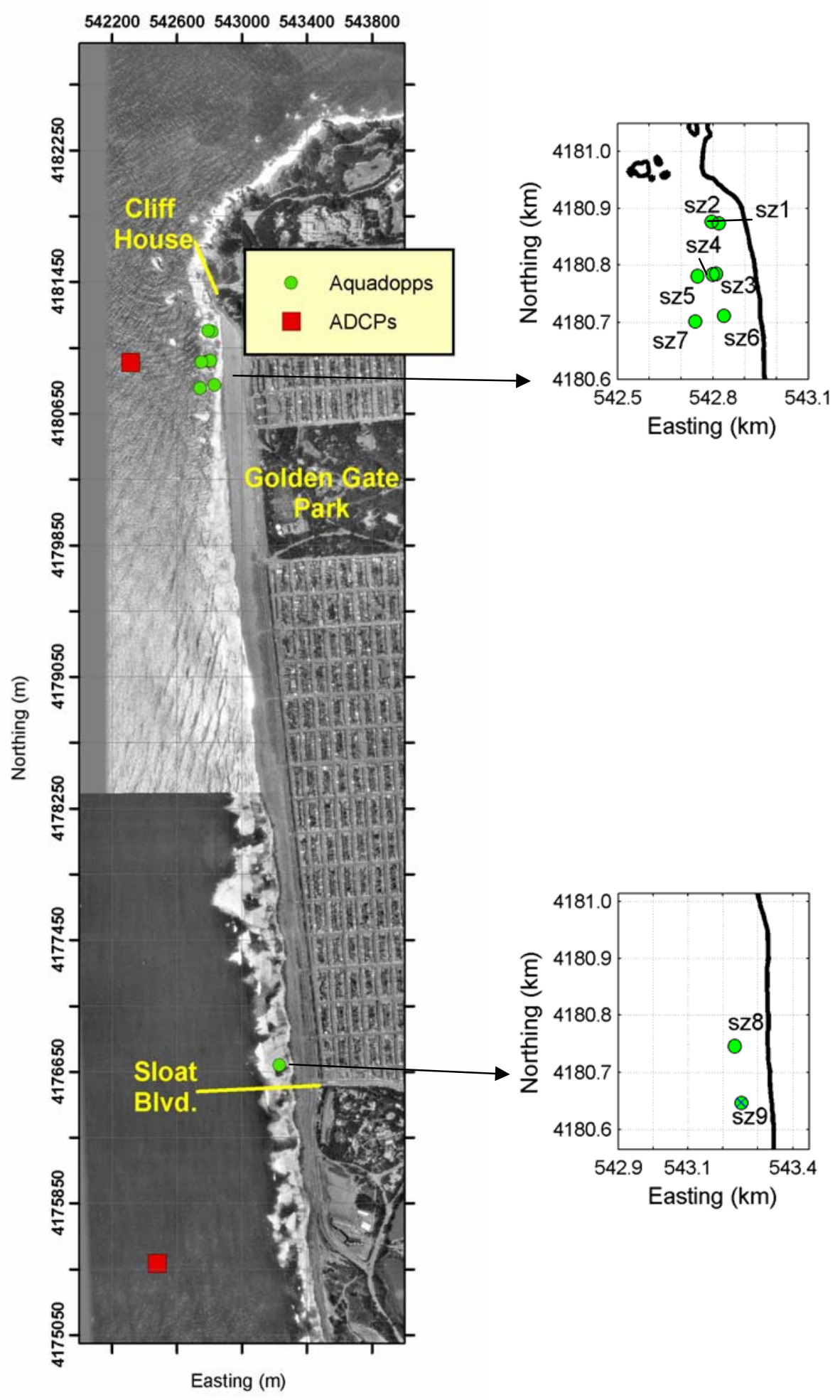

Figure 6.1. Overview of Aquadopp instrument deployments (01/23/06-01/27/06). Data was not recorded at sz9 and the northern ADCP (Site1). 
(a)

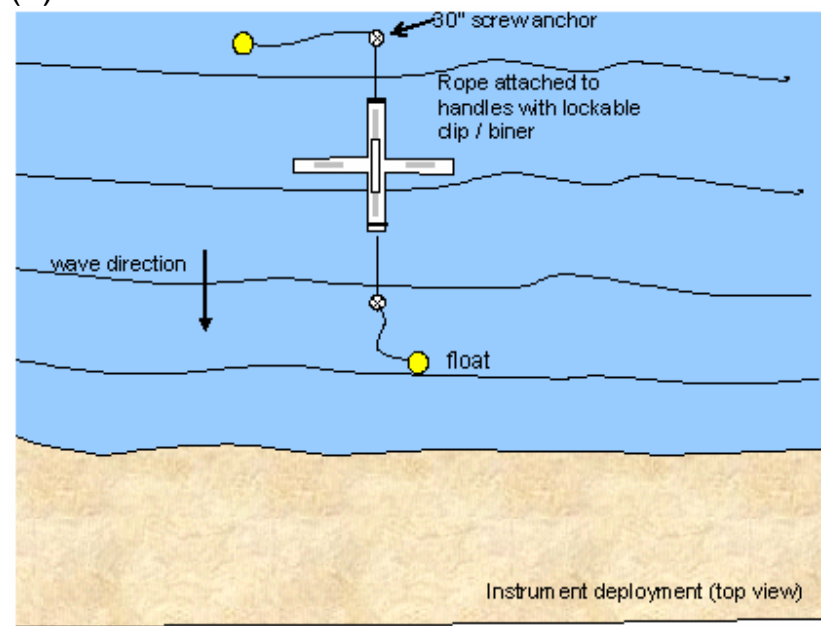

(b)

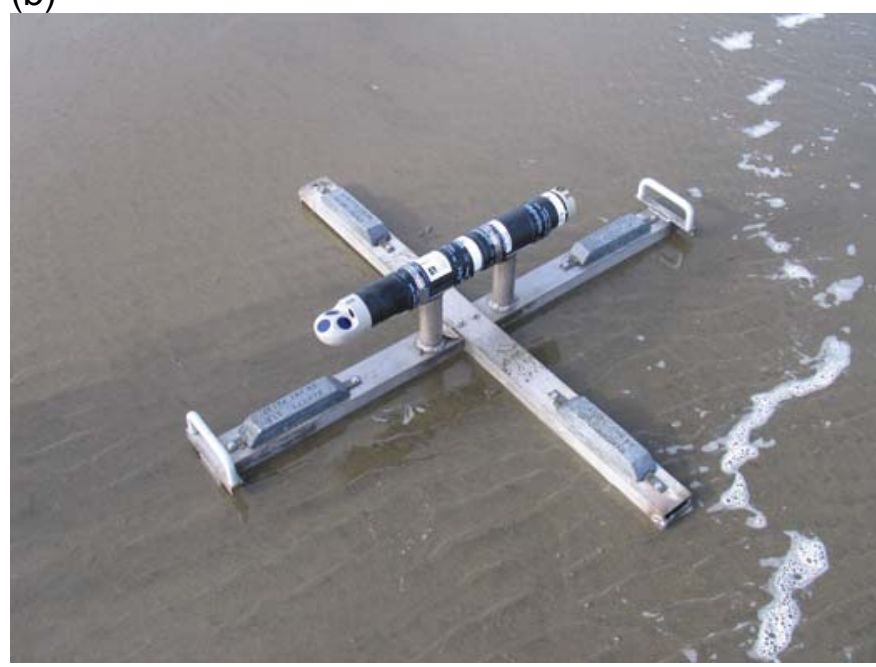

Figure 6.2. Aquadopp frame setup and surf zone deployment scheme: (a) deployment schematic, and (b) photo of instrument and frame. 

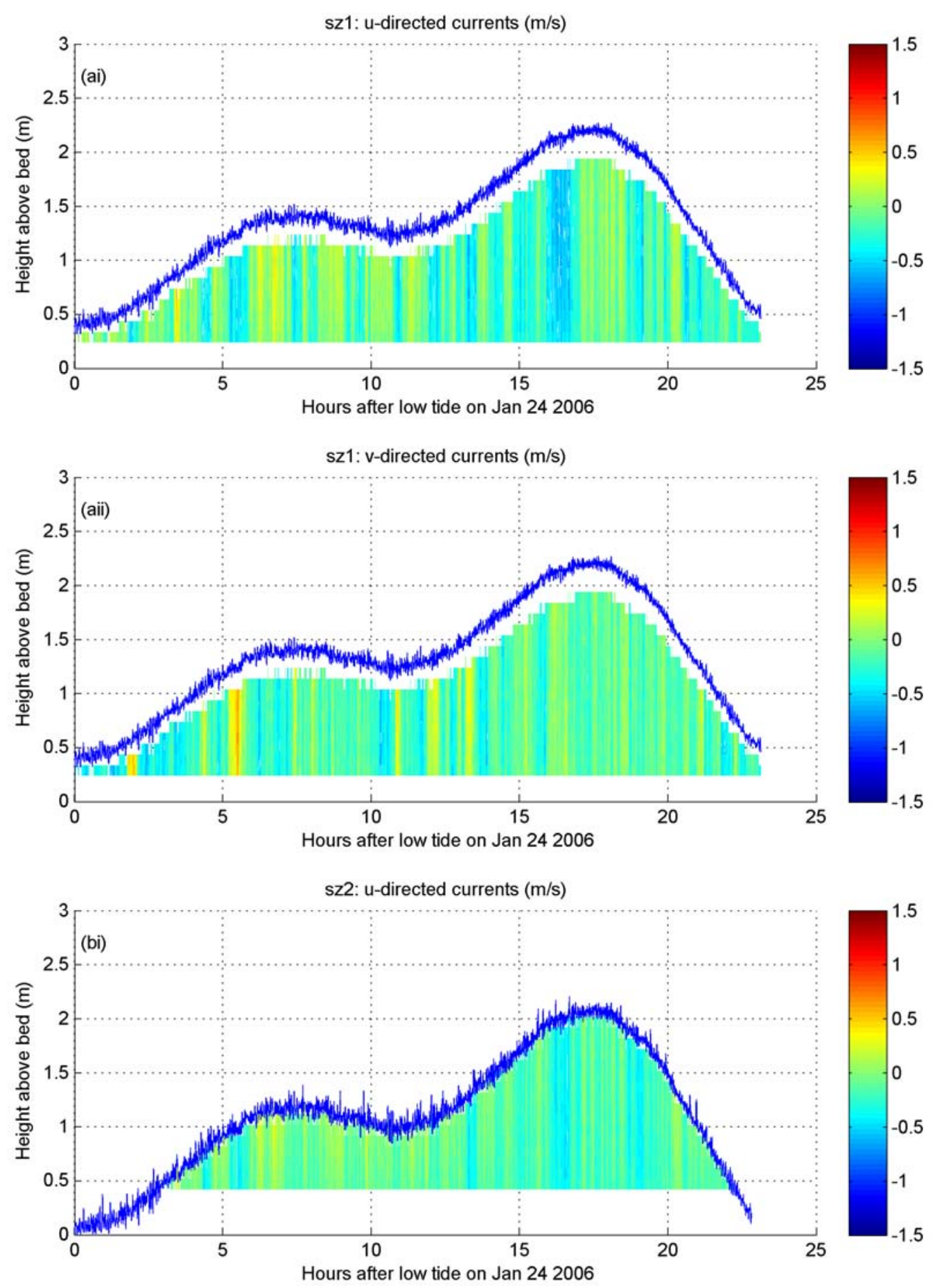

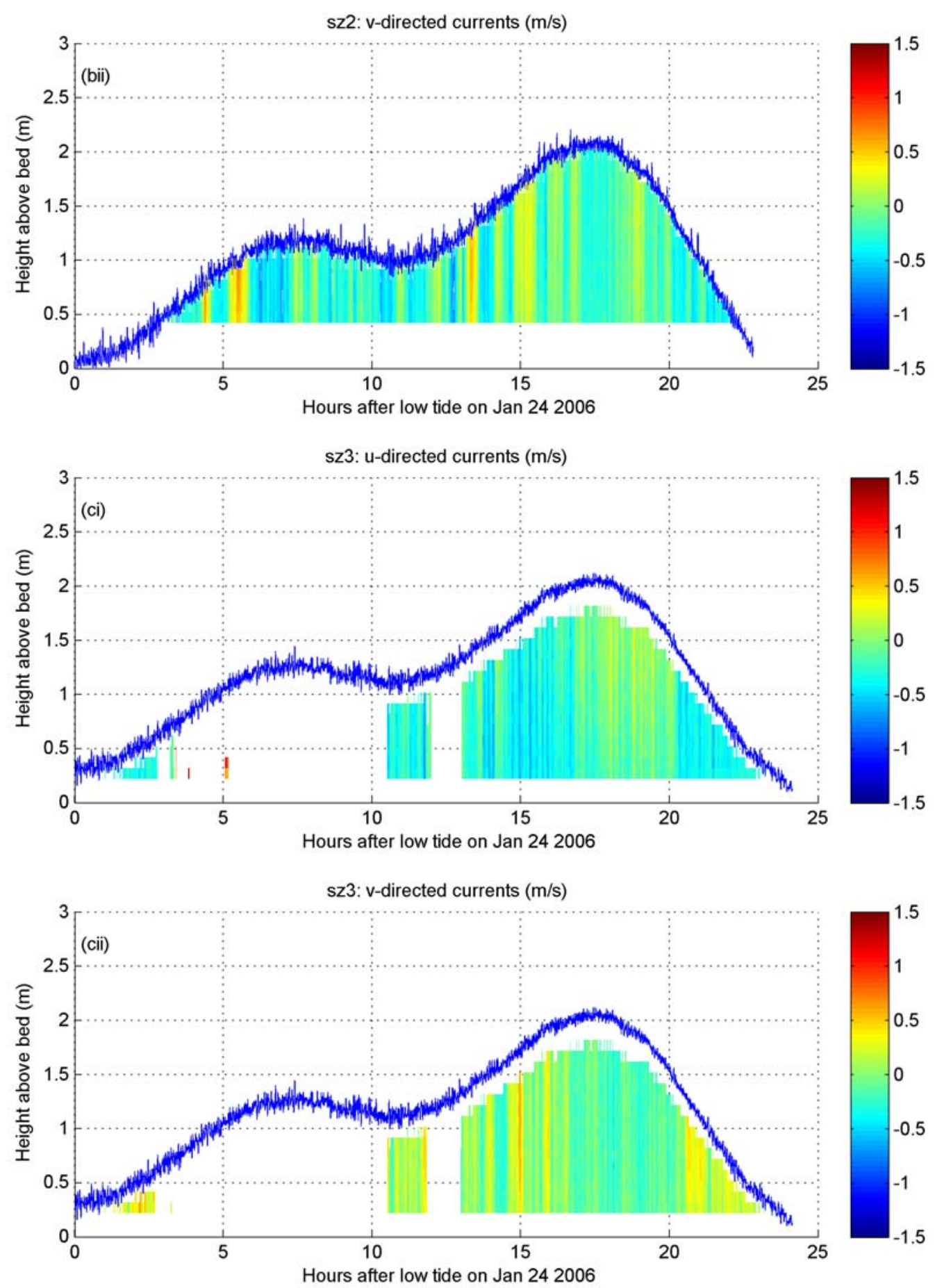

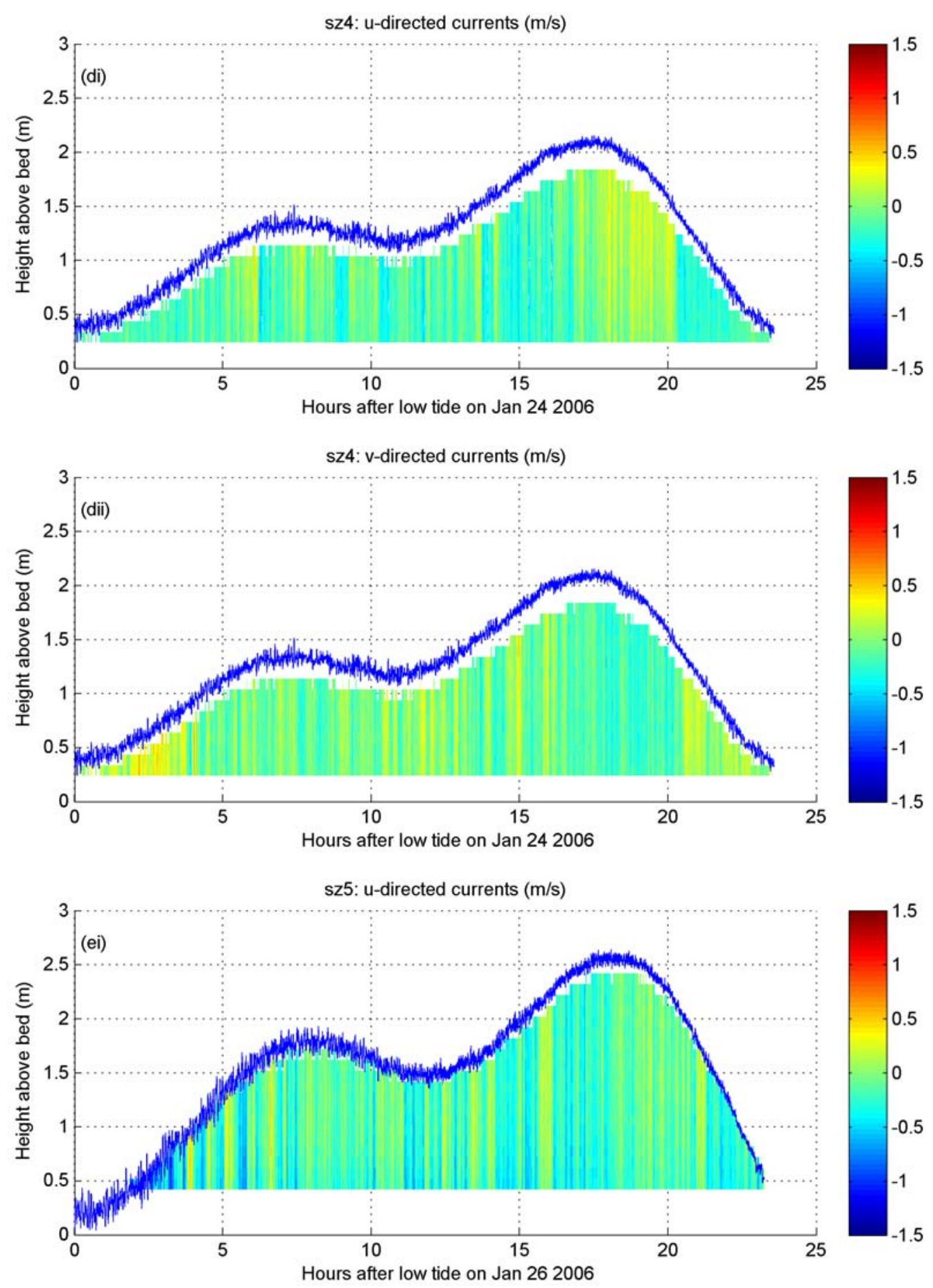

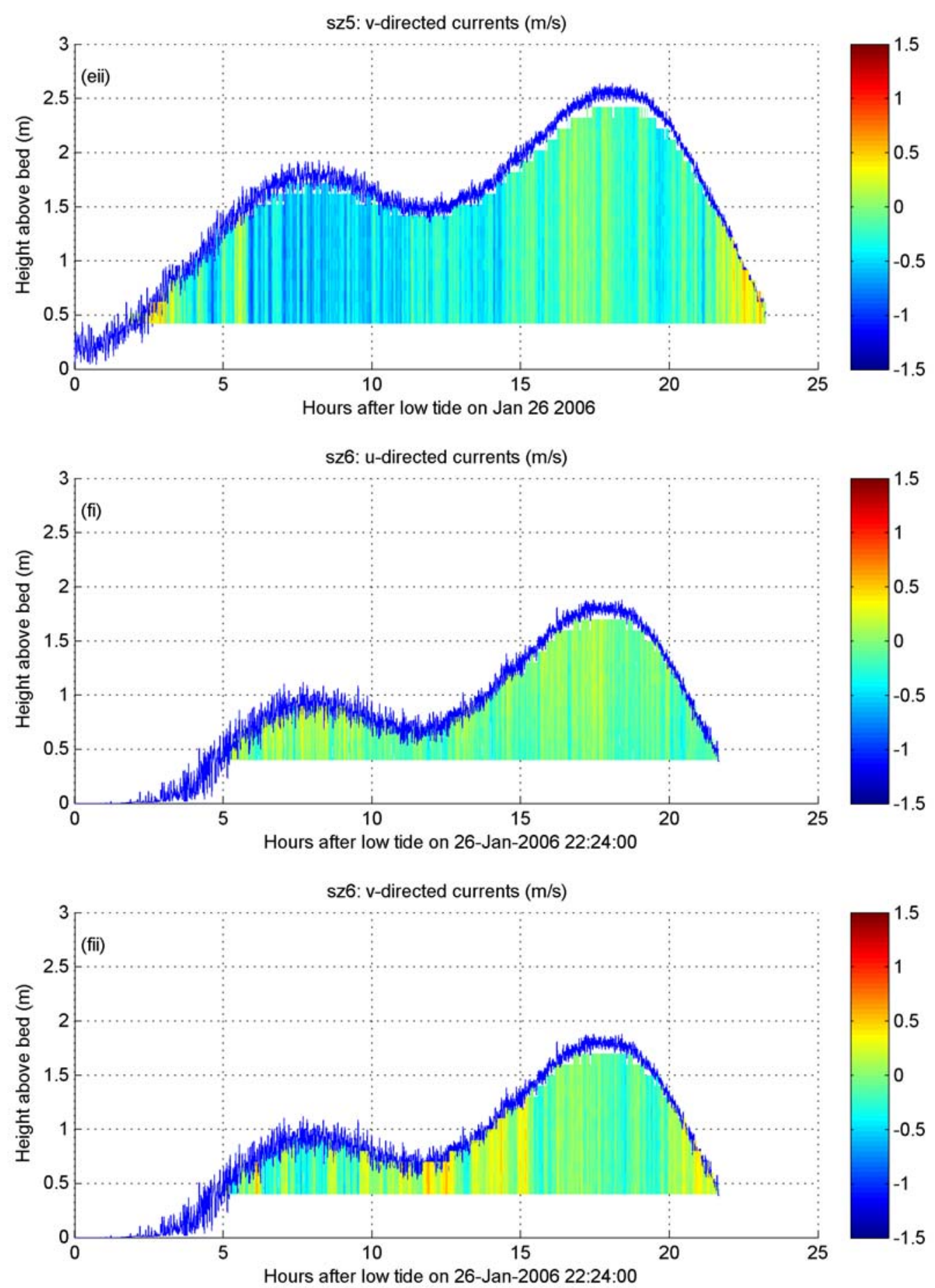

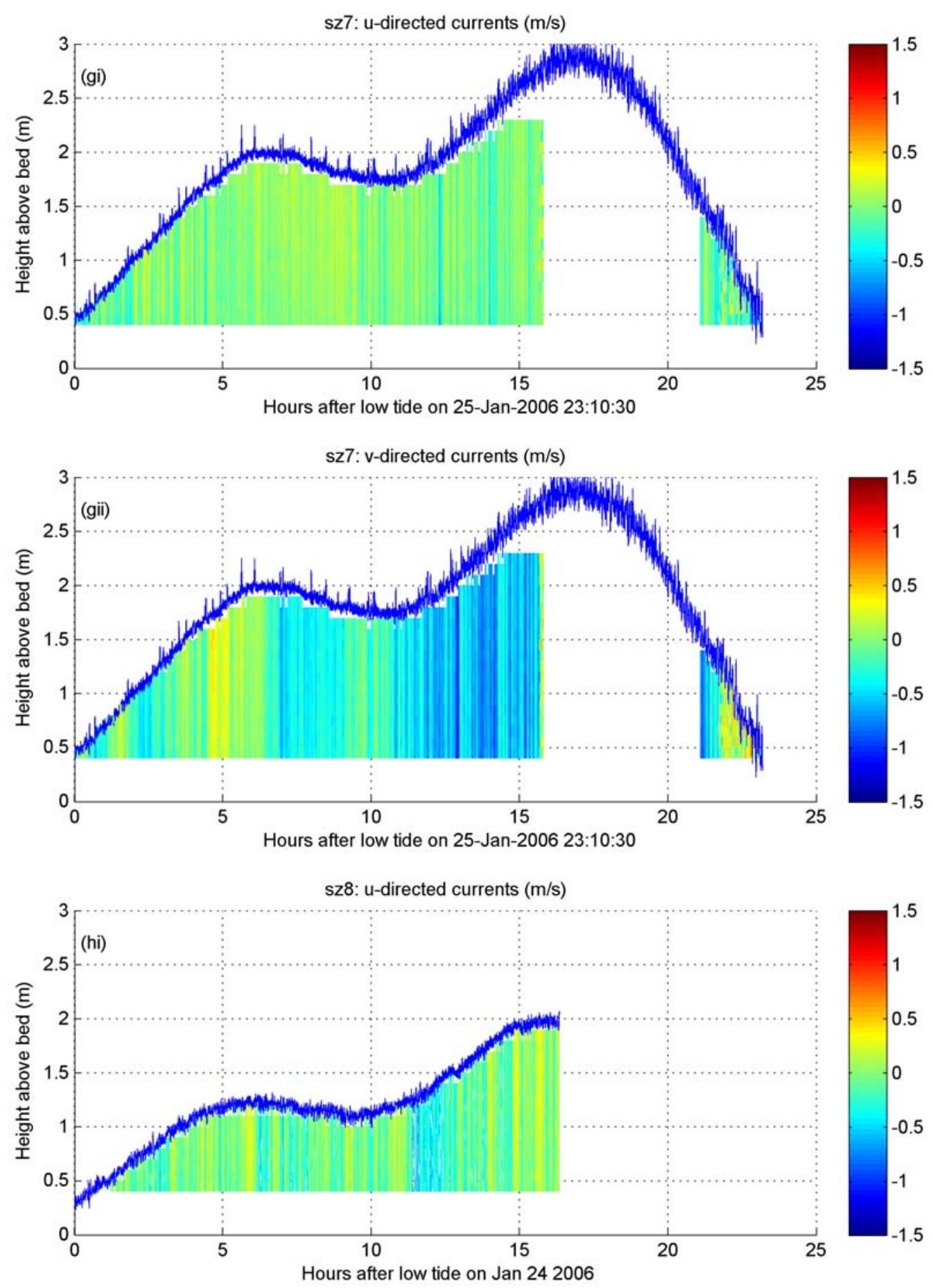


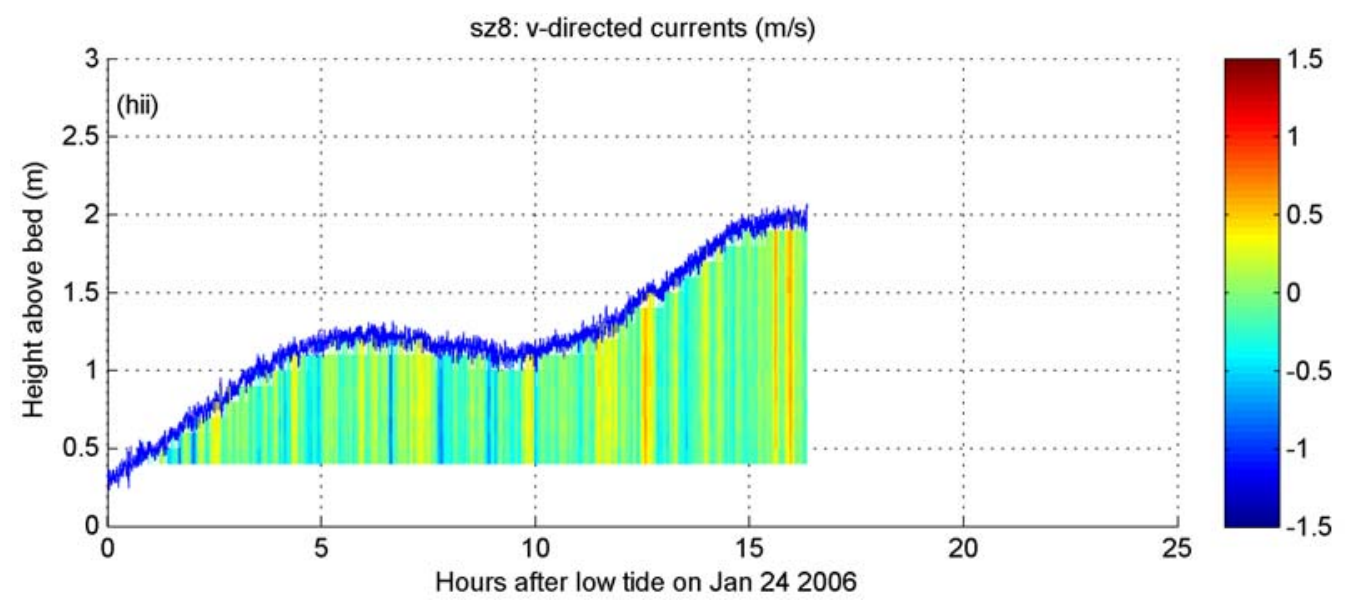

Figure 6.3. Measured water depth and vertical current structure measured with Nortek Aquadopps during the surf zone field study. Data shown are for complete tide cycles (depending on data availability) for measurement sites from north to south (sz1 through sz8); u-directed: east-west with east positive, v-directed: north-south, with north positive. 


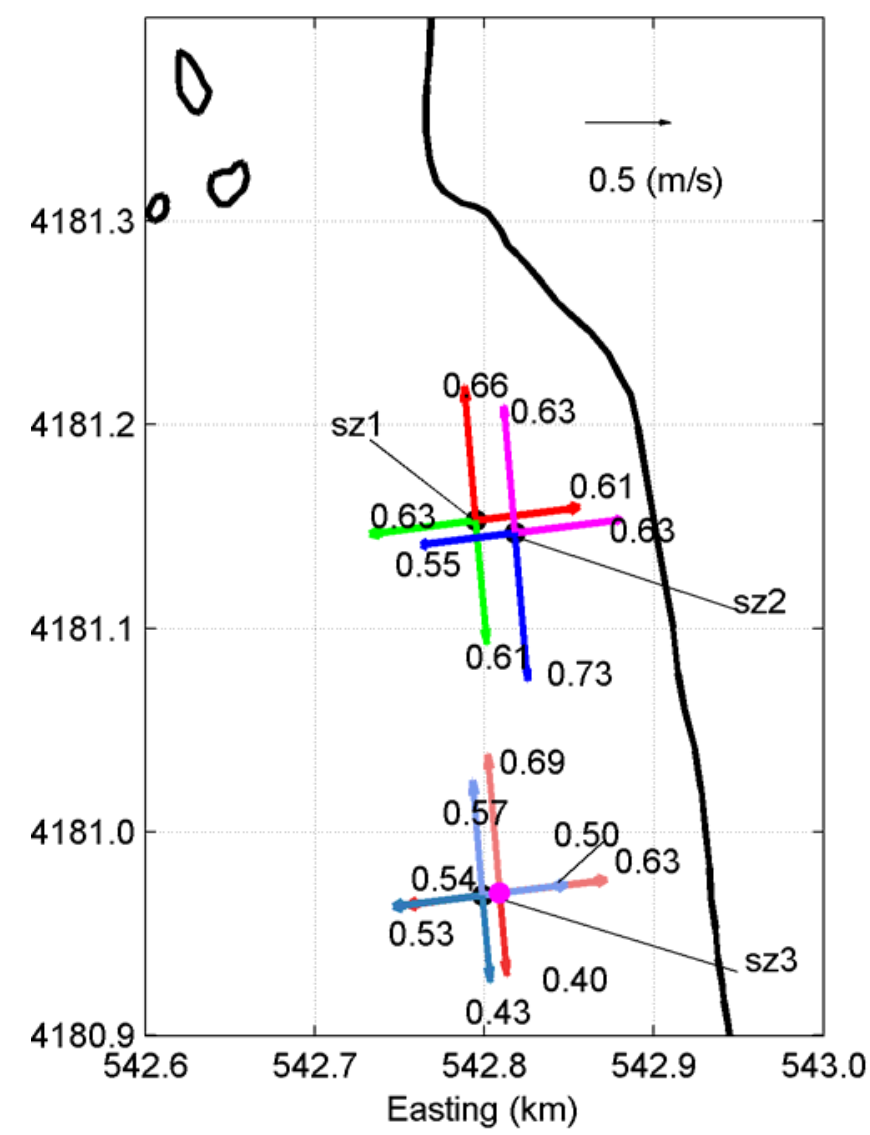

Figure 6.4 Maximum depth averaged currents measured in the surf zone at the north end of Ocean Beach during a complete tide cycle (Jan 24-25, 2006). 
(a)

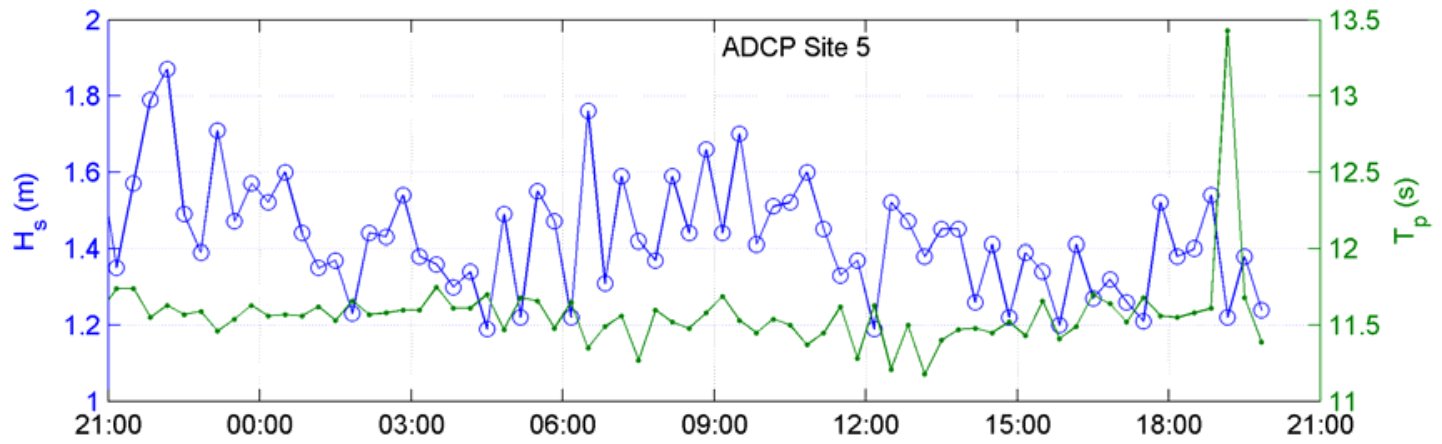

(b)

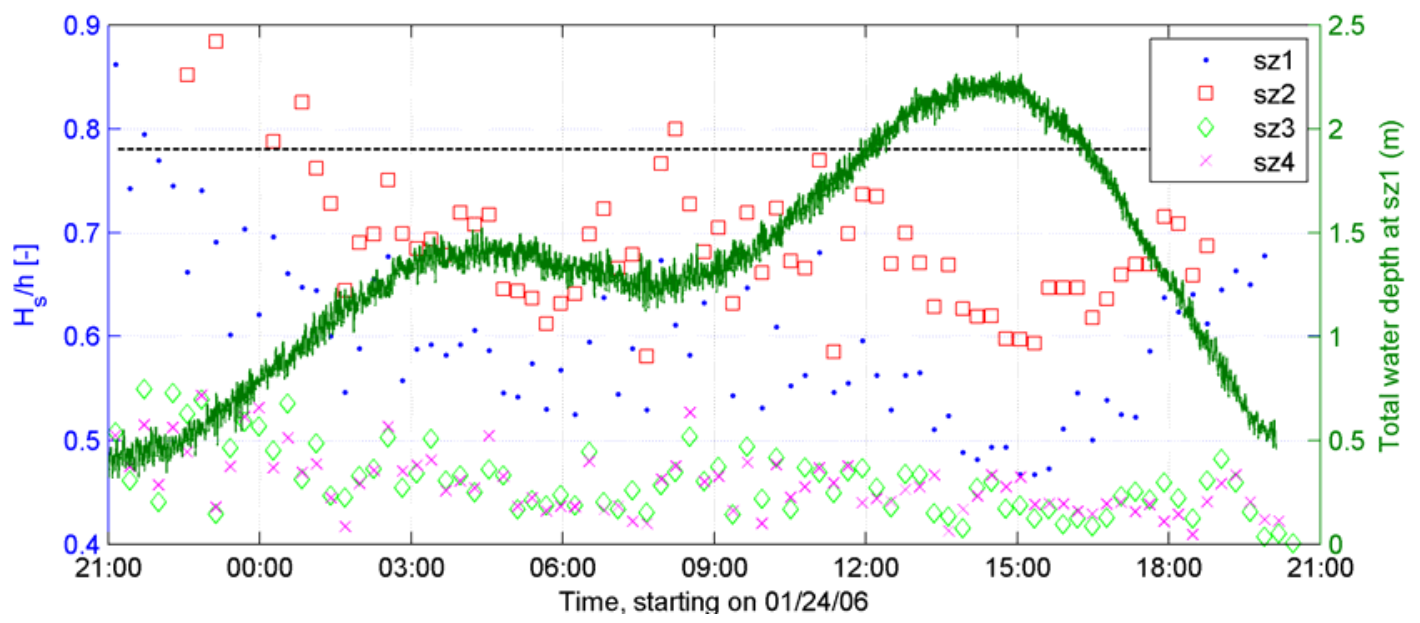

Figure 6.5. Variations of the breaking parameter with tide level at the north end of Ocean Beach. Upper plot (a) shows concurrently measured offshore wave conditions at ADCP Site 5. Lower plot (b) shows calculated breaking parameters for surf zone measurements at sz1 through sz4 and measured water depth at sz1. Dashed horizontal line is the 0.78 breaking ratio. 


\title{
Chapter 7-Multibeam Mapping
}

\author{
By Patrick L. Barnard
}

\section{Introduction}

Forty-four days of multibeam mapping were conducted at the mouth of San Francisco Bay (Figure 7.1) during the fall of 2004 and 2005 through a USGS-USACE-California State University, Monterey Bay Seafloor Mapping Lab (SFML) collaboration (Barnard and others, 2006a; Barnard and others, 2006c). The primary goals of this survey were to:

- evaluate bathymetric change at the mouth of San Francisco Bay since the last comprehensive bathymetric survey was completed in 1956

- document dominant sediment transport pathways

- estimate bedload transport via multiple surveys of a transect through an active bedform field

An additional 7 surveys of the Ocean Beach Disposal Site were completed in the summer of 2005 and 2006 (Barnard and Hanes, 2006). These surveys documented the morphological evolution of a nearshore disposal site.

\section{Methodology}

The mouth of San Francisco Bay was mapped using a Reson 8101 multibeam sonar system aboard the $R / V$ VenTresca operated by the Sea Floor Mapping Lab (SFML) at the California State University of Monterey Bay, between 9/15/2004-10/31/2004, and between 9/17/2005-10/30/2005. Passes over a large bedform field in the Golden Gate were completed October 17, 18, 25 and 30, 2004, and September 17, 18, and October 30, 2005, to measure sand wave migration rates. The 8101 operates at $240 \mathrm{kHz}$ and measures relative water depths within a $150^{\circ}$ swath consisting of $1011.5^{\circ} \times 1.5^{\circ}$ beams. This transducer geometry makes the 8101 capable of taking up to 3,000 soundings per second with swath coverage of up to 7.4 times the water depth. A Trimble ${ }^{\circledR} 4700$ GPS receiver logged position and attitude data with differential corrections provided by a Trimble ${ }^{\circledR}$ ProBeacon receiver. Horizontal positional accuracy of this system is typically $+/-1-2 \mathrm{~m}$. Attitude (pitch, roll, yaw, and heave) data were recorded at $200 \mathrm{~Hz}$ by a TSS Position and Orientation System, Marine Vessel (POS-MV). Attitude accuracy for the POS/MV pitch, roll and yaw measurements averaged $+/-0.03^{\circ}$, while heave accuracy was maintained at $+/-5 \%$ or $5 \mathrm{~cm}$. Sonar, position, and attitude data were logged in XTF format using a Triton Elics Isis data acquisition system running Isis Sonar software. Multibeam data were monitored in real-time using the 8101 Sonar Processor control interface and 2-D and 3-D display windows in the Isis Sonar and DelphMap software. Survey planning and navigation were performed using Coastal Oceanographics Hypack Max software. Surface-to-seafloor profiles of the speed of sound through the water were collected periodically during the surveys with an Applied Microsystems Limited (AML) SV+ sound velocity profiler. These profiles were used to correct for variations in sound velocity due to salinity and temperature changes throughout the water column.

Shipboard data were post-processed using CARIS Hydrographic Information Processing System (HIPS) 5.4 software. Tide and SVP (sound velocity profile) corrections 
were applied, and the sounding data were cleaned to remove erroneous soundings. The HIPS refraction coefficient editor was used where necessary to reduce artifacts due to inadequate sound velocity compensation. The 1138 survey lines yielded a total of $1,108,456,315$ soundings.

For the mouth of San Francisco Bay the tides were obtained from the NOAA (2006b). Verified tides from the tide gauge at San Francisco-Fort Point using a six-minute interval at MLLW were applied. For the rest of the area that was surveyed, verified tides were taken from the NOAA website and subtracted the difference of predicted tides from the Golden Gate minus the predicted tides at the San Francisco ebb-tidal delta. The predicted tides from the Golden Gate and SF Bar were taken from the program Tides and Currents Lite. The vertical error arising from the tide corrections and GPS positioning combined is estimated at $+/-12 \mathrm{~cm}$.

Grids for the entire survey as well as each of the sand wave migration surveys were created from the cleaned $x-y-z$ files using a weighted moving average method. Measurements of sand wave position, slope, wavelength and height were determined using tools in ArcGIS ${ }^{\odot}$, Fledermaus $^{\odot}$ and Matlab ${ }^{\odot}$. Analysis of bedform characteristics from the individual surveys was performed to quantify wavelength, orientation, amplitude, and slope. Difference maps between surveys were generated to quantify the spatial offset through time of the bedform field, migration rates, and bedform morphology evolution.

\section{Results}

\section{Overview}

The bathymetry at the mouth of San Francisco Bay has changed considerably since the last complete survey was conducted by the National Ocean Service (NOS) in 1956. The large-scale trend is sediment loss (Figure 7.2). The average depth change in the region was $-60 \mathrm{~cm}\left(-2.0 \mathrm{ft}\right.$, erosion), which amounts to approximately 92 million $\mathrm{m}^{3}\left(120\right.$ million $\left.\mathrm{yd}^{3}\right)$ of sediment loss in the common survey area in 50 years. The outer lobe of the ebb-tidal delta is dominated by erosion, with the exception of two distinct accretionary mounds in the vicinity of SF-8, the USACE disposal location for ship channel dredging since 1971 (United States Army Corps of Engineers, 1996). Most of the region offshore of the erosion hot spot at Ocean Beach has lost more than $1 \mathrm{~m}$ of sediment since 1956, reducing the wave protection these shoals formerly provided to the adjacent beach, and indicating a general reduction in sediment supply to this reach of the ebb tidal delta.

Mapping of bedform orientations throughout the study area shows that most bedforms are controlled by the dominant tidal current directions associated with flux in and out of San Francisco Bay (Figure 7.3). The lone exception is an area of divergence along the peak of the southern lobe of the ebb tidal delta, along the bar that intersects central Ocean Beach. The largest bedforms (maximum height $=10 \mathrm{~m}$, wavelength $=317 \mathrm{~m}$ ) can be found in the inlet throat (Figure 7.4), near the Golden Gate, where tidal power is focused to produce currents greater than $2.5 \mathrm{~m} / \mathrm{s}$ during ebb and flood tide.

\section{Massive Sand Waves of the Golden Gate}

Some of the largest sand waves in the world are located just west of the Golden Gate Bridge- these waves have been formed by abundant sediment and extremely powerful tidal currents (Figures 7.5-7.6). This massive sand wave field covers an area of approximately 4 
$\mathrm{km}^{2}\left(1.5 \mathrm{mi}^{2}\right)$ in water depths ranging from $30 \mathrm{~m}(98 \mathrm{ft})$ to $106 \mathrm{~m}(348 \mathrm{ft})$. More than 40

distinct sand waves were identified; the waves have an average wavelength of $82 \mathrm{~m} \mathrm{(269 \textrm {ft } )}$ and an average height of $6 \mathrm{~m}(20 \mathrm{ft})$. The maximum wavelength and height are $317 \mathrm{~m}(1040$

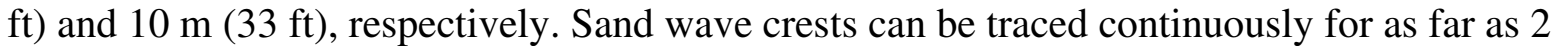
$\mathrm{km}$ across the mouth of this energetic tidal inlet, where each tide forces 2 billion $\mathrm{m}^{3}$ ( 528 billion gallons) of water through the Golden Gate. The resulting strong currents sweep large volumes of sediment between the narrow rocky headlands, spanned by the Golden Gate Bridge, into the Bay during the flooding tide and toward the Pacific Ocean during the ebbing tide.

The complex temporal and spatial variations in wave and tidal current interactions at the mouth of San Francisco Bay result in a diverse array of bedform morphologies, scales, and orientations (Figure 7.7; Barnard and others, 2006). Strong tidal currents peak at over 2.5 $\mathrm{m} / \mathrm{s}(5.6 \mathrm{mi} / \mathrm{hr})$ and rocky headlands and embayments help to create strong eddies and reverse flows, all of which combine to form highly variable bottom features.

Multiple surveys of a $2.5 \mathrm{~km}(1.6 \mathrm{mi})$ track line through the center of the massive sand wave field were completed in 2004 and 2005. Analysis of these surveys enables the calculation of short- (daily) and long-term (annual) rates of bedform migration and sediment transport. In 2004, surveys repeated as frequently as 24 hours (Figure 7.8) showed that crests shifted as much as $3 \mathrm{~m} \mathrm{(10} \mathrm{ft),} \mathrm{whereas} \mathrm{over} \mathrm{the} \mathrm{entire} \mathrm{13-day} \mathrm{sampling} \mathrm{period} \mathrm{the} \mathrm{average}$ migration of each sand wave was just $1.4 \mathrm{~m}(4.4 \mathrm{ft})$, or $11 \mathrm{~cm} /$ day $(4.3 \mathrm{in} /$ day $)$. However, the 2005 surveys indicate that the net migration rate, when averaged over an entire year, is just 7 $\mathrm{m}(23 \mathrm{ft})$, or less than $2 \mathrm{~cm} /$ day $(0.7 \mathrm{in} /$ day) seaward. These data show that strong tidal fluctuations cause daily sand wave oscillations that are a significant percentage of annual migration rates, but flow reversals result in a relatively low rate of net sand wave migration annually (Barnard and others, 2006).

\section{Offshore Ocean Beach}

Offshore of Ocean Beach, the bedform orientation indicates dominance by tidal forcing outside of the surf zone (Figure 7.3; Jordan, 1962). Most bedforms in the northern half of Ocean Beach are oriented with their crests nearly perpendicular to the shoreline (Figure 7.9 a, Inset A), while toward the middle of the beach, approximately $1.5 \mathrm{~km}$ north of the erosion hot spot, there are onshore-directed bedforms, an indication of onshore-directed transport (Figure 7.9, Inset B). The Southwest Ocean Outfall Pipe, constructed in the late 1970's (Woodward Clyde Consultants, 1978), is located in the southern end of Ocean Beach and carries approximately one-third of San Francisco's treated sewage out to sea. The only bedforms observable offshore of the erosion hot spot are scour ripples associated with the Outfall Pipe and ripple scour depressions oriented east-west. The Southwest Ocean Outfall Pipe is exposed and is causing severe scour in the immediate vicinity (Figure 7.10). The ramifications for the structural integrity of the outfall pipe and the influence of this scour on the adjacent coastline are unknown.

\section{Dredge Disposal Monitoring}

In an effort to reduce the erosion south of Sloat Blvd. at Ocean Beach and avoid hazardous navigation conditions at the current disposal site (SF-8), a new plan for the management of sediment dredged annually from the main shipping channel at the mouth of Francisco Bay was implemented in May 2005 by the USACE, San Francisco District. The 
objective for USCAE was to perform a test dredge disposal of approximately $230,000 \mathrm{~m}^{3}$ $\left(300,000 \mathrm{yd}^{3}\right)$ of sand just offshore of the erosion hot spot, in depths between approximately $9 \mathrm{~m}$ and $14 \mathrm{~m}$. This disposal site was chosen because it is in a location where the strong tidal currents associated with the mouth of San Francisco Bay and waves can potentially feed sediment toward the littoral zone in the reach of the beach that is experiencing critical erosion. The onshore migration of sediment from the target disposal location might feed the primary longshore bar or the nearshore zone, and thus provide a buffer to erosion that peaks during winter months when large waves impact the region. The USGS, in collaboration with SFML, monitored the initial bathymetric evolution of the test dredge disposal site and the adjacent coastal region from May 2005 to November 2005. Multibeam surveys of the region were able to track the evolution of the disposal mound for one year. After the initial dispersal of the disposal mound by approximately $50 \%$, the volume remained fairly steady and slowly migrated toward shore. As of May 2006, one year after initial disposal, the mound had migrated $100 \mathrm{~m}$ toward shore. Complete results of this preliminary monitoring effort can be found in (Barnard and Hanes, 2006; Barnard and others, 2006b)

\section{Discussion}

Several likely causes for the observed erosion trend at the mouth of San Francisco Bay include the reduction in tidal prism of approximately 30 percent due to development and loss of wetlands in San Francisco Bay, a decrease in sediment supply due to removal by sand mining inside the bay of approximately 50 million $\mathrm{m}^{3}\left(65\right.$ million $\left.\mathrm{yd}^{3}\right)$ since the middle of 20th Century (Chin and others, 1998; 2004), and a reduced influx of hydraulic mining debris from the Sacramento River (Gilbert, 1917). There are two distinct accretionary mounds just south of the main shipping channel, presumably the result of the annual dredge disposal of shipping channel sediments in this area, that have totaled about 18 million $\mathrm{m}^{3}$ (24 million $\mathrm{yd}^{3}$ ) since disposal commenced on this site (SF-8) in 1971 (USACE, 1996). The dredging of the ship channel and the shrinking of the ebb tidal delta has led to filling in the of the peripheral secondary tidal channels offshore of Ocean Beach and Point Bonita, and therefore may also be at least partially responsible for the observed accretion trend at the northern end of Ocean Beach (see Chapter 2).

The presence of large, alongshore migrating bedforms suggests that tidal currents dominate sediment transport patterns offshore of Ocean Beach despite a robust wave climate. However, erosion of the shoals offshore of the Sloat region over the last 50 years is likely a major cause of the chronic erosion along this stretch of coastline, due to increased susceptibility to wave attack.

\section{Future Work}

The California Coastal Conservancy has commissioned a nearshore multibeam survey within the 3 mile limit extending from Año Nuevo to Bolinas that began in fall 2006 and will fill in the entire inner shelf of the San Francisco Bight not covered in the USGS study. Dredge disposal monitoring continues, as do annual surveys of the sand wave field in the Golden Gate. 


\section{Conclusions}

- The ebb-tidal delta at the mouth of San Francisco Bay has experienced a large scale erosion trend over the last 50 years.

- Erosion of the shoals offshore of southern Ocean Beach has made the adjacent beach more susceptible to wave attack.

- Large, dynamic sand waves are located in the Golden Gate and off Point Lobos.

- Dominant sediment transport patterns outside the surf zone are controlled by tidal forcing, evident by the presence of alongshore migrating bedforms.

- Bedload sediment transport is seaward through the center of the inlet and toward the bay adjacent to Baker Beach. 


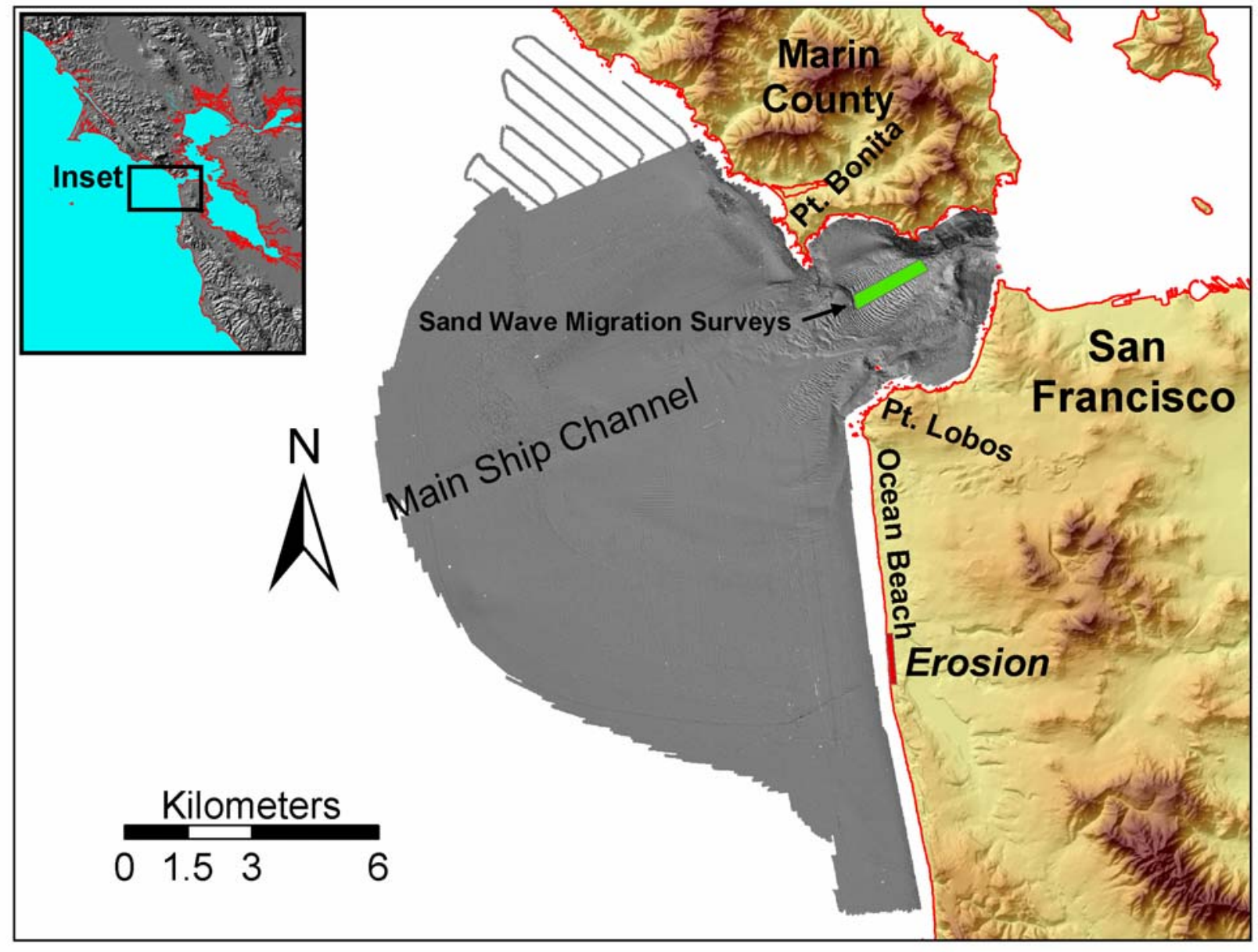

Figure 7.1. Shaded relief image showing the multibeam coverage area from the 2004-2005 survey and the location of sand wave migration surveys in the Golden Gate. 


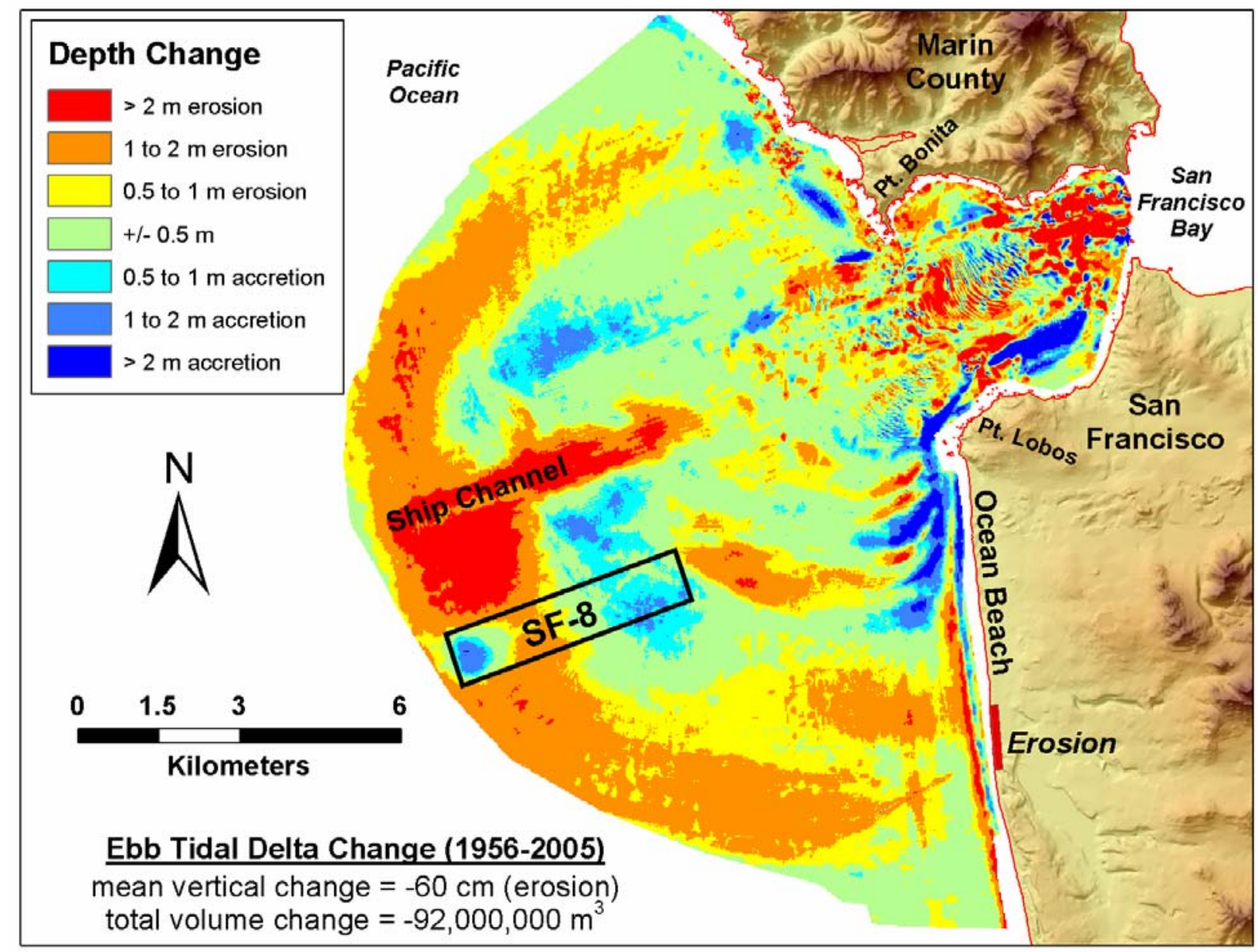

Figure 7.2. Change between bathymetric surveys conducted in 1956 and 2005. 
Figure 7.3. A) Bedform orientation based on sand wave orientation, and B) dominant sediment transport direction as inferred from bedform shape asymmetry.

A

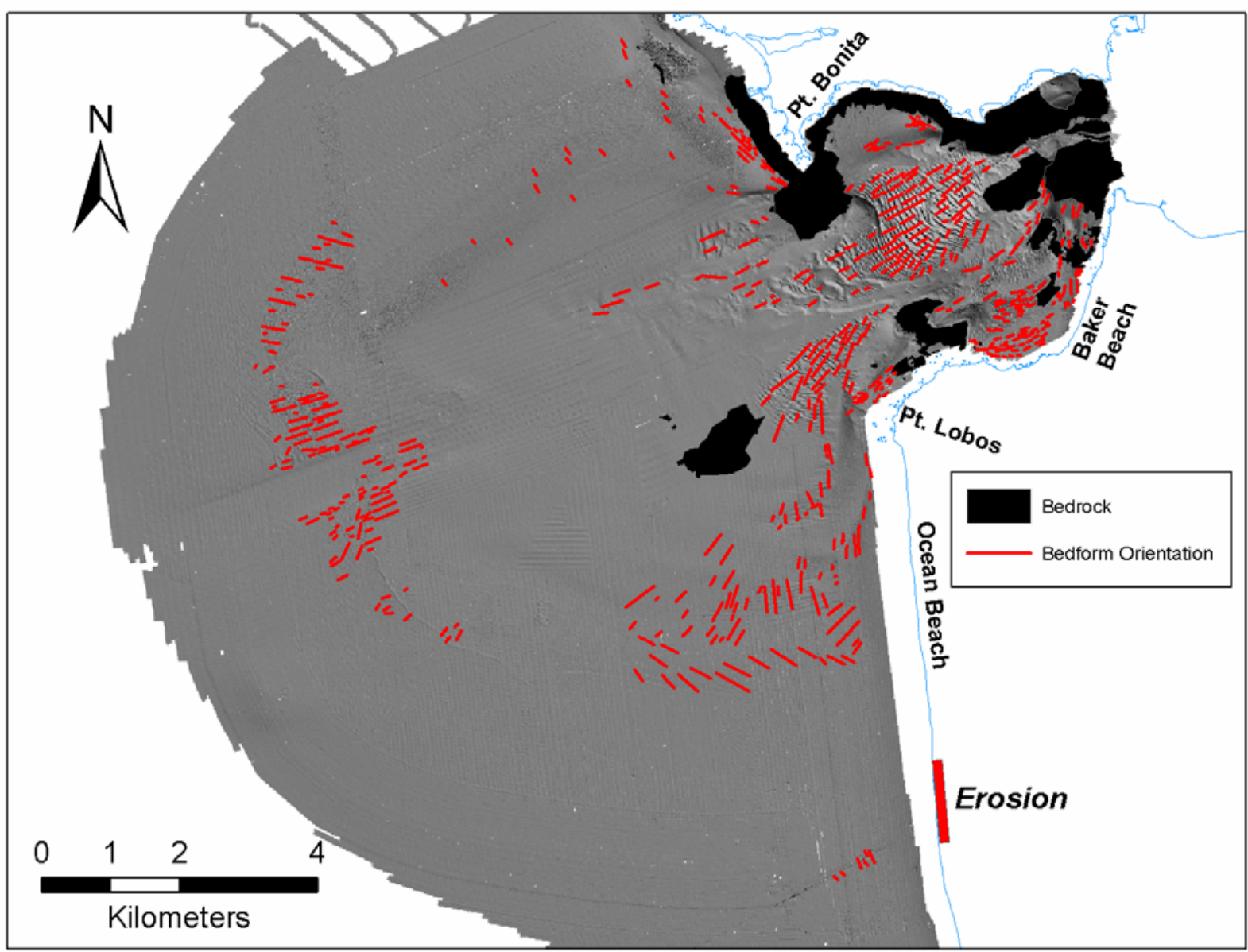




\section{B}

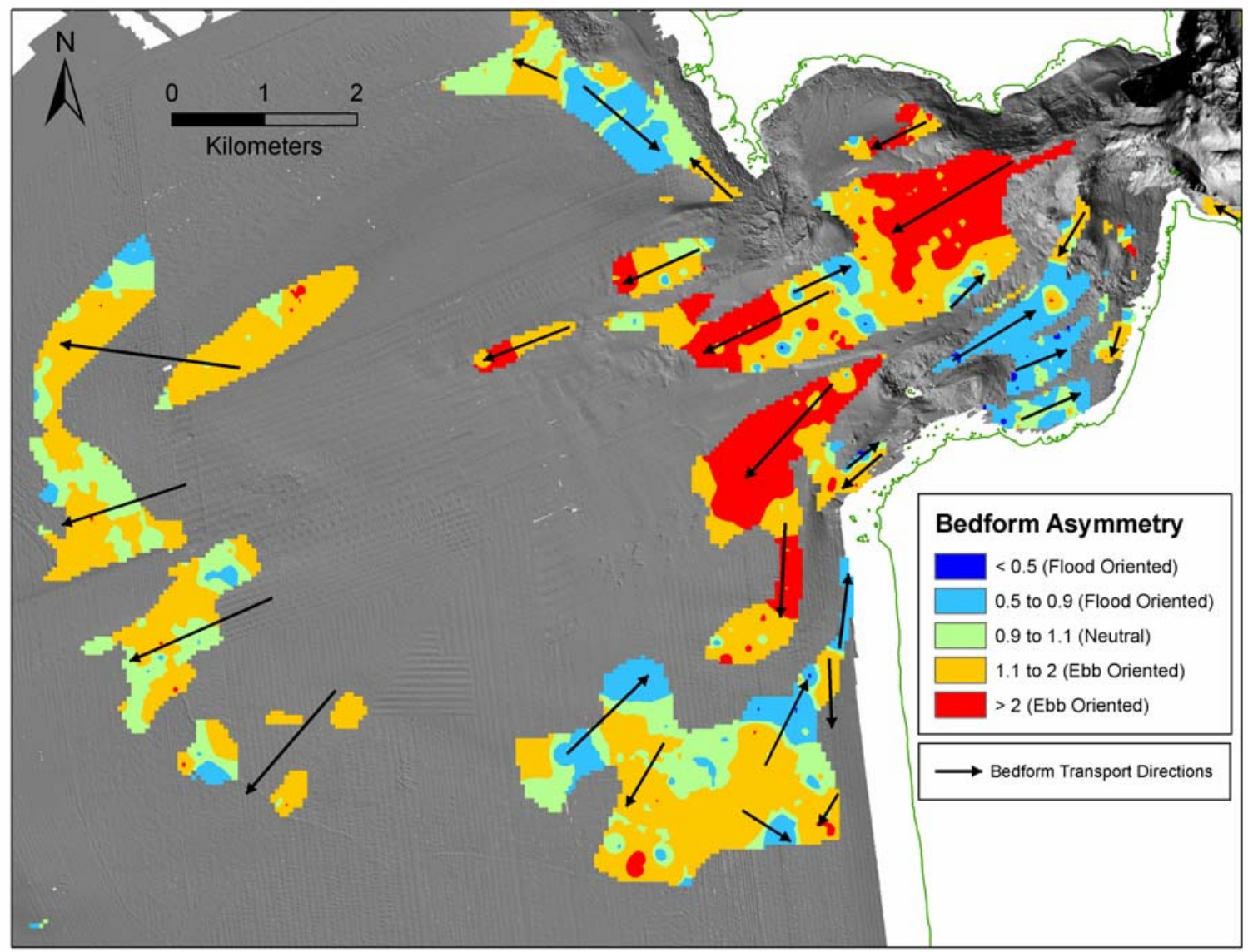


Figure 7.4. Map of bedform A) wavelength and B) height, gridded to $50 \mathrm{~m}$ cell resolution.

A

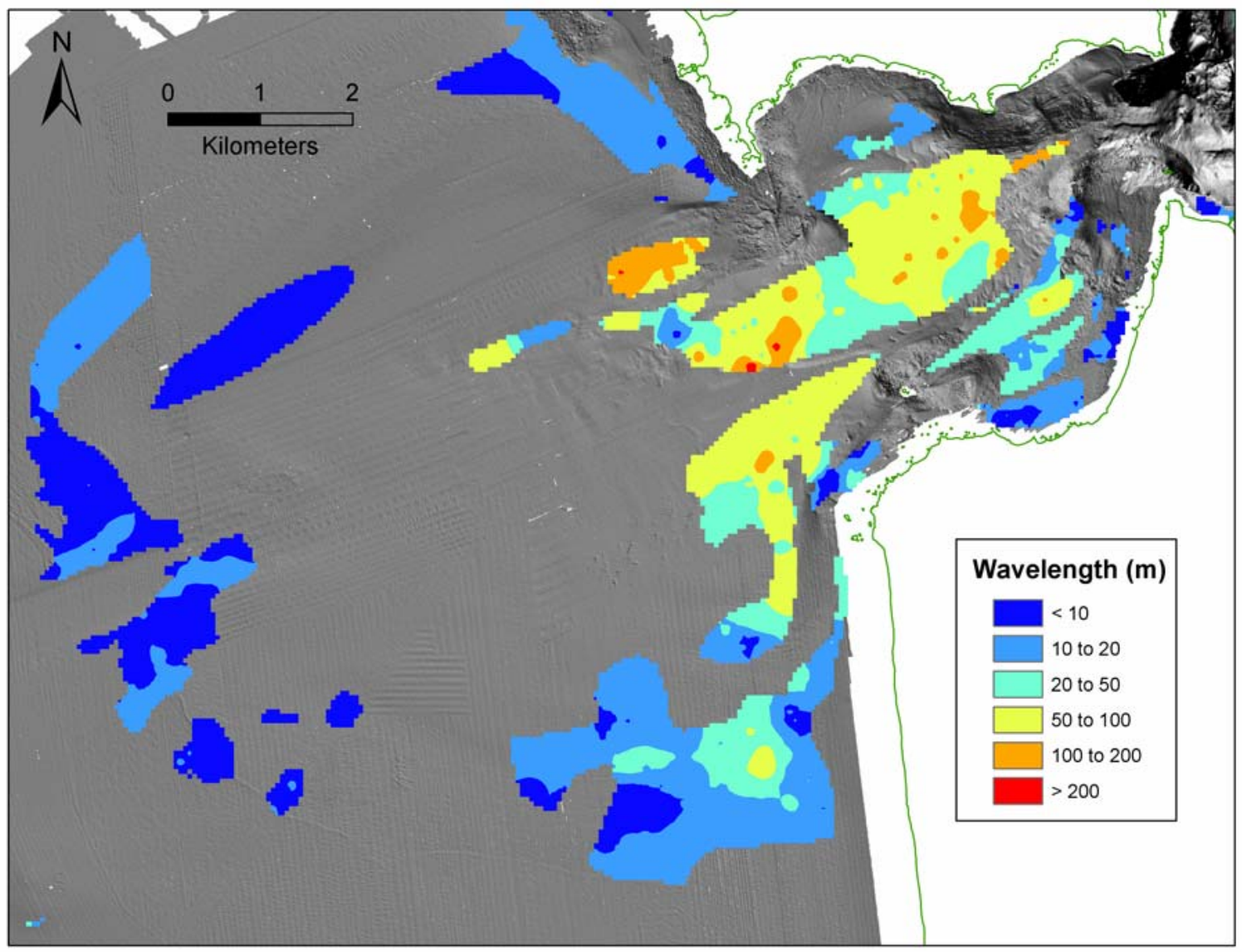


B

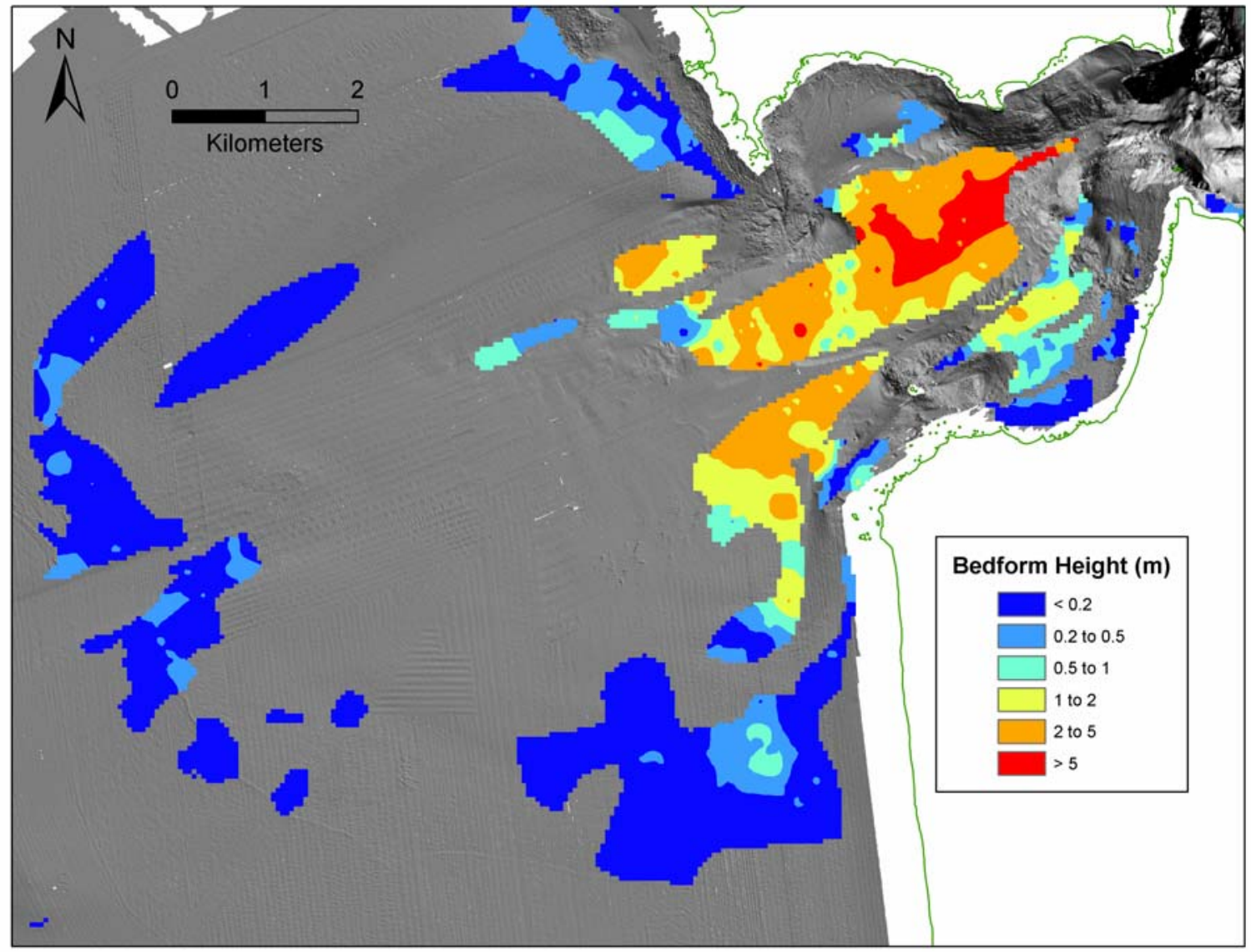




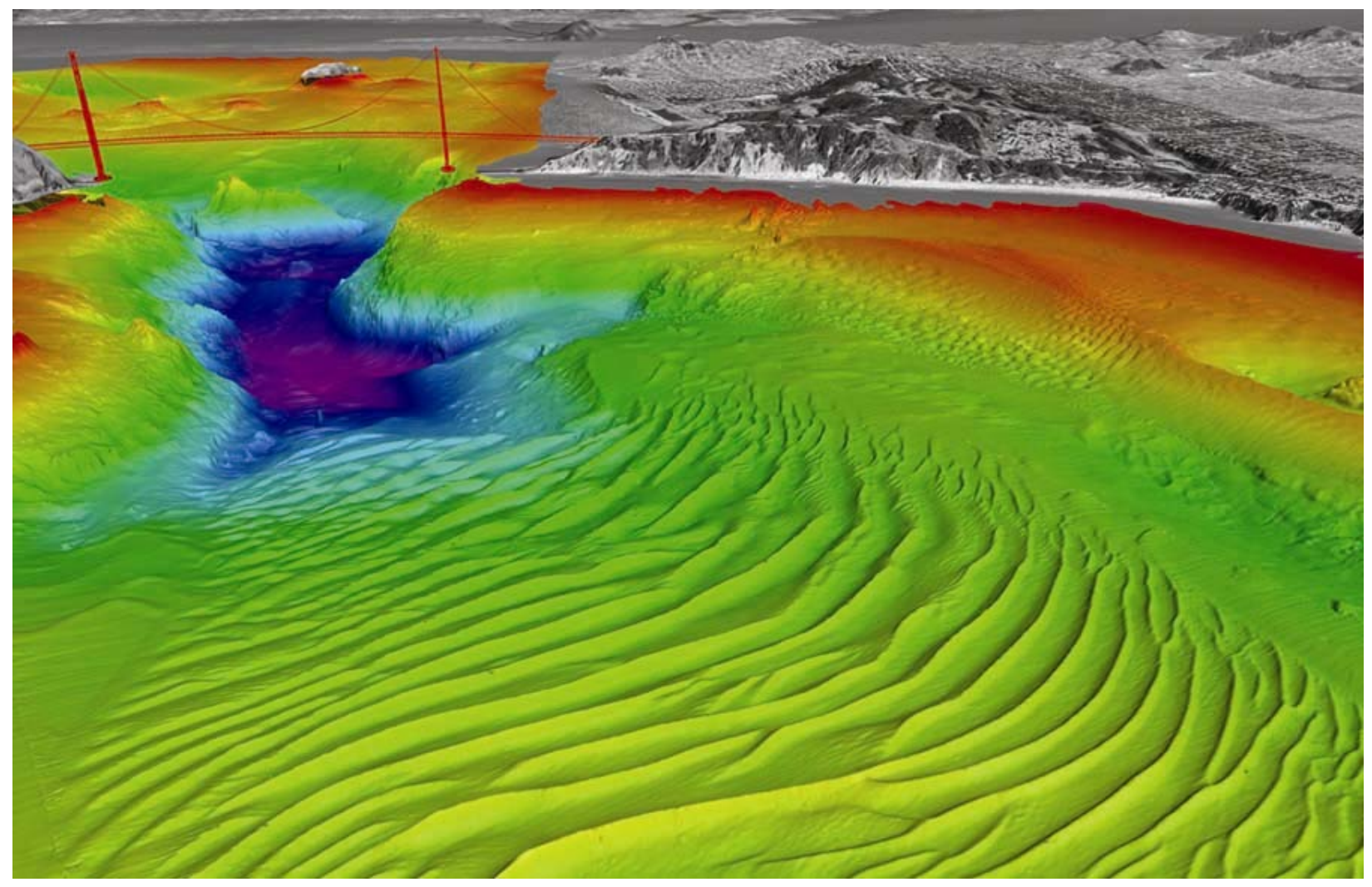

Figure 7.5. View of the giant sand waves at the mouth of San Francisco Bay (from Barnard and others, 2006a). View is to the east toward San Francisco Bay. The Golden Gate Bridge is approximately $2 \mathrm{~km}(1.2 \mathrm{mi})$ long. Shaded relief image created with a 2-m grid, $4 x$ vertical exaggeration, sun azimuth of 240 degrees, and sun angle of 66 degrees. The land topography was generated by overlaying digital orthophoto quadrangles (DOOs) on USGS digital elevation models (DEMs), with a $2 x$ vertical exaggeration. Bathymetry data inside the Bay (that is east of Golden Gate Bridge) is from Dartnell and Gardner (1999). Golden Gate Bridge model courtesy of Interactive Visualization Systems. 


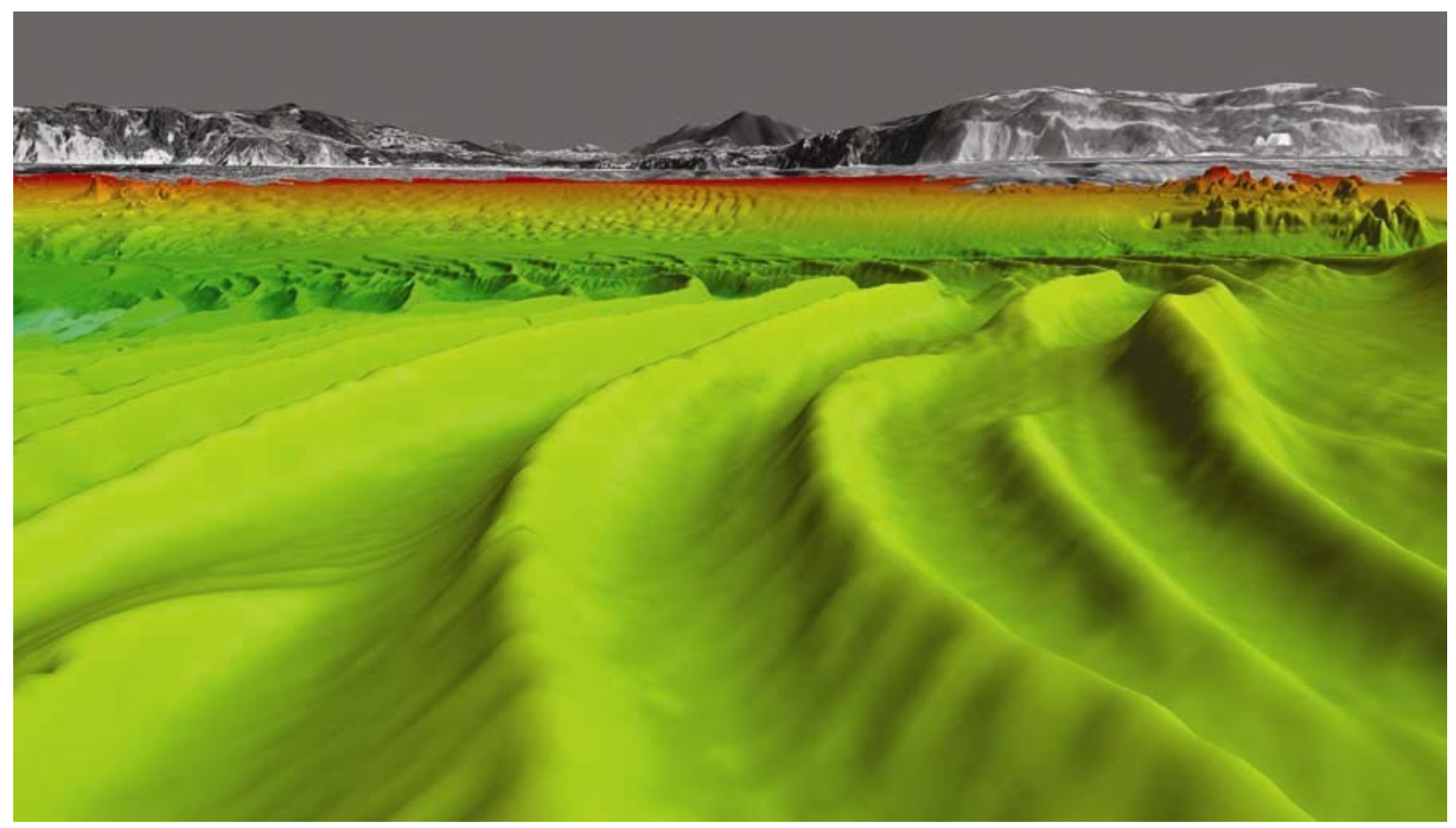

Figure 7.6. Oblique view of the giant sand waves at the mouth of San Francisco Bay (from Barnard and others, 2006a). View is south across the Golden Gate toward Baker Beach and the city of San Francisco. See Figure 7.5 for more image information. 

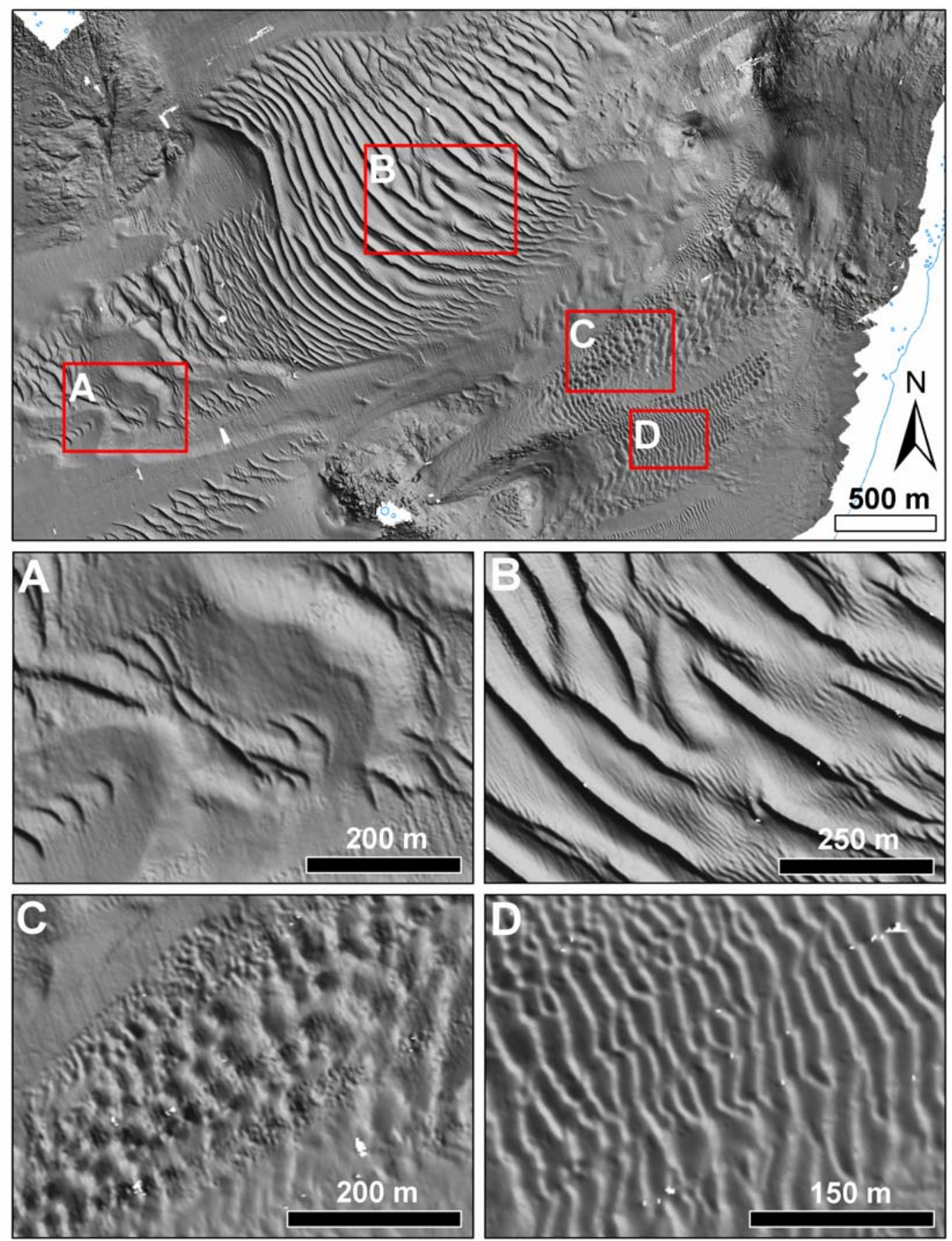

Figure 7.7. Diverse sand waves at the mouth of San Francisco Bay, seaward of the Golden Gate Bridge. Shaded relief image created with $5 x$ vertical exaggeration, sun elevation of 45 degrees, and sun azimuth of 45 degrees. (A) Irregular sand waves seaward of the main sand wave field. (B) Ebb-dominated sand waves with wavelengths as great as $150 \mathrm{~m}$ with superimposed sand waves of $5 \mathrm{~m}$ to $10 \mathrm{~m}$ wavelength. (C) Linguoid sand waves, $20 \mathrm{~m}$ to $30 \mathrm{~m}$ in wavelength. (D) Flood-dominated sand waves, $15 \mathrm{~m}$ to $20 \mathrm{~m}$ in wavelength, just offshore of Baker Beach. 

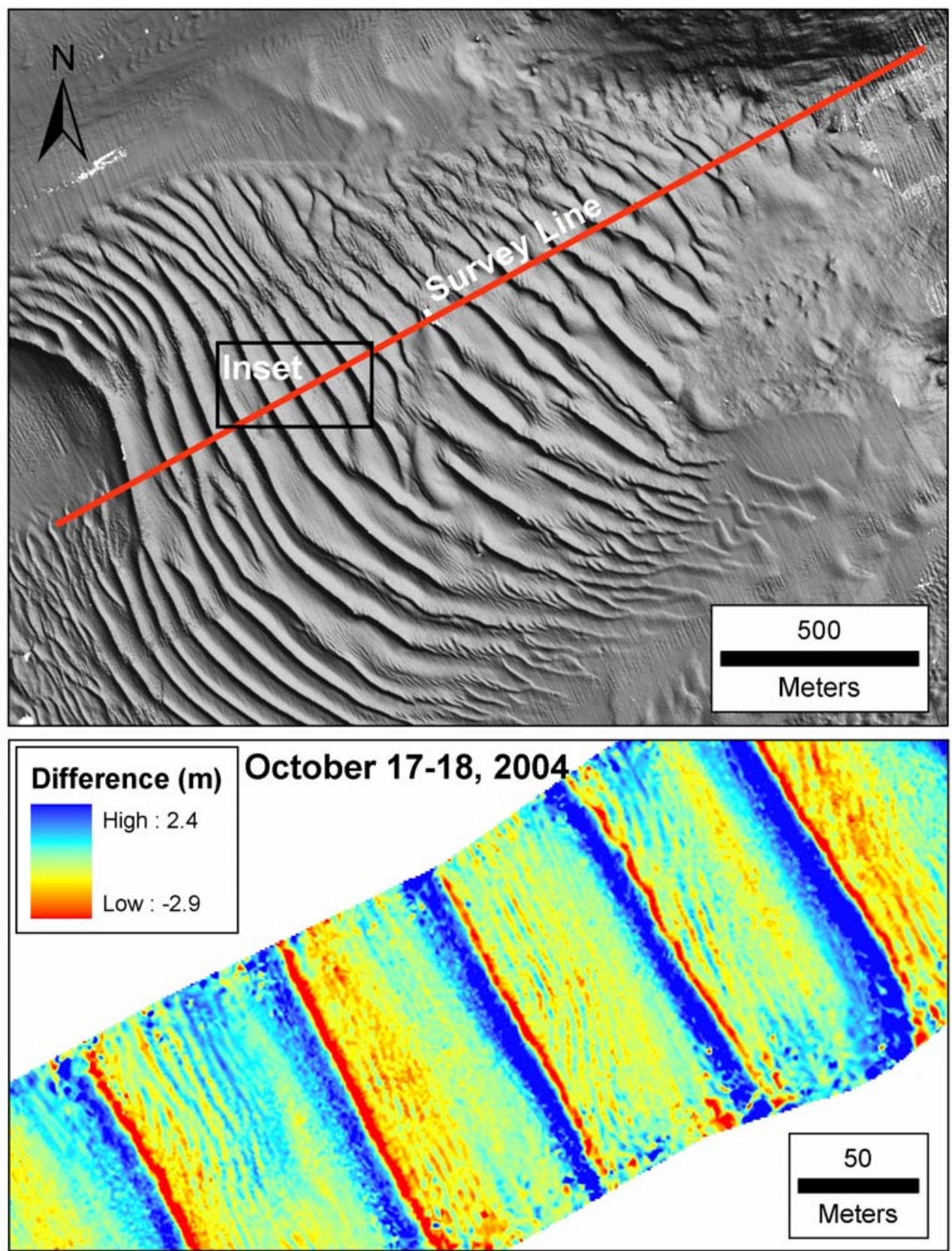

Figure 7.8. Overview of large sand wave field and high resolution difference map of two surveys approximately 21 hours apart illustrating both large-scale and small-scale sand wave migration and orientation. Migration is from right to left. 


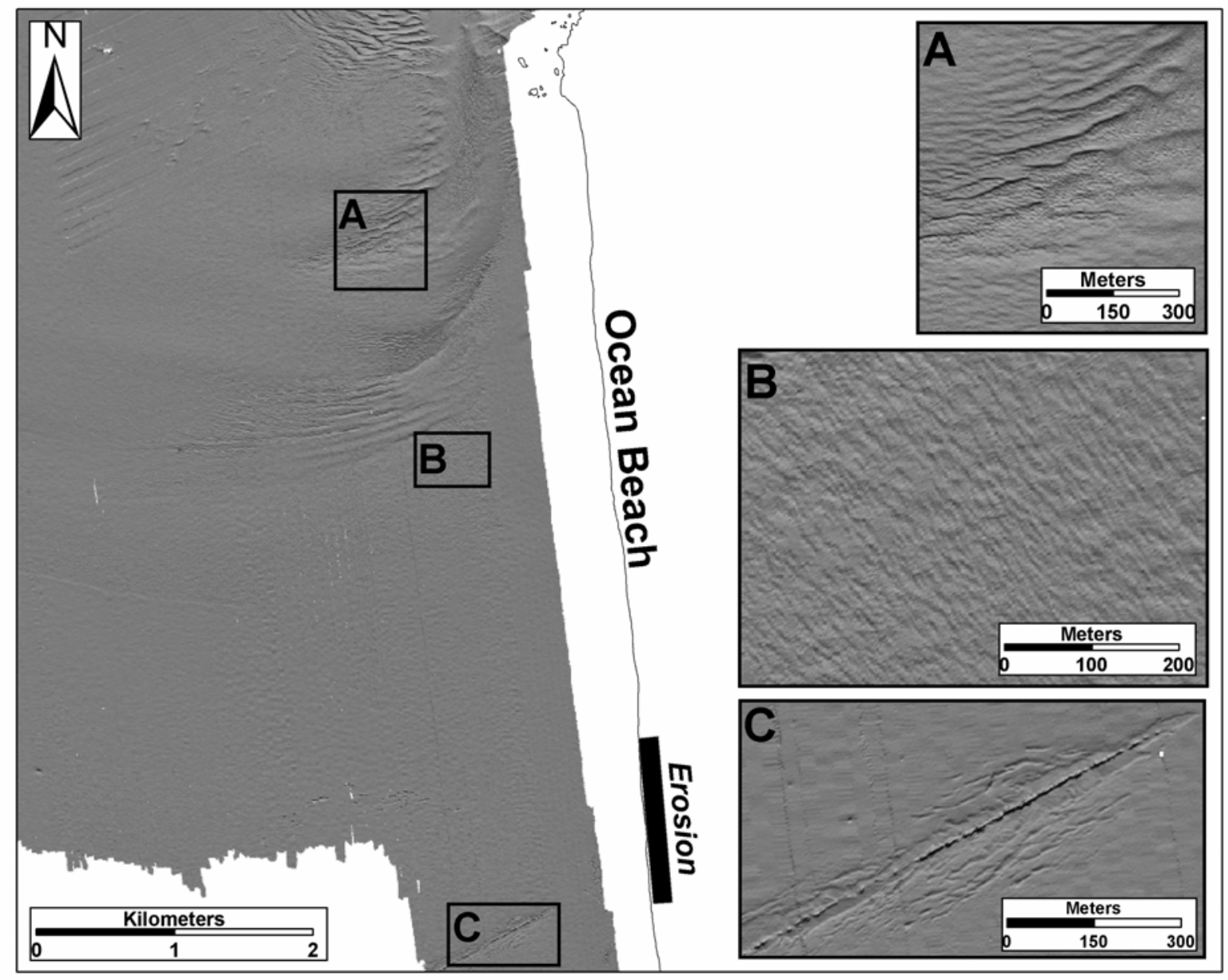

Figure 7.9. Multibeam survey from 2004 showing A) alongshore migrating bedforms, B) onshore-directed bedform morphologies north of the disposal site, and C) intense scour associated with the outfall pipe, the approximate site of the June 2005 dredge disposal (from Barnard and others, 2006b). 


\title{
Chapter 8-Grain Size Mapping
}

\author{
By Patrick L Barnard
}

\section{Introduction}

The USGS has conducted periodic sediment sampling along Ocean Beach to quantify grain size variation alongshore and seasonally. Further, in summer 2005, the USGS performed a regional sediment sampling survey of the mouth of San Francisco Bay, including the region offshore of Ocean Beach, to document large-scale grain size patterns, sediment and sources, and to track the grain size at the Ocean Beach Disposal Site (see Figure 1.2).

\section{Methodology}

Using a digital bed-sediment camera, grain size surveys have been conducted periodically at Ocean Beach as a proxy for tracking variations in the physical energy transporting sediment along the beach. Using an autocorrelation technique developed by Rubin (2004), the grain size of the sample in a digital image can be extracted by statistical analysis of the autocorrelation of pixel intensities. The efficiency of this technique allows us to process over 300 images/samples in less than a day, whereas traditional sieving could take several months of work. Seven Ocean Beach grain size surveys have been completed since April 2004. Swash samples were taken at each of 18 profiles along the shoreward extension of the PWC lines (see Figures 3.2, 8.1). At five of these lines, samples were taken every ten meters along a cross-shore transect. Ocean Beach grain size samples were analyzed with both the settling tube and using the digital camera technique in May 2005 to test the accuracy of the new technique. Results of each method are well correlated with $r^{2}$ values $=\sim 0.70$ for both median and mean grain size (Barnard and others, 2007)

The USGS conducted eight days of sediment sampling in June and July 2005 at mouth of San Francisco Bay. A total of 191 stations were sampled by collecting grab samples or employing a digital bed sediment 'eyeball' camera (Chezar, 2001) at the mouth of San Francisco Bay, with emphasis immediately on and around the Ocean Beach disposal site (Figure 8.2).

The City of San Francisco's Oceanside Biology Laboratory (OBL) has also conducted extensive sediment sampling at the mouth of San Francisco Bay, with emphasis offshore of Ocean Beach. The OBL data set includes over 40 samples stations where thorough sediment, biological and chemical analysis have been performed each year from 1997 to the present.

\section{Results}

Median grain size in the swash along Ocean Beach averages $0.28 \mathrm{~mm}$, with no significant alongshore variation except for localized coarse lags where median grain size can exceed $0.5 \mathrm{~mm}$ (Figure 8.3). Seasonal variation is inconclusive, with several surveys awaiting processing, but at the southern part of Ocean Beach the heavy mineral content noticeably increases during the winter months. Cross-shore surveys of median grain size show only moderate variance, except along the longer profiles where the backbeach is supratidal (e.g. profile 2; Figure 8.4). 
Sediment at the mouth of San Francisco Bay is highly variable, ranging from very fine sand on the outer reaches of the ebb tidal delta, to coarse sand and gravel in the inlet throat, in the heart of the massive bedform field (Figure 8.5). The distribution of sediment grain size is linked to tidal current strength, with the coarsest sediment associated with the strongest currents, as in the inlet throat. Sediment sampling at the nearshore disposal site after the June 2005 disposal indicates a median grain size of $0.18 \mathrm{~mm}$ in that location.

\section{Discussion}

Detailed sampling in the nearshore dredge disposal region indicates that surficial sediments consist of fine sand (median grain size $\left(\mathrm{d}_{50}\right)=0.18 \mathrm{~mm}$ ), broadly consistent with nearshore bar and dune sediment found at Ocean Beach, but finer than beach sand $\left(\mathrm{d}_{50}=0.28\right.$ $\mathrm{mm}$ ). This sediment is therefore not ideally compatible to stay on the beach, but could build up the nearshore bars and help protect the beach from direct wave attack. However, Figure 8.5 shows that there is an abundance of beach compatible sand on the inner part of the ebb tidal delta that ranges from $\mathrm{d}_{50}=0.25$ to $0.50 \mathrm{~mm}$. If the surficial grain size is consistent with sediment several meters below the surface in these 'optimal' locations, then there exists an enormous amount (on the order of 100's of millions of $\mathrm{m}^{3}$ ) of sediment that could be used for future beach nourishment efforts.

\section{Conclusions}

- Median grain size varies minimally along Ocean Beach during the summer with a $\mathrm{d}_{50}=0.28 \mathrm{~mm}$.

- Sediment placed in the nearshore disposal site $\left(\mathrm{d}_{50}=0.18 \mathrm{~mm}\right)$ is finer than swash samples $\left(\mathrm{d}_{50}=0.28 \mathrm{~mm}\right)$ collected at Ocean Beach, and thus it is not likely to be stable on the beach.

- Large bodies of beach quality sand likely exist on the inner parts of the ebb-tidal delta at depths that could be dredged. Chapter 9 shows that a total volume of just over 1 $\mathrm{km}^{3}$ of acoustically transparent sediment is present. 


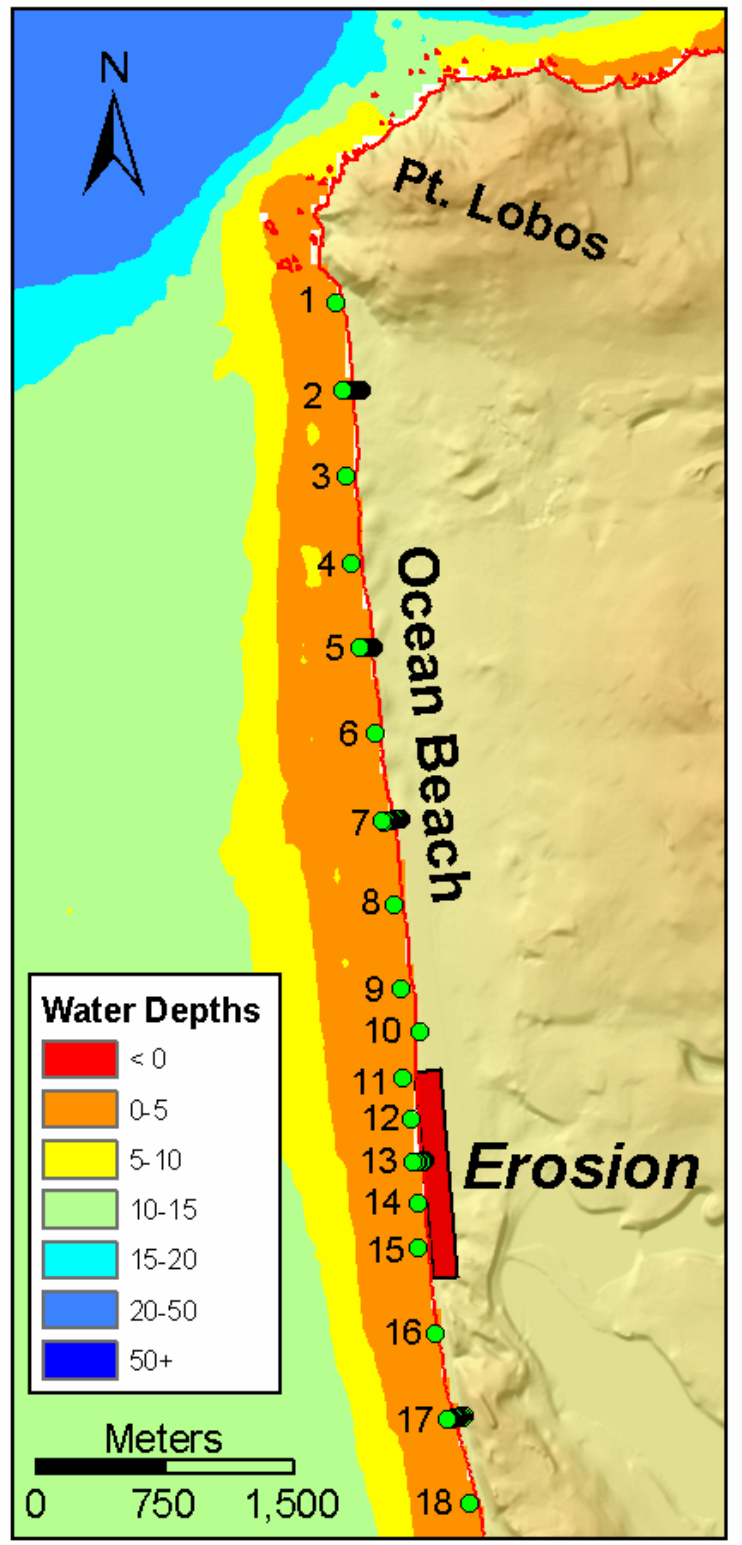

Figure 8.1. Location of beach sediment samples along Ocean Beach, from the May 2004 survey. The profile locations are labeled. 


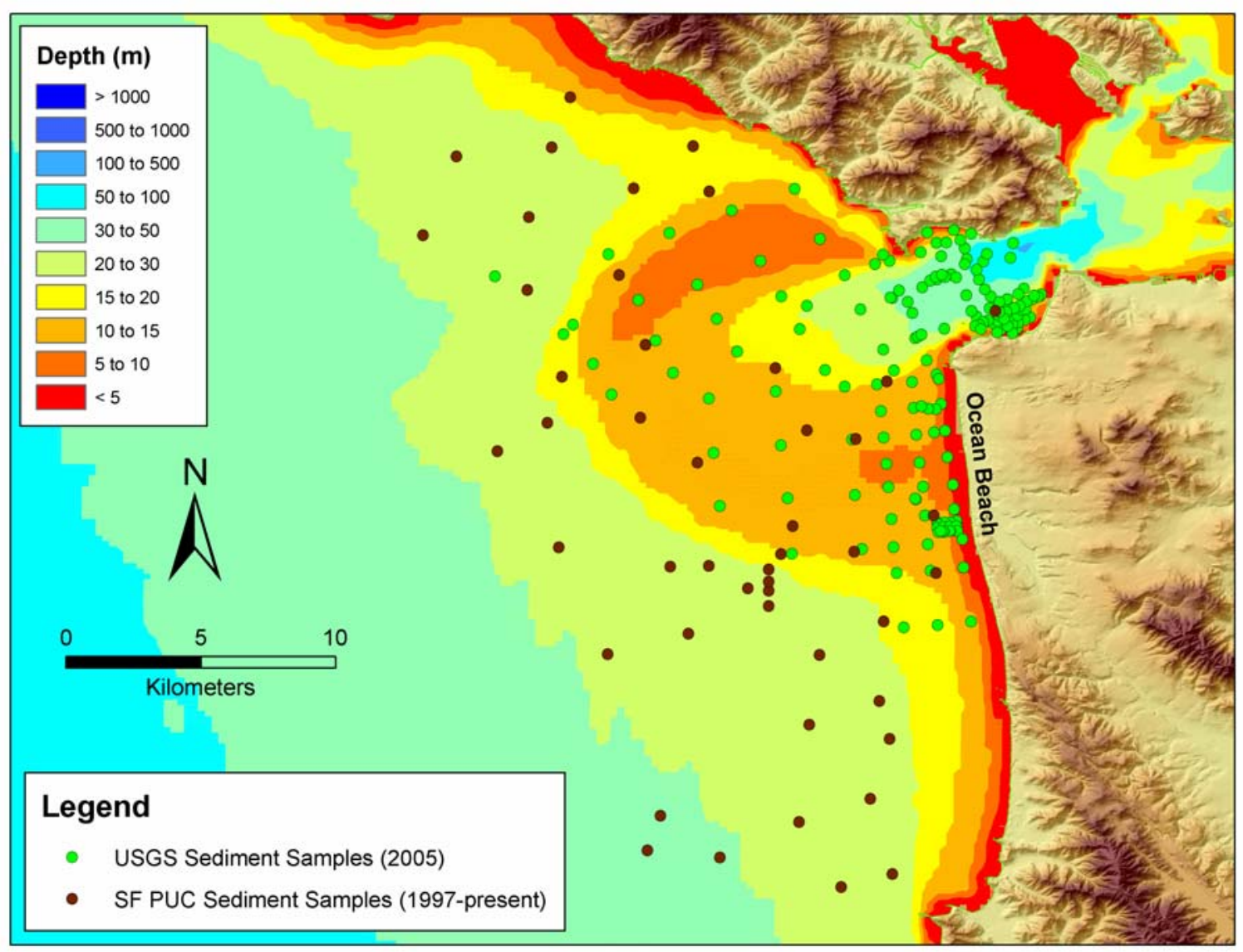

Figure 8.2. Sediment sample locations at the mouth of San Francisco Bay in summer 2005, along with Oceanside Biology Laboratory (OBL) sample stations.

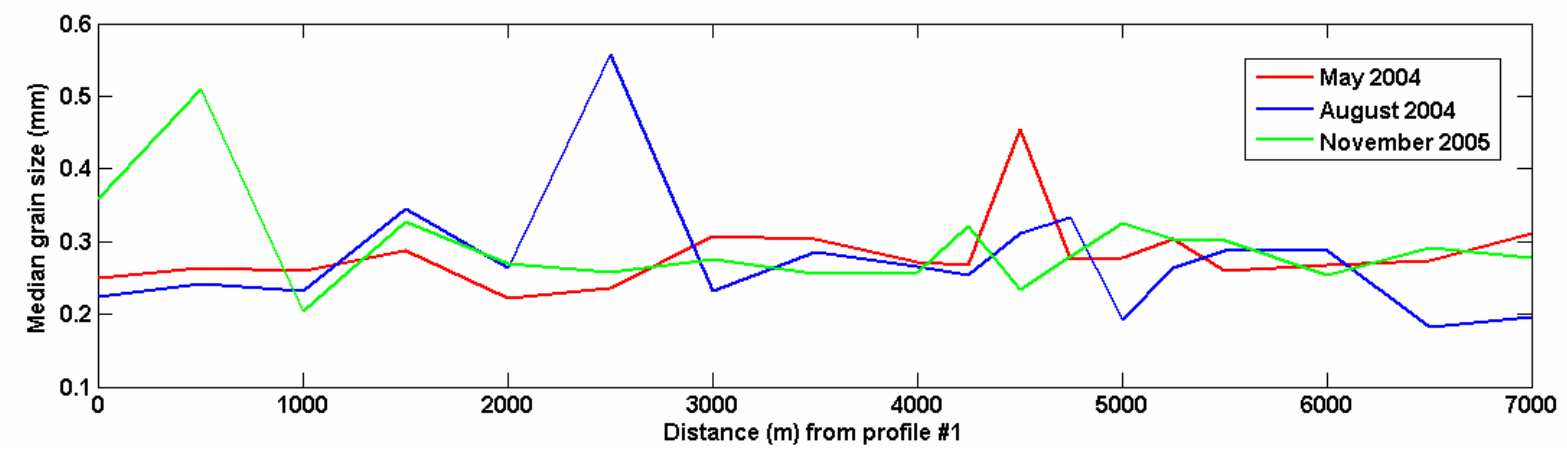

Figure 8.3. Median grain size of swash samples from 3 surveys along 0cean Beach. 


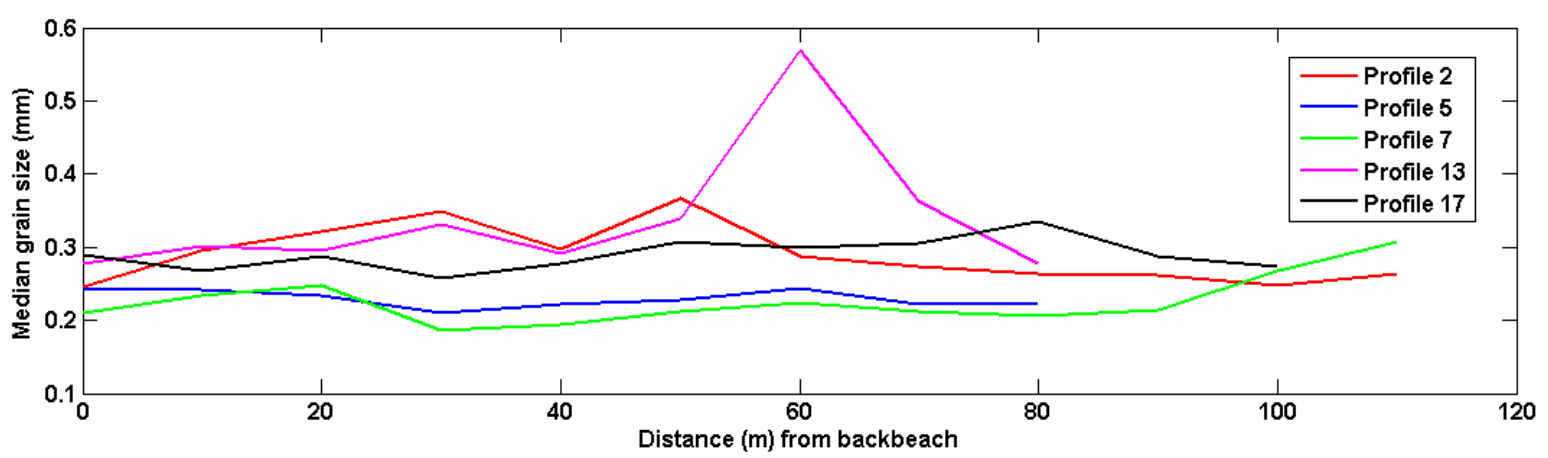

Figure 8.4. Median grain size along five profiles from the May 2004 survey.

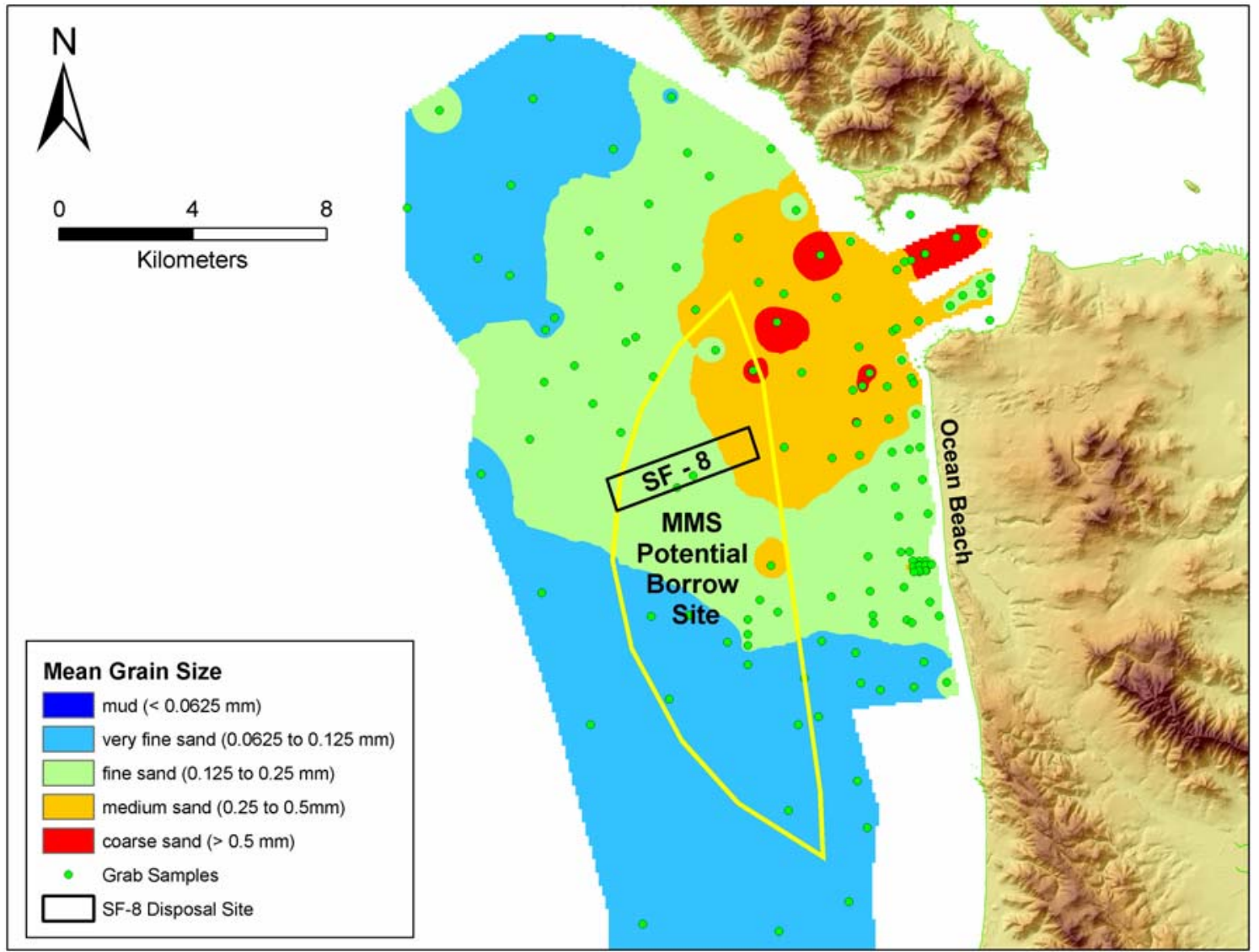

Figure 8.5. Grid of grain size class at the mouth of San Francisco Bay, using the both OBL and USGS samples. 


\section{Chapter 9-0ther Field Data Collection}

This includes data collected that is somewhat peripheral to the Ocean Beach Coastal

Processes Study, but can provide useful information to understanding the coastal system.

\section{High-resolution Subbottom Profiles of Active Faults and Sediment on the Golden Gate Platform}

By Holly Ryan

The USGS collected high-resolution seismic reflection profiles for 10 days in September 2006 in support of tectonic and coastal erosion studies in the area near the epicenter of the Great San Francisco Earthquake of 1906. Data were collected from Fort Funston, south of the Golden Gate, to as far north as Bolinas to image several faults considered capable of producing damaging earthquakes, including the San Gregorio and San Andreas Faults. Another part of the mission was to determine the subsurface structure of gigantic sand waves located immediately west of the Golden Gate and to provide shelfsediment information for the USGS coastal-erosion study off Ocean Beach. This effort included collecting data to calculate the volume of sediment in the ebb-tide delta seaward of the Golden Gate and in Holocene deposits on the continental shelf.

The 54-foot boat Lakota was used as the research vessel with Captain Tim Fleming at the helm. Over $400 \mathrm{~km}$ of high-resolution seismic profiles were collected (Figure 9.1). For studies of fault geometry and Holocene sediment, a 50-tip mini-sparker was used as the sound source and a short, single-channel hydrophone streamer as receiver. The minisparker is towed just beneath the water 5 to $10 \mathrm{~m}$ behind the vessel, where, at regular intervals, it produces an electric spark that vaporizes a small volume of water. Rapid expansion of the vapor bubble generates a sharp pulse of sound that radiates outward through the water. To image the sand waves, an Edgetech 512i subbottom-profiling system composed of a highfrequency Chirp source was used, towed three to five meters below the sea surface and a small hydrophone array. Chirp frequencies were typically swept over the range of 500 to $7200 \mathrm{~Hz}$ during a $30 \mathrm{~ms}$ period. The mini-sparker system provided deeper imaging penetration below the sea floor but less resolution than the CHIRP system. Data for both systems were digitally recorded for post-cruise processing and interpretation. Several profiles were collected with both systems for data comparison.

Results of the seismic-reflection surveys were mixed. In some areas, gas from natural seeps scattered the sound energy, making it difficult to map the subsurface. Evidence of gas in the seismic-reflection data included bright spots caused by pockets of trapped gas, and data "washouts" caused by gas dispersed through the sediment. In addition, over parts of the ebb-tide delta, where thick, sandy deposits are present, sub-bottom penetration was minimal. In many areas, however, especially away from the ebb-tide delta, the data were excellent with subbottom penetration ranging from $75 \mathrm{~ms}$ (about $60 \mathrm{~m}$; Figure 9.2) to as much as 120 ms (about $100 \mathrm{~m}$; Figure 9.3). These data allowed a more accurate mapping of the San Andreas and San Gregorio fault zones, which are the main faults that deform the Golden Gate platform (e.g. Figure 9.2 and 9.3).

Many of the subbottom mini-sparker profiles show an acoustically transparent unit above a layered unit. This transparent unit is interpreted to be comprised primarily of ebbtide delta deposits, but also may include recent sediment deposited in a fault-bounded graben 
(shown in Figure 9.2). To calculate the thickness of the transparent unit, we subtracted the depth to the water bottom from the depth to the top of the layered reflectors in two-way travel time (TWTT), and converted from TWTT to meters by using a velocity of $1.6 \mathrm{~km} / \mathrm{s}$. A velocity of $1.6 \mathrm{~km} / \mathrm{s}$ is probably reasonable if the deposits are composed of coarser, sandier sediment. If finer grained, the thicknesses may be overestimated. These thicknesses were gridded onto a $20 \mathrm{~m}$ grid to create an isopach map (Figure 9.4). The maximum thickness of the transparent unit was $16 \mathrm{~m}$, with the greatest thicknesses occurring between the San Andreas and San Gregorio faults (Figure 9.4). A total volume of just over $1 \mathrm{~km}^{3}$ of acoustically transparent sediment was calculated. 


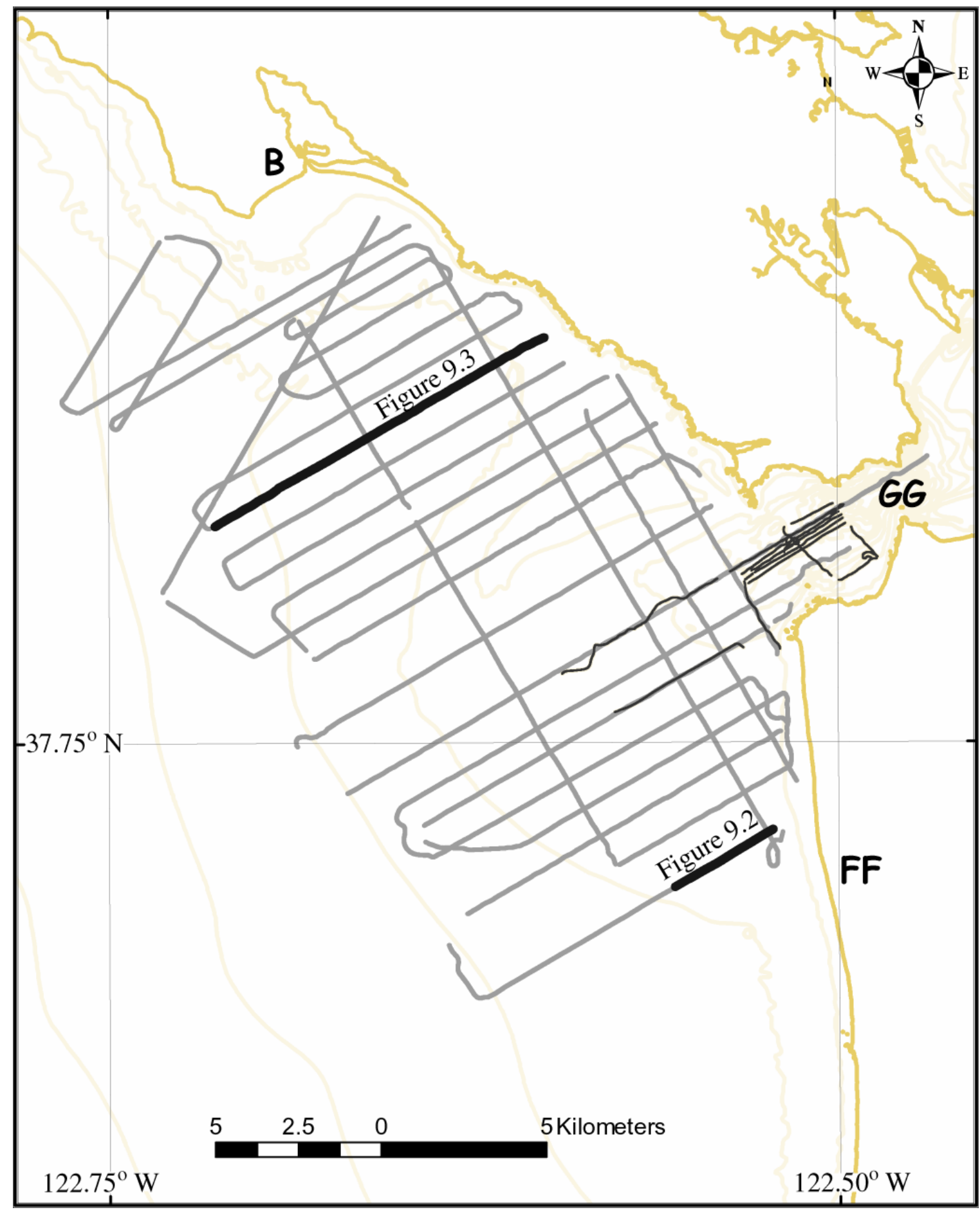

Figure 9.1. Trackline map of subbottom data collected on the Lakota in late September 2006 (for more cruise information: http://walrus.wr.usgs.gov/infobank///106sf/html//-1-06sf.meta.html). Thin black lines correspond to CHIRP profiles; wider gray lines to mini-sparker profiles. Locations of Figures 9.2 and 9.3 are shown by bold black line. B- Bolinas, GG Golden Gate, FF - Fort Funston. 


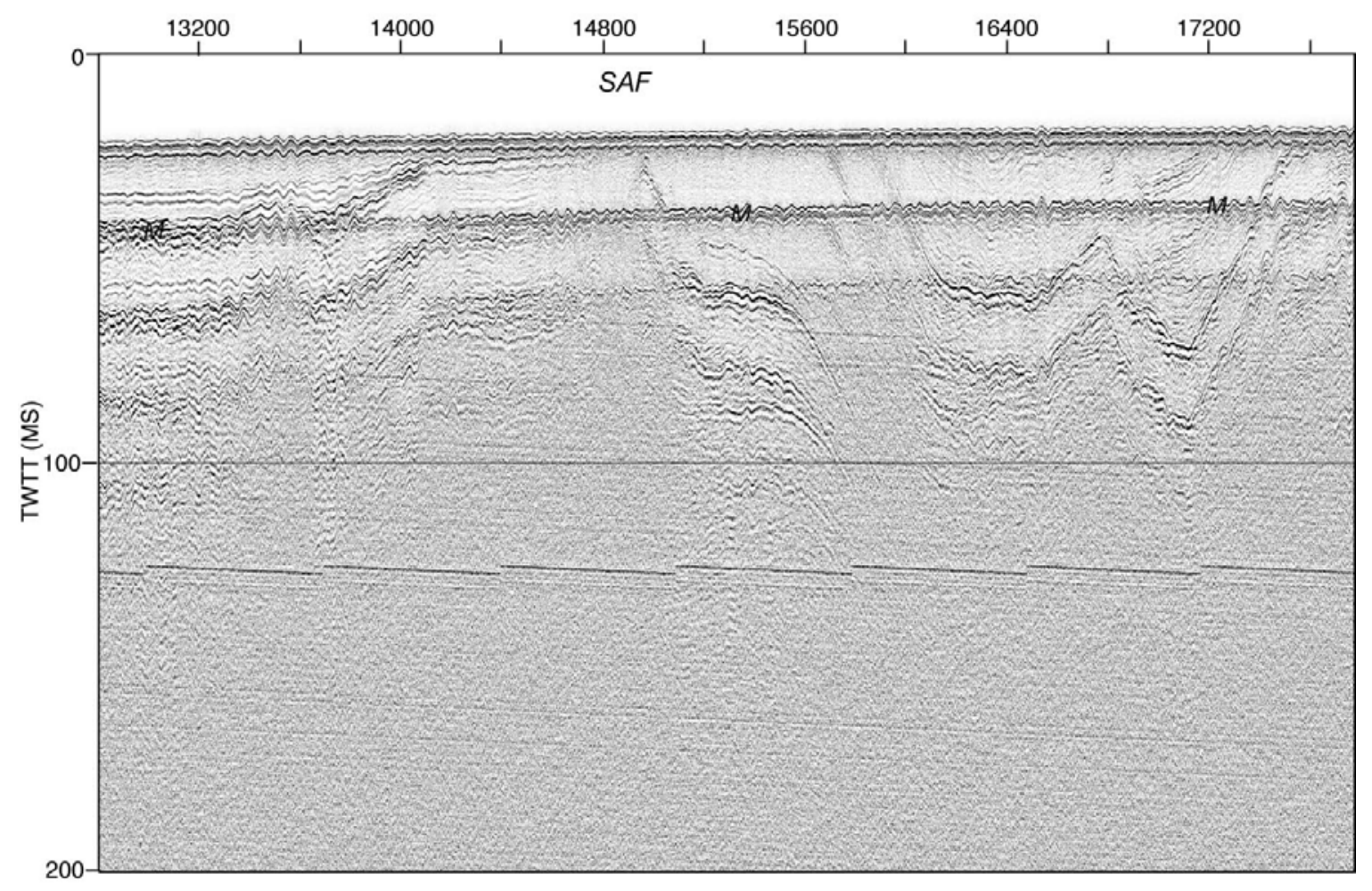

MINI SPARKER PROFILE GG-30

Figure 9.2. Mini-sparker profile GG-30 collected offshore of Fort Funston showing folded and disrupted reflectors associated with the San Andreas Fault (SAF). M - water bottom multiple; TWTT- two-way travel time.

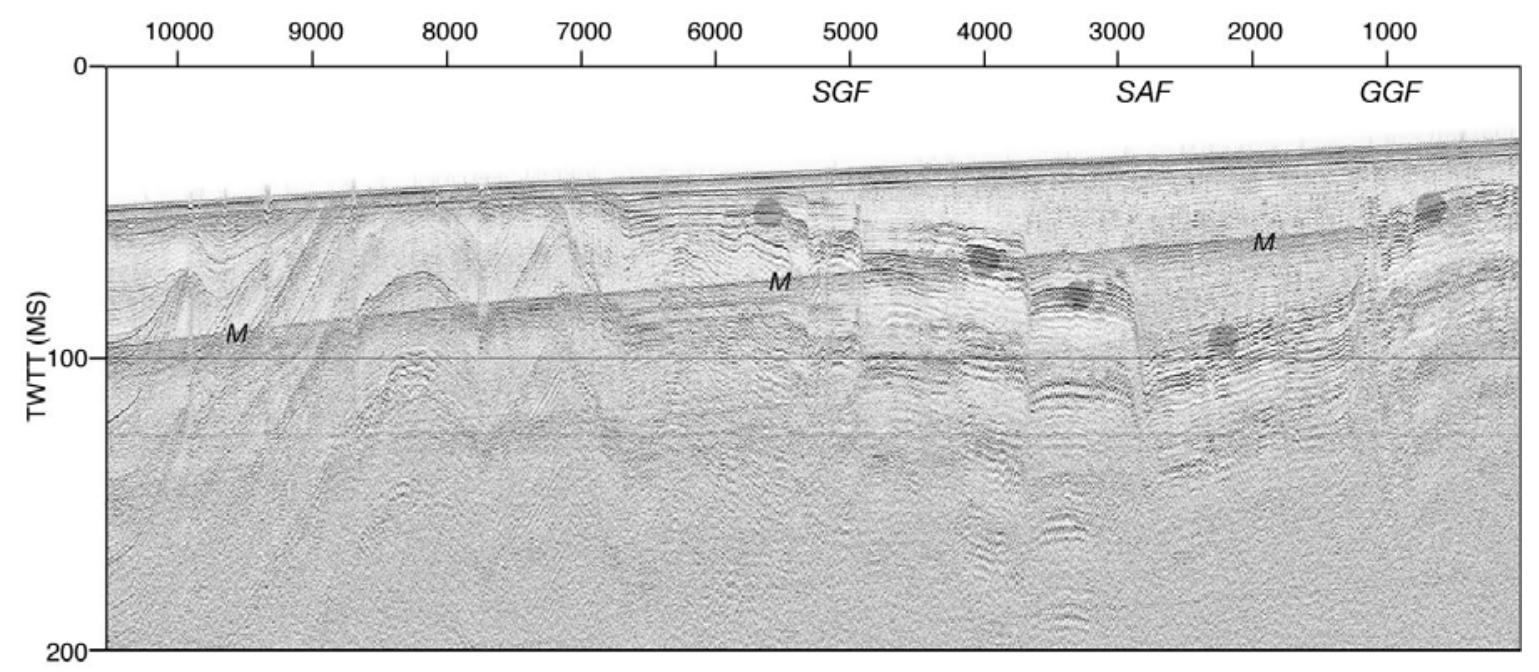

MINI SPARKER PROFILE GG-09b

Figure 9.3. Mini-sparker profile GG-9b collected across a fault-bounded graben located southwest of Bolinas. The dots show the base of the graben, which contains over $50 \mathrm{~m}$ of sediment. M - water bottom multiple; TWTT- two-way travel time; SGF - San Gregorio Fault; SAF - San Andreas Fault; GGF - Golden Gate Fault. 


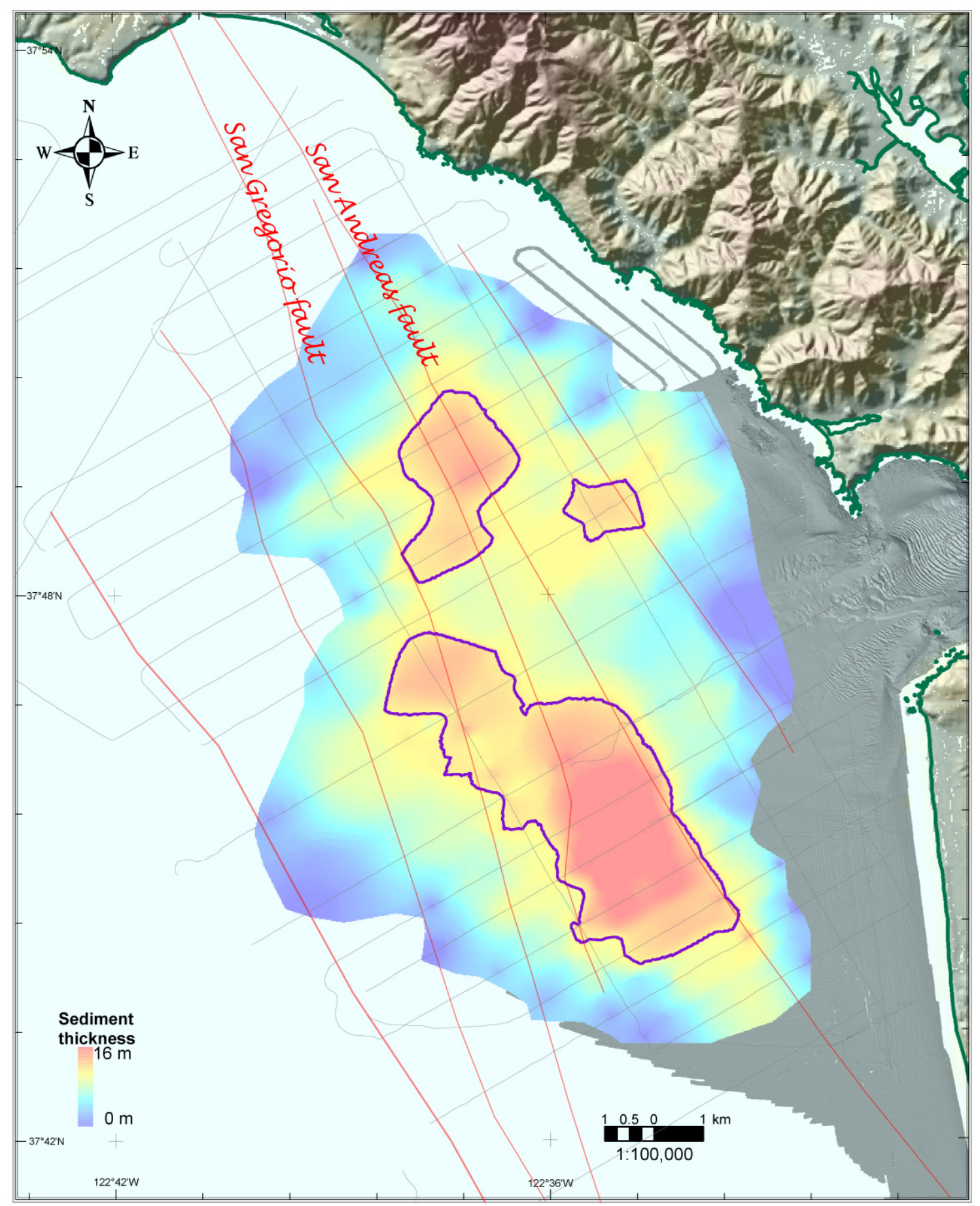

Figure 9.4. Map of the Golden Gate platform that shows thicknesses of acoustically transparent sediment of inferred Holocene age. These sediments are interpreted to be primarily composed of ebb-tidal delta deposits. The contour lines delineate sediment thicknesses that are greater than $10 \mathrm{~m}$. The red lines show offshore fault traces. The gray lines show the locations of profiles used to map the acoustically transparent unit. 


\title{
Chapter 10-Numerical Modeling
}

\author{
By Li Erikson and Patrick L. Barnard
}

\section{Introduction}

An understanding and capability to predict the hydro-and morphodynamics at Ocean Beach is essential to the management and protection of infrastructure and human health and safety along this high-use beach on the west side of San Francisco. These issues are particularly evidenced by chronic erosion encroaching on the wastewater treatment plant at the south end of Ocean Beach, while human health and safety are frequently threatened by shifting sands and strong currents (in the form of along-shore currents and rip-tides). The physical processes at Ocean Beach are a function of several inter-related mechanisms such as offshore wave and wind climate, tidal processes, delta discharge, and sediment management practices (e.g. channel dredging and sand mining). Due to the inter-related nature of these processes, it is essential to include the San Francisco Bight and offshore areas within the model domain in order to understand and predict the hydro- and morphodynamics at Ocean Beach.

In order to analyze a coastal region with high spatial and temporal gradients in wave, wind and tidal energy, it was desirable to employ a process-based numerical model. This allowed the expansion of localized physical process measurements to an enormous study area, analyze gradients in tidal currents and wave focusing patterns, and assess the impact of variable physical forcing conditions (e.g. storms, high discharge events, varying swell direction, high winds, etc.). With a cooperative agreement in place between the USGS and Delft Hydraulics, it was a logical step to set up a process-based numerical model using Delft3D (Delft3D, 2006) to analyze coastal processes in the San Francisco Bight and, once validated, use the model as a predictive tool for coastal change.

Delft3D is capable of providing wave, current and sediment transport estimates on varying spatial- and time-scales. The Delft3D software package consists of a number of modules including those to simulate wave transformation, current flows, and sediment transport. The modules may be coupled according to the needs of the modeling project.

The overall goal of implementing Delft3D is to provide a means to understand and predict hydrodynamics and morphodynamic evolution along Ocean Beach. Specific goals were to

1) assess the return flow of currents at the north end of Ocean Beach,

2) determine the cause of chronic erosion at the south end of Ocean Beach near Sloat Blvd., and

3) provide coastal managers with scientific data necessary to make informed sediment management decisions for mitigating chronic erosion.

\section{Methods}

In this section, a brief description of model calibration, validation, and implementation are presented. For further details on model specifics, the reader is referred to the USGS Open File Report (OFR) entitled 'Toward a validated 2-D hydrodynamic model for the mouth of San Francisco Bay', currently under preparation (Barnard, et al, 2008). 


\section{Model Overview}

The Delft3D model consists of a set of modules which together constitute a system capable of modeling various coastal and estuarine processes including wave propagation, currents, sediment transport, and morphological evolution (Roelvink and van Banning, 1994). The Delft3D model is applied to Ocean Beach and its surrounding region for the purpose of assessing both the hydrodynamics and, in the future, the morphodynamics of the region. However, only a brief description of simulated hydrodynamics is presented herein with a more detailed description in Barnard et al. (2008).

Delft3D can be run in 2 or 3 dimensions, the latter being much more computationally expensive. A 2D mode is often deemed sufficient for situations where a well-mixed water column with little density stratification can be assumed. Ocean Beach is well removed from areas inside the bay where shear and density stratification might be commonplace, and although there may still be some density stratification along Ocean Beach particularly during winter and spring months during high freshwater inputs, up to this point the model has been run in $2 \mathrm{D}$ mode. In addition to ignoring density stratification, running the model in $2 \mathrm{D}$ eliminates undertow as a physical process in the surf zone and therefore, modeling phenomena such as surf zone bar migration cannot be conducted with the model in its present state. Following this present study on hydrodynamics and shoreline impacts, the model will be implemented in 3D mode to better predict surf zone and shoreline evolution.

Hydrodynamics at Ocean Beach have been simulated employing the WAVE and FLOW modules of Delft3D. The WAVE module is a numerical scheme for estimating the propagation of wave parameters from input wind, bathymetry, and offshore wave conditions. The WAVE module is a direct implementation of the SWAN model that accounts for refraction, propagation, wind-induced wave growth, wave-wave interaction, bottom dissipation, depth induced wave breaking, and current dissipation. Wave blocking by currents is also explicitly accounted for in the model. Although the WAVE module can handle either bulk wave parameters or spectral wave conditions as boundary inputs, Delft3D is not yet capable of outputting spectral wave parameters at various times. As a result, all simulations thus far have been run with bulk parameter wave inputs even though the wave conditions are strongly bimodal during the summer (see Chapter 5). The FLOW module is the hydrodynamic routine that accounts for tidal and meteorological forcing.

\section{Grid and Boundary Conditions}

Two separate computational curvilinear grids were generated and employed for the WAVE and FLOW modules (Figure 10.1). The WAVE grid is shown in blue and the FLOW grid is shown in red in Fig. 10.1a. The open boundaries of the curvilinear WAVE grid extend beyond the open boundaries of the FLOW grid by approximately $20 \mathrm{~km}$ at the northern boundary, ten kilometers at the southern boundary, and $70 \mathrm{~km}$ offshore. The wave grid extends beyond the lateral boundaries of the FLOW grid to allow for instabilities in the wave field, due to uniform forcing along all open boundaries, to dissipate prior to entering into the domain of the flow field. If the instabilities were to propagate into the flow domain, unrealistic flows would be forced and would potentially alter the predicted hydrodynamics in areas of interest. The eastern edge of the WAVE grid terminates inside San Francisco Bay just east of the Golden Gate, and therefore does not simulate local wind-generated waves within San Francisco Bay. The primary purpose of the wave model is to propagate swell waves from deep water over the continental shelf and into the study area. 
The application of a curvilinear grid with variable spacing allows for cells aligned with the major direction of wave propagation (to avoid energy losses) and shorter computation time, as only the area of interest along Ocean Beach has a finer meshed grid. Further refinement of the grid is a goal for future morphological simulations. The grid sizes are on the order of $300 \mathrm{~m}$ in each direction at the offshore cells and $20 \mathrm{~m}$ in both directions along Ocean Beach. In all, the WAVE and FLOW grids each consist of 32,000 and $\sim 19,000$ grid cells, respectively.

The model consists of three primary boundaries (Figure $10.1 \mathrm{~b}$ ):

1. Closed- no flow across boundary (i.e. land-sea interface)

2. Discharge- two point sources for time-varying San Joaquin-Sacramento River delta discharge

3. Open- primary driving force of model, populated with time varying physical forcing (i.e. waves and tidal harmonics) along open Pacific Ocean

While considered negligible in terms of large-scale hydrodynamics, time-varying discharge rates from the San Joaquin and Sacramento Rivers into the Bay (Figure 10.1 b) were included in the model. The freshwater discharge to the bay is largely modulated by dams and agricultural use, and thus during even the largest winter storms, freshwater discharge to the bay only accounts for $\sim 3 \%$ of tidal flow. This may however, result in stronger density stratification during winter months, with higher freshwater flows in the upper portion of the water column.

Measured wave conditions at offshore buoys were used to force the model at the open boundaries. The measured wave conditions were collected primarily by the CDIP Pt. Reyes buoy (SCRIPPS Institution of Oceanography, 2006) and secondarily by the NDBC Monterey buoy (National Oceanic and Atmospheric Association, 2006a). The CDIP Pt Reyes buoy, 029 , is located at $37.946^{\circ} \mathrm{N}$ and $123.470^{\circ} \mathrm{W}$ in $550 \mathrm{~m}$ of water depth, about $20 \mathrm{~km}$ offshore. Bulk wave statistics were used to force the wave model. These statistics included significant wave height $\left(H_{\mathrm{s}}\right)$, peak period $\left(T_{\mathrm{p}}\right)$, and mean wave direction $\left(\operatorname{Dir}_{\mathrm{p}}\right)$. The conditions observed at these buoys were applied to all open boundaries, including lateral boundaries, of the model. Our assumption is that because these buoys are located off of the edge of the shelf, deep-water swell observed at these buoys does not vary significantly across the boundaries of the model domain. Because the model was forced with parameterized wave conditions, the potential effects of bimodal wave spectra were not captured. Bimodal wave spectra with one swell and one sea peak are common during the summer months. Two swell peaks, on the other hand, are not common at Ocean Beach, but can occur during the summer months when moderate, bimodal long period swell originating from the southern and northern parts of the Pacific Ocean move into the region.

Bulk atmospheric parameters, collected by the NDBC San Francisco buoy, were used to force the wave and flow models (National Oceanic and Atmospheric Association, 2006a). The San Francisco buoy (Station 46026) is located at $37.759^{\circ} \mathrm{N}$ and $122.833^{\circ} \mathrm{W}$ in approximately $52 \mathrm{~m}$ of water. The anemometer is located five meters above sea level and the barometer elevation is at sea level. The parameters utilized in this study were wind speed, wind direction, and atmospheric pressure, which were all applied uniformly over the domain. 


\section{Time Step}

Since the choice of a model time-step is related to the grid size and flow dynamics, an analysis of simulated currents along Ocean Beach with varying time-steps applied to the given grid was completed. Based on several model runs, a model time-step of 0.5 minutes (30 seconds) was deemed to yield an acceptable numerical error ( $<5 \%$ in phase and magnitude compared to a six second time step; Courant numbers $<10)$.

\section{Bathymetry}

Bathymetry used in the model originates from various sources. In the nearshore region off of Ocean Beach, ATV, multibeam, and PWC surveys were conducted as part of this study. This data was gridded and combined to create a single grid with $25 \mathrm{~m}$ horizontal spacing. Multibeam data obtained by the USGS in 1997, and 1991 NOAA soundings were used to complete the bathymetry of the remaining grid. Depth samples were added to the model domain using simple grid cell averaging and interpolation with the RFGrid tool included in the Delft3D package. Where necessary, a built in smoothing algorithm was applied to reduce inconsistencies between adjacent data sets. The final gridded bathymetry is shown in Figure 10.2 and referenced to NAVD88 in meters.

\section{Calibrations and Parameter Settings}

Tide Constituent Calibrations

Calibration of primary tidal constituents was done via harmonic analysis (T-tide, Pawlocicz and others, 2002) and several model iterations, employing only the FLOW module, until the amplitude ratios and phase differences were less than $0.5 \%$ between predicted and observed water levels. Simulated water levels were compared to measurements obtained at the San Francisco (Ft. Point) Co-Ops water level station (National Oceanic and Atmospheric Association, 2006b), located west of the Golden Gate Bridge for a 64 day contiguous time-series (06/19/05 through 08/07/05). Resulting calibrated major constituents are listed in Table 10.1.

Table 10.1. Calibrated tidal constituent amplitudes and phases.

\begin{tabular}{c|cc|cc}
\hline & \multicolumn{2}{c}{ Northern boundary } & \multicolumn{2}{c}{ Southern boundary } \\
\hline Constituent & Amp $(\mathrm{m})$ & Phase $\left(^{\circ}\right)$ & Amp $(\mathrm{m})$ & Phase $\left(^{\circ}\right)$ \\
\hline M2 & 0.545 & 191.5 & 0.523 & 187.9 \\
K1 & 0.365 & 216.8 & 0.359 & 216.6 \\
O1 & 0.221 & 201.4 & 0.219 & 201.0 \\
S2 & 0.132 & 199.9 & 0.130 & 194.0 \\
P1 & 0.441 & 213.7 & 0.110 & 213.1 \\
N2 & 0.145 & 168.1 & 0.141 & 164.6 \\
\hline
\end{tabular}




\section{Constant Parameters}

Constants used throughout the simulations are listed in Table 10.2. With the exception of the eddy viscosity and bed roughness which were calibrated via numerous simulations, the parameters are default values or derived values based on field surveys. Calibrations of the eddy viscosity and bed roughness were done using the first 28 days (06/19/05 through 07/19/05, including spin-up time) of measurements obtained during the summer field study. The remaining measurement times were used to validate the model.

Table 10.2. FLOW and WAVE module constants employed.

\begin{tabular}{|l|l|l|}
\hline \multicolumn{2}{|l|}{ WAVE module } & \\
\hline & $\begin{array}{l}\text { Battjes and Janssen (1978) bore based } \\
\text { model for depth induced breaking } \alpha / \gamma\end{array}$ & $1 / 0.73$ \\
\hline $\begin{array}{l}\text { Spectral peak enhancement factor } \\
\text { (Jonswap) }\end{array}$ & 3.3 \\
\hline & min/max/number bins in freq. space & $0.05 / 1.0 / 36$ \\
\hline $\begin{array}{l}\text { Non-linear triad wave-wave interactions } \\
\alpha / \beta\end{array}$ & $0.1 / 2.2$ \\
\hline & Bottom friction (Jonswap) & 0.067 \\
\hline & Water density & 1025 \\
\hline & Temperature & $15^{\circ} \mathrm{C}$ \\
\hline FLOW module & $1025 / 1$ \\
\hline & Water/air density (kg/m ${ }^{3}$ ) & 31 \\
\hline & Salinity & 10 \\
\hline & Horizontal eddy viscosity (m $\left.{ }^{2} / \mathrm{s}\right)$ & 0.1 \\
\hline & Threshold depth (m) & Fredsoe, \\
\hline & $\begin{array}{l}\text { bottom stress formulation due to wave } \\
\text { forces }\end{array}$ & 1984 \\
\hline & bottom roughness (Chezy coeff) & 78 \\
\hline
\end{tabular}

\section{Comparison of Model Results with Field Data}

In this section, hydrodynamic model results are compared to field data measured at Sites 2 and 3 (see Chapter 5 for instrument and sampling descriptions). Site 1, also located along-shore of Ocean Beach, was used in the calibration but is not included in this comparison as it was buried 6 days into the validation measurement period. The latter part of the instrument sampling period (from 07/18/05 to 07/30/05) is used for validation while the first 30 days were used for calibration.

The comparisons presented herein include an overview of model performance and residuals between modeled and measured parameters. In an attempt towards a more systematic way of evaluating the model, a set of model performance statistics have been calculated (e.g., Sutherland and others, 2004) and are summarized in Barnard et al (2008).. Note that sampling frequencies and time-averaging periods are not identical between the model and measurement data sets. Whereas the model results represent stationary conditions at half minute time-steps, measured water levels and currents are time-averages over ten minutes and wave parameters are spectral representations of 70 minute sampling periods. For statistical analysis and comparison between the data sets, the model results were down-sampled to the instrument sampling frequencies. 


\section{Water Levels and Wave Parameters}

Predicted and measured water levels are compared in Figures $10.3 \mathrm{a}$ and $10.3 \mathrm{~b}$ for Site 2 and Site 3, respectively. The semi-diurnal tidal signal is clearly evident and varies between $+/-1.4 \mathrm{~m}$, as would be expected for this time period (maximum reported tide range for Ocean Beach is from $-0.6 \mathrm{~m}$ to $+2.2 \mathrm{~m}$ (mean $0.97 \mathrm{~m}$ ) from MLLW). The residuals (measured - predicted) are plotted as blue points, and, considering the fact that they represent errors of both phase and magnitude, are quite small (mean $-0.07 \mathrm{~m}$, maximum $0.09 \mathrm{~m}$, $\mathrm{R}^{2}=0.96$ ).

Significant wave heights are compared in Figure 10.4. Note that the residuals are plotted on the right-hand scale. Model predictions follow the general trend of measured wave heights but tend to slightly under-predict during low wave conditions $\left(H_{\mathrm{s}}<1 \mathrm{~m}\right)$ at Site 2 and for most of the time at Site 3. Residuals suggest a good fit at Site 2 during the storm event from 07/23/05 through 07/28/05, as evidenced by the random error about zero. Overall, the mean random error is about $-0.2 \mathrm{~m}$.

Model results are expected to improve with the use of spectral forcing. The forcing conditions employed in the model thus far have been with bulk parameters. It is clear from field measurements that offshore wave spectra are strongly bimodal, particularly during the summer (with two peaks on the order of $T=8 \mathrm{~s}$ (sea) and $T=15 \mathrm{~s}$ (swell)). At the present time, work is currently underway to enable Delft3D to provide time-dependent spectral outputs. When this capability is included, the model will be run with spectral forcing conditions that are expected to improve the results with respect to measurements.

\section{Longshore Currents}

Modeled longshore currents are compared to depth-averaged measurements at Sites 2 and 3 in Figures 10.5 a and 10.5 b, respectively. Longshore velocities are tidally dominated and strongly influenced by the proximity of the Golden Gate. Peak longshore velocities, only accounting for the larger of the two diurnal cycles, are equal and opposite of the flood (southward) and ebb (northward) tides and are predicted to be $\sim 0.7 \mathrm{~m} / \mathrm{s}$ at Site 2 . At Site 3 , southward directed along-shore currents are predicted to be slightly greater $(0.46 \mathrm{~m} / \mathrm{s})$ than northward directed currents $(0.38 \mathrm{~m} / \mathrm{s})$.

Overall, the model seemed to do well at simulating the longshore currents. Residuals are not plotted as there is a large amount of scatter due to slight phase differences $\left(R^{2}=0.55\right.$ and coherence $=0.97$ ). Model to measurement comparisons for the phase and magnitude are discussed separately in Barnard, et al. (2008) In short, the model does well with the exception of a few instances when it under-predicts longshore currents by about $5 \mathrm{~cm} / \mathrm{s}$ to 10 $\mathrm{cm} / \mathrm{s}$.

\section{Cross-shore Currents}

Modeled cross-shore currents are compared to depth-averaged measurements at Sites 2 and 3 in Figures $10.5 \mathrm{c}$ and $10.5 \mathrm{~d}$, respectively. Similar to the longshore currents, the cross-shore currents are also tidally dominated with peak velocities associated with the ebb tide of the higher tide and with the flood tide of the lower high tide (Fig. $10.5 \mathrm{c}$ and $10.5 \mathrm{~d}$ ). The relative magnitudes are also similar to the longshore currents in that stronger velocities were measured and modeled at Site 2 near the tidal inlet at the Golden Gate as compared to 
Site 3 further south. Peak onshore and offshore velocities were $0.18 \mathrm{~m} / \mathrm{s}$ and $0.14 \mathrm{~m} / \mathrm{s}$, respectively at Site 2 and about half as strong at Site 3 with $0.07 \mathrm{~m} / \mathrm{s}$ in both the on- and offshore directions.

\section{Results}

\section{Flow Patterns at the North End of Ocean Beach}

Modeled flow patterns at the north end of Ocean Beach are shown for a complete tide cycle (the full moon was on 07/21/05) in Figure 10.6. The top panel (Figure 10.6 a) shows the measured tide at Site 2, about halfway down the coast at Ocean Beach. Figures $10.6 \mathrm{~b}$ through $10.6 \mathrm{~m}$ show modeled flow patterns (arrows) and velocity currents (colored scale, $\mathrm{m} / \mathrm{s}$ ) at the times indicated in Figure 10.6 a. Close inspection of the Figures indicate that the flow directions are primarily oriented in the north-south direction and are tidally dominated. Currents are strongest prior to flow reversal at both ebb and flood tides (Figures 10.6d, 10.6g, 10.6h, and 10.6k). At ebb tide, before flow reversal, the currents are oriented southwest at the very north end of Ocean Beach and a shadow zone of lower flow velocities forms along the beach (shown with blue in Figures $10.6 \mathrm{~g}$ and $10.6 \mathrm{~h}$, velocities approximately $0.2 \mathrm{~m} / \mathrm{s}$ ). During flood tides, the currents flow northward, Pt. Lobos headland does not offer any protection, and higher flow velocities extend further shoreward (Figures 10.6d, 10.6j, and $10.6 \mathrm{k})$.

Immediately following the flow reversal after ebb tide (Figure 10.6i), the model predicts that eddies with flow velocities on the order of $0.4 \mathrm{~m} / \mathrm{s}$ will form. An eddy is apparent at about N4180.5 km and a smaller one near the shore at N4181.1 km. Based on analysis of model simulation slightly shorter than one month, the southern most point of eddies reach to about N 4.179E6 as shown in Figure 10.7a. In all cases, eddies only form during low tide. Approximate eddy center locations are plotted against the tidal stage in Figures $10.7 \mathrm{~b}$ and $10.7 \mathrm{c}$. Eddy locations only move slightly in the east-west direction with positive tide levels, while during negative tides (corresponding to the spring cycle), they migrate as much as $1 \mathrm{~km}$ in the east-west direction (Fig. 10.7b). With respect to the northsouth direction (Fig. 10.7c), central eddy locations are within a $1 \mathrm{~km}$ stretch with the furthest southern position with the lower tides.

A consequence of these eddies appears to be rip currents as seen with seaward oriented velocity vectors at about the same locations as observed in the time-averaged images (Chapter 4). Observed rip current locations from the time-averaged images are shown in white on the sub-plots corresponding to low tide in Figure 10.6. The formation of rip currents can also be seen in Figures $10.6 \mathrm{~b}$ and $10.6 \mathrm{~h}$, both of which are associated with low tide. Based on the present model results, rip currents appear to be at least partly related to tidal flows, and in particular near times of flow reversal associated with either low (Figures $10.6 \mathrm{~b}, \mathrm{~g}, \mathrm{~h}$ and i) or high tide (Figure 10.8).

\section{Variable Wave Impact Along the Beach}

Model simulated wave heights along Ocean Beach for four time periods, each with different forcing conditions during the model validation period are shown in Figure 10.9. Conditions measured at Pt. Reyes buoy and used to drive the model are shown for each case and were chosen based on the greatest frequency of occurrence during the summer validation period. The top panel shows the along shore section of Ocean Beach in plan view and with north pointing to the left. The thick red line indicates the erosion hot-spot just south of Sloat 
Blvd. The four panels beneath depict model predicted significant wave height magnitude and direction for four cases with offshore wave heights ranging from $4 \mathrm{~m}$ to $2.3 \mathrm{~m}$. The significant wave heights shown are those output by the model immediately seaward of the predicted breaking line as depicted with the $\otimes$ symbol in Figure 10.10.

Predicted wave heights vary along the shore (Figure 10.10) with a consistent pattern such that greater heights are observed near the hot-spot erosion area than at the far south end of Ocean Beach. The angle of incidence is consistently shore-normal near the hot-spot area, while it deviates southward to a maximum of about 20 degrees from shore-normal at the south end of the beach. Due to the similar offshore wave directions $\left(323^{\circ}\right.$ to $\left.334^{\circ}\right)$, there is little change in approach angle at a given site near the shore; variations in wave height near the shore, as a function of varying offshore wave angles, are further assessed in the next section for a set of hypothetical situations.

Figure 10.10 shows predicted significant wave heights along Ocean Beach and immediate offshore region for the same time steps as in Figure 10.9. The Figure suggests that the focus of increased wave heights near the hot-spot are related to the southern lobe of the ebb tidal shoal. Waves at the north end of the beach, north of the shoal and erosion hotspot, appear to have undergone more refraction as they propagated across the northern ebb tidal shoal, losing energy and decreasing wave height. The lower wave heights immediately to the south of the shoal might be the effect of a shadow zone present during northwest incident waves.

Along-shore variation of longshore sediment transport (Figure 10.11) was estimated with the 'CERC formula' (ERDC, 1984) for the same four time periods as in Figure 10.10. The formula is a function of breaking wave height and angle of incidence and an empirical coefficient related to the grain size (Komar, 1988). It does not account for tidal currents, which are known to be strong in this area, and as such, the estimates should be considered as very crude. Because the incident wave angle of the selected validation time-series is from the northwest with little variation, all the longshore transport is predicted to go south (as was also shown with ADCP measurements in Chapter 5). The estimates suggest high rates of longshore transport from the very north end (approximately $350 \mathrm{~m}^{3} / \mathrm{m} /$ day with offshore $H_{\mathrm{s}}=4 \mathrm{~m}$ ) of the beach past the south end of the erosion hot-spot (approximately 200 $\mathrm{m}^{3} / \mathrm{m} /$ day). A greater rate is predicted just south of the hot-spot than at the hot-spot itself. This is because the Delft model predicted shore-normal incident waves at the hot-spot while the incidence angle is slightly skewed north just south of the hot-spot. Under these types of conditions, it would be expected that erosion at the hot-spot would be due to both variations in longshore sediment transport and direct wave impact from shore-normal incident waves.

\section{Influence of Offshore Wave Direction}

The offshore direction of wave approach has a very large impact on resulting wave heights at Ocean Beach. To help illustrate this, several SWAN runs were completed using the same grid that was coupled with the previous Delft3D simulations, but running SWAN in a stand-alone, stationary, mode. These runs are simplified, and include parameterized wave forcing but do not include wind, tidal currents, or wave-wave interaction. Figure 10.12 includes maps of significant wave heights output from SWAN for wave forcing with varied peak period and peak direction input. Figure $10.13 \mathrm{a}$, and $\mathrm{c}$ represent waves coming from a direction of $330^{\circ}$, which is characteristic of a large majority of waves seen in this region, especially in summer months. There is a drastic difference of almost $2 \mathrm{~m}$ in wave height at Ocean Beach when the same conditions come from a more westerly direction of $280^{\circ}$ (Figure 
$10.13 \mathrm{~b}, \mathrm{~d}$ ), which is more common in winter months (Figure 5.11). This suggests that longperiod, large waves coming directly onshore at Ocean Beach will likely have the largest erosional capability, as waves coming from the northwest tend to dissipate over the ebb tidal delta. Figure $10.13 \mathrm{~b}$, and $\mathrm{d}$ show that waves coming from $280^{\circ}$ are oriented shore-normal along the southern half of Ocean Beach, and coming slightly from the south in northern sections near the erosion hot spot. The waves coming from $330^{\circ}$ still have a northward component in wave direction close to shore along some sections along northern Ocean Beach.

\section{Dredge Disposal Modeling}

Model runs were done to assess the potential of indirectly providing material for beach nourishment by placing dredged material immediately offshore of the erosion hot-spot. In June, 2005, 225,000 $\mathrm{m}^{3}$ of sand were dredged from the Main Shipping Channel at the mouth of San Francisco Bay and placed in depths ranging from 9-14 m approximately $500 \mathrm{~m}$ offshore from the hot-spot. The aim of applying the Delft3D model package was to assess the potential for the strong tidal currents and onshore directed asymmetric wave orbital velocities to potentially feed sediment into the littoral zone, thus providing a buffer to the erosion.

A plot of residual sediment transport based on the tidal forcing alone indicates only minimal transport from the disposal site (Figure 10.14 a), with net transport predominately north-south. However, once waves were incorporated in the model, the residual transport increased substantially in shallower depths (Figure $10.14 \mathrm{~b}$ ), where wave-induced bottom currents due to wave shoaling produced net-onshore directed transport.

\section{Conclusions}

- Comparisons between measurements and model results show that the calibrated Delft3D model is capable of predicting hydrodynamics at Ocean Beach for summer conditions.

- Model simulations predict that currents along Ocean Beach are strongest prior to flow reversal at both flood and ebb tides, and are strongly influenced by the Golden Gate entrance.

- Along- and cross-shore currents are strongly modulated by the tide. The influence of the tidal inlet at the Golden Gate decreases significantly with distance such that the currents are about $30 \%$ stronger at the north end compared to the southern end of Ocean Beach.

- The Pt. Lobos headland provides a shadow zone to the south so that nearshore tidal flows are weaker at ebb tide compared to areas further offshore.

- Model results suggest that rip currents are related to tidal flows and occur near times of flow reversal (high and low tide).

- Model results suggest that the longshore sediment transport is to the south during typical summer conditions and that the section stretching from the north part of Ocean Beach to immediately south of the erosion hot-spot undergoes strong longshore transport rates under high wave conditions $\left(\mathrm{H}_{\mathrm{s}}>2.5 \mathrm{~m}\right)$. Model results also suggest that the erosion hot-spot is directly impacted from shore-normal incident 
waves during storm conditions. Furthermore, the erosion hot-spot appears to be a result of wave focusing caused by the shape of the southern ebb tidal delta.

- Long-period, shore-normal incident large waves at Ocean Beach will likely have the largest erosional capacity, as waves coming from the northwest tend to be dissipated by the northern lobe of the ebb tidal delta. Preliminary modeling suggests that offshore waves originating from the west undergo less energy loss compared to offshore waves originating from the northwest, whose wave height reduces by about $50 \%$ as a result of refraction over the northern lobe of the ebb tidal delta.

- Numerical modeling suggests that despite the strong tidal currents in the region, wave forcing is the dominant factor moving the sediment slowly toward shore, and placing sediment at a depth of about $8 \mathrm{~m}$ will provide indirect beach nourishment. 

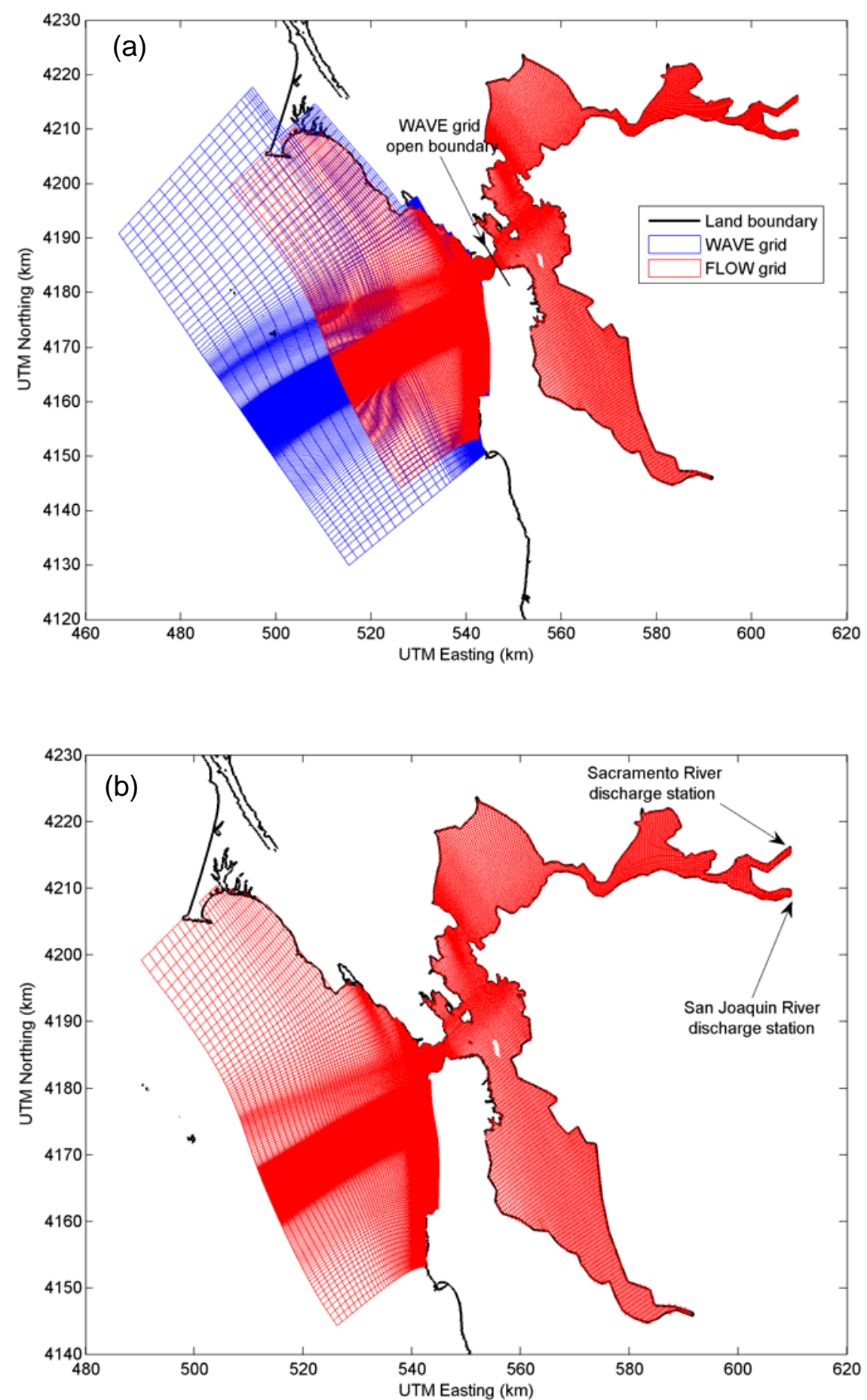

Figure 10.1. Curvilinear grids used for the FLOW and WAVE modules (a) and FLOW grid with boundaries (b). 


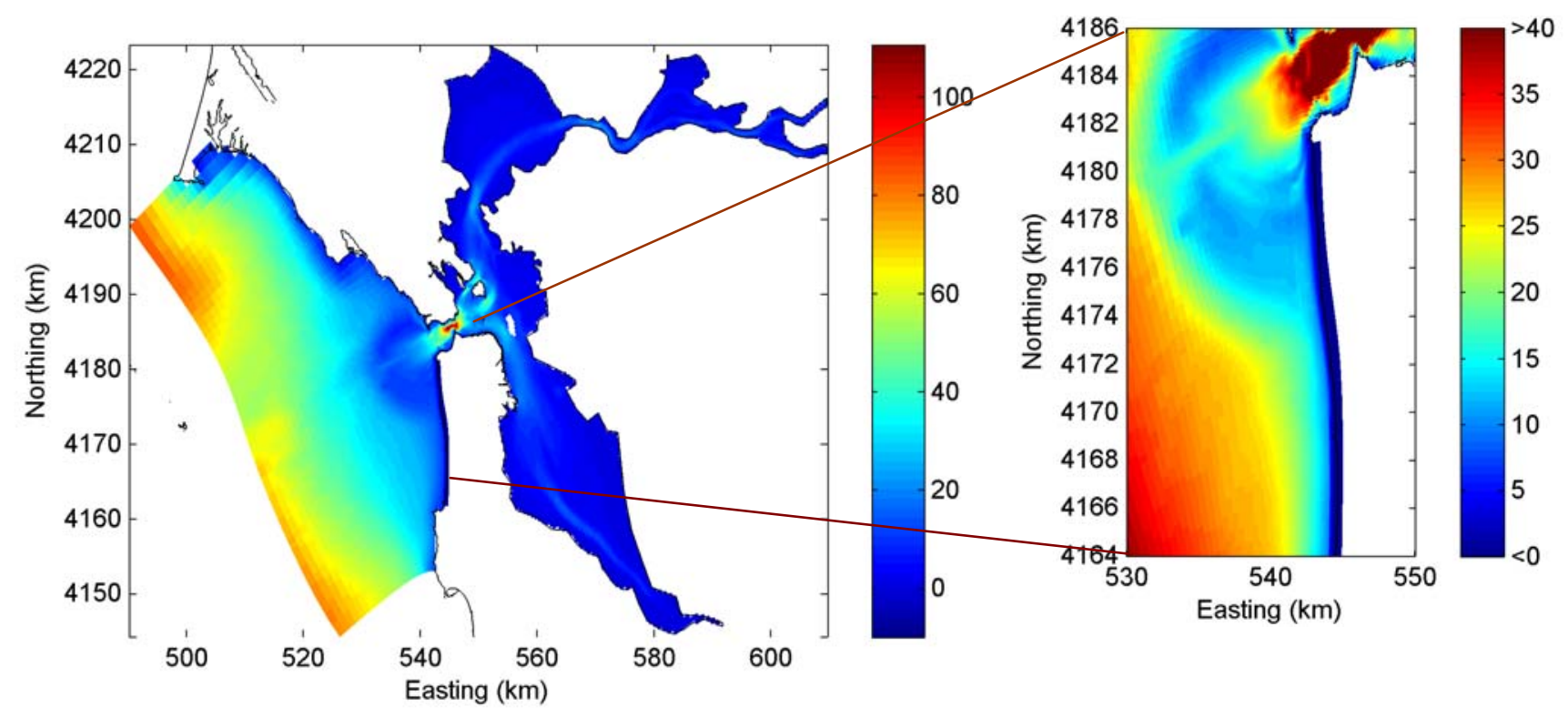

Figure 10.2. Final gridded bathymetry (positive depth in meters relative to mean sea level). 
Site 2

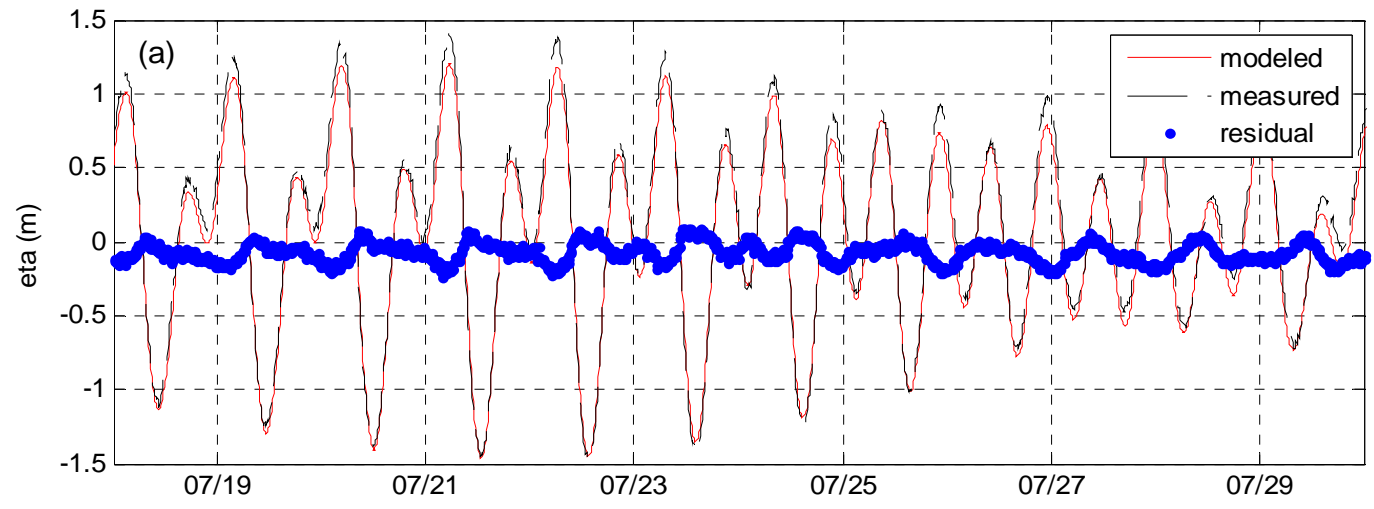

Site 3

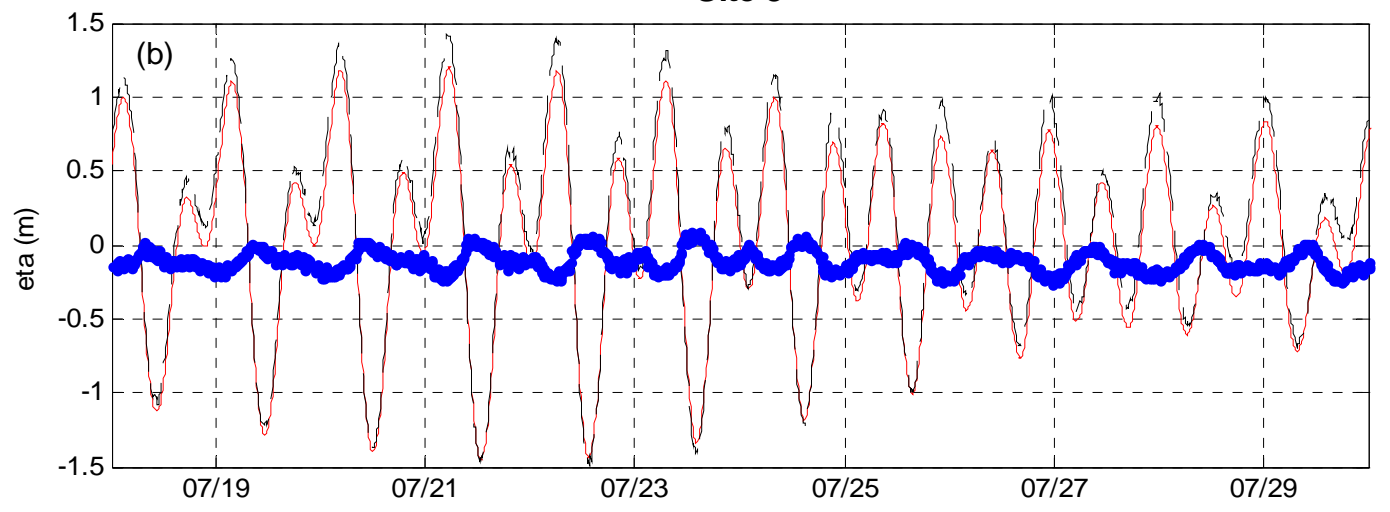

Figure 10.3. Measured and modeled water levels: (a) Site 2; (b) Site 3. Blue circles are residuals (measured - modeled). 

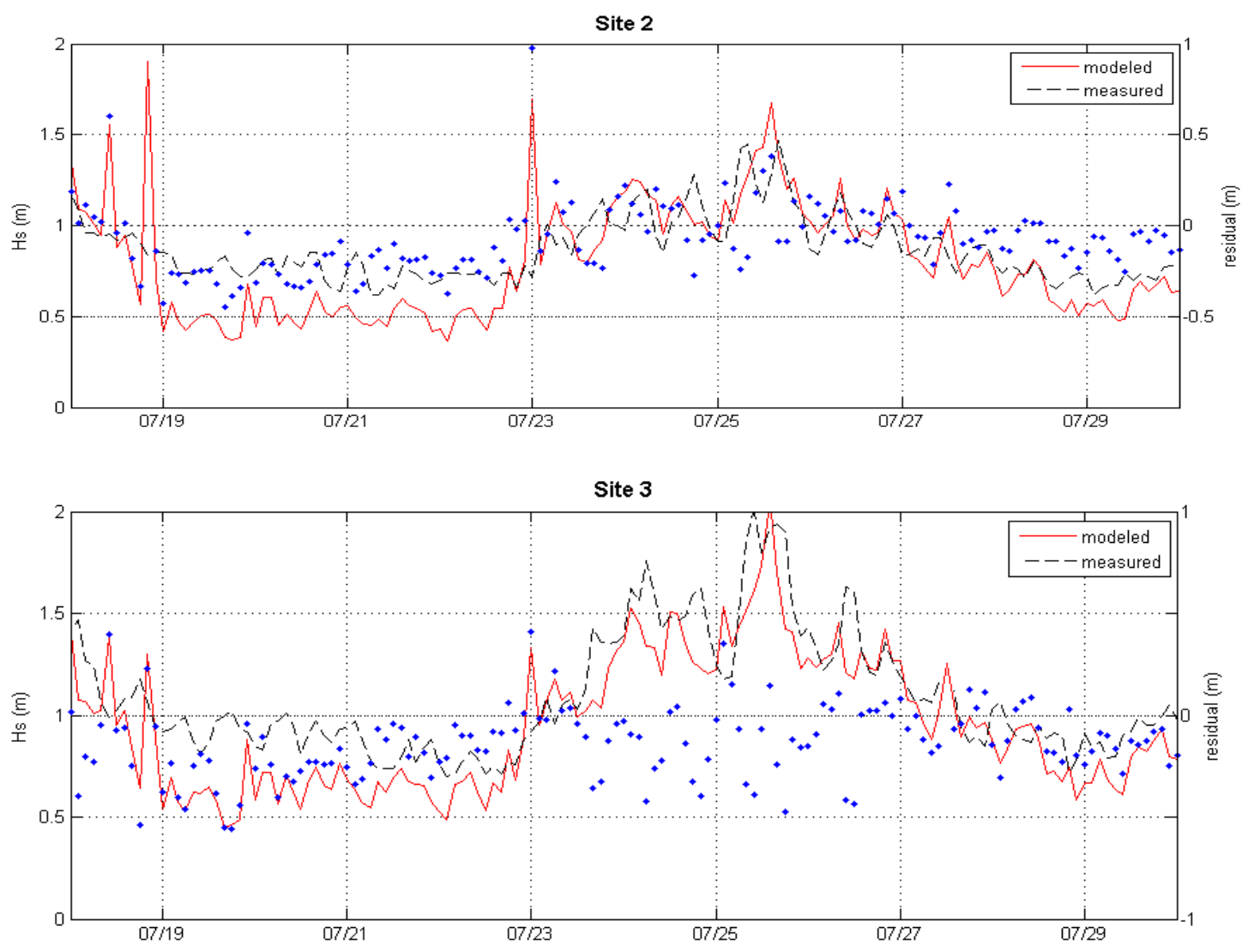

Figure 10.4. Comparison of measured and modeled significant wave heights $\left(H_{s}\right)$. Note the residual (blue diamonds) $y$-axis on the right. 

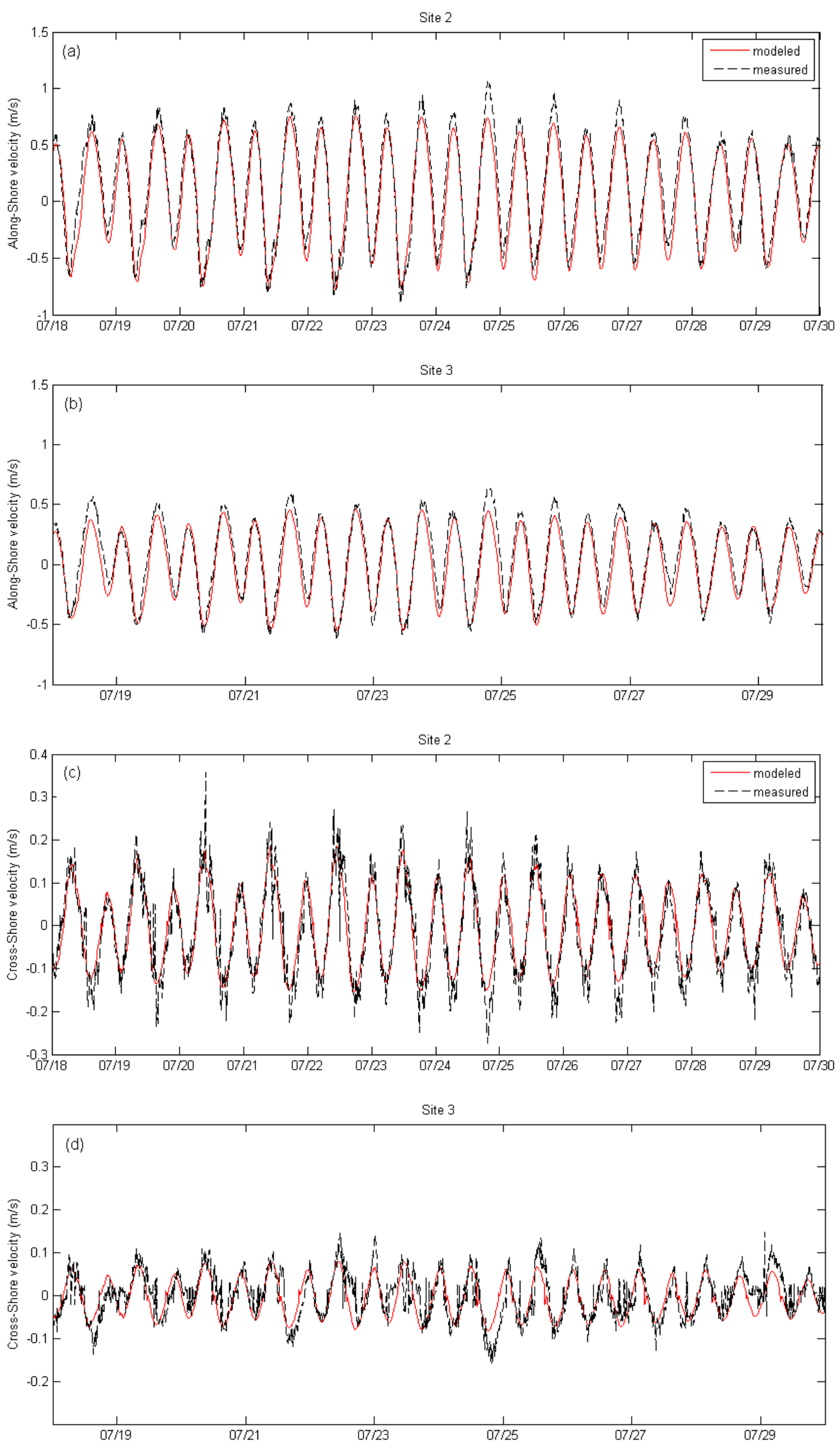

Figure 10.5. Comparison of measured and modeled longshore currents $(a, b)$ and cross-shore currents (c, d) at Sites 2 and 3. 

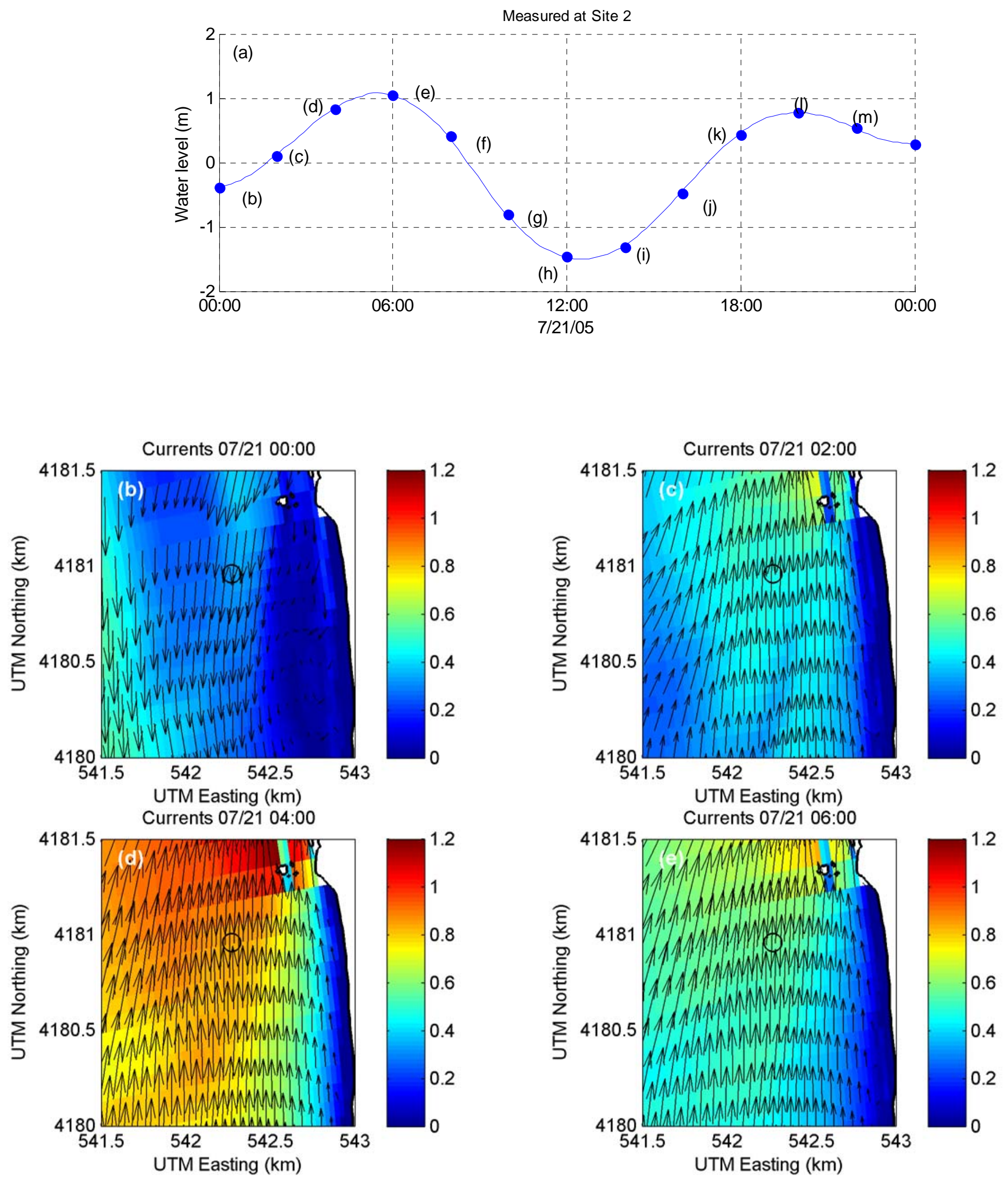

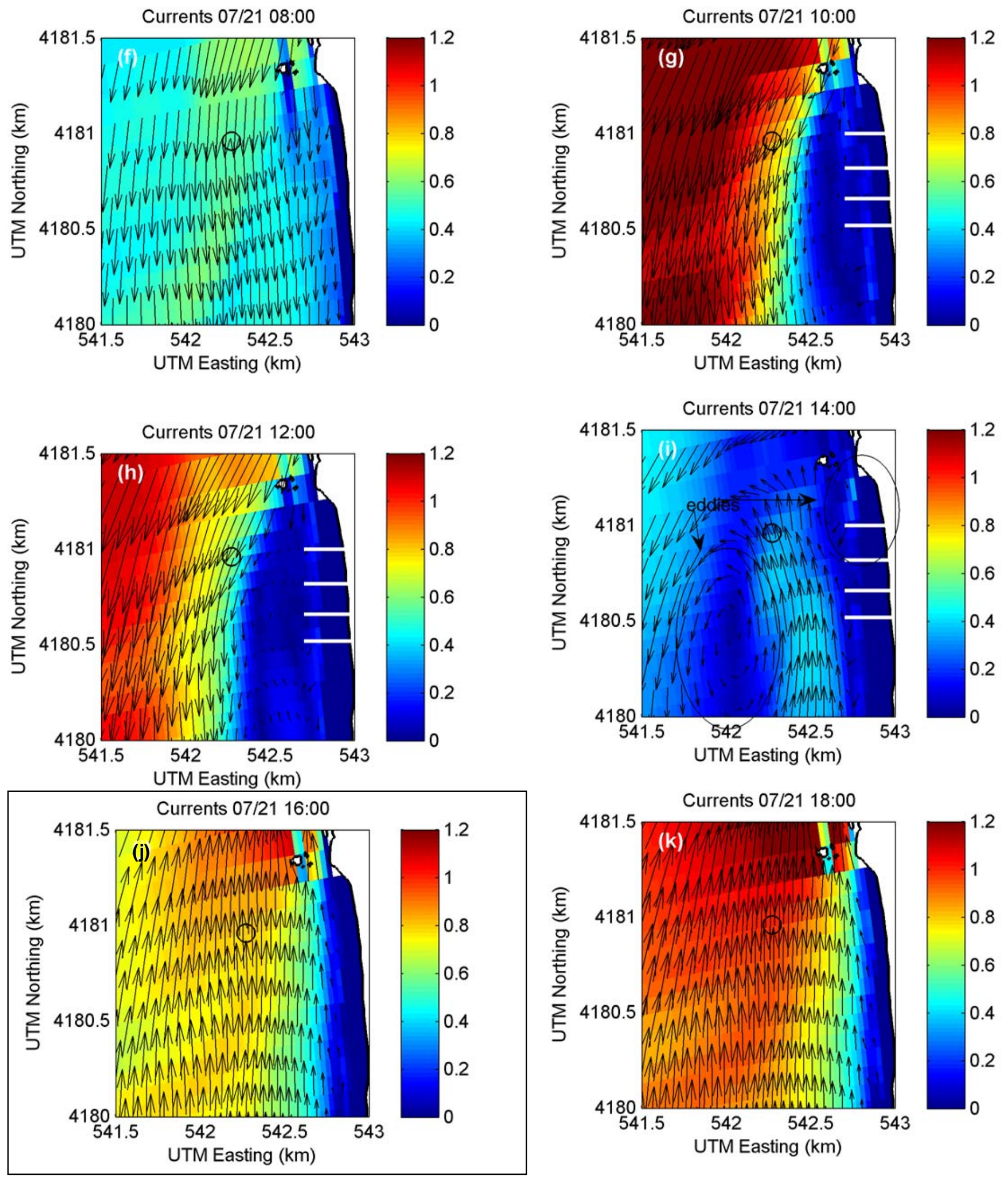

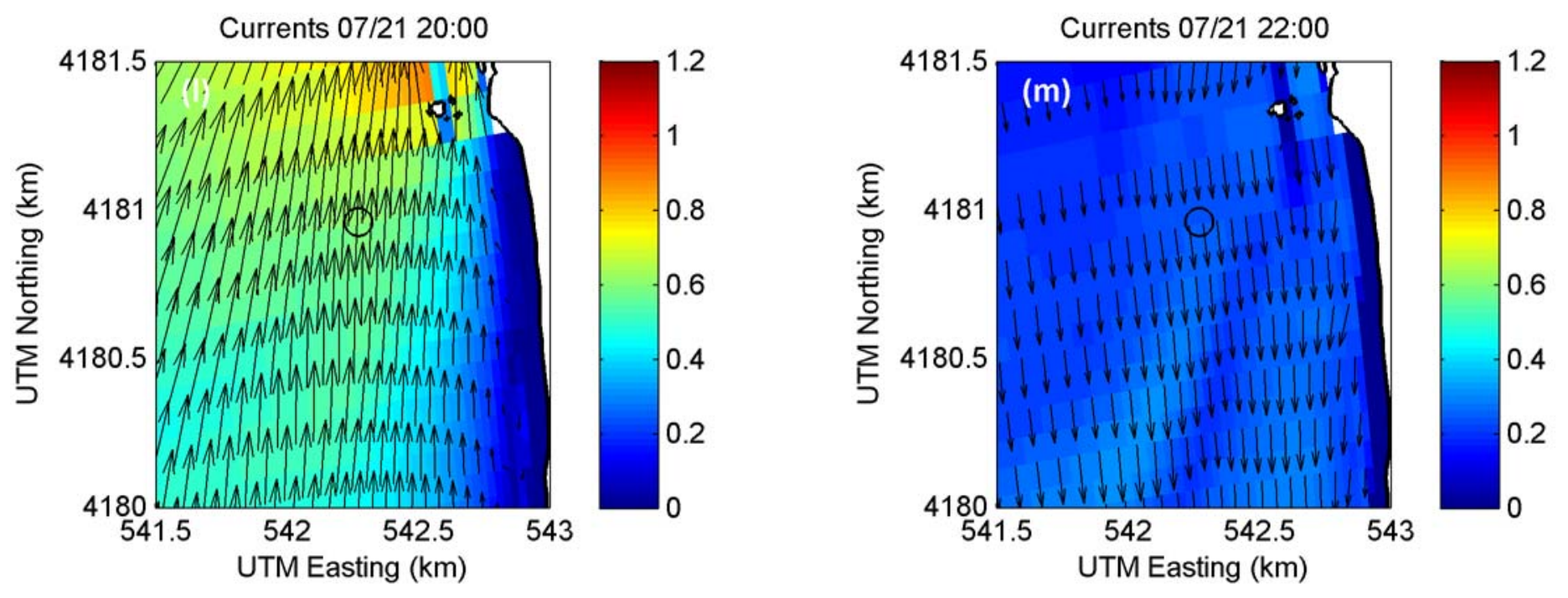

Figure 10.6. Flow patterns at the north end of 0 cean Beach. Plot (a) shows the measured tide at Site 2; points and text refer to snap shots of model results in plots (b) through (m). Open circle is Site 1 sampling station. Flow directions are shown with arrows while current speeds $(\mathrm{m} / \mathrm{s})$ are shown with the color scheme. White horizontal lines in plots $\mathrm{g}, \mathrm{h}$, and $\mathrm{i}$ indicate rip current observations from time-averaged images (Chapter 4). 


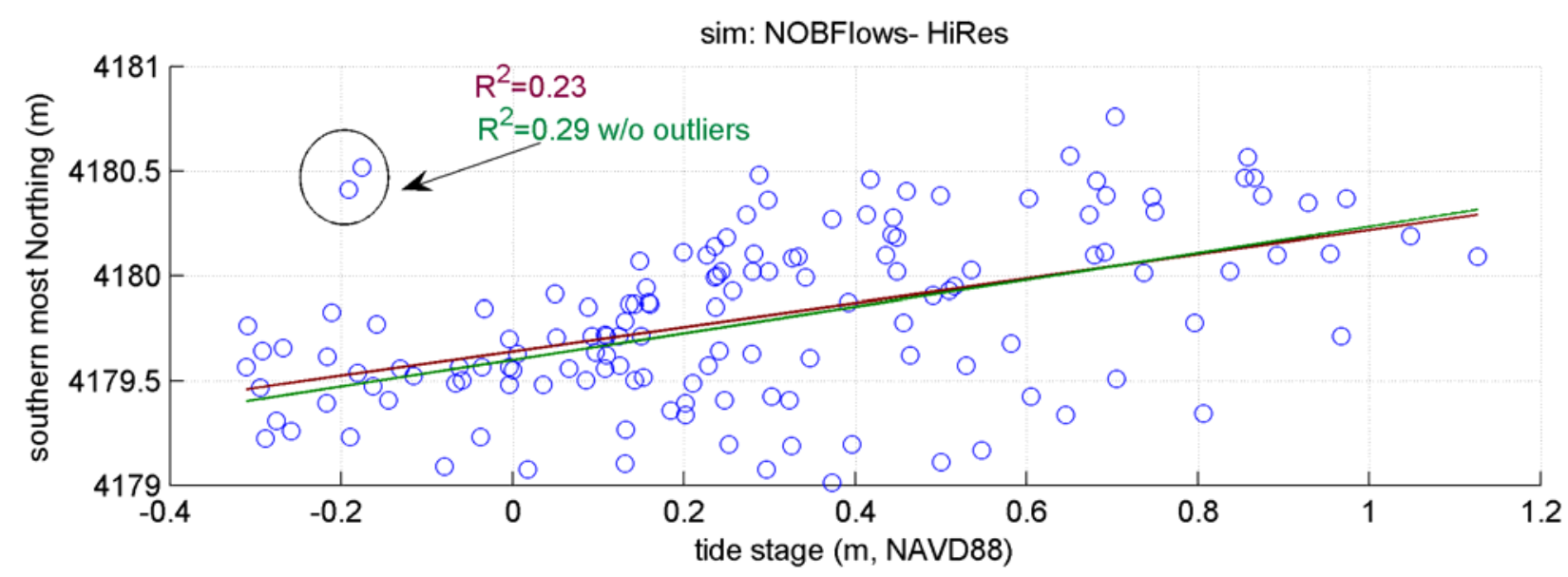

Easting position of eddies vs tide stage at north
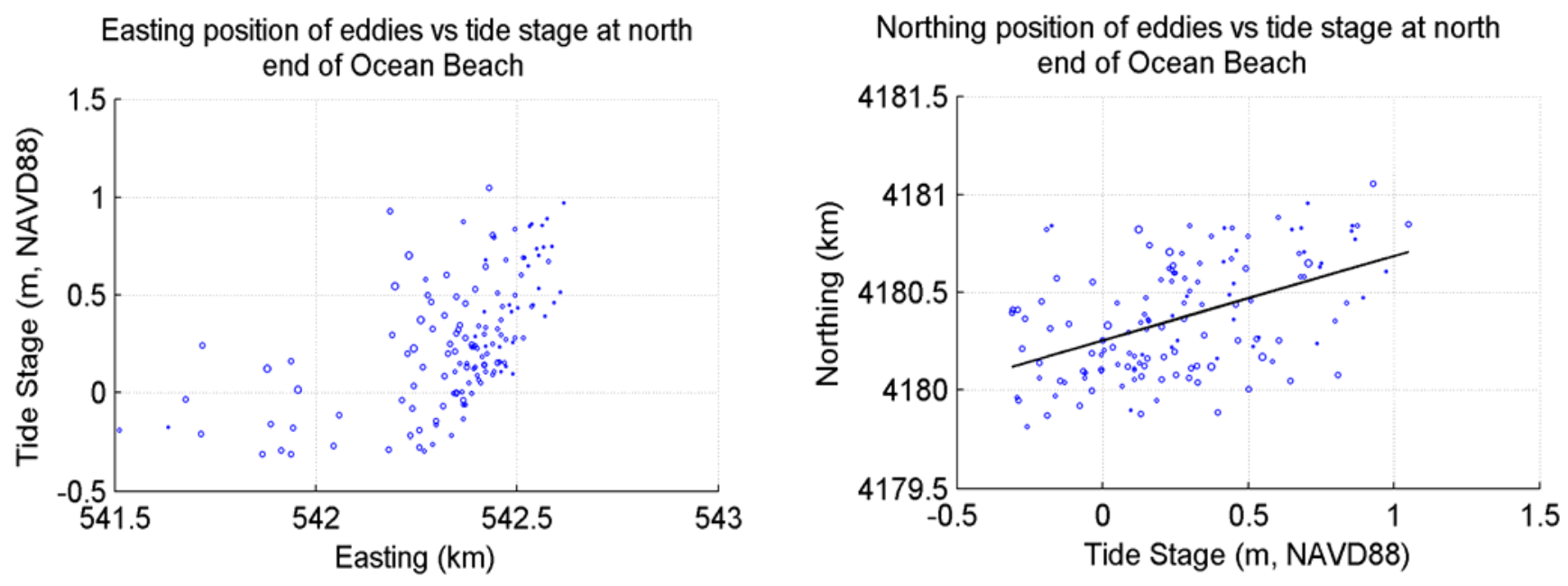

Figure 10.7. Eddy position as a function to tide stage. Based on analysis of model simulation slightly shorter than one month, the southern most point of the eddies reach to about $\mathrm{N}$ 4.179E6, which coincides with PWC transect 5 (a). Approximate eddy center locations are plotted against the tidal stage in (b) and (c) (note that the axis of the Eastings and Northings are switched ease of geographic considerations). Central Easting position only moves slightly with positive tide levels, while at negative tides (corresponding to the spring cycle), the position moves as much as $1 \mathrm{~km}$ in the east-west direction. With respect to the right-hand Figure, the eddies appear to move about $1 \mathrm{~km}$ in the north-south direction with the tide, such that the eddies appear further south with lower tide stage. 
(a)

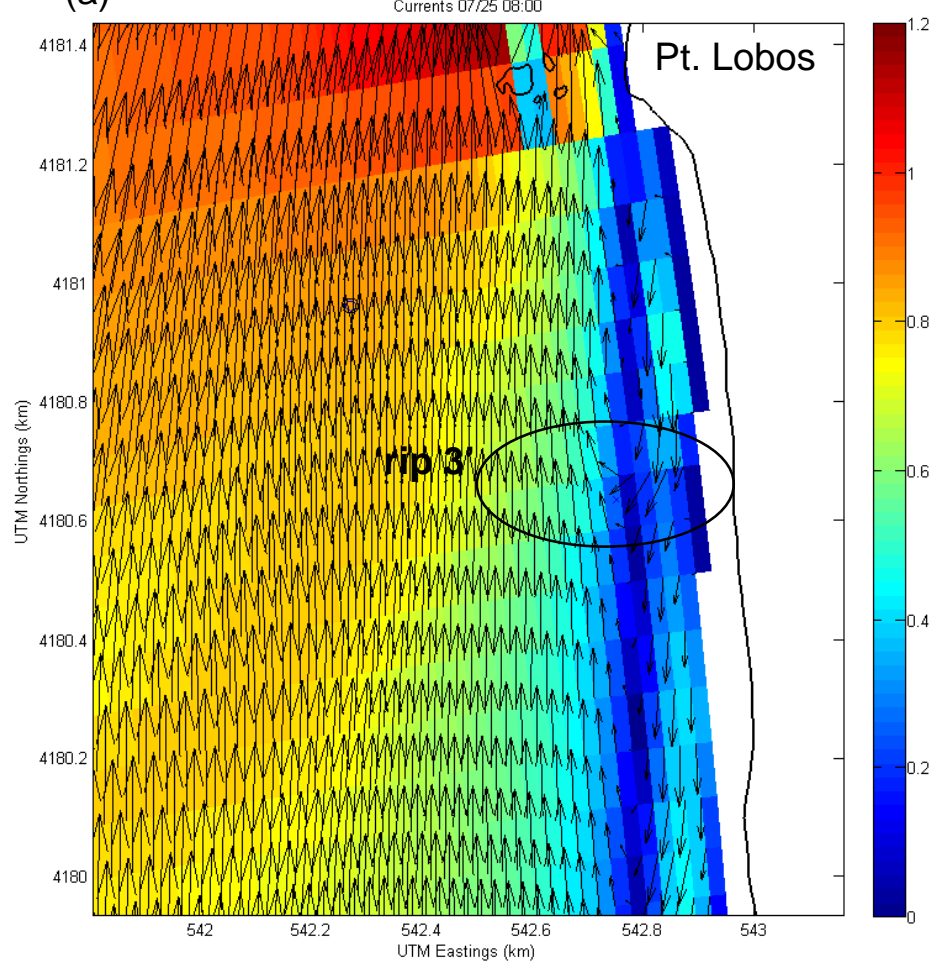

(b)

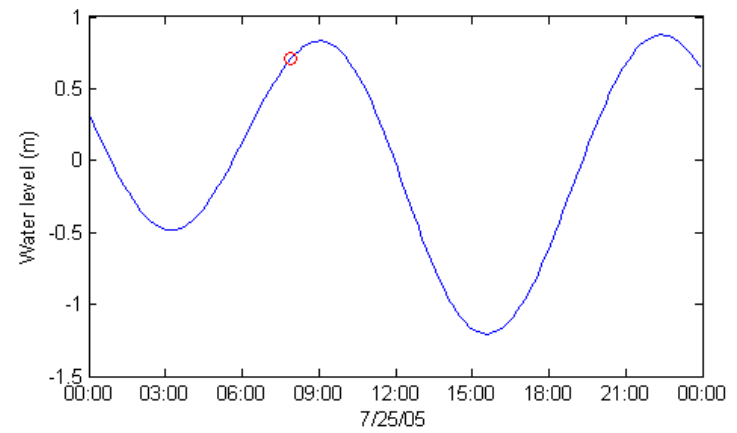

Figure 10.8. Evidence of rip currents at $N 4180.63 \mathrm{~km}$, which coincides with 'rip 3 ' as seen with time-averaged images (see Chapter 4). Plot (a) shows model predicted flow patterns along Ocean Beach; plot (b) shows measured tide at Site 1 and, with the red circle, the time-step of (a). 

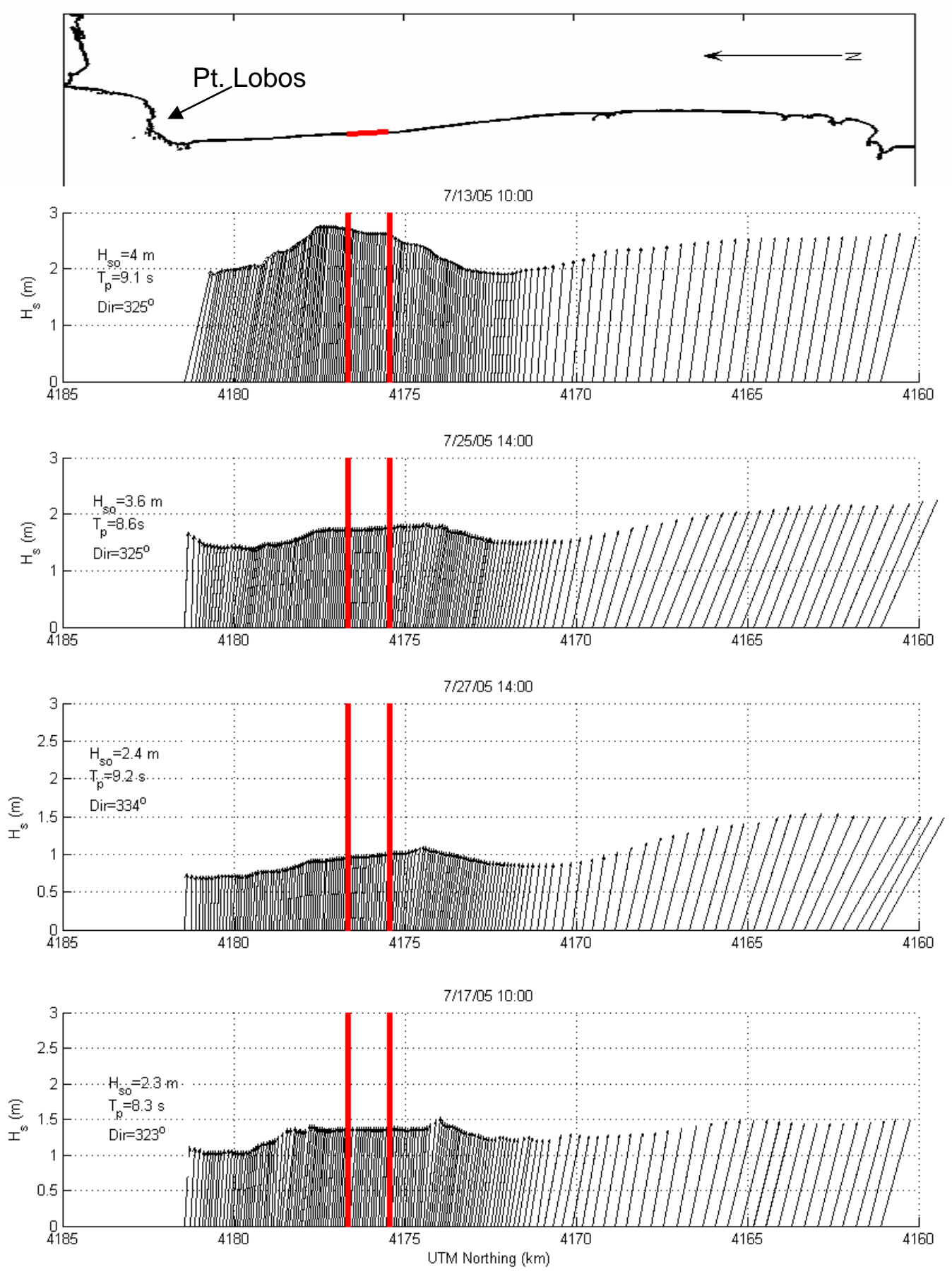

Figure 10.9. Along-shore variation of model predicted wave height and direction at 0 cean Beach. The thick red lines indicate area of erosion 'hot spot'. Variation in line density is due to grid cell spacing. 

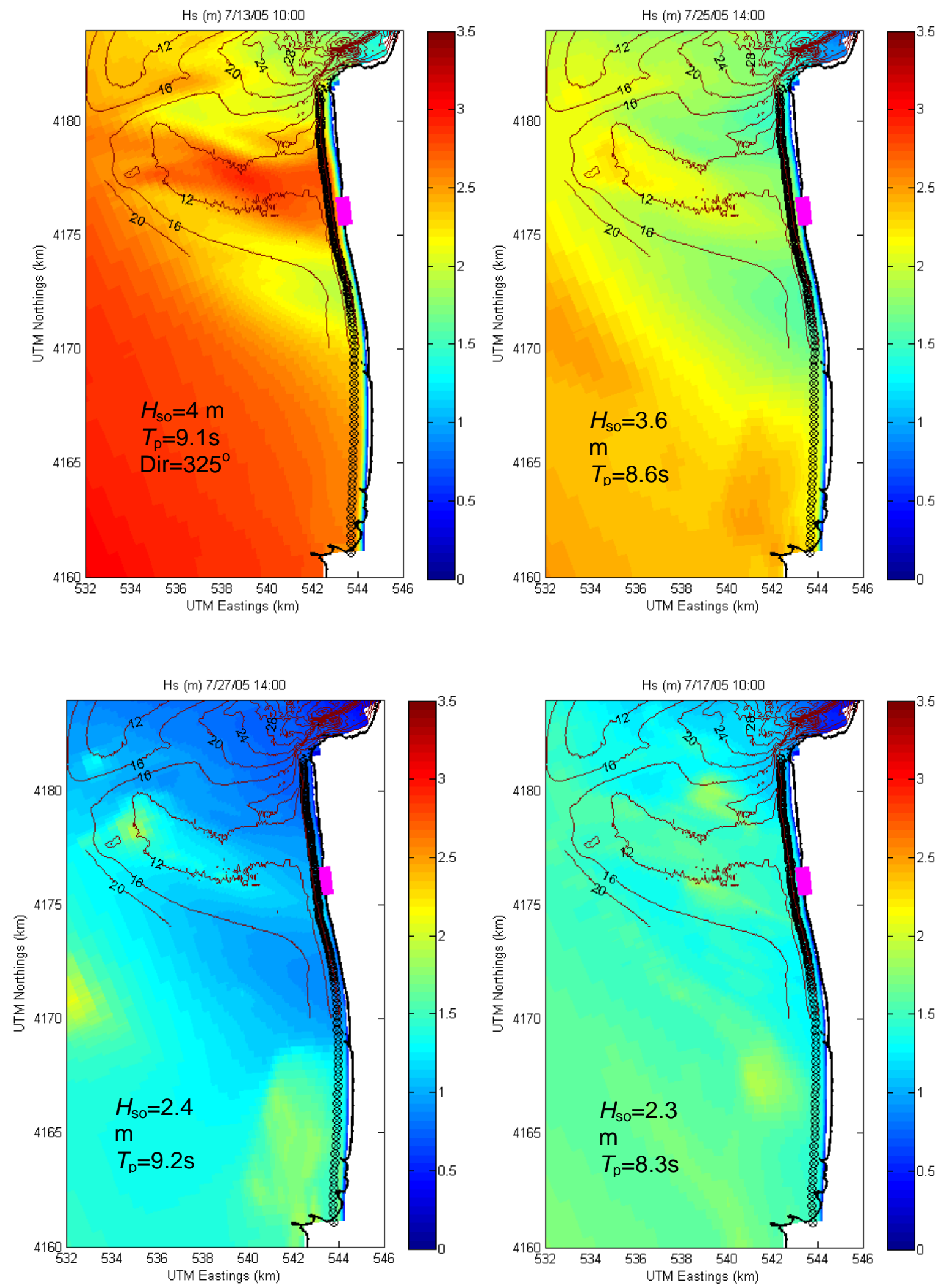

Figure 10.10. Model predicted significant wave heights tor tour ottshore conditions during the summer of 2005. Contour lines are bathymetry as measured with multi-beam surveys. 

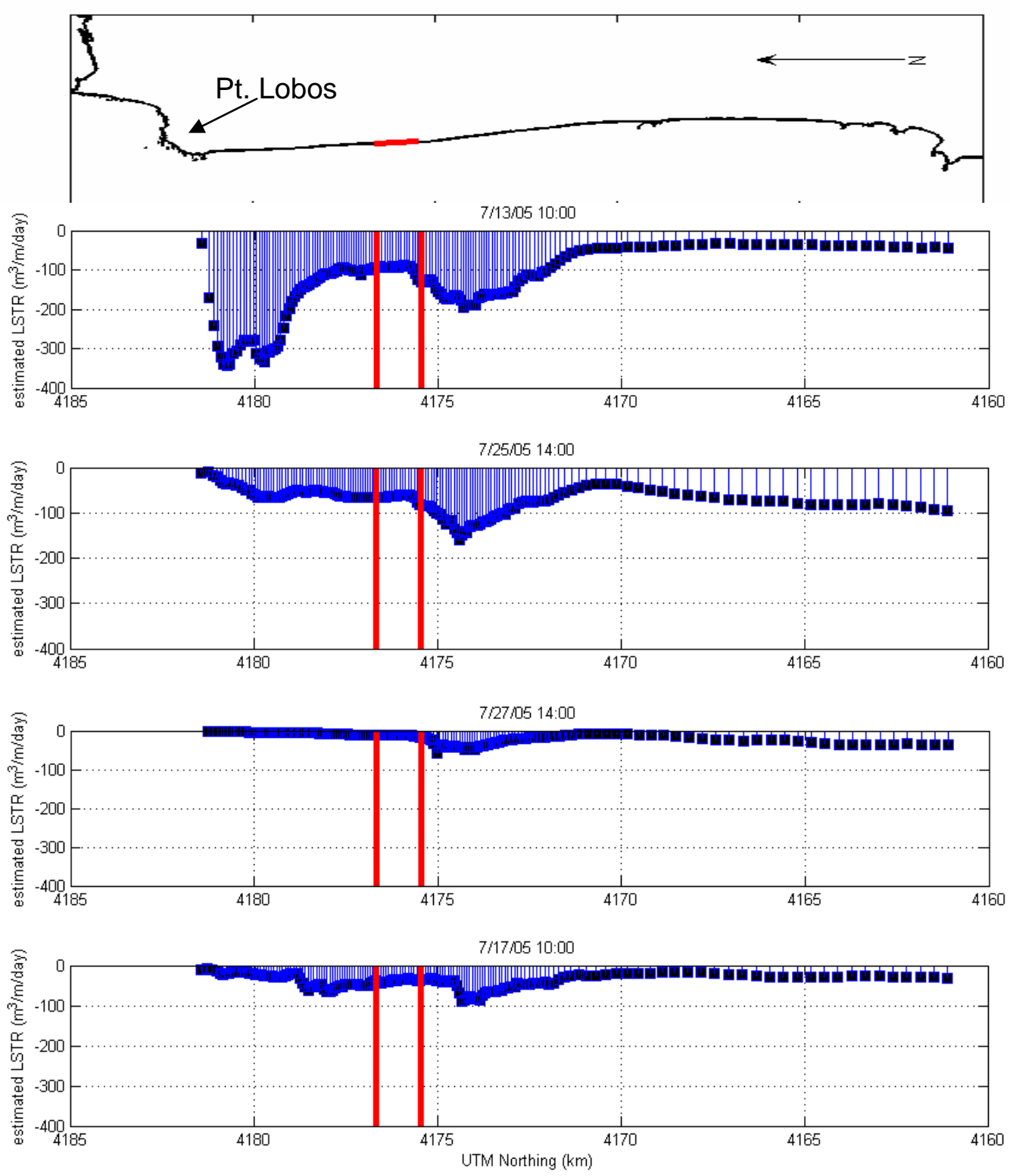

Figure 10.11. Along-shore variation of estimated long-shore sediment transport $\left(\mathrm{m}^{3} / \mathrm{day}\right.$ per alongshore unit width). The thick red lines bound the erosion 'hot spot'. 

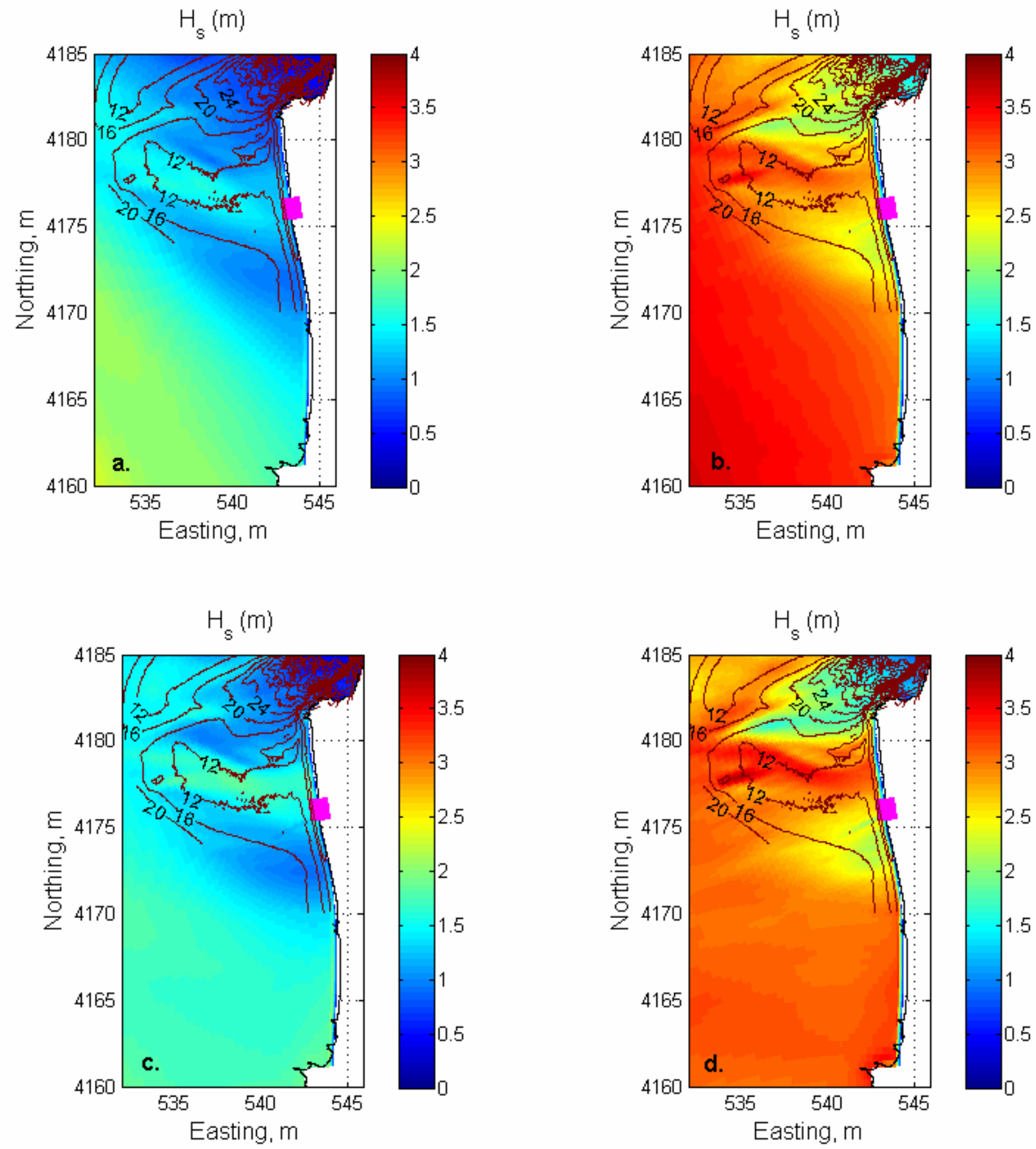

Figure 10.12. Modeled significant wave height values at 0 cean Beach with parameterized forcing of $H_{\mathrm{s}}=4 \mathrm{~m}$ and a) $T_{\mathrm{p}}=10 \mathrm{sec}, D_{\mathrm{p}}=330 \mathrm{deg}$ b) $T_{\mathrm{p}}=10 \mathrm{sec}, D_{\mathrm{p}}=280 \mathrm{deg}$ c) $\left.T_{\mathrm{p}}=20 \mathrm{sec}, D_{\mathrm{p}}=330 \mathrm{deg} \mathrm{d}\right) T_{\mathrm{p}}=20$ sec, $D_{\mathrm{p}}=280 \mathrm{deg}$. 

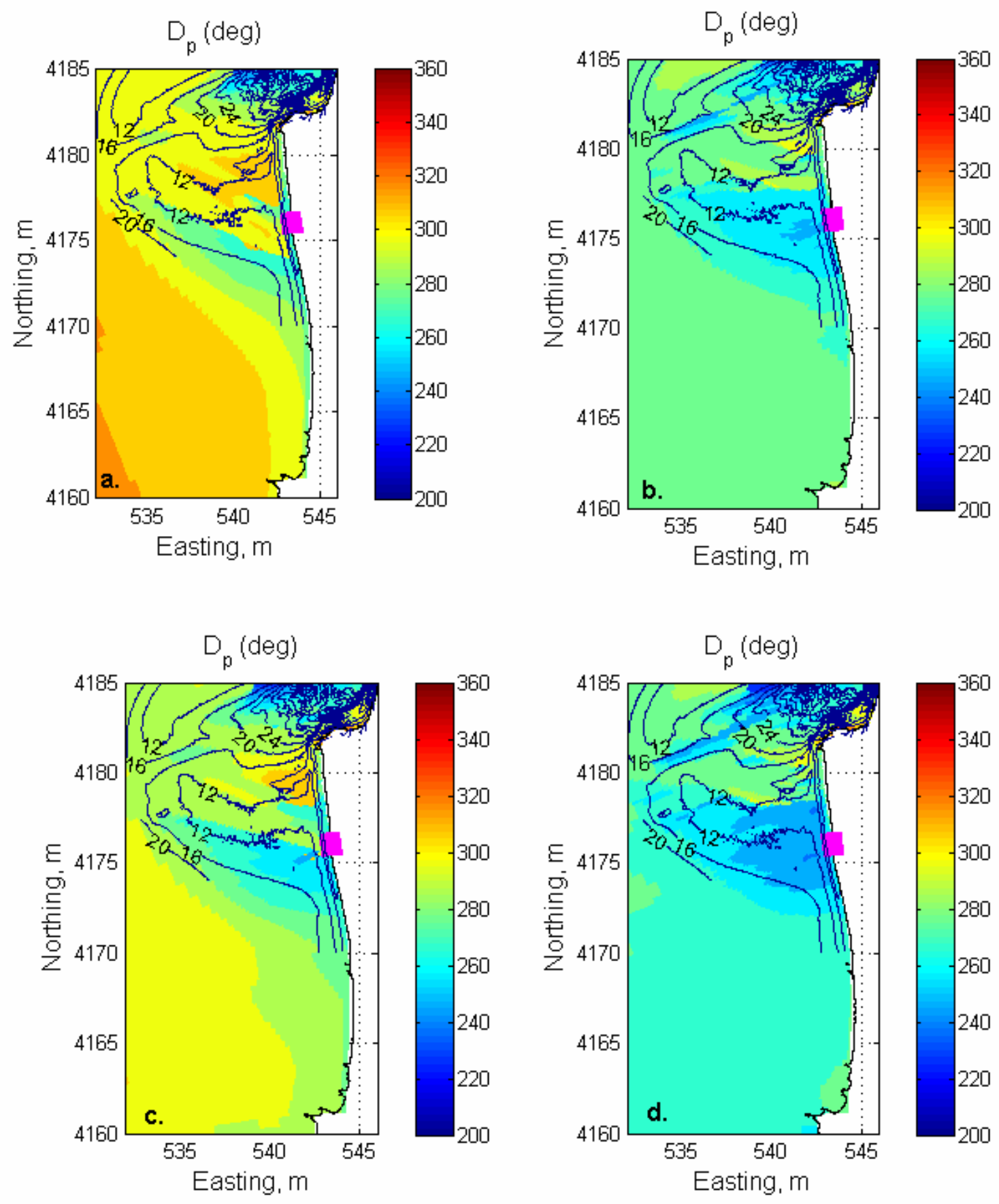

Figure 10.13. Modeled peak wave direction values at 0 cean Beach with parameterized forcing of $\mathrm{Hs}=4 \mathrm{~m}$ and $\mathrm{a}) \mathrm{Tp}=10 \mathrm{sec}, \mathrm{Dp}=330 \mathrm{deg}$ b) $\mathrm{Tp}=10 \mathrm{sec}, \mathrm{Dp}=280 \mathrm{deg}$ c) $\mathrm{Tp}=20 \mathrm{sec}, \mathrm{Dp}=330 \mathrm{deg} \mathrm{d}) \mathrm{T} p=$ $20 \mathrm{sec}, \mathrm{Dp}=280 \mathrm{deg}$. 

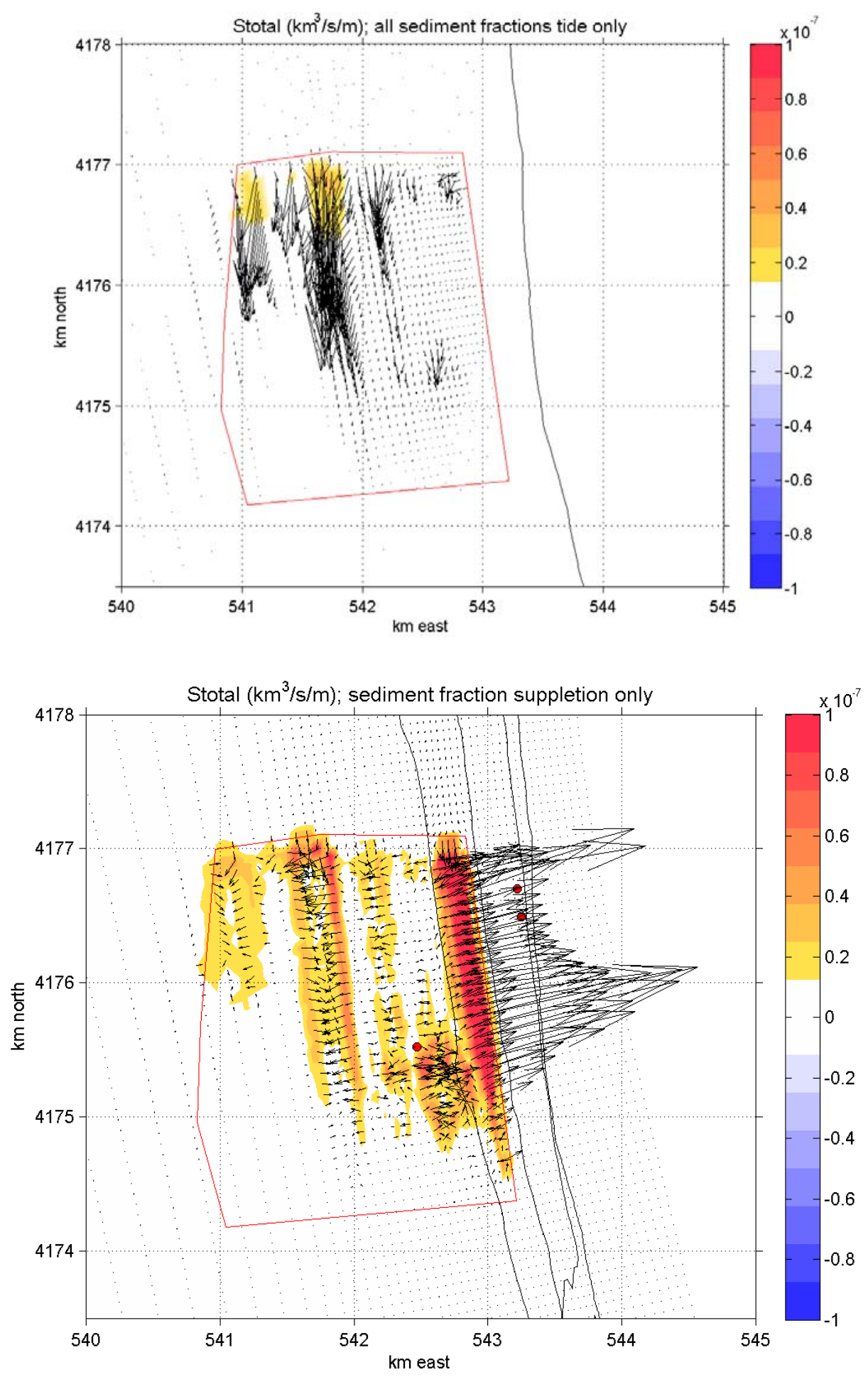

Figure 10.14. Residual transport of the dredge disposal mound with tidal forcing only (a) Residual transport of the dredge disposal mound with tidal and wave forcing, illustrating the importance of wave shoaling in the onshore migration of the disposal material(b). 


\section{Acknowledgements}

Thanks to the USGS Coastal and Marine Geology Team, particularly the Coastal Evolution: Process-based, Multi-scale Modeling Project for the generous support of this project. The United States Army Crops of Engineers, San Francisco District, funded a portion of this study. Peter Mull, in particular, has been extremely supportive. The National Park Service provided site permits and other logistical support. The San Francisco Public Utilities Commission generously granted us access to their secure Oceanside Water Pollution Control Plant to establish a permanent base station for our survey work at Ocean Beach. Peter Ruggiero provided CPS survey support. Thomas Reiss provide GPS support for CPS and beach surveys. Gerry Hatcher assisted with the sediment sampling. Joanne Ferreira directed instrument deployments and recovery. Ann Gibbs maintained the video monitoring system. Jeff Hansen conducted many of the beach surveys. The entire Ocean Beach team is responsible for the success of this project, including Hal Williams, Kevin O'Toole, Walt Olson, Charlene Parsons, Liron Friedman, Andrew Schwartz, Lindsey Doermann, Etienne Kingsley and Patrick Smith. Many thanks to Curt Storlazzi and Ann Gibbs for their through internal reviews. 


\section{References Cited}

Airfield Development Engineering Consultant (ADEC), 2000. SFO- Airfield Development Program, Preliminary Report No. 5 (Task 1). Evaluation of Potential Sand Borrow Sites, 628 p.

Barnard, P.L., 2005. Modern processes at the mouth of San Francisco Bay. American Shore and Beach Preservation Association, Field Trip Guide, 23 p.

Barnard, P.L., and Hanes, D.M., 2005. Integrating field research, modeling and remote sensing to quantify morphodynamics in a high-energy coastal setting, Ocean Beach, San Francisco, California, 5th International Conference on Coastal Dynamics, Barcelona, Spain, American Society of Civil Engineers, CD-ROM, 14 p.

Barnard, P.L. and Hanes, D.M., 2006. Coastal monitoring of the May 2005 dredge disposal offshore of Ocean Beach, San Francisco, California, U.S. Geological Survey Open-File Report, no. 2006-1140, 27 p., http://pubs.usgs.gov/of/2006/1140/

Barnard, P.L., Hanes, D.M., Kvitek, R.G., and Iampietro, P.J., 2006a. Sand Waves at the mouth of San Francisco Bay, California: U.S. Geological Survey Scientific Investigations Map, no. 20062944, 5 map sheets.

Barnard, P.L., Hanes, D.M., Lescinski, J. and Elias, E., 2006b. Monitoring and modeling nearshore dredge disposal for indirect beach nourishment, Ocean Beach, San Francisco. In: Smith, J.M. (ed.), Coastal Engineering 2006, Proceedings of the $30^{\text {th }}$ International Conference, Conference Proceedings, San Diego, CA, USA, 3-8 September 2006, Volume 4, p. 4192-4204

Barnard, P.L., Hanes, D.M., Rubin, D.M., and Kvitek, R.G., 2006c. Giant sand waves at the mouth of San Francisco Bay: Eos, Transactions of the American Geophysical Union, v. 87, no. 29, p. $285,289$.

Barnard, P.L., Rubin, D.M., Harney, J. and Mustain, N., 2007. Field test comparison of an autocorrelation technique for determining grain size using a digital 'beachball' camera versus traditional methods. Sedimentary Geology, v. 201, no. 1-2, p. 180-195, http://dx.doi.org/10.1016/j.sedgeo.2007.05.016

Barnard, P.L. Lescinski, M.R., Lesser, G., Eshleman, J., Erikson, L.H. and Hanes, D.M., under review. Toward a validated 2-D hydrodynamic model for the mouth of San Francisco Bay. U.S. Geological Survey Open-File Report, 67 p.

Battalio, R.T., and Trivedi, D., 1996. Sediment transport processes at Ocean Beach, San Francisco, CA. Proceedings of the 25th International Conference on Coastal Engineering, Orlando, Florida, ASCE, p. 2691-2707.

Battjes, J.A. and J.P.F.M. Janssen, 1978. Energy loss and set-up due to breaking of random waves, Proceedings of the 16th International Conference on Coastal Engineering, ASCE, p. 569-587. 
Constantian, R.K. 1999. Observed kinematics of waves in the surf zone. M.S. Thesis, Naval Postgraduate School, Monterey, CA.

Cote, J.M., Hotchkiss, F.A., Martini, M. and Denham, C.R., 2003. Acoustic Doppler Current Profiler Data Processing System Manual. U.S. Geological Survey Open-File Report, no. 00-458 Version 2, $74 \mathrm{p}$.

Chezar, H., 2001. Underwater Microscope System, U.S. Geological Survey Fact Sheet, 2 p.

Chin, J.L., Carlson, P.R., Wong, F.L. and Cacchione, D.A., 1998. Multibeam data and socioeconomic issues in west-central San Francisco Bay (CA). U.S. Geological Survey Open-File Report, no. 98-139.

Chin, J.L., Wong, F.L., and Carlson, P.R., 2004. Shifting shoals and shattered rocks- how man has transformed the floor of West-central San Francisco Bay. U.S. Geological Survey Circular, no. $1259,38 \mathrm{p}$.

Dartnell, P., Barnard, P.L., Chin, J.L., Hanes, D.M., Kvitek, R.G., Iampietro, P.J., and Gardner, J.V., 2006. Under the Golden Gate Bridge-views of the seafloor near the entrance to San Francisco Bay, California. U.S. Geological Survey Scientific Investigations Map, no. 2006-2917, 1 map sheet.

Delft3D, 2007. Rotterdam, The Netherlands, WL Delft Hydraulics, http://www.wldelft.nl/

Domurat, G.W., Pirie, D.M., and Sustar, J.F., 1979. Beach erosion control study, Ocean Beach, San Francisco, California. Shore and Beach, v. 47, no. 4, p. 20-32.

Engineer Development Research Center, U.S. Army, 1984. Shore Protection Manual, U.S. Government Printing Office, Washington, D.C.

Erdman Video Systems, Inc.1996-2006, http://www.video-monitoring.com/

Erikson, L., Hanes, D.M., Barnard, P.L. and Gibbs, A.E., 2006. Swash zone characteristics at Ocean Beach. In: Smith, J.M. (ed.), Coastal Engineering 2006, Proceedings of the $30^{\text {th }}$ International Conference, Conference Proceedings, San Diego, CA, USA, 3-8 September 2006, Volume 1, p. 909-921

Fredsoe, J.F., 1984. Turbulent boundary layer in wave-current interaction, Journal of Hydraulic Engineering, ASCE, v. 110, p. 1103-1120.

Friends of the Estuary, 1997. Annual Report, 1996-1997, 8 p.

Galvin, C., 1980. Redesign of Ocean Beach San Francisco. City and County of San Francisco Clean Water Program.

Gilbert, G.K., 1917. Hydraulic-mining debris in the Sierra Nevada. U.S. Geological Survey Professional Paper, no. 105, 154 p. 
Hallermeier, R.J., 1978. Uses for a calculated limit depth to beach erosion. Proceedings of the 16th International Conference on Coastal Engineering., ASCE, Hamburg. p. 1493-1512.

Hapke, C.J., Reid, D., Richmond, B.M., Ruggiero, P., and List, J., 2006. National Assessment of Shoreline Change Part 3: Historical Shoreline Change and Associated Coastal Land Loss Along Sandy Shorelines of the California Coast. U.S. Geological Survey Open-File Report, no. 20061251, 79 pp. http://pubs.usgs.gov/of/2006/1251

Hansen, J.E., 2007. Quantifying beach response to episodic large wave events, Ocean Beach, San Francisco. San Francisco State University, Master's Thesis, 68 p.

Herbers, T.H.C., Elgar, S., Sarap, N.A. and Guza, R.T., 2002. Nonlinear dispersion of surface gravity waves in shallow water. Journal of Physical Oceanography, v. 32, p. 1181-1193.

Holland, K., Holman, R. and Lippman, T., 1997. Practical use of video imagery in nearshore oceanographic field studies. Journal of Oceanic Engineering, v. 22, no, 1, p. 81-92.

Hunt, I.A., 1959. Design of seawalls and breakwaters. Journal of Waterways, Harbors Coastal Engineering Division, ASCE, v. 85, p. 123-152.

Johnson, J.W., 1977. Shoreline Characteristics, Ocean Beach, San Francisco, California. Bureau of Sanitary Engineering, Department of Public Works, City and County of San Francisco, 8 p.

Jordan, G.F., 1962. Large submarine sand waves. Science, v. 136, p. 839-848.

Komar, P.D., 1988. Environmental Controls on Littoral Sand Transport. 21st International Coastal Engineering Conference, ASCE, p. 1238-1252.

Lippman, T. and Holman, R., 1989. Quantification of sandbar morphology: a video technique based on wave dissipation. Journal of Geophysical Research, v. 94, p. 995-1011.

Long, J.W. and Ozkan-Haller, H.T., 2005. Offshore controls on nearshore rip currents. Journal of Geophysical Research, v. 110, C12007.

MacMahan, J., 2001. Hydrographic surveying from a personal watercraft. Journal of Surveying Engineering, v. 127, no.1, p. 12-24.

Magellan Navigation, Inc., 2006. Z-Extreme Survey System Data Sheet. http://pro.magellangps.com/en/.

Miche, R. 1951. Le Pouvoir reflechissant des ouvrages maritimes exposes a l'action de la houle, Ann. Ponts Chaussees, v. 121, p. 285-319.

Moffatt and Nichol Engineers, 1994. Shoreline Mapping for Ocean Beach, San Francisco, California, Final Report, 69 p.

Moffatt and Nichol Engineers, 1995. Sediment transport processes study, Ocean Beach, San Francisco, California, Final Report, 69 p. 
National Oceanic and Atmospheric Administration (NOAA), 2006a. National Data Buoy Center: Silver Spring, Maryland, http://www.ndbc.noaa.gov/

National Oceanic and Atmospheric Administration (NOAA), 2006b. Tides \& Currents, Center of Operational Products and Services, http://tidesandcurrents.noaa.gov/

National Oceanic and Atmospheric Administration (NOAA), 2007. Topographic Change Mapping, NOAA Coastal Services Center, http://maps.csc.noaa.gov/TCM/

Nortek AS, 2005. Aquadopp Current Profiler User Guide.

Nortek AS, 2004. AWAC Acoustic Wave and Current Meter User Guide

Pawlocicz, R., Bearsley, B. and Lentz, S., 2002. Classical tidal harmonic analysis including error estimates in MATLAB using T_TIDE. Computers and Geosciences, v. 28, p. 929-937.

RD Instruments, 2002. WorkHorse Sentinal ADCP User's Guide.

Roelvink J.A. and van Banning G.K.F.M., 1994. Design and development of

DELFT3D- an application to coastal morphodynamics. Hydroinformatics '94, Verwey, Minns, Babovic \& Maksimovic (eds.), Balkema, Rotterdam. p. 451-455.

Rubin, D.M., 2004. A simple autocorrelation algorithm for determining grain size from digital images of sediment. Journal of Sedimentary Research, v. 74, no. 1, p. 160-165.

Ruggiero, P., Komar, P.D., McDougal, W.G., Marra, J.J. and Beach, R.A., 2001. Wave runup, extreme water levels and the erosion of properties backing beaches, Journal of Coastal Research, v. 17 , no. 2 , p. $407-419$.

Ruggiero, P., Holman, R.A. and Beach, R.A., 2004. Wave runup on a high energy dissipative beach. Journal of Geophysical Research, v. 109, p. 1-12.

Ruggiero, P., Kaminsky, G.M., Gelfenbaum, G. and Voigt, B., 2005. Seasonal to interannual morphodynamics along a high-energy dissipative littoral cell. Journal of Coastal Research, v. 21, no. 3 , p. 553-578.

Ruessink, B.K., Kleinhans, M.G. and van den Beukel, P.G.L., 1998. Observations of swash under highly dissipative conditions, Journal of Geophysical Research, v. 103, p. 3111-3118.

Sallenger, A.H., Krabill, W., Brock, J., Swift, R., Jansen, M., Manizade, S., Richmond, B., Hampton, M. and Eslinger, D., 1999. Airborne laser study quantifies El Niño-induced coastal change. EOS Transactions of the American Geophysical Union, v. 80, p. 89, 9293.

Sallenger, A.H., Krabill, W., Brock, J., Swift, R., Manizade, S. and Stockdon, H., 2002. Sea-cliff erosion as a function of beach changes and extreme wave runup during the 1997-1998 El Niño. Marine Geology, v. 187, no. 3-4, p. 279-297 
SCRIPPS Institution of Oceanography, 2007. The Coastal Data Information Program. San Diego, Integrative Oceanography Division, Scripps Institution of Oceanography, http://cdip.ucsd.edu

Sea-bird Electronics, Inc, 2007. http://www.seabird.com

Storlazzi, C.D. and Griggs, G.B., 2000. Influence of El Niño-Southern Oscillation (ENSO) events on the evolution of central California's shoreline. Geological Society of America Bulletin, v. 112, no. 2, p. 236-249.

Street, R.L., Mogel, R. and Perry, B., 1969. Computation of the littoral regime of the shore of San Francisco County. Automatic Data Processing Methods, Stanford University.

Sutherland, J., Peet, A.H. and Soulsby, R.L., 2004. Evaluating the performance of morphological models. Coastal Engineering, v. 51, p. 917-939.

Trask, P.D., 1954. San Francisco Bay Sediment Report, Inshore Survey, San Francisco Bay: Final Report. University of California Institute of Engineering Research Series, v. 57, no. 2, Report to Navy Department under contract N220s-72832A.

Trimble Navigation Limited, 1998. 4700 Receiver Operation Manual. Version 1.0, Part Number 36238-00, Revision B.

Trimble Navigation Limited, 2007. http://www.trimble.com

United States Army Corps of Engineers, 1996. Ocean Beach Storm Damage Reduction Feasibility Study, San Francisco District, Final Feasibility Study for the City and County of San Francisco.

USGS/UCSC/NASA/NOAA Collaborative Research Group, 1998. A collaborative program to investigate the impacts of the 1997-98 El Niño winter along the California coast. Shore and Beach, v. 66, no. 3, p. 24-32.

van Duin, M.J.P., Wiersma, N.R., Walstra, D.J.R., van Rijn, L.C. and Stive, M.J.F., 2004. Nourishing the shoreface: observations and hindcasting of the Egmond case, The Netherlands. Coastal Engineering, v. 51, p. 813-837.

Wiegel, R.L., 2001. Guide notes for coach tour of San Francisco coastal sites. Waves Conference Field Trip, 24 p.

WL | Delft Hydraulics, 2005. Delft3D-FLOW, Simulation of multi-dimensional hydrodynamic flows and transport phenomena, including sediments. User Manual, $614 \mathrm{p}$.

WL | Delft Hydraulics, 2006. Delft3D-WAVE, Simulation of short-crested waves with SWAN. User Manual, 166 p.

Woodward-Clyde Consultants, 1978. Coastal Engineering Evaluation Southwest Ocean Outfall Project. Subtask 3-2, Report prepared for PBQ\&D, Inc. 


\section{Appendix}

\section{Publications and Other Resources}

Below is a list of resources released to date and other links related to the Ocean Beach Coastal Processes Study:

\section{Publications}

Barnard, P.L. and Hanes, D.M., 2006. Coastal monitoring of the May 2005 dredge disposal offshore of Ocean Beach, San Francisco, California. U.S. Geological Survey, Open-File Report, Report Series 2006-1140, 27 pp., http://pubs.usgs.gov/of/2006/1140/

Barnard, P.L., Hanes, D.M., Kvitek, R.G, and Iampietro, P.J., 2006. Sand waves at the mouth of San Francisco Bay, California. U.S. Geological Survey, Scientific Investigations Map 2006-2944, 5 map sheets, http://pubs.usgs.gov/sim/2006/2944/

Barnard, P.L., Hanes, D.M., Lescinski, J. and Elias, E., 2007. Monitoring and modeling nearshore dredge disposal for indirect beach nourishment, Ocean Beach, San Francisco. In: Smith, J.M. (ed.), Coastal Engineering 2006, Proceedings of the 30th International Conference, Conference Proceedings, San Diego, CA, USA, 3-8 September 2006, Volume 4, p. $4192-4204$ (for PDF go to: http://walrus.wr.usgs.gov/coastal_processes/pubs.html)

Barnard, P.L., Hanes, D.M, Rubin, D.M. and Kvitek, R.G., 2006. Giant sand waves at the mouth of San Francisco Bay. EOS Transactions, Volume 87, Number 29, p. 285, 289 (for PDF go to: http://walrus.wr.usgs.gov/coastal_processes/pubs.html)

Dartnell, P., Barnard, P.L., Chin, J.L., Hanes, D.M., Kvitek, R.G, Iampietro, P.J. and Gardner, J.V., 2006. Under the Golden Gate Bridge-views of the seafloor near the entrance to San Francisco Bay, California. United States Geological Survey, Scientific Investigations Map 2917. 1 map sheet http://pubs.usgs.gov/sim/2006/2917/

Erikson, L., Hanes, D.M., Barnard, P.L. and Gibbs, A.E., 2007. Swash zone characteristics at Ocean Beach. In: Smith, J.M. (ed.), Coastal Engineering 2006, Proceedings of the 30th International Conference, Conference Proceedings, San Diego, CA, USA, 3-8 September 2006, Volume 1, p. 909-921 (for PDF go to: http://walrus.wr.usgs.gov/coastal_processes/pubs.html)

Barnard, P.L., 2005. Modern processes at the mouth of San Francisco Bay. American Shore and Beach Preservation Association, 2005 Conference Field Trip Guide, 21 pp. (for PDF go to: http://walrus.wr.usgs.gov/coastal_processes/pubs.html)

Barnard, P.L., Hanes, D.M., 2005. Integrating field research, modeling and remote sensing to quantify morphodynamics in a high-energy coastal setting, Ocean Beach, San Francisco, California. 5th International Conference on Coastal Dynamics 2005 Conference Proceedings, Barcelona, Spain, American Society of Civil Engineers, CD-Rom, 14 pp. (for PDF go to: http://walrus.wr.usgs.gov/coastal_processes/pubs.html) 


\section{Online Resources}

- San Francisco Bight Coastal Processes Study Project Website:

http://walrus.wr.usgs.gov/coastal_processes/

- Coastal Evolution Modeling Project Website:

http://walrus.wr.usgs.gov/research/projects/CEM.html

- Ocean Beach webcam:

http://www.evsboca.com/usgs/default.htm

- USGS Online Reports

o Dredge Disposal Monitoring http://pubs.usgs.gov/of/2006/1140/

o Sand Wave Maps

http://pubs.usgs.gov/sim/2006/2944/

- Multibeam Data:

http://seafloor.csumb.edu/SFMLwebDATA.htm

\section{Research Featured in the News}

- Sand Waves

- "City's beautiful but hidden sand dunes" by Glen Martin San Francisco Chronicle, July 20, 2006 http://www.sfgate.com/cgibin/article.cgi?file $=/ c / a / 2006 / 07 / 20 / M N G U 1 K 2 A V 91 . D T L$

- "Sand dunes by the dock of the bay" News.Com, July 20, 2006 http://news.com.com/2300-11395_3-6096457-1.html?tag=ne.gall.pg

- "Scientists map miles of underwater dunes" by Associated Press Appeared in ABC News, CBS News, Boston Globe, San Jose Mercury New, etc., on July 20 and 21, 2006

http://abcnews.go.com/Technology/wireStory? id $=2218566 \& C M P=O T C$ RSSFeeds0312

http://www.cbsnews.com/stories/2006/07/21/ap/tech/mainD8J0DUF00.shtml http://www.boston.com/news/science/articles/2006/07/20/scientists_map_sub merged_sand_dunes_off_sf/ http://www.mercurynews.com/mld/mercurynews/living/health/15092078.htm

- "Giant Underwater Sand Waves Seaward of the Golden Gate Bridge" by Patrick Barnard Soundwaves, United States Geological Survey, Monthly Newsletter, 2 pp., http://soundwaves.usgs.gov/2006/09/research.html 
- Coastal Erosion

"Beach study hopes to unlock mystery of erosion" by Ryder W. Miller Richmond Review, March 2005

http://www.sunsetbeacon.com/archives/richmondreview/2005editions/Mar05/beachstudy.html

- Dredging

"New tack to hold back Ocean Beach erosion: 300,000-ton gift from dredge could curb erosion" by Kelly Hill

San Francisco Chronicle, June 20, 2005

http://www.sfgate.com/cgi-

bin/article.cgi $? f=/ c / a / 2005 / 06 / 10 / B A G 93 D 6 K 5 J 1 . D T L \& h w=O c e a n+B e a c h \& s n=003 \& s c=$ 646

- Winter 2006 Surf Zone Experiment

"USGS Scientists Investigate Surf-Zone Hydrodynamics at San Francisco's Ocean Beach" by Li Erikson, Patrick Barnard and Dan Hanes

USGS Sound Waves, April 2006

http://soundwaves.usgs.gov/2006/04/ 
Field Activity IDs and Web Links
Survey \#

1

2

3

4

5

6

7

8

9

10

11

12

13

14

15

16

17

18

19

20

21
ATV Survey List
Field Activity

ID

$O-B 1-04-C A$

O-B2-04-CA

O-B3-04-CA

$O-B 4-04-C A$

$O-B 5-04-C A$

O-B6-04-CA

O-B7-04-CA

$O-B 1-05-C A$

O-B2-05-CA

$O-B 3-05-C A$

$O-B 4-05-C A$

$O-B 5-05-C A$

O-B6-05-CA

$O-B 7-05-C A$

$O-B 8-05-C A$

$O-B 9-05-C A$

$07 / 22 / 05$

$O-B A-05-C A$

$08 / 22 / 05$

$O-B B-05-C A$

$11 / 17 / 05$

$O-B C-05-C A$

$12 / 15 / 05$

$O-B D-05-C A$

$12 / 22 / 05$

$O-B E-05-C A$

$12 / 29 / 05$

\section{URL For Field Activity ID}

http://walrus.wr.usgs.gov/infobank/o/ob104ca /html/o-b1-04-ca.meta.html

http://walrus.wr.usgs.gov/infobank/o/ob204ca /html/o-b2-04-ca.meta.html

http://walrus.wr.usgs.gov/infobank/o/ob304ca /html/o-b3-04-ca.meta.html

http://walrus.wr.usgs.gov/infobank/o/ob404ca /html/o-b4-04-ca.meta.html

http://walrus.wr.usgs.gov/infobank/o/ob504ca /html/o-b5-04-ca.meta.html

http://walrus.wr.usgs.gov/infobank/o/ob604ca /html/o-b6-04-ca.meta.html

http://walrus.wr.usgs.gov/infobank/o/ob704ca /html/o-b7-04-ca.meta.html

http://walrus.wr.usgs.gov/infobank/o/ob105ca /html/o-b1-05-ca.meta.html

http://walrus.wr.usgs.gov/infobank/o/ob205ca /html/o-b2-05-ca.meta.html

http://walrus.wr.usgs.gov/infobank/o/ob305ca /html/o-b3-05-ca.meta.html

http://walrus.wr.usgs.gov/infobank/o/ob405ca /html/o-b4-05-ca.meta.html

http://walrus.wr.usgs.gov/infobank/o/ob505ca /html/o-b5-05-ca.meta.html

http://walrus.wr.usgs.gov/infobank/o/ob605ca /html/o-b6-05-ca.meta.html

http://walrus.wr.usgs.gov/infobank/o/ob705ca /html/o-b7-05-ca.meta.html

http://walrus.wr.usgs.gov/infobank/o/ob805ca /html/o-b8-05-ca.meta.html

http://walrus.wr.usgs.gov/infobank/o/ob905ca /html/o-b9-05-ca.meta.html

http://walrus.wr.usgs.gov/infobank/o/oba05ca /html/o-ba-05-ca.meta.html

http://walrus.wr.usgs.gov/infobank/o/obb05ca /html/o-bb-05-ca.meta.html

http://walrus.wr.usgs.gov/infobank/o/obc05ca /html/o-bc-05-ca.meta.html

http://walrus.wr.usgs.gov/infobank/o/obd05ca /html/o-bd-05-ca.meta.html

http://walrus.wr.usgs.gov/infobank/o/obe05ca /html/o-be-05-ca.meta.html 
$O-B 1-06-C A$

$O-B 2-06-C A$

01/24/06

O-B3-06-CA

01/26/06

O-B4-06-CA

01/30/06

O-B5-06-CA

O-B6-06-CA

$O-B 7-06-C A$

$O-B 8-06-C A$

$O-B 9-06-C A$

O-10-06-CA

O-11-06-CA

O-12-06-CA

O-13-06-CA

O-14-06-CA

O-15-06-CA

O-16-06-CA

O-17-06-CA

O-18-06-CA

O-19-06-CA

O-20-06-CA

$11 / 20 / 06$

O-21-06-CA

$11 / 24 / 06$

O-22-06-CA

12/05/06

$$
\text { O-23-06-CA }
$$

$12 / 10 / 06$

O-24-06-CA

$12 / 29 / 06$ http://walrus.wr.usgs.gov/infobank/o/ob106ca /html/o-b1-06-ca.meta.html

http://walrus.wr.usgs.gov/infobank/o/ob206ca /html/o-b2-06-ca.meta.html

http://walrus.wr.usgs.gov/infobank/o/ob306ca /html/o-b3-06-ca.meta.html

http://walrus.wr.usgs.gov/infobank/o/ob406ca /html/o-b4-06-ca.meta.html

http://walrus.wr.usgs.gov/infobank/o/ob506ca /html/o-b5-06-ca.meta.html

http://walrus.wr.usgs.gov/infobank/o/ob606ca /html/o-b6-06-ca.meta.html

http://walrus.wr.usgs.gov/infobank/o/ob706ca /html/o-b7-06-ca.meta.html

http://walrus.wr.usgs.gov/infobank/o/ob806ca /html/o-b8-06-ca.meta.html

http://walrus.wr.usgs.gov/infobank/o/ob906ca /html/o-b9-06-ca.meta.html

http://walrus.wr.usgs.gov/infobank/o/o1006ca /html/o-10-06-ca.meta.html

http://walrus.wr.usgs.gov/infobank/o/o1106ca /html/o-11-06-ca.meta.html

http://walrus.wr.usgs.gov/infobank/o/o1206ca /html/o-12-06-ca.meta.html

http://walrus.wr.usgs.gov/infobank/o/o1306ca /html/o-13-06-ca.meta.html

http://walrus.wr.usgs.gov/infobank/o/o1406ca /html/o-14-06-ca.meta.html

http://walrus.wr.usgs.gov/infobank/o/o1506ca /html/o-15-06-ca.meta.html

http://walrus.wr.usgs.gov/infobank/o/o1606ca /html/o-16-06-ca.meta.html

http://walrus.wr.usgs.gov/infobank/o/o1706ca /html/o-17-06-ca.meta.html

http://walrus.wr.usgs.gov/infobank/o/o1806ca /html/o-18-06-ca.meta.html

http://walrus.wr.usgs.gov/infobank/o/o1906ca /html/o-19-06-ca.meta.html

http://walrus.wr.usgs.gov/infobank/o/o2006ca /html/o-20-06-ca.meta.html

http://walrus.wr.usgs.gov/infobank/o/o2106ca /html/o-21-06-ca.meta.html

http://walrus.wr.usgs.gov/infobank/o/o2206ca /html/o-22-06-ca.meta.html

http://walrus.wr.usgs.gov/infobank/o/o2306ca /html/o-23-06-ca.meta.html

http://walrus.wr.usgs.gov/infobank/o/o2406ca /html/o-24-06-ca.meta.html 


\section{PWC Survey List}

\section{Survey \#}

1

2

3

4

5

6

7

8

9

10

11

12

13

\section{Beach Eyeball \\ Survey List}

\section{Survey \#}

1

2

3

4

5

6

7
Field Activity Survey

ID

O-B2-04-CA $\quad 05 / 04 / 04$

O-B4-04-CA $\quad 07 / 20 / 04$

O-B6-O4-CA 11/12/04

$O-B 5-05-C A \quad 05 / 05 / 05$

$O-B 8-05-C A \quad 07 / 05 / 05$

$O-B B-05-C A \quad 11 / 17 / 05$

O-BA-06-CA $\quad 02 / 01 / 06$

$O-B B-06-C A \quad 02 / 10 / 06$

O-BC-06-CA $\quad 05 / 23 / 06$

$O-B D-06-C A \quad 05 / 23 / 06$

O-BD-06_CA 11/06/06

O-22-06-CA 11/21/06

$O-B 2-04-C A \quad 12 / 05 / 06$ http://walrus.wr.usgs.gov/infobank/o/ob204ca /html/o-b2-04-ca.meta.html

http://walrus.wr.usgs.gov/infobank/o/ob404ca /html/o-b4-04-ca.meta.html

http://walrus.wr.usgs.gov/infobank/o/ob604ca /html/o-b6-04-ca.meta.html

http://walrus.wr.usgs.gov/infobank/o/ob505ca /html/o-b5-05-ca.meta.html

http://walrus.wr.usgs.gov/infobank/o/ob805ca /html/o-b8-05-ca.meta.html

http://walrus.wr.usgs.gov/infobank/o/obb05ca /html/o-bb-05-ca.meta.html

http://walrus.wr.usgs.gov/infobank/o/oba06ca /html/o-ba-06-ca.meta.html

http://walrus.wr.usgs.gov/infobank/o/obb06ca /html/o-bb-06-ca.meta.html

http://walrus.wr.usgs.gov/infobank/o/obc06ca /html/o-bc-06-ca.meta.html

http://walrus.wr.usgs.gov/infobank/o/obd06ca /html/o-bd-06-ca.meta.html

http://walrus.wr.usgs.gov/infobank/o/obd06ca /html/o-bd-06-ca.meta.html

http://walrus.wr.usgs.gov/infobank/o/o2206ca /html/o-22-06-ca.meta.html

http://walrus.wr.usgs.gov/infobank/o/ob204ca /html/o-b2-04-ca.meta.html
Field Activity Survey $\underline{\text { ID }}$

$O-B 1-04-C A$

$O-B 2-04-C A$

05/07/04

$O-B 4-04-C A$

08/03/04

O-B3-05-CA $\quad 03 / 07 / 05$

$O-B B-05-C A \quad 11 / 17 / 05$

$O-B 3-06-C A \quad 01 / 26 / 06$

O-19-06-CA $\quad 11 / 06 / 06$ http://walrus.wr.usgs.gov/infobank/o/ob104ca /html/o-b1-04-ca.meta.html http://walrus.wr.usgs.gov/infobank/o/ob204ca /html/o-b2-04-ca.meta.html http://walrus.wr.usgs.gov/infobank/o/ob404ca /html/o-b4-04-ca.meta.html

http://walrus.wr.usgs.gov/infobank/o/ob305ca /html/o-b3-05-ca.meta.html http://walrus.wr.usgs.gov/infobank/o/obb05ca /html/o-bb-05-ca.meta.html http://walrus.wr.usgs.gov/infobank/o/ob306ca /html/o-b3-06-ca.meta.html http://walrus.wr.usgs.gov/infobank/o/o1906ca 


\section{/html/o-19-06-ca.meta.html}

\section{Sediment Sampling Offshore}

Survey \#

1

2

3

4

5

\section{Instrument \\ Deployments/ \\ Recovery}

Survey \#

2

3

4

5

6

7

8

9

10

\section{Multibeam Surveys Survey}

Mouth of SF Bay \#1

Mouth of SF Bay \#2

Dredge Monitoring \#1
Field Activity

ID

S-1-05-NC $\quad 06 / 21 / 05$

S-1-05-NC $\quad 06 / 22 / 05$

S-1-05-NC $\quad 06 / 23 / 05$

S-2-05-NC $\quad 07 / 25 / 05$

S-2-05-NC $\quad 07 / 27 / 05$

Field Activity Survey $\underline{\text { ID }}$

S-1-05-NC $\quad 06 / 21 / 05$

S-2-05-NC 07/26/05 none $\quad 07 / 28 / 05$

none $\quad 08 / 16 / 05$

S-1-06-NC $\quad 01 / 12 / 06$

D-1-06-NC

$01 / 23 / 06$

none

$01 / 27 / 06$

none

$02 / 01 / 06$

S-1-05-NC 07/28/05

S-2-05-NC $\quad 08 / 16 / 05$

Field Activity $\underline{\text { Survey }}$

ID Date

$\begin{array}{cc}V-2-04-N C & 09 / 15 / 04 \\ \text { none } & 09 / 17 / 05 \\ \text { none } & 05 / 16 / 05\end{array}$

http://walrus.wr.usgs.gov/infobank/s/s105nc/h tml/s-1-05-nc.meta.html http://walrus.wr.usgs.gov/infobank/s/s105nc/h tml/s-1-05-nc.meta.html http://walrus.wr.usgs.gov/infobank/s/s105nc/h tml/s-1-05-nc.meta.html http://walrus.wr.usgs.gov/infobank/s/s205nc/h tml/s-2-05-nc.meta.html http://walrus.wr.usgs.gov/infobank/s/s205nc/h tml/s-2-05-nc.meta.html http://walrus.wr.usgs.gov/infobank/s/s105nc/h $\mathrm{tml} / \mathrm{s}-1-05-\mathrm{nc}$.meta.html

http://walrus.wr.usgs.gov/infobank/s/s205nc/h tml/s-2-05-nc.meta.html

http://walrus.wr.usgs.gov/infobank/s/s106nc/h tml/s-1-06-nc.meta.html

http://walrus.wr.usgs.gov/infobank/d/d106nc/ html/d-1-06-nc.meta.html

http://walrus.wr.usgs.gov/infobank/s/s105nc/h tml/s-1-05-nc.meta.html http://walrus.wr.usgs.gov/infobank/s/s205nc/h tml/s-2-05-nc.meta.html

http://walrus.wr.usgs.gov/infobank/v/v204nc/ html/v-2-04-nc.meta.html 


$\begin{array}{lll}\text { Dredge Monitoring \#2 } & \text { none } & 06 / 07 / 05 \\ \text { Dredge Monitoring \#3 } & \text { none } & 07 / 09 / 05 \\ \text { Dredge Monitoring \#4 } & \text { none } & 10 / 19 / 05 \\ \text { Dredge Monitoring \#5 } & \text { none } & 05 / 13 / 06 \\ \text { Dredge Monitoring \#6 } & \text { none } & 06 / 02 / 06 \\ \text { Dredge Monitoring \#7 } & \text { none } & 11 / 30 / 06\end{array}$

